\title{
Heat Exchanger Design Options and Tritium Transport Study for the VHTR System
}

Chang H. Oh

Eung S. Kim

September 2008

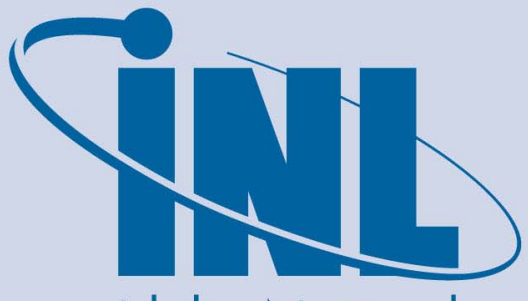

Idaho National Laboratory

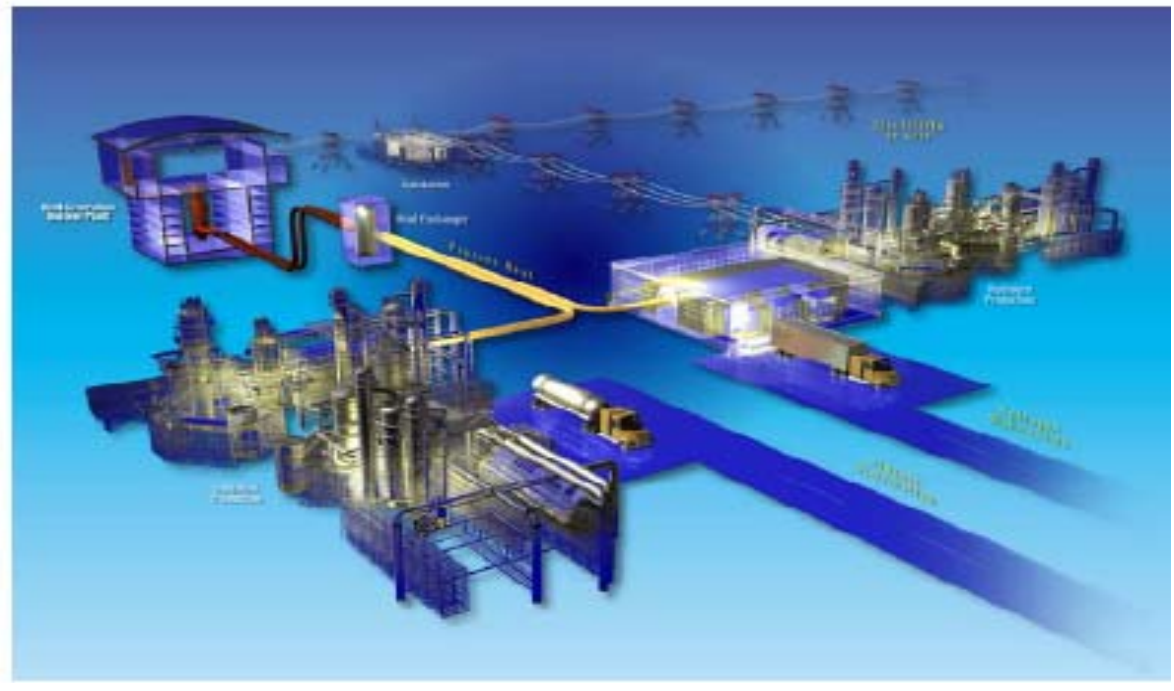

The INL is a U.S. Department of Energy National Laboratory operated by Battelle Energy Alliance 


\title{
Heat Exchanger Design Options and Tritium Transport Study for the VHTR System
}

Chang H. Oh

Eung S. Kim

September 2008

\author{
Idaho National Laboratory \\ Next Generation Nuclear Plant Project \\ Idaho Falls, Idaho 83415
}

http://www.inl.gov

Prepared for the

U.S. Department of Energy

Office of Nuclear Energy

Under DOE Idaho Operations Office

Contract DE-AC07-05ID14517 


\section{DISCLAIMER}

This information was prepared as an account of work sponsored by an agency of the U.S. Government. Neither the U.S. Government nor any agency thereof, nor any of their employees, makes any warranty, expressed or implied, or assumes any legal liability or responsibility for the accuracy, completeness, or usefulness, of any information, apparatus, product, or process disclosed, or represents that its use would not infringe privately owned rights. References herein to any specific commercial product, process, or service by trade name, trade mark, manufacturer, or otherwise, does not necessarily constitute or imply its endorsement, recommendation, or favoring by the U.S. Government or any agency thereof. The views and opinions of authors expressed herein do not necessarily state or reflect those of the U.S. Government or any agency thereof. 


\section{ABSTRACT}

This report presents the results of a study conducted to consider heat exchanger options and tritium transport in a very high temperature reactor (VHTR) system for the Next Generation Nuclear Plant Project.

The heat exchanger options include types, arrangements, channel patterns in printed circuit heat exchangers (PCHE), coolant flow direction, and pipe configuration in shell-and-tube designs. Study considerations include: three types of heat exchanger designs (PCHE, shell-and-tube, and helical coil); single- and two-stage unit arrangements; counter-current and cross flow configurations; and straight pipes and U-tube designs in shell-and-tube type heat exchangers. Thermal designs and simple stress analyses were performed to estimate the heat exchanger options, and the Finite Element Method was applied for more detailed calculations, especially for PCHE designs. Results of the options study show that the PCHE design has the smallest volume and heat transfer area, resulting in the least tritium permeation and greatest cost savings. It is theoretically the most reliable mechanically, leading to a longer lifetime. The two-stage heat exchanger arrangement appears to be safer and more cost effective. The recommended separation temperature between first and second stages in a serial configuration is $800^{\circ} \mathrm{C}$, at which the high temperature unit is about one-half the size of the total heat exchanger core volume. Based on simplified stress analyses, the high temperature unit will need to be replaced two or three times during the plant's lifetime. Stress analysis results recommend the off-set channel pattern configuration for the PCHE because stress reduction was estimated at up to $50 \%$ in this configuration, resulting in a longer lifetime.

The tritium transport study resulted in the development of a tritium behavior analysis code using the MATLAB Simulink code. In parallel, the THYTAN code, previously performed by Ohashi and Sherman (2007) on the Peach Bottom data, was revived and verified. The $600 \mathrm{MWt}$ VHTR core input file developed in preparation for the transient tritium analysis of VHTR systems was replaced with the original steady-state inputs for future calculations. A Finite Element Method analysis was performed using COMSOL Multiphysics software to accurately predict tritium permeation through the PCHE type heat exchanger walls. This effort was able to estimate the effective thickness for tritium permeations and develop a correlation for general channel configurations, which found the effective thickness to be much shorter than the average channel distance because of dead spots on the channel side. 


\section{ACKNOWLEDGMENT}

This work was supported through the U.S. Department of Energy's NGNP-Engineering Program under DOE Idaho Operations Office Contract DE-AC07-05ID14517. 


\section{CONTENTS}

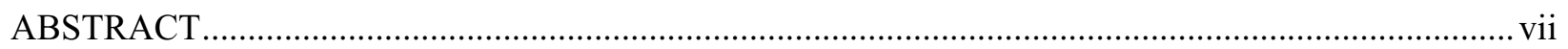

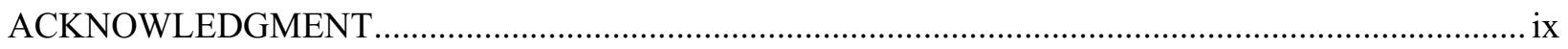

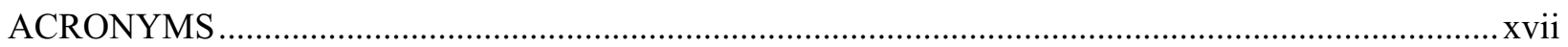

1. HEAT EXCHANGER DESIGN OPTIONS FOR THE NEXT GENERATION NUCLEAR

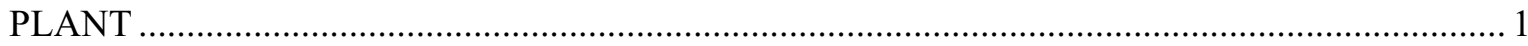

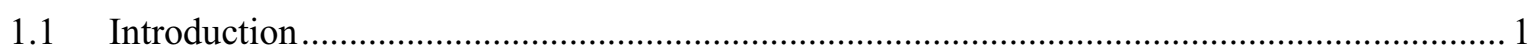

1.2 Heat Exchanger Thermal Design .................................................................................. 2

1.2.1 Heat Exchanger Requirements and Reference Reactor Configurations....................... 2

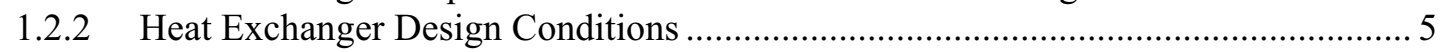

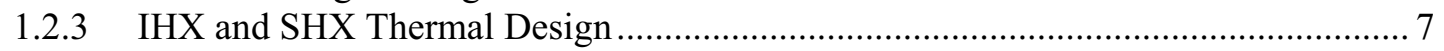

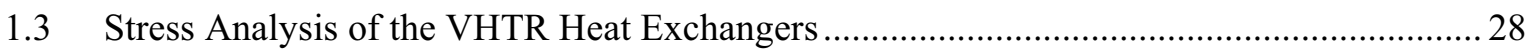

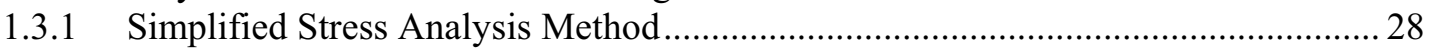

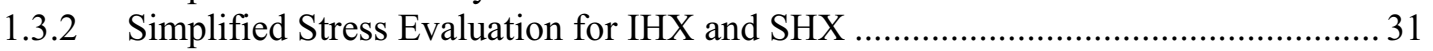

1.4 Computational Analysis on the Printed Circuit Heat Exchanger Channel

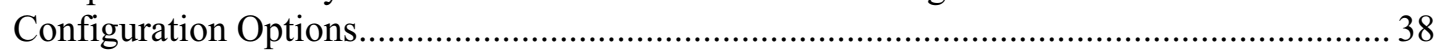

1.4.1 COMSOL Modeling for Heat Transfer and Tritium Penetration in the PCHE........... 38

1.4.2 ABAQUS Modeling for Stress in the PCHE ..................................................... 51

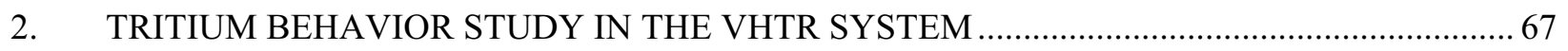

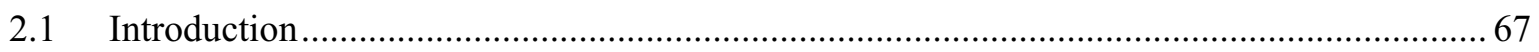

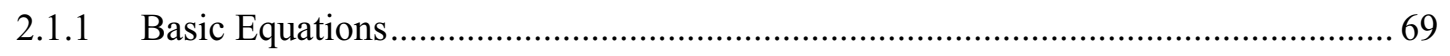

2.1.2 Development of Dynamic Tritium Behavior Analysis Code by MATLAB

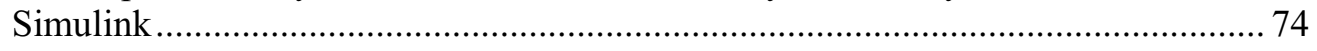

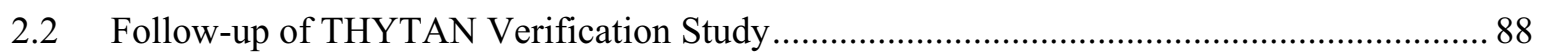

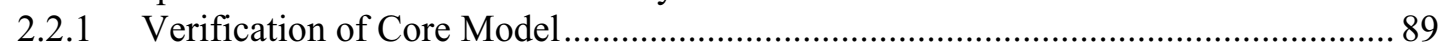

2.2.2 Verification of Permeation Model …….................................................... 95

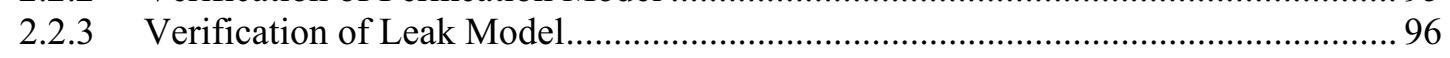

2.2.4 Verification of Purification System Model ............................................................ 97

2.3 Development of THYTAN Core Input for Transient Analysis of VHTR Tritium

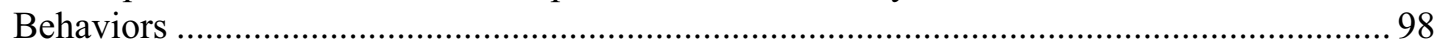

2.3.1 Input Parameters for Tritium Source from Ternary Fission..................................... 99

2.3.2 Input Parameters for Tritium Source from ${ }^{3} \mathrm{He}$ in the Coolant.................................. 99

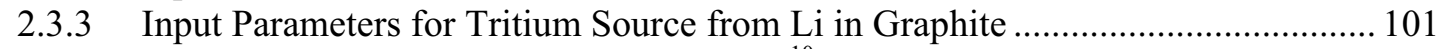

2.3.4 Input Parameters for Tritium Source from ${ }^{10} \mathrm{~B}$ in Graphite..................................... 102

2.4 Evaluation of the Effective Thickness for Tritium Permeation in PCHEs.......................... 102

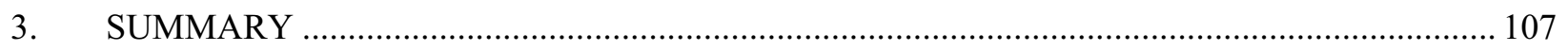

3.1 Design Options for NGNP Heat Exchanger................................................................ 107

3.1.1 Heat Exchanger Thermal Design and Design Options......................................... 107

3.1.2 Stress Analysis of the VHTR Heat Exchangers ................................................... 108

3.1.3 Computational Analysis of PCHE Channel Configuration Options ........................ 108

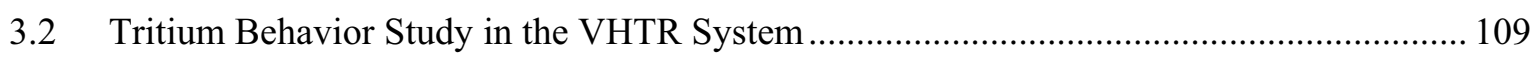

3.2.1 Heat Exchanger Thermal Design and Design Options.......................................... 109 


\section{FIGURES}

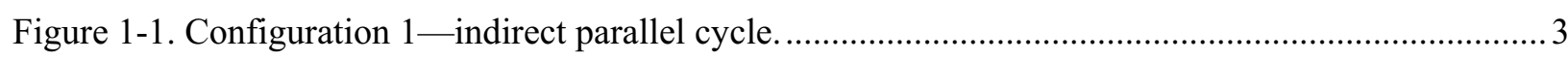

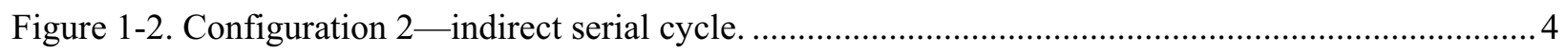

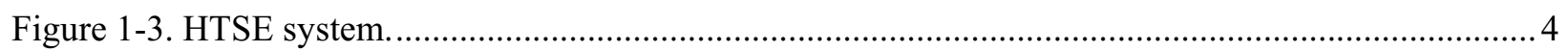

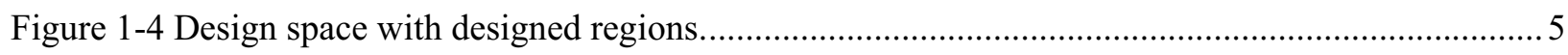

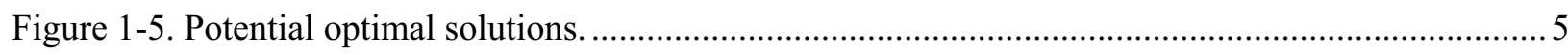

Figure 1-6. LMTD of IHX vs. system overall efficiency for the reference reactor

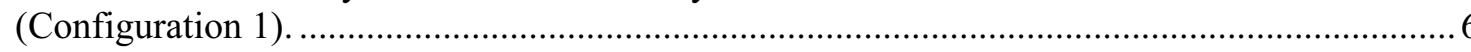

Figure 1-7. Pressure drop (kPa) vs. system efficiency $(\%)$ in the reference reactors

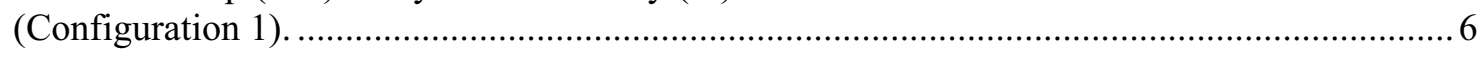

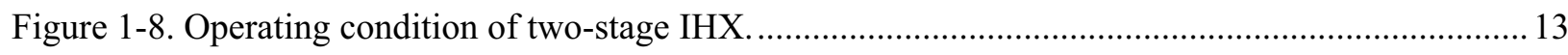

Figure 1-9. Variations of $S_{m}$ and $S_{t}$ of alloy 617 with temperature and time (Natesan et al. 2006)..........28

Figure 1-10. Comparisons of failure theories for a biaxial state of stress (Martin 1962)........................ 30

Figure 1-11. Comparisons of biaxial strength data with failure theories (Collins 1981)...........................30

In this report, the maximum shear stress theory was used for conservative failure estimations................. 31

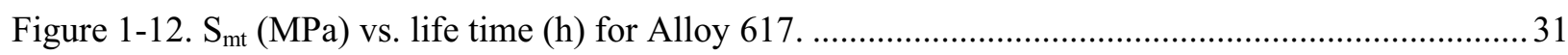

Figure 1-13. Maximum stress as a function of plate thickness-to-diameter ratio (PCHE, $\left.900^{\circ} \mathrm{C}\right)$............33

Figure 1-14. Maximum stress as a function of plate thickness-to-diameter ratio (PCHE, $\left.800^{\circ} \mathrm{C}\right) \ldots \ldots \ldots \ldots . . . .33$

Figure 1-15. Maximum stress as a function of plate thickness-to-diameter ratio ( $\left.\mathrm{PCHE}, 750^{\circ} \mathrm{C}\right) \ldots \ldots \ldots \ldots . . .34$

Figure 1-16. Maximum stress as a function of tube thickness-to-radius ratio (shell-and-tube,

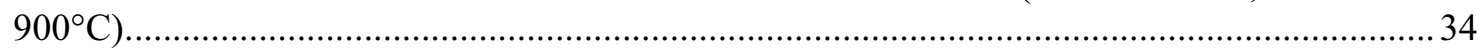

Figure 1-17. Maximum stress as a function of tube thickness-to-radius ratio (shell-and-tube,

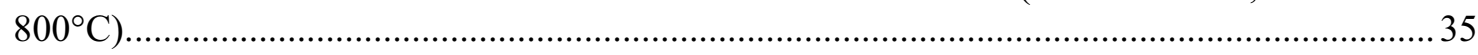

Figure 1-18. Maximum stress as a function of tube thickness-to-radius ratio (shell-and-tube,

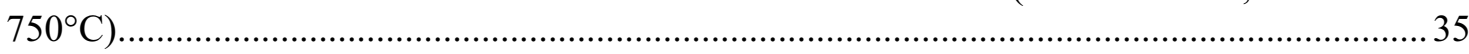

Figure 1-19. Plate thickness-to-diameter ratio vs. estimated heat exchanger lifetime (PCHE)................. 37

Figure 1-20. Tube thickness-to-inner radius ratio vs. estimated heat exchanger lifetime (shell-

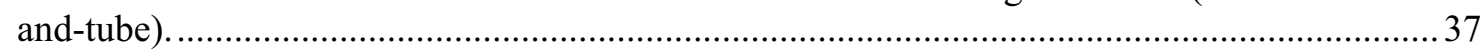

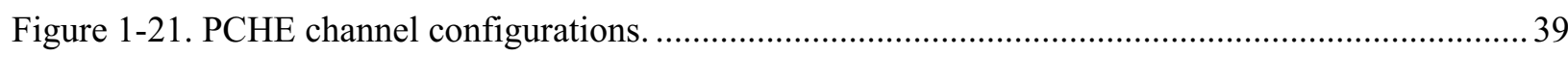

Figure 1-22. Calculated temperature and tritium concentration profiles (for the standard configuration). 
Figure 1-23. Calculated temperature and tritium concentration profiles (for the off-set configuration).

Figure 1-24. Diffusion flux and path of tritium in the PCHE (for the standard configuration)................. 48

Figure 1-25. Diffusion flux and path of tritium in the PCHE (for the off-set configuration)....................49

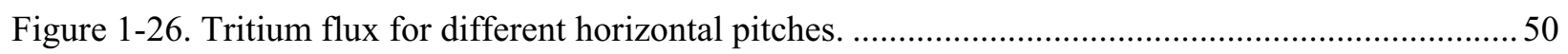

Figure 1-27. Tritium flux for different vertical pitch (plate thickness) .................................................51

Figure 1-28. Normal (left) and offset (right) channel configurations. ...................................................52

Figure 1-29. Stress versus time-to-1\% strain and time to rupture from creep for several

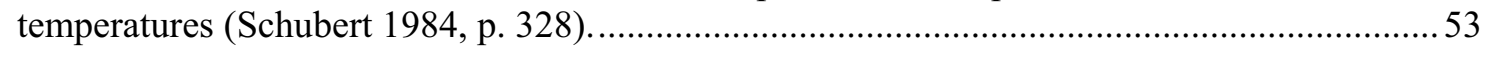

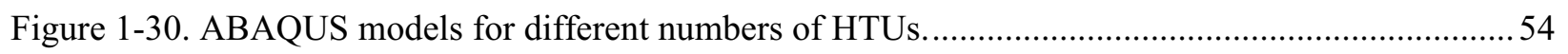

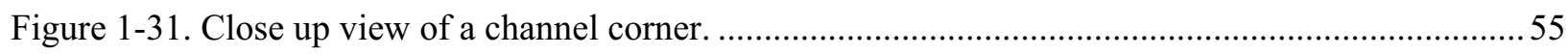

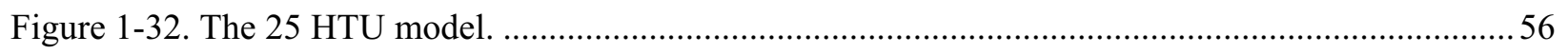

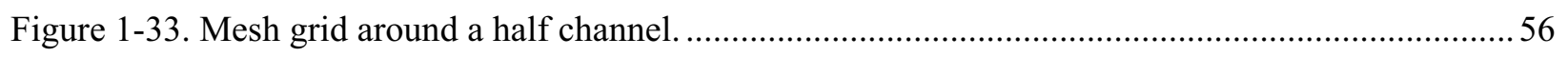

Figure 1-34. Maximum stress as function of heat transfer units used....................................................5

Figure 1-35. Stress distribution of 25 HTUs model, entire model view. ................................................58

Figure 1-36. Stress distribution of 25 HTUs model, top three rows, second and third columns. ..............59

Figure 1-37. Stress distribution of 25 HTUs model, left corner of second row, second column

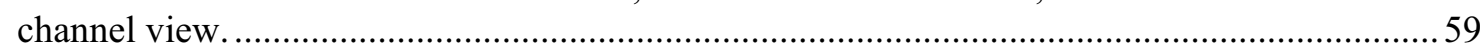

Figure 1-38. Maximum stress as function of the outside pressure for the normal configuration. ..............60

Figure 1-39. Maximum stress as function of the vertical pitch for normal and shifted

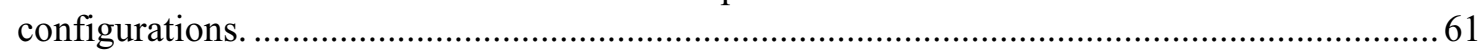

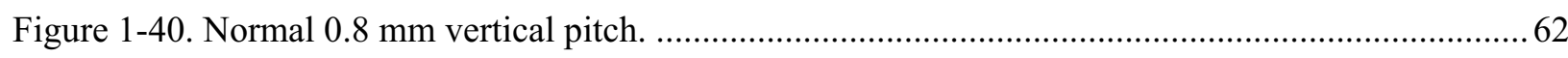

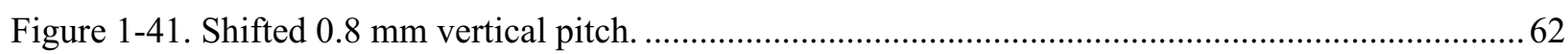

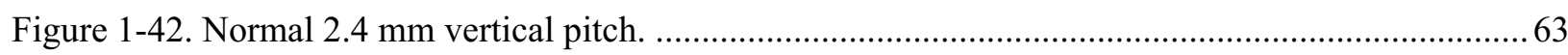

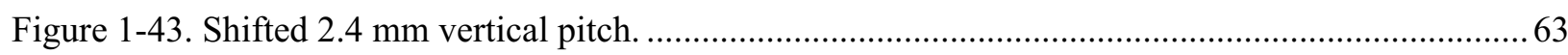

Figure 1-44. Maximum stress as function of the horizontal pitch for normal and shifted

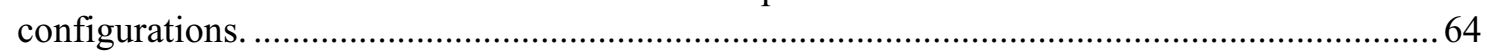

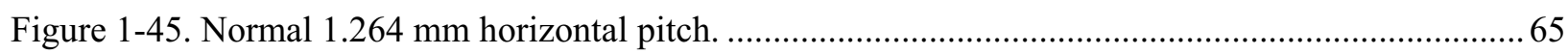

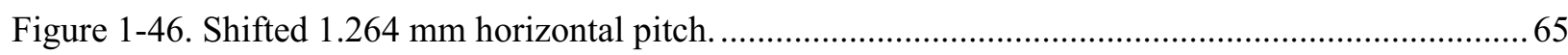

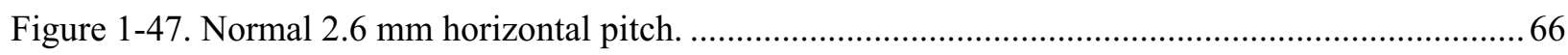

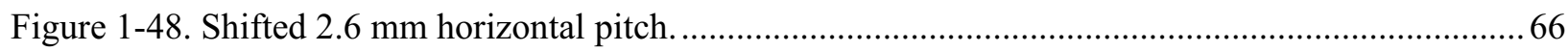

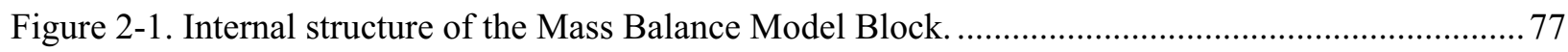

Figure 2-2. Internal block diagram of Core Model Block. ..................................................................... 78

Figure 2-3. Parameter setting window for the tritium source from tertiary fission.................................. 79

Figure 2-4. Submodel for tritium source from tertiary fission........................................................... 79

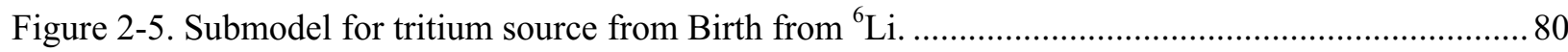




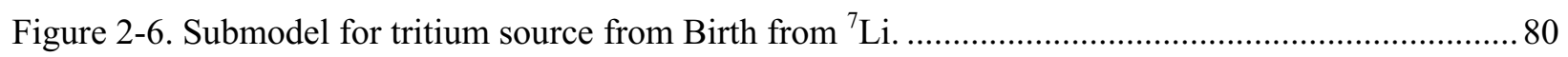

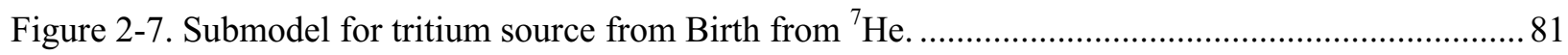

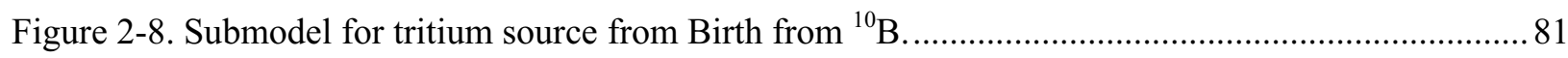

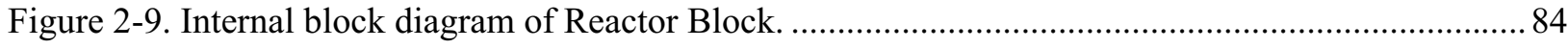

Figure 2-10. Internal block diagram of the Heat Exchanger Block..................................................... 86

Figure 2-11. GUI and workspace of the current tritium behavior analysis code. ................................... 88

Figure 2-12. Primary coolant system of the Peach Bottom reactor (Wichner and Dyer 1979)................. 89

Figure 2-13. Comparison of tritium concentrations in the containment vessel of the Peach Bottom

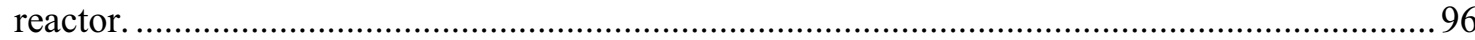

Figure 2-14. Comparisons between analytical solution and THYTAN results for verification of

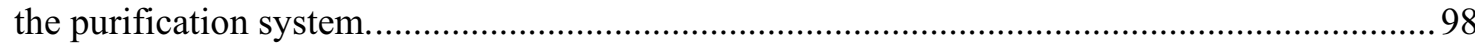

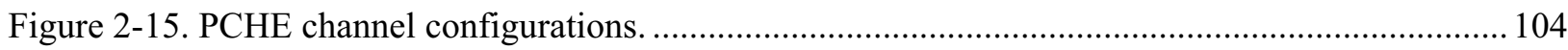

Figure 2-16. Effective thickness for various channel dimensions (diameter, pitch and thickness). ......... 105

\section{TABLES}

Table 1-1. Heat exchanger design conditions for Configuration 1 (Figure 1-1)..................................... 7

Table 1-2. Heat exchanger design conditions for Configuration 2 (Figure 1-2)...................................... 7

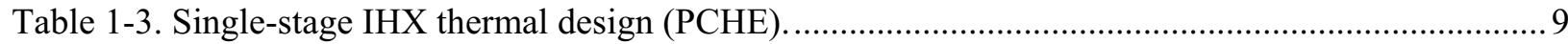

Table 1-4 Single stage IHX thermal design (shell-and-tube)................................................................. 10

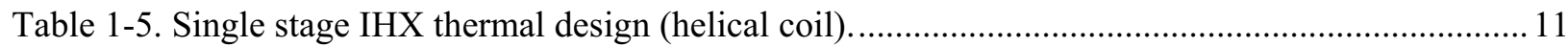

Table 1-6. Two-stage IHX thermal design (high temperature section, PCHE). ....................................... 14

Table 1-7. Two-stage IHX thermal design (high temperature section, shell-and-tube)............................ 15

Table 1-8. Two-stage IHX thermal design (high temperature section, helical coil)............................... 15

Table 1-9. Two-stage IHX thermal design (low temperature section, PCHE). ...................................... 16

Table 1-10. Two-stage IHX thermal design (low temperature section, shell and tube) ............................ 17

Table 1-11. Two-stage IHX thermal design (low temperature section, helical coil)................................ 17

Table 1-12. Summary of heat exchanger types in the two-stage IHX in series..................................... 18

Table 1-13. Volume of heat exchangers for two-stage IHX............................................................. 18

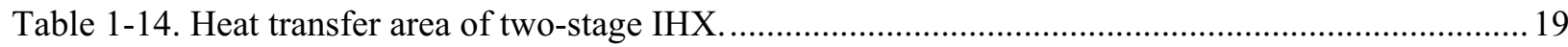

Table 1-15. Two-stage IHX thermal design (high temperature section, PCHE, $\mathrm{T}_{\text {sep }}=800^{\circ} \mathrm{C}$ )...............20

Table 1-16. Two-stage IHX thermal design (high temperature section, shell-and-tube, $\mathrm{T}_{\mathrm{sep}}=$

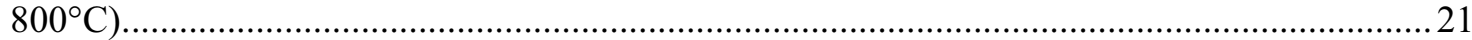

Table 1-17. Two-stage IHX thermal design (high temperature section, helical coil, $\mathrm{T}_{\text {sep }}=800^{\circ} \mathrm{C}$ )......... 21

Table 1-18. Two-stage IHX Thermal design (low temperature section, $\mathrm{PCHE}, \mathrm{T}_{\text {sep }}=800^{\circ} \mathrm{C}$ )................22

Table 1-19. Two-stage IHX thermal design (low temperature section, shell-and-tube, $\mathrm{T}_{\text {sep }}=$ $\left.800^{\circ} \mathrm{C}\right)$ 
Table 1-20. Two-stage IHX thermal design (low temperature section, helical coil, $\mathrm{T}_{\text {sep }}=800^{\circ} \mathrm{C}$ ).......... 23

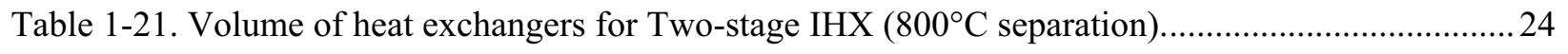

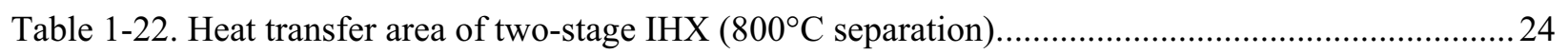

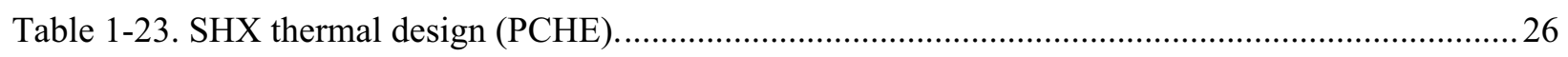

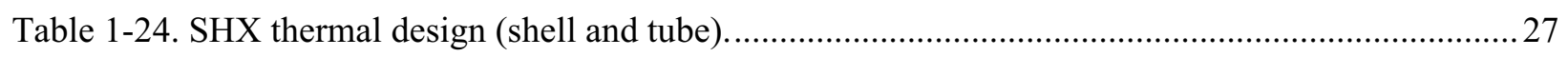

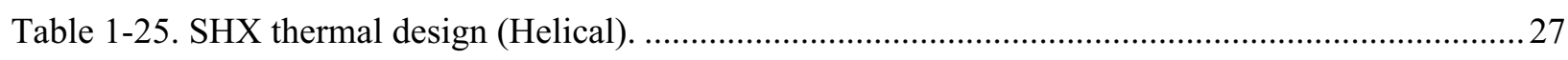

Table 1-26. Assumed allowable stresses for Alloy 617 ...................................................................... 31

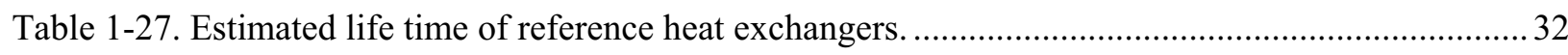

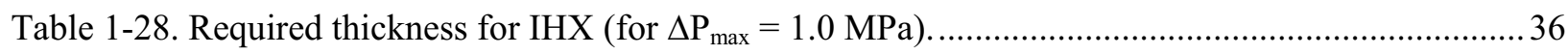

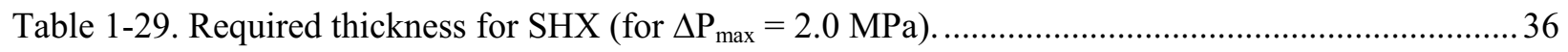

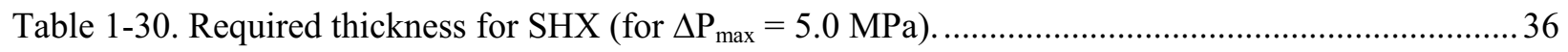

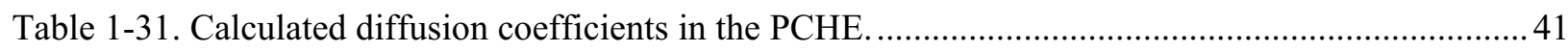

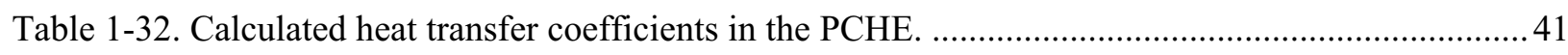

Table 1-33. Default channel dimensions and operating conditions. ......................................................52

Table 1-34. Alloy 617 mechanical properties (Special Metals Corporation, 2006, p. 2-3)....................53

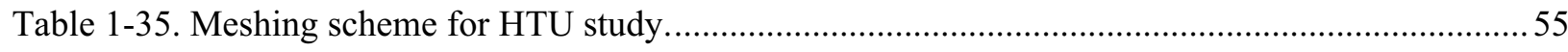

Table 1-36. Meshing scheme for vertical pitch and horizontal pitch studies......................................... 61

Table 2-1. Comparison of tritium activity by ternary fission................................................................ 90

Table 2-2. Comparison of tritium activity from $6 \mathrm{Li}$ at the Core 2 operation of the Peach Bottom

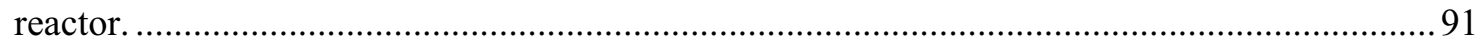

Table 2-3. Parameters for the calculation of tritium birth from ${ }^{6} \mathrm{Li}$ (Ohashi and Sherman 2007).............91

Table 2-4. Input data of THYTAN for calculation of tritium birth from ${ }^{6} \mathrm{Li}$ (Ohashi and Sherman 2007)

Table 2-5. Comparison of tritium activity from ${ }^{3} \mathrm{He}$ at the Core 2 operation of the Peach Bottom HTGR.

Table 2-6. Input data of THYTAN for calculation of tritium birth from ${ }^{3} \mathrm{He}$ (Ohashi and Sherman 2007).

Table 2-7. Input data for the subnode of THYTAN for the calculation of tritium birth from ${ }^{3} \mathrm{He}$ (Ohashi and Sherman 2007).

Table 2-8. Comparison of tritium activity from ${ }^{10} \mathrm{~B}$ in the poisoned spine at the Core 2 operation of Peach Bottom reactor.

Table 2-9. The heat transfer tube dimensions of the steam generator in the Peach Bottom reactor

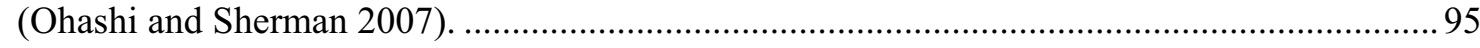

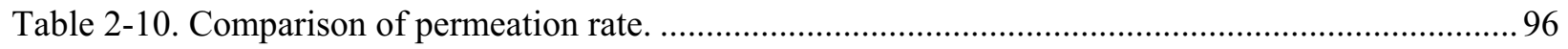

Table 2-11. Input data of THYTAN for verification of the leak model (Ohashi and Sherman 2007). 
Table 2-12. THYTAN boundary conditions for verification of the purification system model

(Ohashi and Sherman 2007). .98

Table 2-13. Tritium production reaction and cross section (Wichner 1979). ..........................................99

Table 2-14. Basic data for THYTAN evaluation of ternary fission........................................................ 99

Table 2-15. Basic data for THYTAN evaluation of ${ }^{3} \mathrm{He}$ Source............................................................ 100

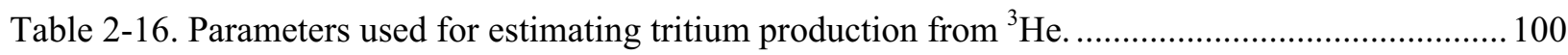

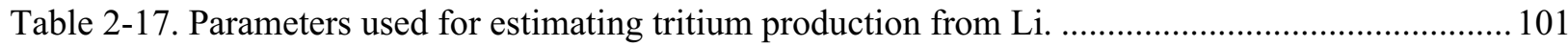

Table 2-18. Parameters used for estimating tritium production from Li. ................................................ 102

Table 2-19. Effective Thickness over a Temperature Range............................................................... 104 


\section{ACRONYMS}

ASME American Society of Mechanical Engineers

CFD computational fluid dynamics

FEM Finite Element Method

GCI grid convergence index

GUI graphical user interface

HTE high-temperature electrolysis

HTR-10 High Temperature Reactor (10 MW)

HTGR high temperature gas-cooled reactor

HTSE high temperature steam electrolysis

HTTR high temperature test reactor

HTU heat transfer unit

IHX intermediate heat exchanger

LMTD $\quad \log$ mean temperature difference

NGNP Next Generation Nuclear Plant

PCU power conversion unit

PCHE printed circuit heat exchanger

PHX process heat exchangers

SHX secondary heat exchanger

VHTR Very High Temperature Gas-Cooled Reactor 
xviii 


\section{Heat Exchanger Design Options and Tritium Transport Study for the VHTR System}

\section{HEAT EXCHANGER DESIGN OPTIONS FOR THE NEXT GENERATION NUCLEAR PLANT}

\subsection{Introduction}

One Next Generation Nuclear Plant (NGNP) reference concept consists of a very high temperature gas-cooled Reactor (VHTR) that provides the first demonstration of a closed-loop Brayton cycle at a commercial scale of a few hundred megawatts electric and hydrogen production. The power conversion system for the NGNP will take advantage of the significantly higher reactor outlet temperatures to provide higher efficiencies than can be achieved in the current generation of light water reactors. Besides demonstrating a system design that can be used directly for subsequent commercial deployment, the NGNP will demonstrate key technological elements that can be used in subsequent advanced power conversion systems for other Generation IV reactors. In anticipation of the design, development, and procurement of an advanced power conversion system for the NGNP, the system integration of NGNP with a hydrogen plant was initiated to identify the important design and technology options that must be considered in evaluating the performance of the proposed NGNP.

Integrating the VHTR and hydrogen production plant will require an intermediate heat exchanger (IHX) to transfer the process heat from the VHTR to the hydrogen plant. The selection, design, and configuration of this IHX is important because its effectiveness is directly related to the overall efficiency of the system, the gas coolant has poor heat transfer capabilities, and it is operating under critical conditions $\left(900^{\circ} \mathrm{C}, 7 \mathrm{MPa}\right)$.

The main purpose of this study was to investigate and estimate the various heat exchanger options for application with VHTRs. Three different types of heat exchangers were considered: printed circuit heat exchanger (PCHE), shell-and-tube heat exchanger, and helical coil heat exchanger. A PCHE is a compact heat exchanger, and a reference design is manufactured by Heatric ${ }^{\mathrm{TM}}$ through a chemical etching and diffusion bonding process. The PCHE provides large heat transfer surface area density (as high as 2,500 $\mathrm{m}^{2} / \mathrm{m}^{3}$ ) that allows operation at very high temperatures and pressures (up to $900^{\circ} \mathrm{C}$ and $50 \mathrm{MPa}$ ). This high compactness implies an appreciable reduction in material, reducing cost. A shell-and-tube heat exchanger is the most classical and common type of heat exchanger, generally used in oil refineries and other large chemical processes. It consists of a shell with a bundle of tubes inside of it; one fluid runs through the tubes and the other flows over the tubes. This heat exchanger is suitable for high pressure applications. The helical coil heat exchanger is a variation of the shell-and-tube heat exchanger. It is composed of helically coiled tubes and a shell that usually provide higher heat transfer enhancement and reliability during thermal expansion than the classical shell and tube design.

This study investigated two IHX arrangements: single-stage and two-stage (Patterson 2007), the single-stage being the most common. In the single-stage concept, one big IHX unit is connected to the reactor's primary side and secondary side to exchange heat between them. Sometimes, the size of the IHX is almost the same scale as the reactor vessel or power conversion units. In the two-stage concept, we split the IHX into high temperature and low temperature sections. The low temperature section, downstream of the high temperature section connected to the VHTR outlet, is designed for the full lifetime, and the high temperature section for replacement within plant lifetime. The maximum temperature of the low temperature section is around $760^{\circ} \mathrm{C}$, which allows use of American Society of Mechanical Engineers (ASME) Section III, Subsection NH materials such as Alloy $800 \mathrm{H}$. In the high temperature section, potential candidates include alloys 617 and 230 or ceramics. The two-stage method is expected to have 
some cost, safety, and maintenance advantages. For example, if the IHX is split into two parts, the material cost can be saved because relatively inexpensive commercial materials like stainless steel or Alloy $800 \mathrm{H}$ can be used for the low temperature section-only the high temperature heat exchanger requires expensive alloy or ceramic materials. In addition, having two heat exchangers will reduce the thermal stress problem, because the temperature differences in the two component concept will be reduced. It is also easier to manage and reduce the risk, since the safety problems are concentrated mainly on the high temperature heat exchanger side operating in more severe conditions.

The overall organization of this section is as follows:

- Section 1.2 presents the results of extensive comparisons in the relative size and thermal performance of the three heat exchangers.

- Section 1.3 presents the results of simple stress analyses carried out order to estimate the lifetime and mechanical performance of the heat exchanger options.

- Section 1.4 focuses on the heat performance and mechanical stress of the PCHE, which are calculated in detail by Finite Element Method (FEM) using ABAQUS code.

\subsection{Heat Exchanger Thermal Design}

As a first step, IHX thermal design was performed for various heat exchanger types and arrangements. The process consisted of determining the IHX requirements, determining the IHX design conditions for some reference reactor configurations, and performing thermal design of the IHX based on the design conditions. Various design options were considered. The design methods and guidelines used in this report are summarized in Appendix A.

\subsubsection{Heat Exchanger Requirements and Reference Reactor Configurations}

In order to design an IHX for VHTR applications, the following reference design requirements and conditions were determined:

- Maximum operating temperature: $\sim 1000^{\circ} \mathrm{C}$

- Pressure: 50-100 bar

- Duty: $600 \mathrm{MWt}$

- Effectiveness: $95 \%$

- Helium environment

- Low pressure drop

- 30-60 year design life.

The design conditions of the IHX were obtained from the previous research report by Oh et al. (2006). A number of VHTR system configurations are recommended in this report. Among them, two configurations were selected: indirect parallel system, and indirect serial system. In the indirect parallel system (see Figure 1-1), the flow in the secondary coolant system is divided, with most of the flow going towards the power conversion unit (PCU) and the remainder going through a secondary heat exchanger (SHX) that directs heat towards the high temperature steam electrolysis (HTSE) plant. The flow through the hot side of the SHX is then mixed with the flow from the PCU to feed the cold side of the IHX. However, some of the flow is diverted away from the PCU, which acts to decrease the efficiency of the cycle. 


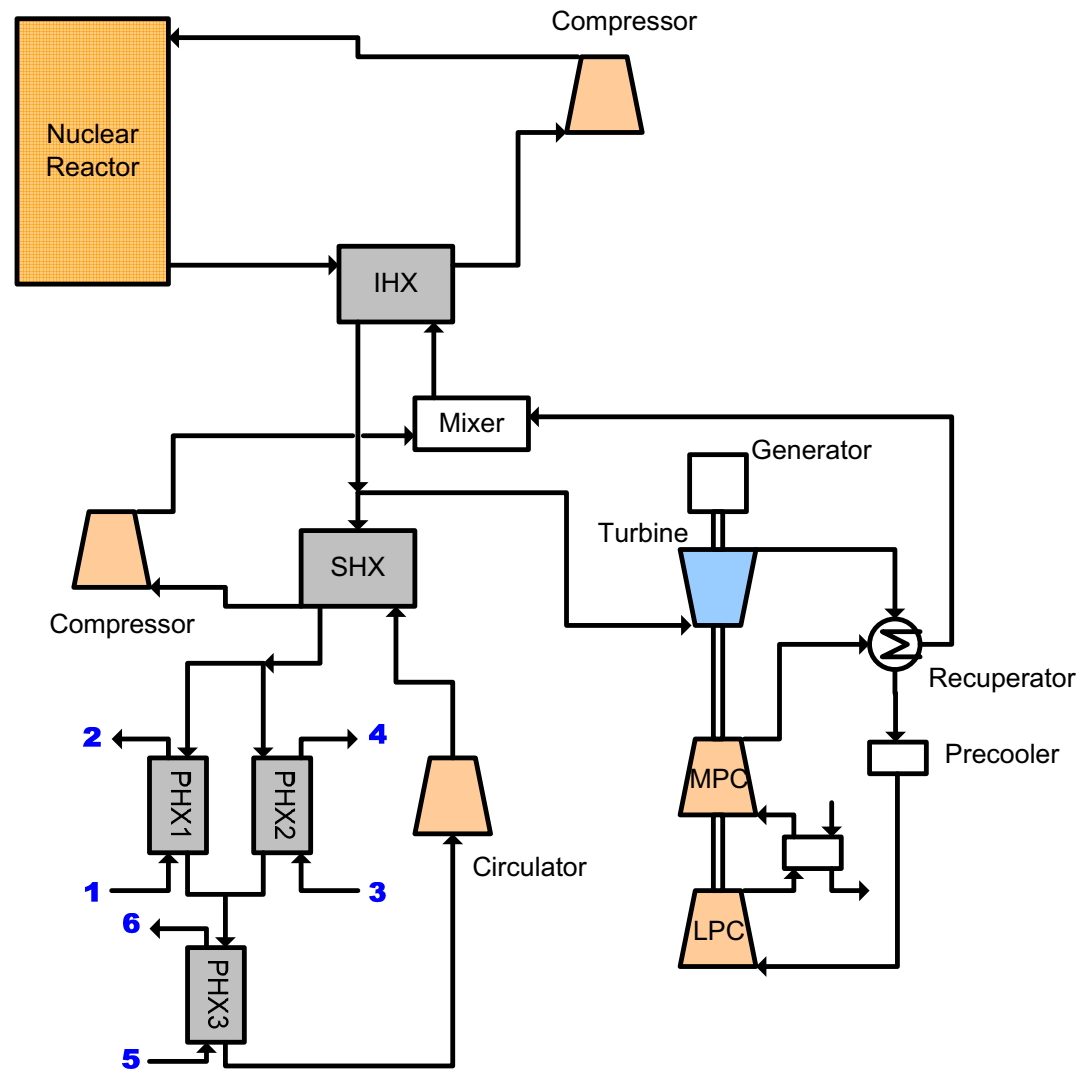

Figure 1-1. Configuration 1-indirect parallel cycle.

There are three coolant loops. The primary coolant system contains the nuclear reactor, the hot side of the IHX, and a compressor. The secondary coolant system contains the cold side of the IHX, the hot side of the SHX, the PCU, and connecting piping, which is assumed to be short. The intermediate heat transport loop connects the secondary coolant system to the HTSE plant through several process heat exchangers (PHXs).

In the indirect serial configuration (see Figure 1-2), the SHX is located upstream of the IHX that is linked to the PCU. Therefore, the heat from the VHTR is transferred to the HTSE system first, and then to the PCU. This configuration is able to supply higher temperatures to the HTSE system, but decreases the PCU maximum temperature, resulting in a decreased PCU efficiency. However, in this configuration, the system is more controllable because of its decreased connectivity. The reduction in the number of circulators can reduce the cost and increase the overall efficiency. The same HTSE system configuration shown in Figure 1-3 is used here in terms of coupling the VHTR and the HTSE.

Figure 1-3 shows the High Temperature Steam Electrolysis (HTSE) system. For electrolysis, the steam is heated up to $830^{\circ} \mathrm{C}$ by the SHX. The heated steam is converted into hydrogen and oxygen in the electrolyzer and discharged through the fuel and oxidizer outlet, respectively, as shown in Figure 1-2. The heat of the discharged gases is recovered through three recuperators. The product gas in the fuel side contains hydrogen and steam, and the oxidizer outlet gas contains oxygen and steam. Hydrogen and steam separated from the electrolyzer are recycled back to the separator where hydrogen is separated as a product at the top of the separator and steam is fed back to the electrolyzer. A small fraction of hydrogen is recycled back to the electrolyzer to minimize the nickel oxidation in the hydrogen side of the electrolyzer. Stream heat is first recuperated in the oxidizer outlet and then run through an expander to recover work. The oxygen and water components of the stream are then separated. 


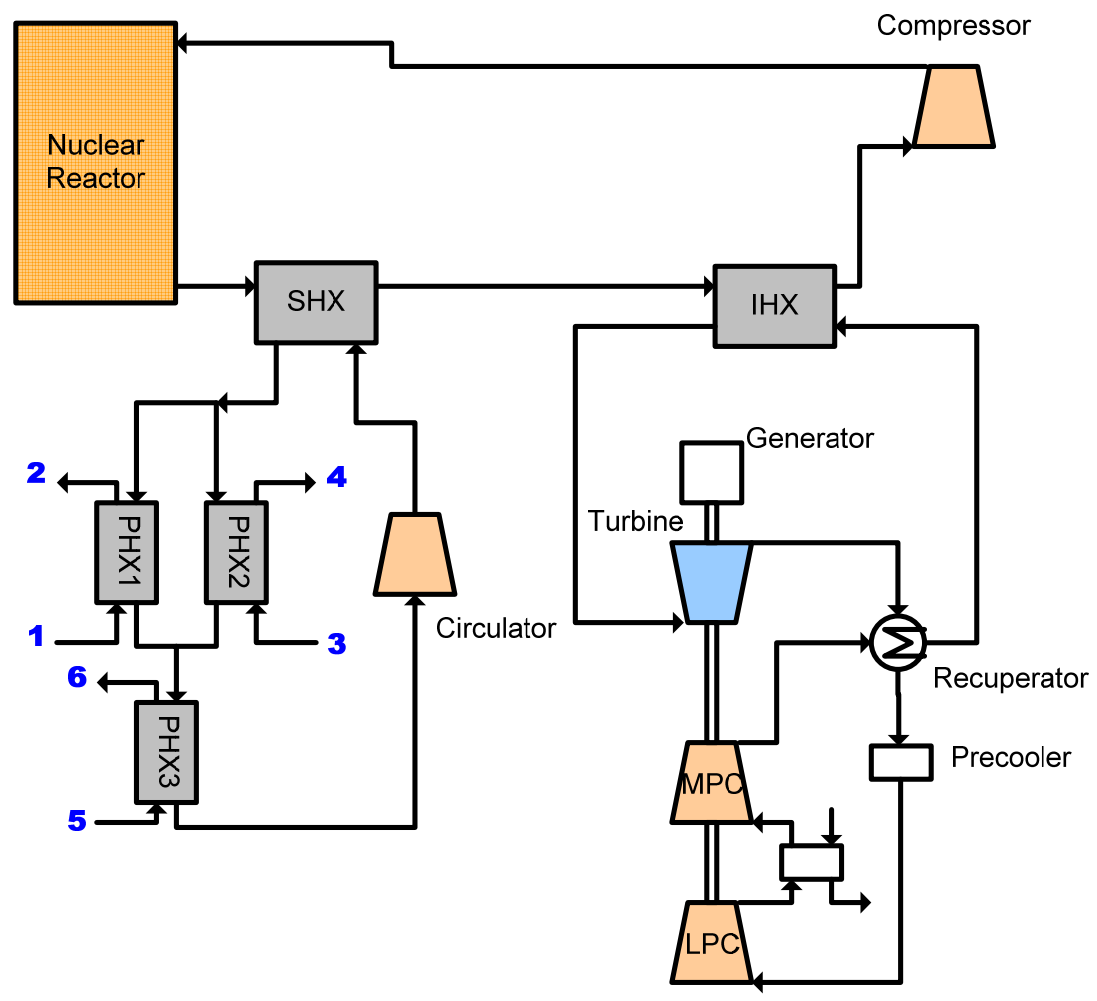

Figure 1-2. Configuration 2-indirect serial cycle.

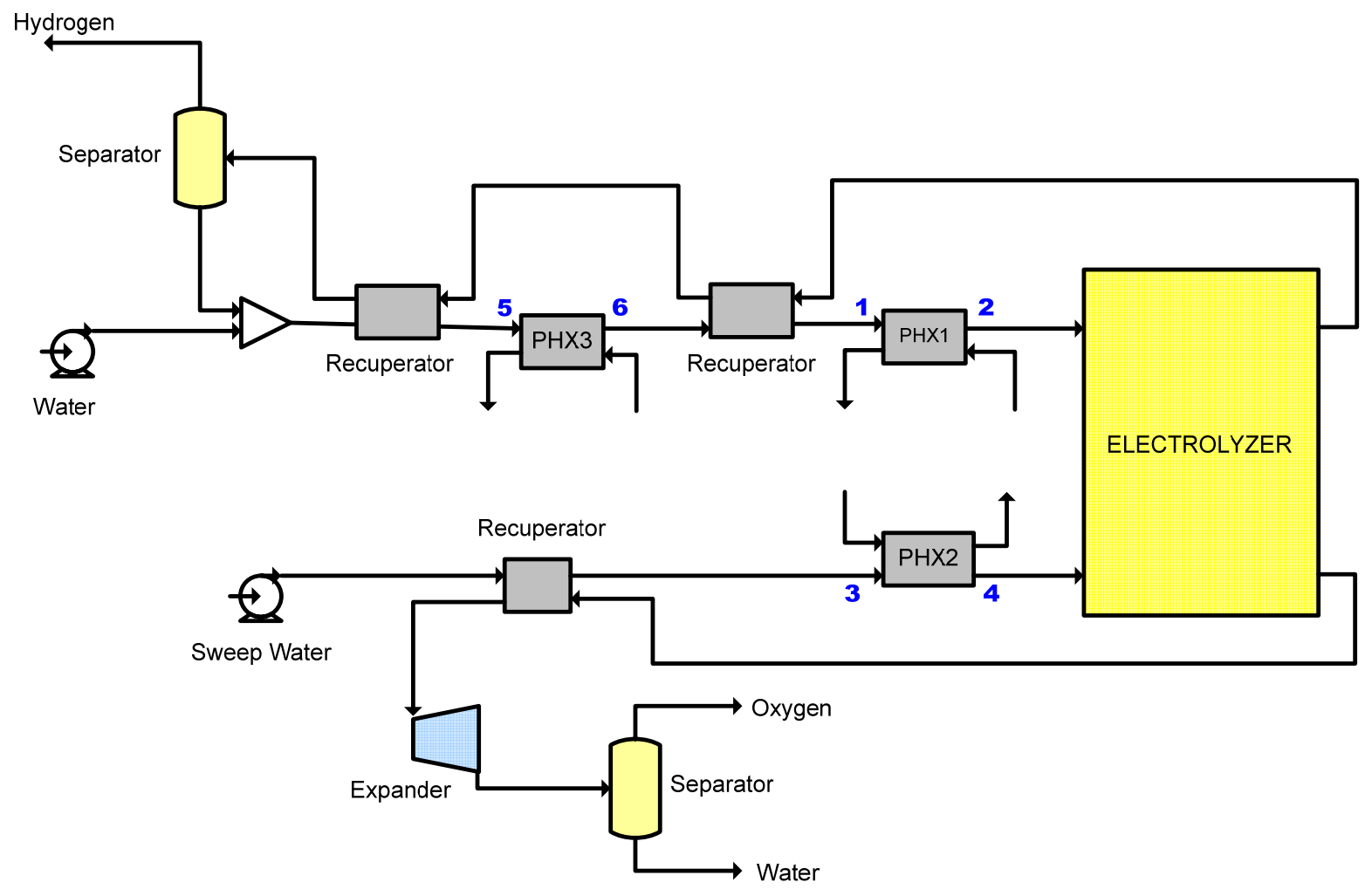

Figure 1-3. HTSE system. 


\subsubsection{Heat Exchanger Design Conditions}

In this section, IHX design conditions were determined for the thermal design. Two parameters are important in performing this: the log mean temperature difference (LMTD) and the maximum pressure drop in the reactor channel. If we decrease the LMTD of the IHX, we can obtain higher thermal efficiencies, but it requires a large heat exchanger. Similarly, if we increase the maximum pressure drop in the IHX, we can make the IHX smaller, but this results in a significant efficiency drop. Therefore, to adequately design the IHX, these two parameters need to be determined very carefully. The process we used in determining these parameters is discussed below.

In order to determine the IHX design conditions, the IHX was considered in view of its overall system performance. HYSYS process modeling software was used (ASPEN 2005) to optimize this analysis. HYSYS has a built in optimization tool to integrate the simulation model of the system. The optimization program searches for the maximum value of a given objective function subject to a number of imposed constraints. Figure 1-4 shows a two-dimensional (2-D) design space with defined regions. The goal is to maximize $f(x 1, x 2, x 3, \ldots)$ where $x 1, x 2, x 3$ are independent variables such as mass flow, pressure, temperature, etc. For the optimization, the $\mathrm{x}$ variables are manipulated within a specified range of a lower and upper bound. The regions in Figure 1-5 are defined by a feasible design space within functional constraints and an infeasible design space outside of the constraint boundaries (Mckellar 1992). Functional constraints are material and energy balances such as positive pressure drop in every stream in the direction of flow, positive power in turbine and compressor, temperature requirements at the inlet and outlet of the heat exchangers, etc. The function, $\mathrm{f}$, is the objective function defined as the overall plant efficiency above. Constant values of the objective function define contours on the design space. Figure 1-5 shows the optimal design points of the 2-D design vector. First, the initial calculation should be in the feasible design space and the search continues towards a direction in the design space until a maximum is reached. A new direction is found and the search continues in that direction as long as the objective function value increases. Once a maximum is reached, the search continues towards the optimal design point. However, if the optimal design point is outside of the feasible design space, the closest contour to the optimal solution that coincides with the constraint boundary can be the optimal solution within the constraints specified.

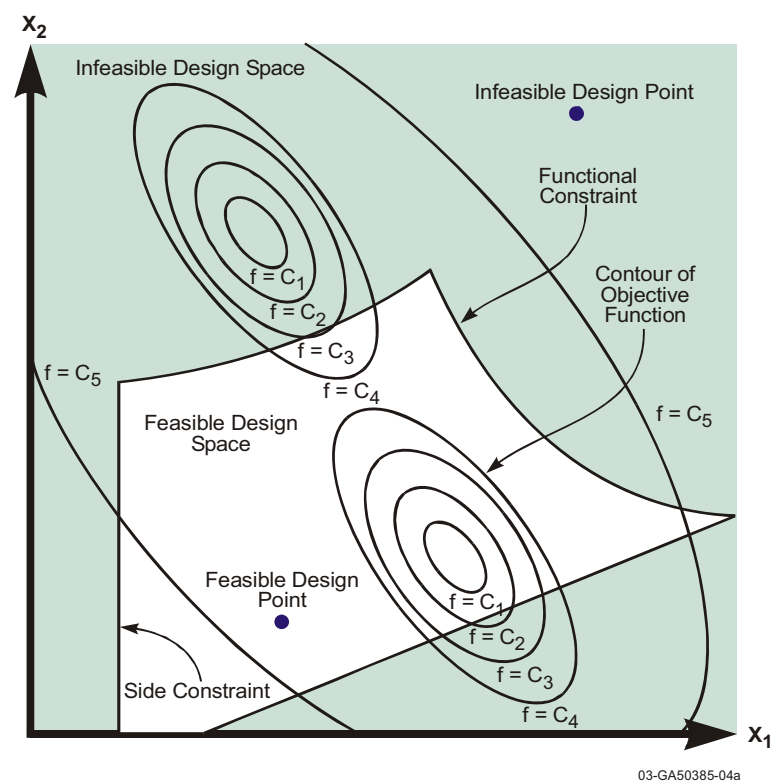

Figure 1-4 Design space with designed regions.

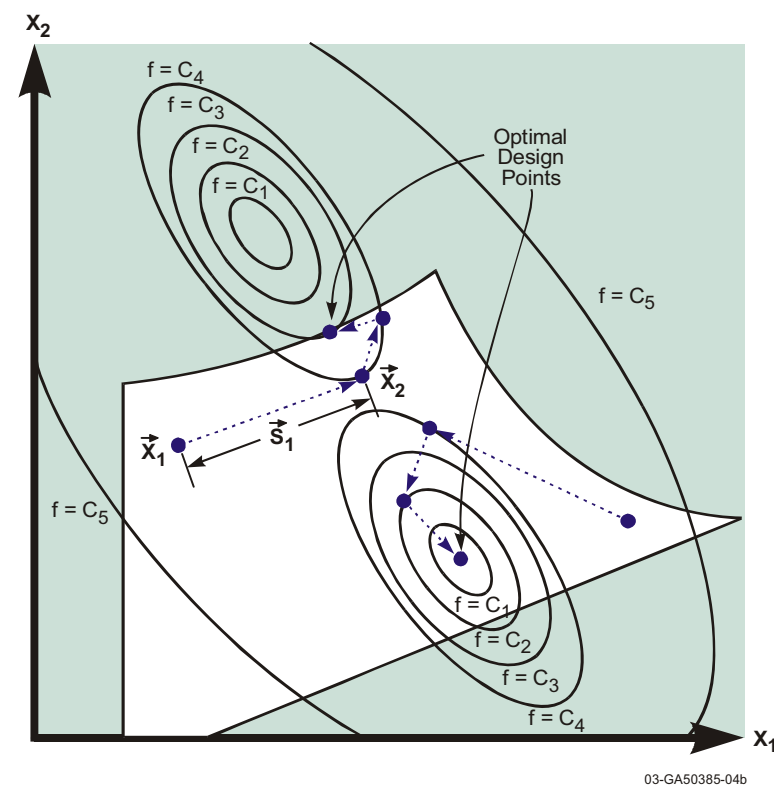

Figure 1-5. Potential optimal solutions. 
In the electrolyzer model (Oh et al. 2006a), the oxygen stream produced at the anode is assumed to mix with a sweep gas stream that is introduced at the anode. The combined stream then exits the electrolyzer. The hydrogen stream produced at the cathode is assumed to mix with a feed stream that is introduced at the cathode. The feed stream is composed of water vapor to be electrolyzed, hydrogen gas for maintaining reducing environment, and possibly an inert gas, presently assumed to be nitrogen.

Figure 1-6 shows the LMTD vs. System overall efficiency for system Configuration 1 (see Figure 1-1). As shown in this figure, the large LMTD decreases the efficiency. The decrease rate is smooth before point $4($ LMTD $=66.5)$, but the efficiency is sharply decreased to lower than $40 \%$ after this point. So, the operating condition was determined at Point 3 in this report, where both high efficiency and high LMTD can be obtained.

Figure 1-7 shows the relationship of the IHX pressure drop and system efficiency. The square symbol is the primary side, and the circle the secondary PCU side. This figure shows that the efficiency decreases with pressure drop linearly. The decrease rates are $0.0167 \% / \mathrm{kPa}$ in the Primary side, and $0.0092 \% / \mathrm{kPa}$ in the secondary side. The lower decrease rate in the PCU side is because of the lower mass flow rate than the primary side. Lower mass flow rate generally requires less pumping power. In this report, the pressure drops in both sides were constrained to $70 \mathrm{kPa}$ for thermal design. In this constraint, system efficiency higher than $44 \%$ can always be achieved.

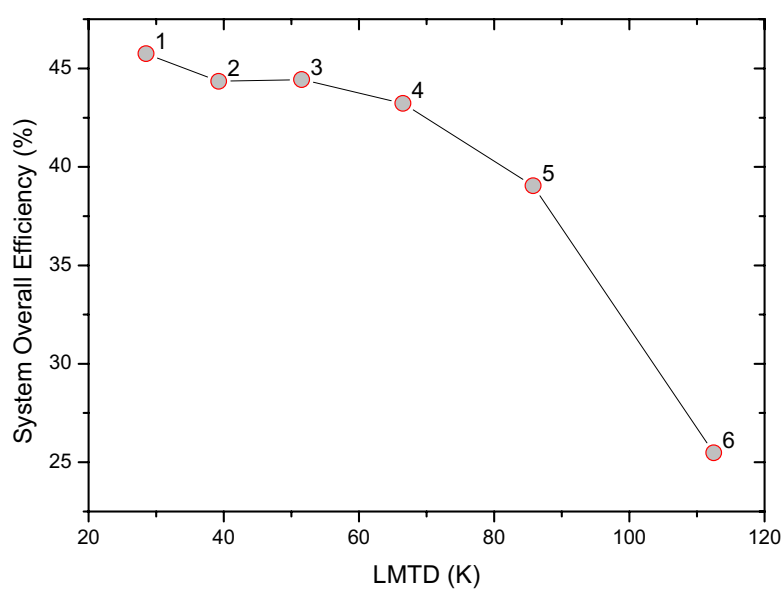

Figure 1-6. LMTD of IHX vs. system overall efficiency for the reference reactor (Configuration 1).

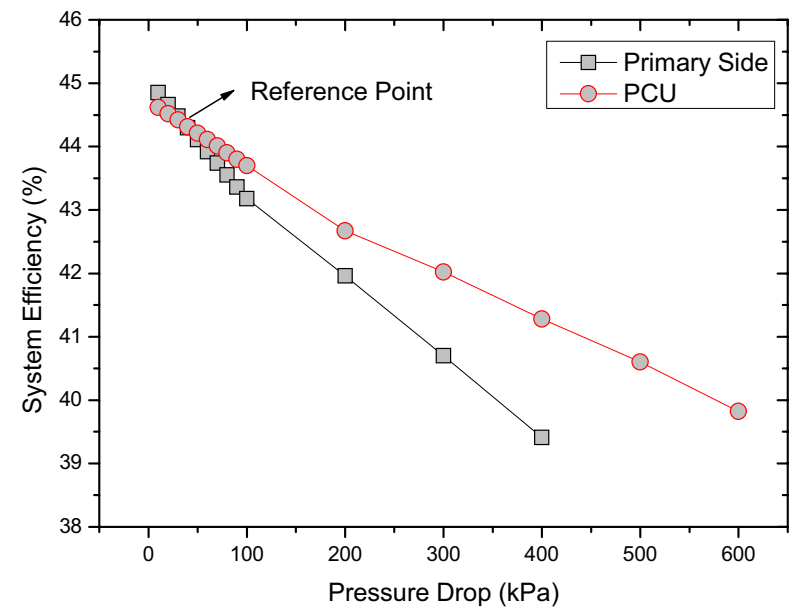

Figure 1-7. Pressure drop $(\mathrm{kPa})$ vs. system efficiency (\%) in the reference reactors (Configuration 1).

From the above estimations, the IHX design conditions were obtained for both Configuration 1 and Configuration 2. They are summarized in Table 1-1 (Configuration 1) and Table 1-2 (Configuration 2). In addition to the IHX design, this work considered SHX design, because SHXs usually experience much more serious operating conditions. The SHX usually requires a $900^{\circ} \mathrm{C}$ operating temperature and 2-5 MPa in the maximum pressure differences between the hot and cold side channels. 
Table 1-1. Heat exchanger design conditions for Configuration 1 (Figure 1-1).

\begin{tabular}{|l|c|c|}
\hline \multicolumn{1}{|c|}{ Conditions } & IHX & SHX \\
\hline Duty [MWt] & 611 & 53 \\
\hline LMTD $\left[{ }^{\circ} \mathrm{C}\right]$ & 45.37 & 50 \\
\hline Tube Side Coolant & $\mathrm{He}$ & $\mathrm{He}$ \\
\hline Shell Side Coolant & $\mathrm{He}$ & $\mathrm{He}$ \\
\hline Tube Inlet Temperature $\left[{ }^{\circ} \mathrm{C}\right]$ & 900 & 885 \\
\hline Tube Outlet Temperature $\left[{ }^{\circ} \mathrm{C}\right]$ & 594.5 & 480.9 \\
\hline Tube Side Pressure $[\mathrm{MPa}]$ & 7 & 7.535 \\
\hline Mass Flow in Tube Side $[\mathrm{kg} / \mathrm{s}]$ & 385.3 & 25.3 \\
\hline Shell Inlet Temperature $\left[{ }^{\circ} \mathrm{C}\right]$ & 492.5 & 337.2 \\
\hline Shell Outlet Temperature $\left[{ }^{\circ} \mathrm{C}\right]$ & 884.8 & 875.1 \\
\hline Shell Side Pressure $[\mathrm{MPa}]$ & 7.584 & 1.95 \\
\hline Mass Flow in Shell Side $[\mathrm{kg} / \mathrm{s}]$ & 300 & 19 \\
\hline
\end{tabular}

Table 1-2. Heat exchanger design conditions for Configuration 2 (Figure 1-2).

\begin{tabular}{|l|c|c|}
\hline \multicolumn{1}{|c|}{ Conditions } & IHX & SHX \\
\hline Duty $[\mathrm{MWt}]$ & 565 & 55 \\
\hline LMTD $\left[{ }^{\circ} \mathrm{C}\right]$ & 34 & 50 \\
\hline Tube Side Coolant & $\mathrm{He}$ & $\mathrm{He}$ \\
\hline Shell Side Coolant & $\mathrm{He}$ & $\mathrm{He}$ \\
\hline Tube Inlet Temperature $\left[{ }^{\circ} \mathrm{C}\right]$ & 877.9 & 900 \\
\hline Tube Outlet Temperature $\left[{ }^{\circ} \mathrm{C}\right]$ & 649.6 & 877.9 \\
\hline Tube Side Pressure $[\mathrm{MPa}]$ & 6.97 & 7 \\
\hline Mass Flow in Tube Side $[\mathrm{kg} / \mathrm{s}]$ & 476.2 & 476.2 \\
\hline Shell Inlet Temperature $\left[{ }^{\circ} \mathrm{C}\right]$ & 610.4 & 321 \\
\hline Shell Outlet Temperature $\left[{ }^{\circ} \mathrm{C}\right]$ & 850 & 875.1 \\
\hline Shell Side Pressure $[\mathrm{MPa}]$ & 7.323 & 1.92 \\
\hline Mass Flow in Shell Side $[\mathrm{kg} / \mathrm{s}]$ & 454 & 19 \\
\hline
\end{tabular}

\subsubsection{IHX and SHX Thermal Design}

This section describes thermal designs of the IHX and SHX, which are two major heat exchangers in the VHTR/HTSE system. The IHX transfers heat from primary side to gas turbine system for electric generation. Generally, almost $90-100 \%$ of the heat $(550-600 \mathrm{MWt})$ generated in the reactor core is exchanged by this heat exchanger. On the other hand, the SHX transfers heat from the primary side or PCU side to the hydrogen production system, depending on the system configurations. About $8-10 \%$ of heat is transferred here. Although SHX transfers only a small portion of heat, it suffers the most serious operating conditions in the system. In this section, we carried out parametric studies of the preliminary thermal design of those two heat exchangers. 
The following factors were taken into consideration in our thermal design:

- System configuration

- Configuration 1-Indirect Parallel System (Figure 1-1)

- Configuration 2-Indirect Serial System (Figure 1-2)

- Heat Exchanger type

- PCHE

- Counter Current Flow

- Cross Flow

- Shell-and-Tube

- Straight Pipe Design

- U-Tube Design

- Helical Coil

- Heat exchanger arrangement

- Single Stage

- $\quad$ Two Stage.

We used separate design methods and guidelines for three different heat exchanger types. For thermal design of PCHEs, we followed the general compact heat exchanger design procedure with the equations and parameters summarized by Hesselgreaves (2001). In the thermal design, the printed circuit heat exchangers are generally subjected to few constraints compared to the shell-and-tube heat exchanger. Fluids may be liquid, gas, or two-phase. Multistream and multipass configurations can be assembled and flow arrangements can be truly counter-current, co-current, cross-flow, or a combination of these, at any required pressure drop. The guidelines and constraint used for design of this heat exchanger are well summarized in Appendix A.

The shell-and-tube heat exchanger is the most common heat exchanger type. So the design methods are very well established. In designing this heat exchanger, we followed the general design guidelines provided by the heat transfer and heat exchanger handbooks (Kakac 2002, Hewitt 2002, Kern 1991). Basically, we followed Kern's Method (1991). The design guidelines and criteria for this heat exchanger are summarized in Appendix A.

The helical coil heat exchanger is not a common heat exchanger type. So, there is no good established design method or guideline to follow yet. However, this heat exchanger is a variation of the shell-andtube type. So, we developed our design method for this heat exchanger based on the shell-and-tube heat exchanger design method. The heat transfer and friction loss correlations for helical coils were obtained from the general heat transfer reference books (Kakac 2001, Bejan 2003). The design method of helical coil heat exchangers is described in detail in Appendix B.

Before we carried out the thermal design, some basic design parameters were predetermined in advance. The parameters include channel diameters and pitches. In our PCHE design, the channel diameter was $1.2 \mathrm{~mm}$ and the channel horizontal pitch was $1.46 \mathrm{~mm}$. The channel shape was semicircular. In the shell-and-tube design, the tube inner diameter was $18 \mathrm{~mm}$ and the outer diameter was $20 \mathrm{~mm}$. The tube horizontal pitch was $30 \mathrm{~mm}$ and the pitch arrangement was triangular. In the helical coil design, the diameters, thickness and pitches of the tubes were determined to be the same as the shell-and-tube design. However, in the practical applications, this exchanger type usually requires larger tube size than general shell-and-tube heat exchangers because of manufacturing difficulties. Therefore, the calculated design variables could be different from the real designs. In the helical coil design, the tube arrangement was parallel in line. 


\subsubsection{Single-Stage IHX Thermal Design}

This subsection summarizes the estimated IHX design for the single-stage heat exchanger arrangement. In this layout, the IHX consists of one heat exchanger unit or separate modules aligned in parallel. There are no serial combinations of IHX. Three different heat exchanger types were designed: PCHE, shell-and-tube, and helical coil.

Table 1-3 summarizes the design specifications of PCHEs. Two simple flow configurations - counter current flow and cross flow-were considered for the PCHE design. According to this result, the total core volume of the heat exchanger ranges between 4.78 and $6.028 \mathrm{~m}^{3}$, respectively, and the heat transfer area ranges between 4,645 and $6,466 \mathrm{~m}^{2}$, respectively, for given pressure drop requirements $(\mathrm{dP}<70 \mathrm{kPa})$. These values are based on preliminary calculations that may change in the final design after mechanical or thermal stress is considered. Thermal stress results can limit the channel length because there are large temperature variations in the flow direction.

Table 1-3. Single-stage IHX thermal design (PCHE).

\begin{tabular}{|l|c|c|c|c|}
\hline \multirow{2}{*}{} & \multicolumn{2}{|c|}{ Configuration 1 } & \multicolumn{2}{c|}{ Configuration 2 } \\
\cline { 2 - 5 } & $\begin{array}{c}\text { Counter } \\
\text { Current }\end{array}$ & Cross Flow & $\begin{array}{c}\text { Counter } \\
\text { Current }\end{array}$ & Cross Flow \\
\hline Duty [MWt] & 612 & 612 & 565 & 565 \\
\hline LMTD [ $\left.{ }^{\circ} \mathrm{C}\right]$ & 45.57 & 45.54 & 33.3 & 33.3 \\
\hline $\mathrm{U}\left[\mathrm{W} / \mathrm{m}^{2} \mathrm{~K}\right]$ & 2,313 & 2,564 & 2,565 & 2,625 \\
\hline A $\left[\mathrm{m}^{2}\right]$ & 5,805 & 5,241 & 4,645 & 6,466 \\
\hline Channel Diameter $[\mathrm{m}]$ & $1.20 \mathrm{E}-03$ & $1.20 \mathrm{E}-03$ & $1.20 \mathrm{E}-03$ & $1.20 \mathrm{E}-03$ \\
\hline Channel Pitch [m] & $1.46 \mathrm{E}-03$ & $1.46 \mathrm{E}-03$ & $1.46 \mathrm{E}-03$ & $1.46 \mathrm{E}-03$ \\
\hline Plate Thickness [m] & $9.60 \mathrm{E}-04$ & $9.60 \mathrm{E}-04$ & $9.60 \mathrm{E}-04$ & $9.60 \mathrm{E}-04$ \\
\hline Surface Area Density $\left[\mathrm{m}^{2}\right]$ & 2,195 & 2,195 & 2,195 & 2,195 \\
\hline Ratio of free flow and frontal area & 0.2148 & 0.2148 & 0.4024 & 0.4024 \\
\hline Effective Diameter [m] & $7.33 \mathrm{E}-04$ & $7.33 \mathrm{E}-04$ & $7.33 \mathrm{E}-04$ & $7.33 \mathrm{E}-04$ \\
\hline Stack Width [m] & 0.6 & 0.55 & 0.6 & 0.42 \\
\hline Stack Length [m] & 0.43 & 0.38 & 0.41 & 0.41 \\
\hline Stack Height [m] & 0.6 & 0.6 & 0.6 & 0.6 \\
\hline \# of Stacks & 34 & 39 & 41 & 57.02 \\
\hline Total Core Volume $\left[\mathrm{m}^{3}\right]$ & 5.29 & 4.78 & 6.028 & 5.891 \\
\hline HTC-Primary [W/m $\left.{ }^{2} \mathrm{~K}\right]$ & 5,514 & 5,428 & 5,562 & 5,657 \\
\hline HTC-Secondary $\left[\mathrm{W} / \mathrm{m}^{2} \mathrm{~K}\right]$ & 4,116 & 5,058 & 4,949 & 5,103 \\
\hline Pressure Drop $($ Primary) $[\mathrm{kPa}]$ & 66.83 & 56.34 & 67.75 & 67.59 \\
\hline Pressure Drop $($ Secondary) $[\mathrm{kPa}]$ & 31.76 & 70.02 & 51.57 & 57.53 \\
\hline
\end{tabular}


Table 1-4 summarizes the design specifications of shell-and-tube-type heat exchangers. The design constraints and guidelines for this design are described in Appendix A. Two different tube configurations were considered for this design: straight pipe and U-tube. The total estimated core volumes of the heat exchangers range between 379 and $483 \mathrm{~m}^{3}$, and the heat transfer areas range between 28,300 and $42,300 \mathrm{~m}^{2}$. The U-tube design is smaller and much more resistant to the thermal expansion than the straight pipe design, making it the generally preferred design for the high temperature application. Compared to the PCHE design, the volume is about 60 times larger and the heat transfer area is about seven times larger than the shell-and-tube design. The difference is PCHE's large surface area density and large heat transfer coefficient caused by a small channel size.

Table 1-4 Single stage IHX thermal design (shell-and-tube).

\begin{tabular}{|l|c|c|c|c|}
\hline \multirow{2}{*}{\multicolumn{1}{c|}{ Conditions }} & \multicolumn{2}{c|}{ Configuration 1 } & \multicolumn{2}{c|}{ Configuration 2 } \\
\cline { 2 - 5 } & Straight Pipe & U Tube & Straight Pipe & U Tube \\
\hline Duty [MWt] & 612 & 612 & 565 & 565 \\
\hline LMTD $\left[{ }^{\circ} \mathrm{C}\right]$ & 45.57 & 45.54 & 33.3 & 33.3 \\
\hline $\mathrm{U}\left[\mathrm{W} / \mathrm{m}^{2} \mathrm{~K}\right]$ & 380.5 & 474 & 405.7 & 496.7 \\
\hline A $\left[\mathrm{m}^{2}\right]$ & $3.53 \mathrm{E}+04$ & $2.83 \mathrm{E}+04$ & $4.13 \mathrm{E}+04$ & $3.42 \mathrm{E}+04$ \\
\hline Tube Inner Diameter [mm] & $1.80 \mathrm{E}+01$ & $1.80 \mathrm{E}+01$ & $1.80 \mathrm{E}+01$ & $1.80 \mathrm{E}+01$ \\
\hline Tube Outer Diameter [mm] & $2.00 \mathrm{E}+01$ & $2.00 \mathrm{E}+01$ & $2.00 \mathrm{E}+01$ & $2.00 \mathrm{E}+01$ \\
\hline Tube Pitch [mm] & $3.00 \mathrm{E}+01$ & $3.00 \mathrm{E}+01$ & $3.00 \mathrm{E}+01$ & $3.00 \mathrm{E}+01$ \\
\hline Pitch-to-diameter ratio & 1.5 & 1.5 & 1.5 & 1.5 \\
\hline Tube Length [m] & 19.56 & 15.42 & 19.6 & 14.69 \\
\hline Tube Thickness [mm] & $1.00 \mathrm{E}+00$ & $1.00 \mathrm{E}+00$ & $1.00 \mathrm{E}+00$ & $1.00 \mathrm{E}+00$ \\
\hline \# of Tubes & $2.87 \mathrm{E}+04$ & 2.924 & $2.36 \mathrm{E}+04$ & $3.70 \mathrm{E}+04$ \\
\hline Shell Diameter [m] & 5,550 & 5,600 & 6,000 & 6,300 \\
\hline Baffle Spacing [m] & 4,000 & 4,000 & 5,200 & 5,000 \\
\hline Aspect Ratio & 0.28 & 0.3631 & 0.3061 & 0.4287 \\
\hline Total Core Volume [m $\left.{ }^{3}\right]$ & 473 & 379.9 & 554.2 & 458.1 \\
\hline Pressure Drop (Tube Side) $[\mathrm{kPa}]$ & 13 & 73.11 & 14.6 & 69.36 \\
\hline Pressure Drop (Shell Side) $[\mathrm{kPa}]$ & 69.83 & 57.15 & 69.88 & 59.56 \\
\hline
\end{tabular}

Table 1-5 summarizes the design specifications of the helical coil heat exchanger. A detailed design method is described in Appendix B. Diameters, thickness, and pitches of the tubes were determined to be the same as the standard shell-and-tube heat exchangers. The total estimated core volumes of the heat exchangers range between 163 and $192 \mathrm{~m}^{3}$, and the heat transfer area ranges between 13,200 and $13,500 \mathrm{~m}^{2}$, which is about one-half the size of the standard shell-and-tube design. The size reduction is due to the heat transfer enhancement in the helical coil. However, its size is still much larger than the PCHE type. In addition, helical coil heat exchangers usually require larger sized tubes in practice because of the manufacturing problems. Therefore, the actual size of the helical coil heat exchanger would be a little larger than the dimensions given in Table 1-5. 
Table 1-5. Single stage IHX thermal design (helical coil).

\begin{tabular}{|l|c|c|}
\hline \multicolumn{1}{|c|}{ Conditions } & Configuration 1 & Configuration 2 \\
\hline Duty [MWt] & 612 & 565 \\
\hline LMTD $\left[{ }^{\circ} \mathrm{C}\right]$ & 45.58 & 33.31 \\
\hline $\mathrm{U}\left[\mathrm{W} / \mathrm{m}^{2} \mathrm{~K}\right]$ & 1,189 & 1,284 \\
\hline A $\left[\mathrm{m}^{2}\right]$ & $1.354 \mathrm{e} 4$ & $1.32 \mathrm{e} 4$ \\
\hline Tube Inner Diameter $[\mathrm{mm}]$ & 18 & 18 \\
\hline Tube Outer Diameter $[\mathrm{mm}]$ & 2 & 2 \\
\hline Tube Pitch [mm] & 30 & 30 \\
\hline Pitch-to-diameter Ratio & 1.5 & 1.5 \\
\hline Number of Tubes & 5,025 & 5,899 \\
\hline Number of Coiled Columns & 3.33 & 3.8 \\
\hline Shell Inner Diameter $[\mathrm{m}]$ & 0.49 & 0.57 \\
\hline Shell Outer Diameter $[\mathrm{m}]$ & 4.6 & 5.4 \\
\hline Shell Length $[\mathrm{m}]$ & 9.86 & 8.37 \\
\hline Volume $\left[\mathrm{m}^{3}\right]$ & 163.8 & 191.6 \\
\hline Aspect Ratio (Ds/L) & 0.47 & 0.65 \\
\hline dP (tube) $[\mathrm{kPa}]$ & 66.57 & 70.27 \\
\hline dP (shell) $[\mathrm{kPa}]$ & 62.51 & 72.45 \\
\hline
\end{tabular}

An extensive comparison of these three heat changer types was conducted to determine their advantages and disadvantages with VHTR IHX applications. The results are summarized below.

Using the PCHE type heat exchanger as an IHX would have the following advantages in the thermal design:

- Smaller Size. A heat exchanger's size can be represented by its total volume. A smaller volume is generally preferred in high temperature applications because high-alloy metals or ceramics are very costly and a smaller heat exchanger reduces the total system size. As shown in Tables 1-3, 1-4, and 1-5 the PCHE with cross flow is the smallest, the helical tube next, and shell-and-tube the largest.

- Smaller Heat Transfer Area. Tritium permeation into a hydrogen plant is a serious problem that can occur when the hydrogen production system is integrated with a VHTR. Since tritium permeation is proportional to the heat transfer surface area, a smaller heat transfer area is preferred. The PCHE has the smallest heat transfer area, the helical coil type is next, and shell-and-tube type has the largest heat transfer area.

Compared with PCHEs, the tubular heat exchanger design (shell-and-tube and helical coil) has the following advantages as an IHX:

- Greater Simplicity. The number of modules is related to the system complexity, fewer modules are preferred to simplify the design. The PCHE design requires rather complex manifold and flow connections between modules, which is not the case in the tubular design. A shell-and-tube design would make the system simpler.

- Lower Thermal Stress. In high temperature applications, thermal stress is an important issue. The compactness of the PCHE provides excellent heat performance, but the fast temperature variations in the flow direction seems to create extensive thermal stress. 
- System Readiness. Tubular type heat exchangers are a well proven technology in the industry. Helical coil heat exchangers have an especially good operating history such as its application in the Japanese High Temperature Test Reactor (HTTR). Technically, the PCHE type appears to have great potential for use high temperature applications, but they are not proven for large-scale, long-lifetime applications.

- Easier Maintenance. Tubular type heat exchangers are a proven technology with well known problems and limitations throughout the industry. Generally, tubular heat exchangers allow for inservice inspection and have well-established maintenance methods. Conversely, finding defects and failures in PCHE operations appears difficult and it will not be easy to perform maintenance compared to the tubular design.

In summary, the PCHE has a definite size and heat transfer advantage, which would lead to enormous cost savings and enhanced safety. But the tubular-type heat exchanger is a ready-to-use technology, especially the helical coil heat exchanger, which has good operating records such as the HTTR in Japan. Technically, the PCHE type is strongly recommended for the VHTR-hydrogen production application because of its significantly reduced size, cost efficiency, and safety. However, the tubular-type heat exchanger can be a good near-term option that avoids some long-term operation and maintenance risks associated with the unproven PCHE. The heat exchanger design specifications shown in Tables 1-3, 1-4, and 1-5 above were calculated based on design conditions listed in Tables 1-1 and 1-2.

\subsubsection{Two-Stage IHX Thermal Design}

Another option for the IHX layout is the two-stage arrangement where the IHX is split into two units: High Temperature Unit and Low Temperature Unit. This option was recommended to reduce associated risk and cost. In this concept, two heat exchangers are arranged and connected in serial. The low temperature unit is designed to last the full plant lifetime where the maximum temperature is proposed to be around $760^{\circ} \mathrm{C}$, allowed in ASME Section III, Subsection NH materials. The high temperature unit is designed for replacement within the plant lifetime. Alloys 617 and 230 are considered potential candidates for this unit. Figure 1-8 shows the flow schematics and design conditions for each unit estimated by HYSYS code (ASPEN 2005). The overall design conditions are the same as the single-stage IHX in Tables 1-1 and 1-2, but is split into two units, which affects the LMTD required for both. For example: the LMTD in the high temperature unit decreases to $31.69^{\circ} \mathrm{C}$ as seen in Configuration 1 , while the LMDT in the low temperature unit increases to $77.74^{\circ} \mathrm{C}$ compared to the value in the single-stage IHX of $45.37^{\circ} \mathrm{C}$.

As in the single-stage layout, each unit was designed for three different heat exchanger types: PCHE, shell-and-tube, and helical coil. Even though Alloy 617 was the proposed construction material, the effect of materials on the heat exchanger has not been considered in the current thermal analysis because the type of material has only a slight effect on the heat exchanger thermal design according to Natesan et al. (2006)'s research. The reason is that the thermal resistance in the heat exchanger wall is much smaller than in the gas fluids. Even for the ceramic materials, Natesan's report (2006) only showed a size reduction of about $13 \%$. 
(a) Configuration 1

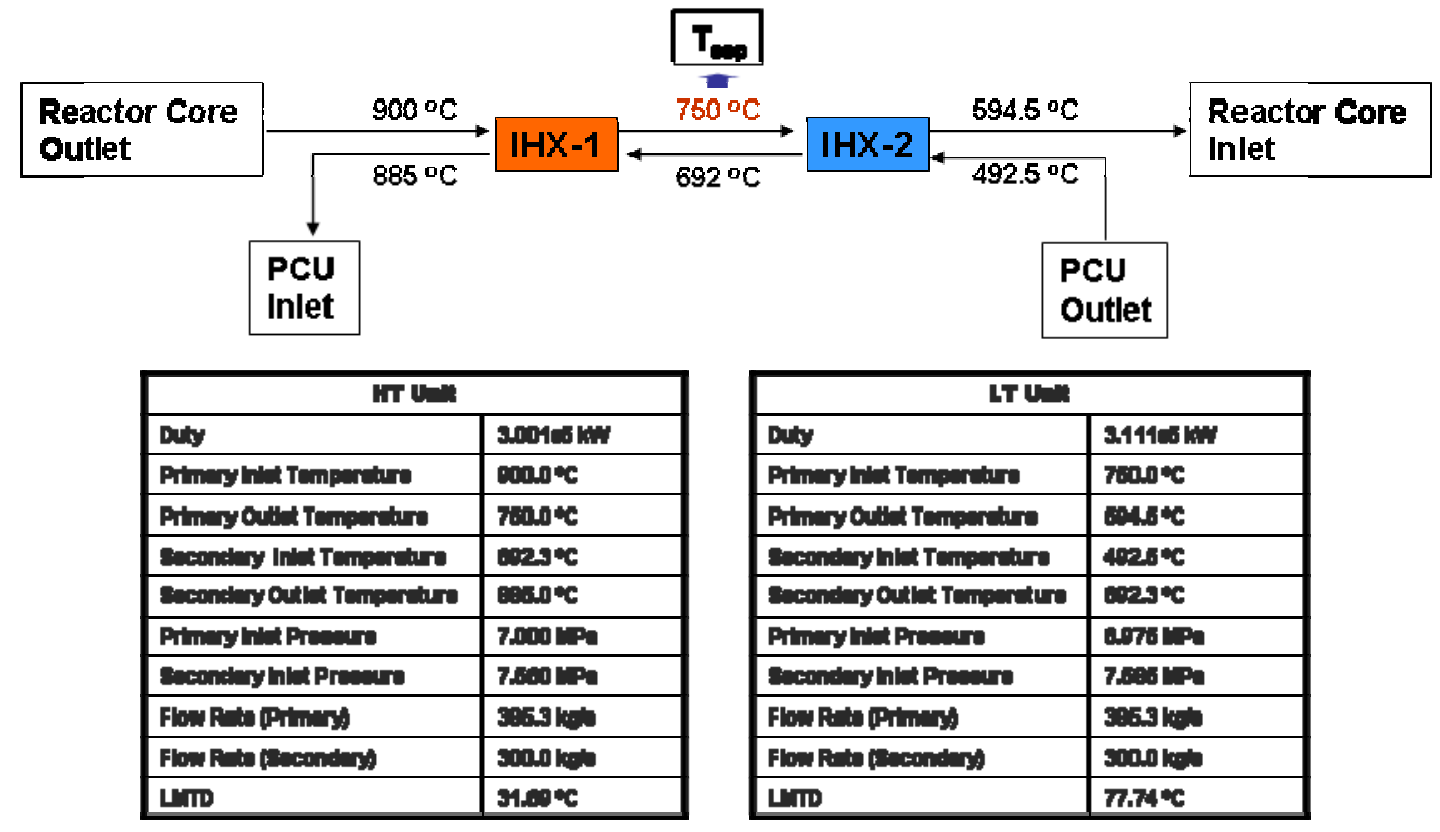

(b) Configuration 2

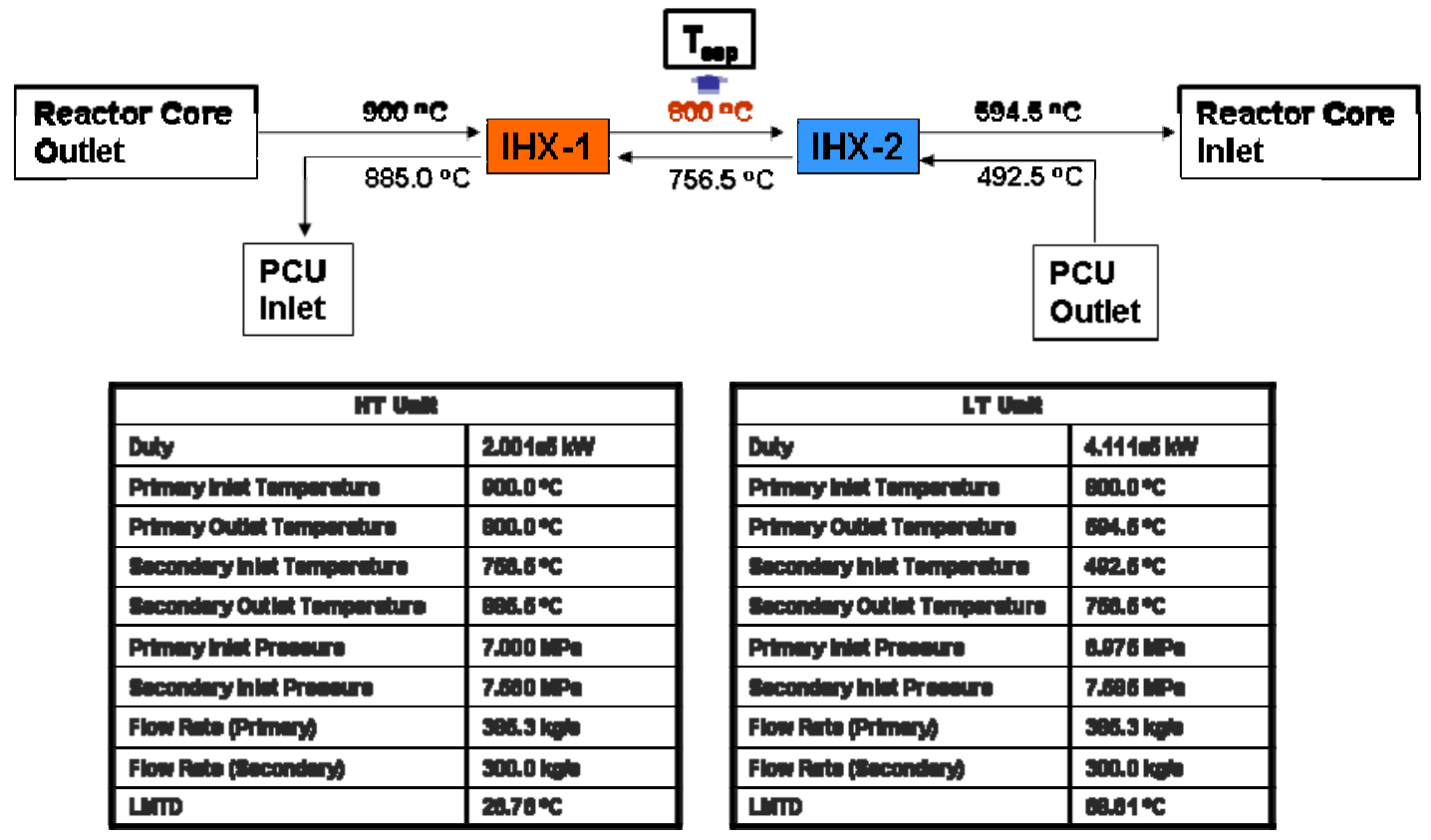

Figure 1-8. Operating condition of two-stage IHX.

Tables 1-6 through 1-8 summarize the design specifications of high temperature unit and Tables 1-9 through 1-11 summarize the design specifications of low temperature unit. PCHE, shell-and-tube, and helical coil types of heat exchangers were designed for both units. The pressure drop for each unit was also determined within the total pressure drop (in the high temperature section + low temperature section), $70 \mathrm{kPa}$ to match the single-stage IHX design. 
Table 1-6. Two-stage IHX thermal design (high temperature section, PCHE).

\begin{tabular}{|c|c|c|c|c|}
\hline \multirow[b]{2}{*}{ Conditions } & \multicolumn{2}{|c|}{ Configuration 1} & \multicolumn{2}{|c|}{ Configuration 2} \\
\hline & $\begin{array}{l}\text { Counter } \\
\text { Current } \\
\end{array}$ & Cross Flow & $\begin{array}{l}\text { Counter } \\
\text { Current } \\
\end{array}$ & Cross Flow \\
\hline Duty [MWt] & 300 & 300 & 317 & 317 \\
\hline LMTD $\left[{ }^{\circ} \mathrm{C}\right]$ & 31.74 & 31.73 & 30.97 & 30.97 \\
\hline $\mathrm{U}\left[\mathrm{W} / \mathrm{m}^{2} \mathrm{~K}\right]$ & 2410 & 2443 & 2615 & 2440 \\
\hline $\mathrm{A}\left[\mathrm{m}^{2}\right]$ & 3928 & 3877 & 3911 & 4191 \\
\hline Channel Diameter [m] & $1.20 \mathrm{E}-03$ & $1.20 \mathrm{E}-03$ & $1.20 \mathrm{E}-03$ & $1.20 \mathrm{E}-03$ \\
\hline Channel Pitch [m] & $1.46 \mathrm{E}-03$ & $1.46 \mathrm{E}-03$ & $1.46 \mathrm{E}-03$ & $1.46 \mathrm{E}-03$ \\
\hline Plate Thickness [m] & $9.60 \mathrm{E}-04$ & $9.60 \mathrm{E}-04$ & $9.60 \mathrm{E}-04$ & $9.60 \mathrm{E}-04$ \\
\hline Surface Area Density $\left[\mathrm{m}^{2}\right]$ & 2195 & 2195 & 2195 & 2195 \\
\hline Ratio of free flow and frontal area & 0.2148 & 0.2148 & 0.4024 & 0.4024 \\
\hline Effective Diameter [m] & $7.33 \mathrm{E}-04$ & 7.33E-04 & 7.33E-04 & 7.33E-04 \\
\hline Stack Width [m] & 0.6 & 0.34 & 0.6 & 0.23 \\
\hline Stack Length [m] & 0.29 & 0.25 & 0.24 & 0.23 \\
\hline Stack Height [m] & 0.6 & 0.6 & 0.6 & 0.6 \\
\hline \# of Stacks & 34 & 70 & 41 & 120 \\
\hline Total Core Volume $\left[\mathrm{m}^{3}\right]$ & 3.569 & 3.5 & 3.564 & 3.819 \\
\hline HTC-Primary $\left[\mathrm{W} / \mathrm{m}^{2} \mathrm{~K}\right]$ & 5505 & 5060 & 5561 & 5182 \\
\hline HTC-Secondary $\left[\mathrm{W} / \mathrm{m}^{2} \mathrm{~K}\right]$ & 4440 & 4908 & 5138 & 4788 \\
\hline Pressure Drop (Primary) [kPa] & 49.2 & 33.67 & 42.36 & 1.82 \\
\hline Pressure Drop (Secondary) $[\mathrm{kPa}]$ & 26.89 & 40.94 & 34.11 & 26.92 \\
\hline
\end{tabular}


Table 1-7. Two-stage IHX thermal design (high temperature section, shell-and-tube).

\begin{tabular}{|l|c|c|c|c|}
\hline \multirow{2}{*}{\multicolumn{1}{c|}{ Conditions }} & \multicolumn{2}{c|}{ Configuration 1 } & \multicolumn{2}{c|}{ Configuration 2 } \\
\cline { 2 - 5 } & Straight Pipe & U Tube & Straight Pipe & U Tube \\
\hline Duty $[\mathrm{MWt}]$ & 300 & 300 & 316 & 316 \\
\hline LMTD [ $\left.{ }^{\circ}\right]$ & 31.74 & 31.74 & 31.77 & 31.77 \\
\hline $\mathrm{U}\left[\mathrm{W} / \mathrm{m}^{2} \mathrm{~K}\right]$ & $3.96 \mathrm{E}+02$ & $4.90 \mathrm{E}+02$ & $4.13 \mathrm{E}+02$ & $5.08 \mathrm{E}+02$ \\
\hline A $\left[\mathrm{m}^{2}\right]$ & $2.39 \mathrm{E}+04$ & $1.93 \mathrm{E}+04$ & $2.41 \mathrm{E}+04$ & $2.01 \mathrm{E}+04$ \\
\hline Tube Inner Diameter [mm] & $1.80 \mathrm{E}+01$ & $1.80 \mathrm{E}+01$ & $1.80 \mathrm{E}+01$ & $1.80 \mathrm{E}+01$ \\
\hline Tube Outer Diameter $[\mathrm{mm}]$ & $2.00 \mathrm{E}+01$ & $2.00 \mathrm{E}+01$ & $2.00 \mathrm{E}+01$ & $2.00 \mathrm{E}+01$ \\
\hline Tube Pitch [mm] & $3.00 \mathrm{E}+01$ & $3.00 \mathrm{E}+01$ & $3.00 \mathrm{E}+01$ & $3.00 \mathrm{E}+01$ \\
\hline Pitch-to-diameter ratio & 1.5 & 1.5 & 1.5 & 1.5 \\
\hline Tube Length [m] & $1.04 \mathrm{E}+01$ & 10.16 & $1.14 \mathrm{E}+01$ & $8.65 \mathrm{E}+01$ \\
\hline Tube Thickness [mm] & $1.00 \mathrm{E}+00$ & $1.00 \mathrm{E}+00$ & $1.00 \mathrm{E}+00$ & $1.00 \mathrm{E}+00$ \\
\hline \# of Tubes & $2.87 \mathrm{E}+04$ & $3.03 \mathrm{E}+04$ & $3.357 \mathrm{E}+04$ & $3.701 \mathrm{E}+04$ \\
\hline Shell Diameter [m] & 5550 & 5700 & 6000 & 6300 \\
\hline Baffle Spacing [m] & 4000 & 4000 & 5200 & 5000 \\
\hline Aspect Ratio & 0.72 & 0.56 & 0.52 & 0.72 \\
\hline Total Core Volume $\left[\mathrm{m}^{3}\right]$ & 320 & 259 & 323 & 269.8 \\
\hline Pressure Drop (Tube Side) $[\mathrm{kPa}]$ & 10 & 53.88 & 9.54 & 48.65 \\
\hline Pressure Drop (Shell Side) $[\mathrm{kPa}]$ & 51.16 & 41.07 & 46.89 & 41.30 \\
\hline
\end{tabular}

Table 1-8. Two-stage IHX thermal design (high temperature section, helical coil).

\begin{tabular}{|l|c|c|}
\hline & Configuration 1 & Configuration 2 \\
\hline Duty $[\mathrm{MWt}]$ & 300 & 317 \\
\hline $\mathrm{LMTD}\left[{ }^{\circ} \mathrm{C}\right]$ & 31.74 & 30.97 \\
\hline $\mathrm{U}\left[\mathrm{W} / \mathrm{m}^{2} \mathrm{~K}\right]$ & 1249 & 1314 \\
\hline $\mathrm{A}\left[\mathrm{m}^{2}\right]$ & 7580 & 7780 \\
\hline Tube Inner Diameter $[\mathrm{mm}]$ & 18 & 18 \\
\hline Tube Outer Diameter $[\mathrm{mm}]$ & 2 & 2 \\
\hline Tube Pitch $[\mathrm{mm}]$ & 30 & 30 \\
\hline Pitch-to-diameter Ratio & 1.5 & 1.5 \\
\hline Number of Tubes & 5025 & 5899 \\
\hline Number of Coiled Columns & 3.007 & 2.239 \\
\hline Shell Inner Diameter $[\mathrm{m}]$ & 0.4883 & 0.57 \\
\hline Shell Outer Diameter $[\mathrm{m}]$ & 4.6 & 5.4 \\
\hline Shell Length $[\mathrm{m}]$ & 6.614 & 4.9 \\
\hline Volume $\left[\mathrm{m}^{3}\right]$ & 109.9 & 112.8 \\
\hline Aspect Ratio (Ds/L) & 0.7 & 1.1 \\
\hline dP (tube) $[\mathrm{kPa}]$ & 44.67 & 41.37 \\
\hline dP (shell) $[\mathrm{kPa}]$ & 52.87 & 47.73 \\
\hline
\end{tabular}


Table 1-9. Two-stage IHX thermal design (low temperature section, PCHE).

\begin{tabular}{|c|c|c|c|c|}
\hline & \multicolumn{2}{|c|}{ Configuration 1} & \multicolumn{2}{|c|}{ Configuration 2} \\
\hline & $\begin{array}{l}\text { Counter } \\
\text { Current }\end{array}$ & Cross Flow & $\begin{array}{l}\text { Counter } \\
\text { Current }\end{array}$ & Cross Flow \\
\hline Duty [MWt] & 312 & 312 & 249 & 249 \\
\hline LMTD $\left[{ }^{\circ} \mathrm{C}\right]$ & 77.83 & 77.82 & 36.69 & 36.69 \\
\hline $\mathrm{U}\left[\mathrm{W} / \mathrm{m}^{2} \mathrm{~K}\right]$ & 2259 & 2735 & 2518 & 2603 \\
\hline $\mathrm{A}\left[\mathrm{m}^{2}\right]$ & 1772 & 1464 & 2691 & 2604 \\
\hline Channel Diameter $[\mathrm{m}]$ & $1.20 \mathrm{E}-03$ & $1.20 \mathrm{E}-03$ & $1.20 \mathrm{E}-03$ & $1.20 \mathrm{E}-03$ \\
\hline Channel Pitch [m] & $1.46 \mathrm{E}-03$ & $1.46 \mathrm{E}-03$ & $1.46 \mathrm{E}-03$ & $1.46 \mathrm{E}-03$ \\
\hline Plate Thickness [m] & $9.60 \mathrm{E}-04$ & $9.60 \mathrm{E}-04$ & $9.60 \mathrm{E}-04$ & $9.60 \mathrm{E}-04$ \\
\hline Surface Area Density $\left[\mathrm{m}^{2}\right]$ & 2195 & 2195 & 2195 & 2195 \\
\hline Ratio of free flow and frontal area & 0.2148 & 0.2148 & 0.4024 & 0.4024 \\
\hline Effective Diameter [m] & 7.33E-04 & 7.33E-04 & $7.33 \mathrm{E}-04$ & 7.33E-04 \\
\hline Stack Width [m] & 0.6 & 0.16 & 0.6 & 0.17 \\
\hline Stack Length [m] & 0.13 & 0.14 & 0.16 & 0.17 \\
\hline Stack Height [m] & 0.6 & 0.6 & 0.6 & 0.6 \\
\hline \# of Stacks & 34 & 100 & 41 & 136.8 \\
\hline Total Core Volume $\left[\mathrm{m}^{3}\right]$ & 1.606 & 1.334 & 2.452 & 2.373 \\
\hline HTC-Primary $\left[\mathrm{W} / \mathrm{m}^{2} \mathrm{~K}\right]$ & 5259 & 8125 & 5348 & 5531 \\
\hline HTC-Secondary $\left[\mathrm{W} / \mathrm{m}^{2} \mathrm{~K}\right]$ & 4110 & 5146 & 4948 & 5117 \\
\hline Pressure Drop (Primary) $[\mathrm{kPa}]$ & 19.02 & 30.45 & 26.11 & 27.38 \\
\hline Pressure Drop (Secondary) $[\mathrm{kPa}]$ & 9.6 & 21.74 & 20.97 & 23.48 \\
\hline
\end{tabular}


Table 1-10. Two-stage IHX thermal design (low temperature section, shell and tube).

\begin{tabular}{|l|c|c|c|c|}
\hline & \multicolumn{2}{|c|}{ Configuration 1 } & \multicolumn{2}{c|}{ Configuration 2 } \\
\hline & $\begin{array}{c}\text { Straight } \\
\text { Pipe }\end{array}$ & U Tube & $\begin{array}{c}\text { Straight } \\
\text { Pipe }\end{array}$ & U Tube \\
\hline Duty [MWt] & 312 & 312 & 249 & 249 \\
\hline LMTD [ $\left.{ }^{\circ}\right]$ & 77.83 & 77.83 & 37.09 & 36.69 \\
\hline $\mathrm{U}\left[\mathrm{W} / \mathrm{m}^{2} \mathrm{~K}\right]$ & $3.74 \mathrm{E}+02$ & $4.61 \mathrm{E}+02$ & $4.00 \mathrm{E}+02$ & $4.91 \mathrm{E}+02$ \\
\hline A $\left[\mathrm{m}^{2}\right]$ & $1.07 \mathrm{E}+04$ & $8.69 \mathrm{E}+03$ & $1.677 \mathrm{E}+04$ & $1.38 \mathrm{E}+04$ \\
\hline Tube Inner Diameter $[\mathrm{mm}]$ & $1.80 \mathrm{E}+01$ & $1.80 \mathrm{E}+01$ & $1.80 \mathrm{E}+01$ & $1.80 \mathrm{E}+01$ \\
\hline Tube Outer Diameter $[\mathrm{mm}]$ & $2.00 \mathrm{E}+01$ & $2.00 \mathrm{E}+01$ & $2.00 \mathrm{E}+01$ & $2.00 \mathrm{E}+01$ \\
\hline Tube Pitch [mm] & $3.00 \mathrm{E}+01$ & $3.00 \mathrm{E}+01$ & $3.00 \mathrm{E}+01$ & $3.00 \mathrm{E}+01$ \\
\hline Pitch-to-diameter ratio & 1.5 & 1.5 & 1.5 & 1.5 \\
\hline Tube Length [m] & $5.97 \mathrm{E}+00$ & 4.564 & $7.95 \mathrm{E}+00$ & 5.933 \\
\hline Tube Thickness [mm] & $1.00 \mathrm{E}+00$ & $1.00 \mathrm{E}+00$ & $1.00 \mathrm{E}+00$ & $1.00 \mathrm{E}+00$ \\
\hline \# of Tubes & $2.87 \mathrm{E}+04$ & $3.03 \mathrm{E}+04$ & $3.357 \mathrm{E}+04$ & $3.701 \mathrm{E}+04$ \\
\hline Shell Diameter [m] & 5550 & 5700 & 6000 & 6300 \\
\hline Baffle Spacing [m] & 4000 & 4000 & 5200 & 5000 \\
\hline Aspect Ratio & 0.9394 & 1.249 & 0.75 & 0.79 \\
\hline Total Core Volume $\left[\mathrm{m}^{3}\right]$ & 143.4 & 116.5 & 224 & 185.0 \\
\hline Pressure Drop (Tube Side) $[\mathrm{kPa}]$ & 4.793 & 26.95 & 6.463 & 33.61 \\
\hline Pressure Drop (Shell Side) $[\mathrm{kPa}]$ & 29.42 & 24.84 & 37.06 & 33.07 \\
\hline
\end{tabular}

Table 1-11. Two-stage IHX thermal design (low temperature section, helical coil).

\begin{tabular}{|l|c|c|}
\hline & Configuration 1 & Configuration 2 \\
\hline Duty $[\mathrm{MWt}]$ & 312 & 249 \\
\hline LMTD $\left[{ }^{\circ} \mathrm{C}\right]$ & 77.83 & 36.69 \\
\hline $\mathrm{U}\left[\mathrm{W} / \mathrm{m}^{2} \mathrm{~K}\right]$ & 1176 & 1271 \\
\hline $\mathrm{A}\left[\mathrm{m}^{2}\right]$ & 3405 & 5332 \\
\hline Tube Inner Diameter $[\mathrm{mm}]$ & 18 & 18 \\
\hline Tube Outer Diameter $[\mathrm{mm}]$ & 2 & 2 \\
\hline Tube Pitch $[\mathrm{mm}]$ & 30 & 30 \\
\hline Pitch-to-diameter Ratio & 1.5 & 1.5 \\
\hline Number of Tubes & 5025 & 5899 \\
\hline Number of Coiled Columns & 1.35 & 1.54 \\
\hline Shell Inner Diameter $[\mathrm{m}]$ & 0.49 & 0.57 \\
\hline Shell Outer Diameter $[\mathrm{m}]$ & 4.6 & 5.4 \\
\hline Shell Length $[\mathrm{m}]$ & 2.97 & 3.376 \\
\hline Volume $\left[\mathrm{m}^{3}\right]$ & 49.38 & 77.32 \\
\hline Aspect Ratio $(\mathrm{Ds} / \mathrm{L})$ & 1.5 & 1.6 \\
\hline dP (tube) $[\mathrm{kPa}]$ & 17.51 & 25.21 \\
\hline dP (shell) $[\mathrm{kPa}]$ & 18.84 & 29.23 \\
\hline
\end{tabular}


In the two-stage IHX layout, each unit can have three different heat exchanger types independently in series such that nine serial combinations are available as shown in Table 1-12.

Table 1-12. Summary of heat exchanger types in the two-stage IHX in series.

\begin{tabular}{|l|l|l|}
\hline Case & \multicolumn{1}{|c|}{ HT Unit } & \multicolumn{1}{|c|}{ LT Unit } \\
\hline C1 & PCHE & PCHE \\
\hline C2 & PCHE & Shell and Tube \\
\hline C3 & PCHE & Helical Coil \\
\hline C4 & Shell and Tube & PCHE \\
\hline C5 & Shell and Tube & Shell and Tube \\
\hline C6 & Shell and Tube & Helical Coil \\
\hline C7 & Helical Coil & PCHE \\
\hline C8 & Helical Coil & Shell and Tube \\
\hline C9 & Helical Coil & Helical Coil \\
\hline
\end{tabular}

Table 1-13 summarizes the heat exchanger core volumes for each option in Table 1-12. The volumes specified in this table were taken from Tables 1-6 though 1-11. Table 1-13 apparently shows that $\mathrm{C} 1$ (PCHE-PCHE) has the smallest total volume thanks to the highest compactness (surface area density = $2,195 \mathrm{~m}^{2}$ ). The smaller size of high temperature unit is highly recommended for cost saving and safety enhancement. Because of the material problems from severe high temperature conditions, careful considerations are necessary for selection and design of the high-temperature-related components. If the high temperature unit becomes smaller, the less effort and cost will be required for manufacturing and maintenance. In addition, the size reduction will enhance the component safety by reducing the probability of an incident.

Table 1-13. Volume of heat exchangers for two-stage IHX.

\begin{tabular}{|l|c|c|c|c|c|c|}
\hline Conditions & \multicolumn{3}{|c|}{ Configuration 1 } & \multicolumn{3}{c|}{ Configuration 2 } \\
\hline Table 1-12 & HT Unit & LT Unit & Total & HT Unit & LT Unit & Total \\
\hline C1 & 3.5 & 1.334 & 4.834 & 3.6 & 2.37 & 5.97 \\
\hline C2 & 3.5 & 116.5 & 120 & 3.6 & 185 & 188.6 \\
\hline C3 & 3.5 & 49.38 & 52.88 & 3.6 & 77.32 & 80.92 \\
\hline C4 & 259 & 1.334 & 260.334 & 269 & 2.37 & 271.37 \\
\hline C5 & 259 & 116.5 & 375.5 & 269 & 185 & 454 \\
\hline C6 & 259 & 49.38 & 308.38 & 269 & 77.32 & 346.32 \\
\hline C7 & 109.9 & 1.334 & 111.23 & 112.8 & 2.37 & 115.17 \\
\hline C8 & 109.9 & 116.5 & 225 & 112.8 & 185 & 297.8 \\
\hline C9 & 109.9 & 49.38 & 159.28 & 112.8 & 77.32 & 189.32 \\
\hline
\end{tabular}

Table 1-14 shows the estimated heat transfer area for the heat exchangers in the serial configurations. As predicted, C1 (PCHE-PCHE) shows the smallest heat transfer area because of the decreased thermal boundary layer with reduced channel diameters. The heat transfer surface areas of other combinations are at least three times larger than that of $\mathrm{C} 1$. 
Table 1-14. Heat transfer area of two-stage IHX.

\begin{tabular}{|l|c|c|c|c|c|c|}
\hline \multirow{2}{*}{$\begin{array}{l}\text { Conditions } \\
\text { Table 1-12 }\end{array}$} & \multicolumn{3}{|c|}{ Configuration 1 } & \multicolumn{3}{c|}{ Configuration 2 } \\
\cline { 2 - 7 } C1 & HT Unit & LT Unit & Total & HT Unit & LT Unit & Total \\
\hline C2 & 3877 & 1464 & 5341 & 3911 & 2604 & 6515 \\
\hline C3 & 3877 & 8690 & 12567 & 3911 & 13800 & 17711 \\
\hline C4 & 3877 & 3405 & 7282 & 3911 & 5332 & 9241 \\
\hline C5 & 19300 & 1464 & 20764 & 20100 & 2604 & 22704 \\
\hline C6 & 19300 & 8690 & 27990 & 20100 & 13800 & 33900 \\
\hline C7 & 19300 & 3405 & 22705 & 20100 & 5332 & 25432 \\
\hline C8 & 7580 & 1464 & 9044 & 7780 & 2604 & 10384 \\
\hline C9 & 7580 & 8690 & 16270 & 7780 & 13800 & 21580 \\
\hline
\end{tabular}

The total duty in the two-stage IHX design was split in half (300 MWt/300 MWt). However, because of the reduced LMTD in the high temperature unit, it requires more than twice of the volume and surface area of the low temperature unit. The total average LMTD of the Configuration 1 system is $45-50^{\circ} \mathrm{C}$, but it reduces to about $30^{\circ} \mathrm{C}$ in the high temperature unit as it is increased up to $70^{\circ} \mathrm{C}$ in the low temperature unit. Since the decrease of the LMTD requires larger heat transfer surface area for the same duty, most parts of the IHX should be operated in the high temperature region.

To reduce the size of the high temperature unit, the separation temperature $\left(\mathrm{T}_{\text {sep }}\right)$ shown in Figure 1-8 has been adjusted to $800^{\circ} \mathrm{C}$. The increase of the separation temperature leads to the decrease of duty in the high temperature unit. It also leads to a decrease in heat exchanger size. However, the increase of the separation temperature makes the low temperature section more vulnerable to the stress. The details about the stress analysis are described in Tables 1-15, 1-16, 1-17, and 1-18. 
Table 1-15. Two-stage IHX thermal design (high temperature section, $\mathrm{PCHE}, \mathrm{T}_{\mathrm{sep}}=800^{\circ} \mathrm{C}$ ).

\begin{tabular}{|c|c|c|c|c|}
\hline \multirow[b]{2}{*}{ Conditions } & \multicolumn{2}{|c|}{ Configuration 1} & \multicolumn{2}{|c|}{ Configuration 2} \\
\hline & $\begin{array}{l}\text { Counter } \\
\text { Current } \\
\end{array}$ & Cross Flow & $\begin{array}{l}\text { Counter } \\
\text { Current } \\
\end{array}$ & Cross Flow \\
\hline Duty $[\mathrm{MWt}]$ & 200 & 200 & 193 & 193 \\
\hline $\operatorname{LMTD}\left[{ }^{\circ} \mathrm{C}\right]$ & 26.81 & 27.36 & 29.75 & 29.75 \\
\hline $\mathrm{U}\left[\mathrm{W} / \mathrm{m}^{2} \mathrm{~K}\right]$ & 2438 & 2617 & 2638 & 2844 \\
\hline $\mathrm{A}\left[\mathrm{m}^{2}\right]$ & 3064 & 2792 & 2458 & 2279 \\
\hline Channel Diameter [m] & $1.20 \mathrm{E}-03$ & $1.20 \mathrm{E}-03$ & $1.20 \mathrm{E}-03$ & $1.20 \mathrm{E}-03$ \\
\hline Channel Pitch [m] & $1.46 \mathrm{E}-03$ & $1.46 \mathrm{E}-03$ & $1.46 \mathrm{E}-03$ & $1.46 \mathrm{E}-03$ \\
\hline Plate Thickness [m] & $9.60 \mathrm{E}-04$ & $9.60 \mathrm{E}-04$ & $9.60 \mathrm{E}-04$ & $9.60 \mathrm{E}-04$ \\
\hline Surface Area Density $\left[\mathrm{m}^{2}\right]$ & 2195 & 2195 & 2195 & 2195 \\
\hline Ratio of free flow and frontal area & 0.2148 & 0.2148 & 0.4024 & 0.4024 \\
\hline Effective Diameter [m] & 7.33E-04 & 7.33E-04 & 7.33E-04 & 7.33E-04 \\
\hline Stack Width $[\mathrm{m}]$ & 0.6 & 0.27 & 0.6 & 0.16 \\
\hline Stack Length [m] & 0.23 & 0.2 & 0.15 & 0.16 \\
\hline Stack Height $[\mathrm{m}]$ & 0.6 & 0.6 & 0.6 & 0.6 \\
\hline \# of Stacks & 34 & 79 & 41 & 135.2 \\
\hline Total Core Volume $\left[\mathrm{m}^{3}\right]$ & 2.784 & 2.549 & 2.239 & 2.077 \\
\hline HTC_-Primary $\left[\mathrm{W} / \mathrm{m}^{2} \mathrm{~K}\right]$ & 5505 & 5384 & 5561 & 6007 \\
\hline $\mathrm{HTC}$-Secondary $\left[\mathrm{W} / \mathrm{m}^{2} \mathrm{~K}\right]$ & 4536 & 5311 & 5228 & 5647 \\
\hline Pressure Drop (Primary) [kPa] & 39.35 & 32.59 & 27.29 & 33.65 \\
\hline Pressure Drop (Secondary) $[\mathrm{kPa}]$ & 22.37 & 40.4 & 22.57 & 29.24 \\
\hline
\end{tabular}


Table 1-16. Two-stage IHX thermal design (high temperature section, shell-and-tube, $\mathrm{T}_{\mathrm{sep}}=800^{\circ} \mathrm{C}$ ).

\begin{tabular}{|c|c|c|c|c|}
\hline \multirow[b]{2}{*}{ Conditions } & \multicolumn{2}{|c|}{ Configuration 1} & \multicolumn{2}{|c|}{ Configuration 2} \\
\hline & Straight Pipe & U Tube & Straight Pipe & U Tube \\
\hline Duty $[\mathrm{MWt}]$ & 200 & 200 & 193 & 193 \\
\hline LMTD $\left[{ }^{\circ} \mathrm{C}\right]$ & 26.82 & 26.82 & 29.75 & 29.75 \\
\hline $\mathrm{U}\left[\mathrm{W} / \mathrm{m}^{2} \mathrm{~K}\right]$ & $4.00 \mathrm{E}+02$ & $4.96 \mathrm{E}+02$ & $4.17 \mathrm{E}+02$ & $5.13 \mathrm{E}+02$ \\
\hline $\mathrm{A}\left[\mathrm{m}^{2}\right]$ & $1.87 \mathrm{E}+04$ & $1.50 \mathrm{E}+04$ & $1.57 \mathrm{E}+04$ & $1.26 \mathrm{E}+04$ \\
\hline Tube Inner Diameter [mm] & $1.80 \mathrm{E}+01$ & $1.80 \mathrm{E}+01$ & $1.80 \mathrm{E}+01$ & $1.80 \mathrm{E}+01$ \\
\hline Tube Outer Diameter [mm] & $2.00 \mathrm{E}+01$ & $2.00 \mathrm{E}+01$ & $2.00 \mathrm{E}+01$ & $2.00 \mathrm{E}+01$ \\
\hline Tube Pitch [mm] & $3.00 \mathrm{E}+01$ & $3.00 \mathrm{E}+01$ & $3.00 \mathrm{E}+01$ & $3.00 \mathrm{E}+01$ \\
\hline Pitch-to-diameter ratio & 1.5 & 1.5 & 1.5 & 1.5 \\
\hline Tube Length [m] & $1.04 \mathrm{E}+01$ & 7.911 & $7.376 \mathrm{E}+01$ & 5.43 \\
\hline Tube Thickness [mm] & $1.00 \mathrm{E}+00$ & $1.00 \mathrm{E}+00$ & $1.00 \mathrm{E}+00$ & $1.00 \mathrm{E}+00$ \\
\hline \# of Tubes & $2.87 \mathrm{E}+04$ & $3.03 \mathrm{E}+04$ & $3.357 \mathrm{E}+04$ & $3.70 \mathrm{E}+04$ \\
\hline Shell Diameter [m] & 5550 & 5700 & 6000 & 6300 \\
\hline Baffle Spacing [m] & 4000 & 4000 & 5200 & 5000 \\
\hline Aspect Ratio & 0.53 & 0.72 & 0.813 & 1.16 \\
\hline Total Core Volume $\left[\mathrm{m}^{3}\right]$ & 250 & 201.9 & 208.6 & 169.3 \\
\hline Pressure Drop (Tube Side) $[\mathrm{kPa}]$ & 13 & 45.98 & 7.004 & 36.35 \\
\hline Pressure Drop (Shell Side) $[\mathrm{kPa}]$ & 69.83 & 34.55 & 35.44 & 31.54 \\
\hline
\end{tabular}

Table 1-17. Two-stage IHX thermal design (high temperature section, helical coil, $\mathrm{T}_{\text {sep }}=800^{\circ} \mathrm{C}$ ).

\begin{tabular}{|l|c|c|}
\hline \multicolumn{1}{|c|}{ Conditions } & Configuration 1 & Configuration 2 \\
\hline Duty $[\mathrm{MWt}]$ & 200 & 193 \\
\hline $\mathrm{LMTD}\left[{ }^{\circ} \mathrm{C}\right]$ & 26.81 & 29.75 \\
\hline $\mathrm{U}\left[\mathrm{W} / \mathrm{m}^{2} \mathrm{~K}\right]$ & 1266 & 1329 \\
\hline $\mathrm{A}\left[\mathrm{m}^{2}\right]$ & 5901 & 4880 \\
\hline Tube Inner Diameter $[\mathrm{mm}]$ & 18 & 18 \\
\hline Tube Outer Diameter $[\mathrm{mm}]$ & 2 & 2 \\
\hline Tube Pitch $[\mathrm{mm}]$ & 30 & 30 \\
\hline Pitch-to-diameter Ratio & 1.5 & 1.5 \\
\hline Number of Tubes & 5025 & 5899 \\
\hline Number of Coiled Columns & 2.34 & 1.4 \\
\hline Shell Inner Diameter $[\mathrm{m}]$ & 0.488 & 0.57 \\
\hline Shell Outer Diameter $[\mathrm{m}]$ & 4.6 & 5.4 \\
\hline Shell Length $[\mathrm{m}]$ & 5.15 & 3.09 \\
\hline Volume $\left[\mathrm{m}^{3}\right]$ & 85.58 & 70.76 \\
\hline Aspect Ratio $(\mathrm{Ds} / \mathrm{L})$ & 0.89 & 1.743 \\
\hline dP (tube) $[\mathrm{kPa}]$ & 34.78 & 25.95 \\
\hline dP (shell) $[\mathrm{kPa}]$ & 43.89 & 31.53 \\
\hline
\end{tabular}


Table 1-18. Two-stage IHX Thermal design (low temperature section, $\mathrm{PCHE}, \mathrm{T}_{\text {sep }}=800^{\circ} \mathrm{C}$ ).

\begin{tabular}{|c|c|c|c|c|}
\hline \multirow[b]{2}{*}{ Conditions } & \multicolumn{2}{|c|}{ Configuration 1} & \multicolumn{2}{|c|}{ Configuration 2} \\
\hline & $\begin{array}{l}\text { Counter } \\
\text { Current }\end{array}$ & Cross Flow & $\begin{array}{l}\text { Counter } \\
\text { Current }\end{array}$ & Cross Flow \\
\hline Duty $[\mathrm{MWt}]$ & 400 & 400 & $3.72 \mathrm{E}+05$ & $3.72 \mathrm{E}+05$ \\
\hline $\operatorname{LMTD}\left[{ }^{\circ} \mathrm{C}\right]$ & 66.72 & 66.71 & 35.4 & 35.4 \\
\hline $\mathrm{U}\left[\mathrm{W} / \mathrm{m}^{2} \mathrm{~K}\right]$ & 2281 & 2704 & 2537 & 2452 \\
\hline $\mathrm{A}\left[\mathrm{m}^{2}\right]$ & 2627 & 2216 & 4147 & 4292 \\
\hline Channel Diameter [m] & $1.20 \mathrm{E}-03$ & $1.20 \mathrm{E}-03$ & $1.20 \mathrm{E}-03$ & $1.20 \mathrm{E}-03$ \\
\hline Channel Pitch [m] & $1.46 \mathrm{E}-03$ & $1.46 \mathrm{E}-03$ & $1.46 \mathrm{E}-03$ & $1.46 \mathrm{E}-03$ \\
\hline Plate Thickness [m] & $9.60 \mathrm{E}-04$ & $9.60 \mathrm{E}-04$ & $9.60 \mathrm{E}-04$ & $9.60 \mathrm{E}-04$ \\
\hline Surface Area Density $\left[\mathrm{m}^{2}\right]$ & 2195 & 2195 & 2195 & 2195 \\
\hline Ratio of free flow and frontal area & 0.2148 & 0.2148 & 0.4024 & 0.4024 \\
\hline Effective Diameter [m] & 7.33E-04 & 7.33E-04 & 7.33E-04 & 7.33E-04 \\
\hline Stack Width $[\mathrm{m}]$ & 0.6 & 0.24 & 0.6 & 0.25 \\
\hline Stack Length [m] & 0.2 & 0.2 & 0.26 & 0.25 \\
\hline Stack Height $[\mathrm{m}]$ & 0.6 & 0.6 & 0.6 & 0.6 \\
\hline \# of Stacks & 34 & 70 & 41 & 104.3 \\
\hline Total Core Volume $\left[\mathrm{m}^{3}\right]$ & 2.387 & 2.019 & 3.779 & 3.91 \\
\hline HTC_Primary $\left[\mathrm{W} / \mathrm{m}^{2} \mathrm{~K}\right]$ & 5344 & 6009 & 5433 & 5248 \\
\hline HTC-Secondary $\left[\mathrm{W} / \mathrm{m}^{2} \mathrm{~K}\right]$ & 4110 & 5117 & 4948 & 4778 \\
\hline Pressure Drop (Primary) [kPa] & 28.89 & 40.49 & 41.15 & 34.86 \\
\hline Pressure Drop (Secondary) $[\mathrm{kPa}]$ & 14.27 & 32.13 & 32.32 & 28.77 \\
\hline
\end{tabular}


Table 1-19. Two-stage IHX thermal design (low temperature section, shell-and-tube, $\mathrm{T}_{\text {sep }}=800^{\circ} \mathrm{C}$ ).

\begin{tabular}{|l|c|c|c|c|}
\hline \multirow{2}{*}{\multicolumn{1}{|c|}{ Conditions }} & \multicolumn{2}{c|}{ Configuration 1 } & \multicolumn{2}{c|}{ Configuration 2 } \\
\cline { 2 - 5 } & Straight Pipe & U Tube & Straight Pipe & U Tube \\
\hline Duty [MWt] & 400 & 400 & 372 & 372 \\
\hline LMTD [ $\left.{ }^{\circ}\right]$ & 68.72 & 68.72 & 35.80 & 35.80 \\
\hline $\mathrm{U}\left[\mathrm{W} / \mathrm{m}^{2} \mathrm{~K}\right]$ & $3.76 \mathrm{E}+02$ & $4.63 \mathrm{E}+02$ & $4.02 \mathrm{E}+02$ & $4.93 \mathrm{E}+02$ \\
\hline A $\left[\mathrm{m}^{2}\right]$ & $1.59 \mathrm{E}+04$ & $1.30 \mathrm{E}+04$ & $2.59 \mathrm{E}+04$ & $2.13 \mathrm{E}+04$ \\
\hline Tube Inner Diameter [mm] & $1.80 \mathrm{E}+01$ & $1.80 \mathrm{E}+01$ & $1.80 \mathrm{E}+01$ & $1.80 \mathrm{E}+01$ \\
\hline Tube Outer Diameter $[\mathrm{mm}]$ & $2.00 \mathrm{E}+01$ & $2.00 \mathrm{E}+01$ & $2.00 \mathrm{E}+01$ & $2.00 \mathrm{E}+01$ \\
\hline Tube Pitch [mm] & $3.00 \mathrm{E}+01$ & $3.00 \mathrm{E}+01$ & $3.00 \mathrm{E}+01$ & $3.00 \mathrm{E}+01$ \\
\hline Pitch-to-diameter ratio & 1.5 & 1.5 & 1.5 & 1.5 \\
\hline Tube Length [m] & $8.82 \mathrm{E}+00$ & 6.803 & 12.27 & 9.17 \\
\hline Tube Thickness [mm] & $1.00 \mathrm{E}+00$ & $1.00 \mathrm{E}+00$ & $1.00 \mathrm{E}+00$ & $1.00 \mathrm{E}+00$ \\
\hline \# of Tubes & $2.87 \mathrm{E}+04$ & $3.03 \mathrm{E}+04$ & $2.87 \mathrm{E}+04$ & $3.701 \mathrm{E}+04$ \\
\hline Shell Diameter [m] & 5550 & 5700 & 6000 & 6300 \\
\hline Baffle Spacing [m] & 4000 & 4000 & 5200 & 5000 \\
\hline Aspect Ratio & 0.6293 & 0.8379 & 0.4891 & 0.69 \\
\hline Total Core Volume [m $\left.{ }^{3}\right]$ & 213.4 & 173.6 & 346.8 & 285.9 \\
\hline Pressure Drop (Tube Side) $[\mathrm{kPa}]$ & 6.513 & 35.45 & 9.244 & 46.50 \\
\hline Pressure Drop (Shell Side) $[\mathrm{kPa}]$ & 38 & 31.33 & 49.22 & 42.86 \\
\hline
\end{tabular}

Table 1-20. Two-stage IHX thermal design (low temperature section, helical coil, $\mathrm{T}_{\text {sep }}=800^{\circ} \mathrm{C}$ ).

\begin{tabular}{|l|c|c|}
\hline \multicolumn{1}{|c|}{ Conditions } & Configuration 1 & Configuration 2 \\
\hline Duty $[\mathrm{MWt}]$ & 415 & 372 \\
\hline $\mathrm{LMTD}\left[{ }^{\circ} \mathrm{C}\right]$ & 68.72 & 35.40 \\
\hline $\mathrm{U}\left[\mathrm{W} / \mathrm{m}^{2} \mathrm{~K}\right]$ & 1180 & 1276 \\
\hline $\mathrm{A}\left[\mathrm{m}^{2}\right]$ & 5077 & 8244 \\
\hline Tube Inner Diameter $[\mathrm{mm}]$ & 18 & 18 \\
\hline Tube Outer Diameter $[\mathrm{mm}]$ & 2 & 2 \\
\hline Tube Pitch $[\mathrm{mm}]$ & 30 & 30 \\
\hline Pitch-to-diameter Ratio & 1.5 & 1.5 \\
\hline Number of Tubes & 5025 & 5899 \\
\hline Number of Coiled Columns & 2.0 & 2.4 \\
\hline Shell Inner Diameter $[\mathrm{m}]$ & 0.488 & 0.57 \\
\hline Shell Outer Diameter $[\mathrm{m}]$ & 4.6 & 5.4 \\
\hline Shell Length $[\mathrm{m}]$ & 4.43 & 5.22 \\
\hline Volume $\left[\mathrm{m}^{3}\right]$ & 73.63 & 119 \\
\hline Aspect Ratio $(\mathrm{Ds} / \mathrm{L})$ & 1.038 & 1.034 \\
\hline dP (tube) $[\mathrm{kPa}]$ & 27.37 & 40.88 \\
\hline dP (shell) $[\mathrm{kPa}]$ & 28.09 & 45.20 \\
\hline
\end{tabular}


Tables 1-21 and 1-22 summarize the volumes and heat transfer surface areas for two-stage IHXs at the increased separation temperature $\left(800^{\circ} \mathrm{C}\right)$. The volumes and surface areas were estimated by the same method used for the design at the original separation temperature $\left(750^{\circ} \mathrm{C}\right)$. When we increase the separation temperature to $800^{\circ} \mathrm{C}$, the size of the high temperature unit is reduced to about a half of the total volume as shown in Table 1-21. Since the high temperature unit is a replaceable during the plant lifetime, the smaller PCHEs will be more beneficial, leading to lower cost and easier maintenance. In addition, the smaller surface area of the PCHE in high temperature operations will greatly reduce the tritium penetration rate from the primary to secondary side. On the other hands, the low temperature unit is a nonreplicable component and unit reliability over the plant's lifetime is important. Also, tritium penetration in the low temperature unit is much lower than in the high temperature unit, since the diffusion coefficient is exponential to the material temperature.

Table 1-21. Volume of heat exchangers for Two-stage IHX $\left(800^{\circ} \mathrm{C}\right.$ separation).

\begin{tabular}{|l|c|c|c|c|c|c|}
\hline \multirow{2}{*}{} & \multicolumn{3}{|c|}{ Configuration 1 } & \multicolumn{3}{c|}{ Configuration 2 } \\
\cline { 2 - 7 } & HT Unit & LT Unit & Total & HT Unit & LT Unit & Total \\
\hline C1 & 2.549 & 2.019 & 4.568 & 2.08 & 3.78 & 5.86 \\
\hline C2 & 2.549 & 173.6 & 176.15 & 2.08 & 285.9 & 288.0 \\
\hline C3 & 2.549 & 73.63 & 76.179 & 2.08 & 119 & 121.08 \\
\hline C4 & 201.9 & 2.019 & 203.92 & 169 & 3.78 & 172.8 \\
\hline C5 & 201.9 & 173.6 & 375.5 & 169 & 285.9 & 454.9 \\
\hline C6 & 201.9 & 73.63 & 275.53 & 169 & 119 & 288 \\
\hline C7 & 85.58 & 2.019 & 87.599 & 70.76 & 3.78 & 74.54 \\
\hline C8 & 85.58 & 173.6 & 259.18 & 70.76 & 285.9 & 356.7 \\
\hline C9 & 85.58 & 73.63 & 159.21 & 70.76 & 119 & 189.76 \\
\hline
\end{tabular}

Table 1-22. Heat transfer area of two-stage IHX $\left(800^{\circ} \mathrm{C}\right.$ separation).

\begin{tabular}{|c|c|c|c|c|c|c|}
\hline & \multicolumn{3}{|c|}{ Configuration 1 } & \multicolumn{3}{c|}{ Configuration 2 } \\
\cline { 2 - 7 } & HT Unit & LT Unit & Total & HT Unit & LT Unit & Total \\
\hline C1 & 2792 & 2216 & 5008 & 2279 & 4147 & 6426 \\
\hline C2 & 2792 & 13000 & 15792 & 2279 & 21300 & 23579 \\
\hline C3 & 2792 & 5077 & 7869 & 2279 & 8244 & 10523 \\
\hline C4 & 19300 & 2216 & 17216 & 12600 & 4147 & 16747 \\
\hline C5 & 19300 & 13000 & 28000 & 12600 & 21300 & 33900 \\
\hline C6 & 19300 & 5077 & 24377 & 12600 & 8244 & 20844 \\
\hline C7 & 5901 & 2216 & 8117 & 4880 & 4147 & 9027 \\
\hline C8 & 5901 & 13000 & 18901 & 4880 & 21300 & 26180 \\
\hline C9 & 5901 & 5077 & 10978 & 4880 & 8244 & 13124 \\
\hline
\end{tabular}




\subsubsection{Comparisons of Two-Stage IHX vs. Single-Stage IHX}

The results of a comparison of the single-stage IHX and two-stage IHX, as presented in Tables 1-3 through $1-22$, is summarized as follows:

- Total IHX volume. In high temperature applications, the smaller IHX is generally preferred. However, the total volume of the IHX is not affected by IHX layout, meaning that splitting the IHX does not lead to any volume increases or decreases. Practically, a two-stage IHX will require more space for manifold of flow distribution, but this is also negligible.

- Total Heat Transfer Area. The total heat transfer area is another important parameter in VHTR applications. In the hydrogen production system integrated with the VHTRs, tritium permeation into a hydrogen plant will be affected by the surface area. A smaller heat transfer area can reduce the tritium permeation rate, but the total heat transfer area of the IHX is not affected by its layout. It means that splitting the IHX does not lead to any size increases or decrease of the IHX surface area.

- Size of high temperature section. The smaller size of the high temperature unit is preferred because it can reduce the maintenance cost and enhance component safety. The two-stage IHX unit with an $800^{\circ} \mathrm{C}$ separation temperature is the smallest. A single-stage IHX unit is the largest.

- System complexity. The number of modules relates to the system complexity. Fewer modules are preferred for simplicity. The single-stage IHX has the simplest design because it requires less modules.

According to the above comparisons, the two-stage PCHEs are conceptually expected to offer more advantages in system cost, safety, and maintenance compared to the single-stage IHXs. For example: material cost can be saved in the two-stage IHXs because some cheap commercial materials like stainless steel or Alloy $800 \mathrm{H}$ can replace high-alloy materials in the low temperature units. It is also easier to manage and control for risks by concentrating safety issues on the high temperature units. The thermal stress can be relieved in the two-stage IHXs by reducing temperature differences in the two components. On the other hand, a single stage PCHE provides a quite small size and simplicity.

\subsubsection{SHX Thermal Design}

A SHX transfers heat from the primary or secondary side to the hydrogen production system. In Configuration 1 of Figure 1-1, the SHX is placed in the bypass stream in the PCU cycle. In Configuration 2 of Figure 1-2, the SHX is placed in the primary system between the reactor core and an IHX. The two-stage concept was not considered for SHX design in this study. First, the SHX is much smaller than the IHX because it exchanges only $1 / 11$ of the total power. Therefore, the benefit of replacing an SHX is very slight. On the other hand, this concept makes the system more complicated by increasing the number of modules. In addition, the total volume and heat transfer area of the SHX are not significantly affected by the IHX arrangement (e.g., one-stage, two-stage). Therefore, most of the valuable specifications (total volume, heat transfer area, LMTD, heat transfer coefficient) can be obtained for the SHX using a single-stage design. It is also obvious that the PCHE type is more advantageous in SHX applications than the other types because for the same reasons as the IHX. Tables 1-24, 1-25 and 1-26 summarize the SHX thermal design specifications for PCHE, shell-and-tube, and helical coil types, respectively. 
Table 1-23. SHX thermal design (PCHE).

\begin{tabular}{|c|c|c|c|c|}
\hline & \multicolumn{2}{|c|}{ Configuration 1} & \multicolumn{2}{|c|}{ Configuration 2} \\
\hline & $\begin{array}{l}\text { Counter } \\
\text { Current } \\
\end{array}$ & Cross Flow & $\begin{array}{l}\text { Counter } \\
\text { Current } \\
\end{array}$ & Cross Flow \\
\hline Duty [MWt] & 53 & 53 & 54.7 & 54.7 \\
\hline $\operatorname{LMTD}\left[{ }^{\circ} \mathrm{C}\right]$ & 50.67 & 50.67 & 171 & 171 \\
\hline $\mathrm{U}\left[\mathrm{W} / \mathrm{m}^{2} \mathrm{~K}\right]$ & 1547 & 1446 & 1018 & 1188 \\
\hline $\mathrm{A}\left[\mathrm{m}_{2}\right]$ & 678 & 746.9 & 314.2 & 269.3 \\
\hline Channel Diameter [m] & $1.20 \mathrm{E}-03$ & $1.20 \mathrm{E}-03$ & $1.20 \mathrm{E}-03$ & $1.20 \mathrm{E}-03$ \\
\hline Channel Pitch $[\mathrm{m}]$ & $1.46 \mathrm{E}-03$ & $1.46 \mathrm{E}-03$ & $1.46 \mathrm{E}-03$ & $1.46 \mathrm{E}-03$ \\
\hline Plate Thickness [m] & $9.60 \mathrm{E}-04$ & $9.60 \mathrm{E}-04$ & $9.60 \mathrm{E}-04$ & $9.60 \mathrm{E}-04$ \\
\hline Surface Area Density $\left[\mathrm{m}^{2}\right]$ & 2195 & 2195 & 2195 & 2195 \\
\hline Ratio of free flow and frontal area & 0.2148 & 0.2148 & 0.4024 & 0.4024 \\
\hline Effective Diameter [m] & 7.33E-04 & 7.33E-04 & 7.33E-04 & 7.33E-04 \\
\hline Stack Width $[\mathrm{m}]$ & 0.6 & 0.38 & 0.6 & 0.06 \\
\hline Stack Length [m] & 0.6 & 0.5 & 0.053 & 0.05 \\
\hline Stack Height [m] & 0.42 & 0.6 & 0.6 & 0.6 \\
\hline \# of Stacks & 4 & 4.675 & 15 & 136.3 \\
\hline Total Core Volume $\left[\mathrm{m}^{3}\right]$ & 0.6162 & 0.6805 & 0.29 & 0.25 \\
\hline HTC_-Primary $\left[\mathrm{W} / \mathrm{m}^{2} \mathrm{~K}\right]$ & 3863 & 4003 & $1.23 \mathrm{E}+04$ & $1.84 \mathrm{E}+04$ \\
\hline HTC-Secondary $\left[\mathrm{W} / \mathrm{m}^{2} \mathrm{~K}\right]$ & 2635 & 2307 & 1141 & 1348 \\
\hline Pressure Drop (Primary) [kPa] & 22.05 & 28.32 & 49.65 & 52.16 \\
\hline Pressure Drop (Secondary) $[\mathrm{kPa}]$ & 3.73 & 22.62 & 0.53 & 0.942 \\
\hline
\end{tabular}


Table 1-24. SHX thermal design (shell and tube).

\begin{tabular}{|l|c|c|c|c|}
\hline \multirow{2}{*}{} & \multicolumn{2}{|c|}{ Configuration 1 } & \multicolumn{2}{c|}{ Configuration 2 } \\
\cline { 2 - 5 } & Straight Pipe & U Tube & Straight Pipe & U Tube \\
\hline Duty [MWt] & 53 & 53 & 55 & 55 \\
\hline LMTD [ ${ }^{\circ}$ ] & 49.25 & 49.25 & 171.1 & 171.1 \\
\hline $\mathrm{U}\left[\mathrm{W} / \mathrm{m}^{2} \mathrm{~K}\right]$ & 226.9 & 342.3 & 238.5 & 200.2 \\
\hline A $\left[\mathrm{m}^{2}\right]$ & $4.76 \mathrm{E}+03$ & $3.15 \mathrm{E}+03$ & $1.34 \mathrm{E}+03$ & $1.60 \mathrm{E}+03$ \\
\hline Tube Inner Diameter [mm] & $1.80 \mathrm{E}+01$ & $1.80 \mathrm{E}+01$ & $1.80 \mathrm{E}+01$ & $1.80 \mathrm{E}+01$ \\
\hline Tube Outer Diameter $[\mathrm{mm}]$ & $2.00 \mathrm{E}+01$ & $2.00 \mathrm{E}+01$ & $2.00 \mathrm{E}+01$ & $2.00 \mathrm{E}+01$ \\
\hline Tube Pitch [mm] & $3.00 \mathrm{E}+01$ & $3.00 \mathrm{E}+01$ & $3.00 \mathrm{E}+01$ & $3.00 \mathrm{E}+01$ \\
\hline Pitch-to-diameter ratio & 1.5 & 1.5 & 1.5 & 1.5 \\
\hline Tube Length [m] & 20.3 & 20.3 & 1.869 & 1.092 \\
\hline Tube Thickness [mm] & $1.00 \mathrm{E}+00$ & $1.00 \mathrm{E}+00$ & $1.00 \mathrm{E}+00$ & $1.00 \mathrm{E}+00$ \\
\hline \# of Tubes & $3.74 \mathrm{E}+03$ & 3021 & $1.14 \mathrm{E}+04$ & $2.33 \mathrm{E}+04$ \\
\hline Shell Diameter [m] & 2000 & 1800 & 3500 & 5000 \\
\hline Baffle Spacing [m] & 1500 & 1200 & 2000 & 2000 \\
\hline Aspect Ratio & 0.099 & 0.1083 & 1.873 & 4.581 \\
\hline Total Core Volume [m $\left.{ }^{3}\right]$ & 63.78 & 42.28 & 17.98 & 46.6 \\
\hline Pressure Drop (Tube Side) $[\mathrm{kPa}]$ & 3.297 & 28.85 & 28.29 & 28.29 \\
\hline Pressure Drop (Shell Side) $[\mathrm{kPa}]$ & 17.75 & 26.24 & 0.7915 & 0.47 \\
\hline
\end{tabular}

Table 1-25. SHX thermal design (Helical).

\begin{tabular}{|l|c|c|}
\hline & Configuration 1 & Configuration 2 \\
\hline Duty $[\mathrm{MWt}]$ & 53 & 55 \\
\hline LMTD $\left[{ }^{\circ} \mathrm{C}\right]$ & 50 & 171 \\
\hline $\mathrm{U}\left[\mathrm{W} / \mathrm{m}^{2} \mathrm{~K}\right]$ & 701 & 238 \\
\hline $\mathrm{A}\left[\mathrm{m}^{2}\right]$ & 1519 & 1337 \\
\hline Tube Inner Diameter $[\mathrm{mm}]$ & 18 & 2 \\
\hline Tube Outer Diameter $[\mathrm{mm}]$ & 2 & 30 \\
\hline Tube Pitch $[\mathrm{mm}]$ & 30 & 1.5 \\
\hline Pitch-to-diameter Ratio & 1.5 & 3724 \\
\hline Number of Tubes & 795 & 0.66 \\
\hline Number of Coiled Columns & 10.95 & 0.53 \\
\hline Shell Inner Diameter $[\mathrm{m}]$ & 0.17 & 5.0 \\
\hline Shell Outer Diameter $[\mathrm{m}]$ & 1.6 & 0.98 \\
\hline Shell Length $[\mathrm{m}]$ & 10.95 & 19.36 \\
\hline Volume $\left[\mathrm{m}^{3}\right]$ & 22.03 & 5.1 \\
\hline Aspect Ratio $(\mathrm{Ds} / \mathrm{L})$ & 0.14 & 26.47 \\
\hline dP (tube) $[\mathrm{kPa}]$ & 12.77 & 0.025 \\
\hline dP (shell) $[\mathrm{kPa}]$ & 17.28 & \\
\hline
\end{tabular}




\subsection{Stress Analysis of the VHTR Heat Exchangers}

\subsubsection{Simplified Stress Analysis Method}

\subsubsection{Maximum Allowable Stress}

This section presents the results of a simplified stress analysis performed for the VHTR heat exchangers. The heat exchanger lifetime and required thickness is estimated so that the circumferential stress was less than or equal to an assumed allowable value. The use of consistent stresses allowed us to identify limiting components and make a fair comparison between different configurations.

Since the VHTR heat exchangers (IHX and SHX) are operating in the high temperature environment, the creep deformation is important; Subsection NH of ASME Code, Section III applies. However, there are several problems with applying ASME Section III code rules at this time because the use of the primary candidate structural Alloy 617 is currently not approved in Subsection NH. For this reason, we used the draft Code Case for Alloy 617 in this report. The reported allowable stress data in the draft Code for Alloy 617 are shown in Figure 1-9. The primary stress limit of Alloy 617 draft code case is determined as follows (Natesan et al. 2006):

A basic high temperature primary stress limit is $\mathrm{S}_{\mathrm{mt}}$, which is the lesser of $\mathrm{S}_{\mathrm{m}}$ and $\mathrm{S}_{\mathrm{t}}$ and a function of both time and temperature. $\mathrm{S}_{\mathrm{m}}$ is basically defined as follows:

$$
S_{m}=\min \left(\frac{1}{3} S_{u}, \frac{2}{3} S_{y}\right)
$$

where $S_{u}$ is the lesser of ultimate tensile strength at temperature and the minimum ultimate tensile strength at room temperature and $\mathrm{S}_{\mathrm{y}}$ is the lesser of yield strength at temperature and the minimum yield strength at room temperature. For each specific time $t$ and temperature $T, S_{t}$ is defined as the least of the following three stresses:

- $100 \%$ of the average stress required to obtain a total strain of $1 \%$

- $80 \%$ of the minimum stress to cause initiation of tertiary creep

- $67 \%$ of the minimum stress to cause ruptures.

In the draft code case for Alloy 617, bullet 2 above is dropped because nickel alloy does not exhibit classical creep behavior. Figure 1-9 plots the reported $\mathrm{S}_{\mathrm{m}}$ and $\mathrm{S}_{\mathrm{t}}$ values for Alloy 617. For this report, the allowable stress is assumed to be the minimum value of $\mathrm{S}_{\mathrm{m}}$ and $\mathrm{S}_{\mathrm{t}}$.

\subsubsection{Calculation of Stress and Failure Theory}

The simple stress and failure theories used to determine the internal pressure required to yield the inner surface of the tubular-type heat exchangers are presented below. The method used for the PCHE type heat exchangers is first. Generally, the design of the heat exchanger channels is defined by the channel diameter $(d)$, pitch $(p)$, and plate thickness, $\left(t_{p}\right)$. According to the method used by Dostal et al. (2004), the minimum wall thickness between channels, $\mathrm{t}_{\mathrm{f}}$, can

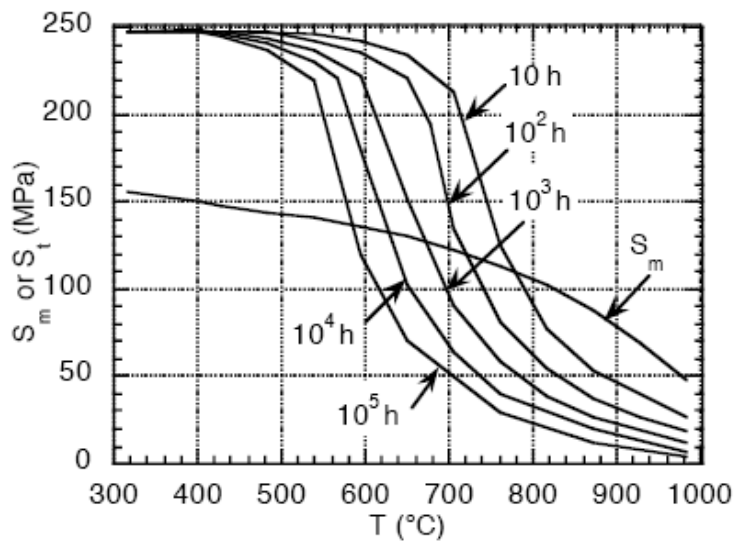

Figure 1-9. Variations of $S_{m}$ and $S_{t}$ of alloy 617 with temperature and time (Natesan et al. 2006). 
be approximated as

$$
t_{f} \geq \frac{p}{\frac{\sigma_{D}}{\Delta P}+1}
$$

where $\sigma_{D}$ is the allowable stress, $p$ is the channel horizontal pitch, and $\Delta P$ is the differential pressure between the hot and cold streams. Expressing Equation (1-5) in terms of $\Delta P$ yields

$$
\Delta P \leq\left(\frac{p}{t_{f}}-1\right) \sigma_{D} .
$$

The required plate thickness can be calculated based on the method of Dostal et al. (2004). The plate is assumed to be a thick-walled cylinder, with an inner radius of $d / 2$ and an outer radius of $t_{p}$. For thick walled cylinders, the tangential stress, $\sigma_{t}$, is calculated as (Crandall et al. 1972)

$$
\sigma_{t}=\frac{P_{i}\left[\left(r_{0} / r_{i}\right)^{2}+1\right]-P_{0}\left[\left(r_{0} / r_{i}\right)^{2}+\left(r_{0} / r\right)^{2}\right]}{\left(r_{0} / r_{i}\right)^{2}-1}
$$

where $r$ is the radius, $\mathrm{P}$ is the pressure, and the subscript $i$ and o refer to the inner and outer surface, respectively. The stress is negative if the external pressure exceeds the internal pressure, but the maximum magnitude always occurs at the inner surface. The radius ratio that causes the maximum stress to be less than or equal to the allowable stress, $\sigma_{D}$, can be calculated from Equation (1-3). For cases where the internal pressure exceeds the external pressure, the limiting ratio is

$$
\frac{r_{o}}{r_{i}} \geq \sqrt{\frac{\sigma_{D}+P_{i}}{\sigma_{D}+2 P_{0}-P_{i}}} .
$$

For cases where the external pressure exceeds the internal pressure, the maximum, absolute value of the stress will be less than or equal to the allowable stress when the radius ratio is

$$
\frac{r_{o}}{r_{i}} \geq \sqrt{\frac{\sigma_{D}-P_{i}}{\sigma_{D}-2 P_{0}-P_{i}}} .
$$

Engineering problems concerned with the design and development of structural or machine parts are generally involving biaxial (occasionally triaxial) stresses. However, available strength data usually pertain to uniaxial stress, and often only to uniaxial tension. To resolve this problem, a failure theory is used in the engineering practice. The failure theories are generally based on the assumption that tensile yielding occurs as a result of exceeding the capacity of the materials in one or more respects, such as:

1. Capacity to withstand normal stress (Maximum Normal Stress Theory)

2. Capacity to withstand shear stress (Maximum Shear Stress Theory)

3. Capacity to withstand normal strain (Maximum Normal Strain Theory)

4. Capacity to withstand shear strain (Maximum Shear Strain Theory)

5. Capacity to absorb strain energy (Total Strain Energy Theory)

6. Capacity to absorb distortion energy (Maximum Distortion Energy Theory). 
Hence, in the simple classical theories of failure, it is assumed that the same amount of whatever caused the selected tensile specimen to fail will also cause any part made of the materials to fail regardless of the state of stress involved. The model details are well described in Collins (1981). The failure theories are compared graphically for a biaxial state of stress in Figures 1-10 and 1-11 (Wolf et al. 2004).

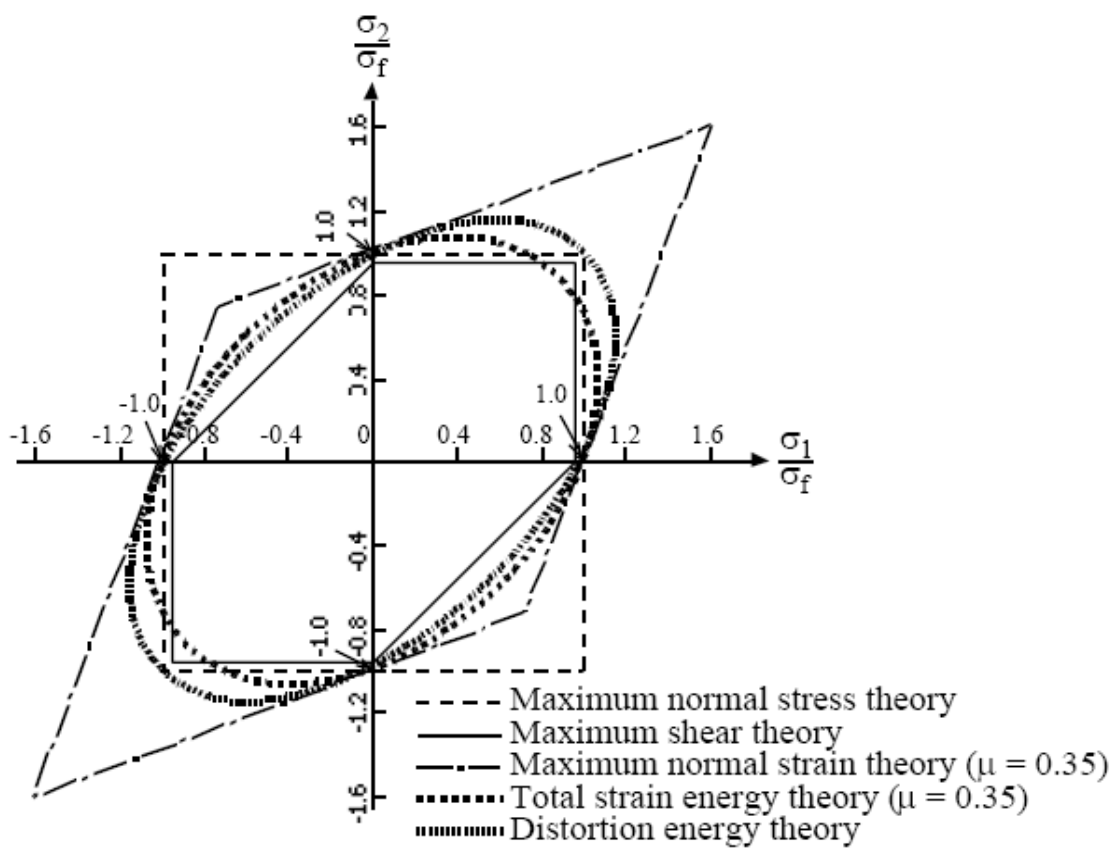

Figure 1-10. Comparisons of failure theories for a biaxial state of stress (Martin 1962).
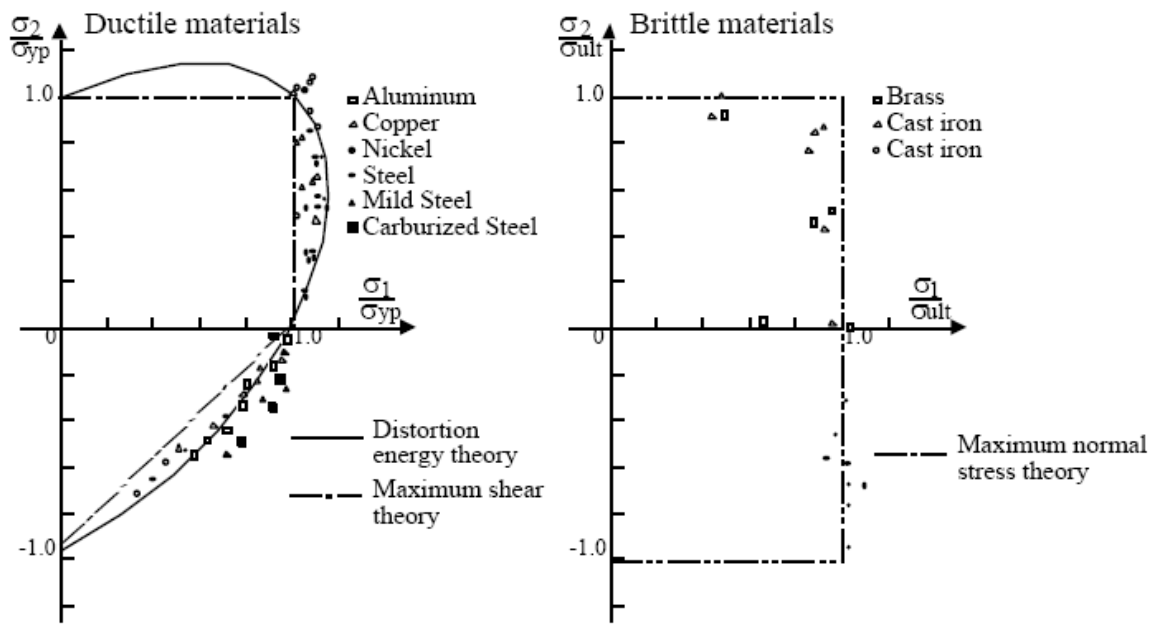

Figure 1-11. Comparisons of biaxial strength data with failure theories (Collins 1981).

From Figure 1-10 it can be seen that:

1. The distortion energy and maximum shear stress theories predict similar results with the shear stress theory being more conservative. 
2. The maximum normal stress and maximum shear stress theories agree in the first and third quadrants where the signs of the principal stresses are the same but not in the second and fourth quadrants.

Biaxial strength data for a variety of ductile and brittle materials are shown in Figure 1-11 with several failure theory limits. From this figure it can be seen that experimental data support:

1. Maximum normal stress theory is appropriate for brittle behavior.

2. Distortion energy or Maximum shear stress theories is appropriate for ductile failure.

In this report, the maximum shear stress theory was used for conservative failure estimations.

\subsubsection{Simplified Stress Evaluation for IHX and SHX}

This section describes the results of the simplified stress evaluation for the VHTR heat exchangers. The construction material used in this estimate was assumed to be Alloy 617, which is the potential candidate for the VHTR IHXs. Figure 1-12 shows the relations between the lifetime and the stress limit $\left(\mathrm{S}_{\mathrm{mt}}\right)$ of this material for three different temperatures; 750,800 , and $900^{\circ} \mathrm{C}$. Each data of the graph represents the maximum operational lifetime under the given stress load and temperature. According to this graph, the lifetime of this material exponentially decreases as the stress increases. Because of the limited reported lifetime data over $1 \times 10^{5} \mathrm{hrs}$ (about 10 years), a simple extrapolation method was used for estimations over this range. Table 1-26 summarizes the allowable stresses of Alloy 617 assumed in this work based on the data in Figure 1-12. To obtain more accurate analyses, available experimental data or proven extrapolation methods will need to be measured or developed.

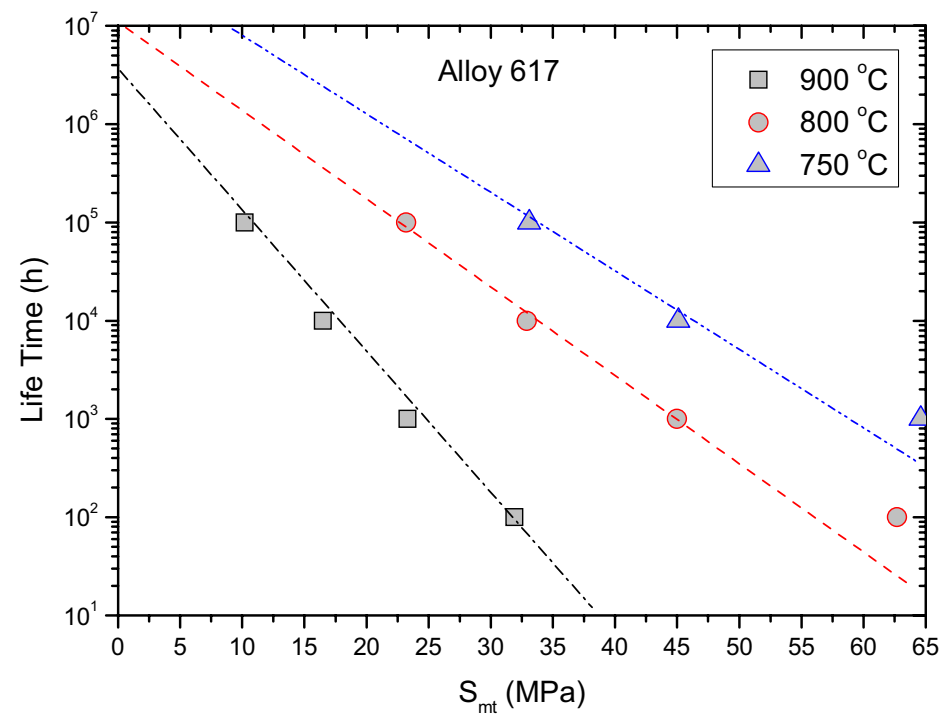

Figure 1-12. $\mathrm{S}_{\mathrm{mt}}(\mathrm{MPa})$ vs. life time (h) for Alloy 617.

Table 1-26. Assumed allowable stresses for Alloy 617.

\begin{tabular}{|c|c|c|c|}
\hline \multirow[b]{2}{*}{ Temperature } & \multicolumn{3}{|c|}{ Allowable Stress (MPa) } \\
\hline & $\begin{array}{l}10^{5} \text { hours } \\
(11 \text { years })\end{array}$ & $\begin{array}{c}5 \times 10^{5} \text { hours } \\
(57 \text { years })\end{array}$ & $\begin{array}{c}10^{6} \text { hours } \\
(114 \text { years })\end{array}$ \\
\hline $750^{\circ} \mathrm{C}$ & 33.1 & 25 & 22.5 \\
\hline $800^{\circ} \mathrm{C}$ & 23.2 & 15 & 12.3 \\
\hline $900^{\circ} \mathrm{C}$ & 10.2 & 5 & 3.5 \\
\hline
\end{tabular}


Table 1-27 summarizes the estimated lifetime of the referenced heat exchangers designed in the previous section. In those heat exchangers, the thickness-to-inner radius ratios $\left(\mathrm{t} / \mathrm{r}_{\mathrm{i}}\right)$ are 0.57 for the PCHE and 0.1 for the tubular-types (See Section 1.2). The maximum pressure differences $\left(\Delta \mathrm{P}_{\max }\right)$ between hot and cold channels was assumed to be $1.0 \mathrm{MPa}$ for the IHX, and 0.2 and $0.5 \mathrm{MPa}$ for the SHX. The maximum shear stress theory was applied to obtain the most conservative estimation of the lifetime. Theoretically, PCHE has larger $\mathrm{t} / \mathrm{r}_{\mathrm{i}}$ values than tubular-type heat exchangers because it shows a larger lifetime. However, as the thickness-to-inner radius ratio in the tubular type heat exchanger is increased, the lifetime of the tubular heat exchanger gets closer to the PCHE's. However, the common $t / r_{i}$ values in commercial tubing range from 0.1 to 0.5 , and most of them are within 0.3 ; the designed tube thickness should not be larger than this.

Table 1-27 shows that the PCHE can be operated in $900^{\circ} \mathrm{C}$ for about 35 years as an IHX and a SHX $\left(\mathrm{P}_{\max }=2.0 \mathrm{MPa}\right)$ with the reference design. However, the tubular heat exchangers (shell-and-tube or helical coil) can only be operated for about 13 years $\left(1.16 \times 10^{5}\right.$ hours $)$ as an IHX and about 0.5 year $(4,040$ hours $)$ as a SHX $\left(\mathrm{P}_{\max }=2.0 \mathrm{MPa}\right)$ with the reference design. With a differential pressure of 5.0 MPa between the hot and cold channels, the PCHE heat exchangers cannot be operated for more than 1.6 years $\left(1.44 \times 10^{4}\right.$ hours), whereas the tubular type heat exchangers cannot be operated at all for this condition.

Table 1-27. Estimated life time of reference heat exchangers.

\begin{tabular}{|l|c|c|c|c|}
\hline \multirow{2}{*}{ Temperature } & \multicolumn{4}{|c|}{ Life Time (hrs) } \\
\cline { 2 - 5 } & \multicolumn{2}{|c|}{ IHX (1 MPa) } & SHX (2.0 MPa/5.0 MPa) \\
\cline { 2 - 6 } & PCHE & Shell-and-Tube & PCHE & Shell-and-Tube \\
\hline $750^{\circ} \mathrm{C}$ & $1.34 \times 10^{7} \mathrm{hrs}$ & $7.42 \times 10^{6} \mathrm{hrs}$ & $\begin{array}{c}1.34 \times 10^{7} \mathrm{hrs} / \\
2.62 \times 10^{6} \mathrm{hrs}\end{array}$ & $\begin{array}{c}1.16 \times 10^{6} \mathrm{hrs} / \\
5290 \mathrm{hrs}\end{array}$ \\
\hline $800^{\circ} \mathrm{C}$ & $2.62 \times 10^{6} \mathrm{hrs}$ & $1.32 \times 10^{6} \mathrm{hrs}$ & $\begin{array}{c}2.62 \times 10^{6} \mathrm{hrs} / \\
4.08 \times 10^{5} \mathrm{hrs}\end{array}$ & $\begin{array}{c}1.98 \times 10^{5} \mathrm{hrs} / \\
155 \mathrm{hrs}\end{array}$ \\
\hline $900^{\circ} \mathrm{C}$ & $3.12 \times 10^{5} \mathrm{hrs}$ & $1.16 \times 10^{5} \mathrm{hrs}$ & $\begin{array}{c}3.12 \times 10^{5} \mathrm{hrs} / \\
1.44 \times 10^{4} \mathrm{hrs}\end{array}$ & $\begin{array}{c}4040 \mathrm{hrs} / \\
\text { NONE }\end{array}$ \\
\hline
\end{tabular}

Figures 1-13 through 1-15 show the maximum effective stress of the PCHEs as a function of pate thickness-to-diameter ratio $\left(\mathrm{t}_{\mathrm{p}} / \mathrm{d}\right)$ for three different applications; (1) IHX ( $\left.\triangle \mathrm{Pmax}=1 \mathrm{MPa}\right),(2) \mathrm{SHX}$ $\left(\Delta \mathrm{P}_{\max }=2 \mathrm{MPa}\right)$ and (3) $\mathrm{SH}\left(\Delta \mathrm{P}_{\max }=5 \mathrm{MPa}\right)$. The blue lines in this graph show the rupture stress for the given lifetime (see Figure 1-12). As described, in this report, the effective stresses were calculated based on the maximum shear stress theory, the most conservative failure theory. Therefore, for reliable operation, the effective maximum stress should always be designed to be lower than the rupture stress. According to these graphs, as the plate thickness-to-diameter ratio increases, the effective stress is exponentially decreased. In addition, lower pressure differences between hot and cold channels led to much less effective stress, meaning that the thicker the plate, the stronger the mechanical integrity gets. Figures 1-16 through 1-18 show the maximum effective stress for the tubular heat exchangers as a function of tube thickness-to-inner radius ratio, which is basically the same trend as the PCHEs. The required thicknesses for the IHXs and SHXs were estimated based on these results. 


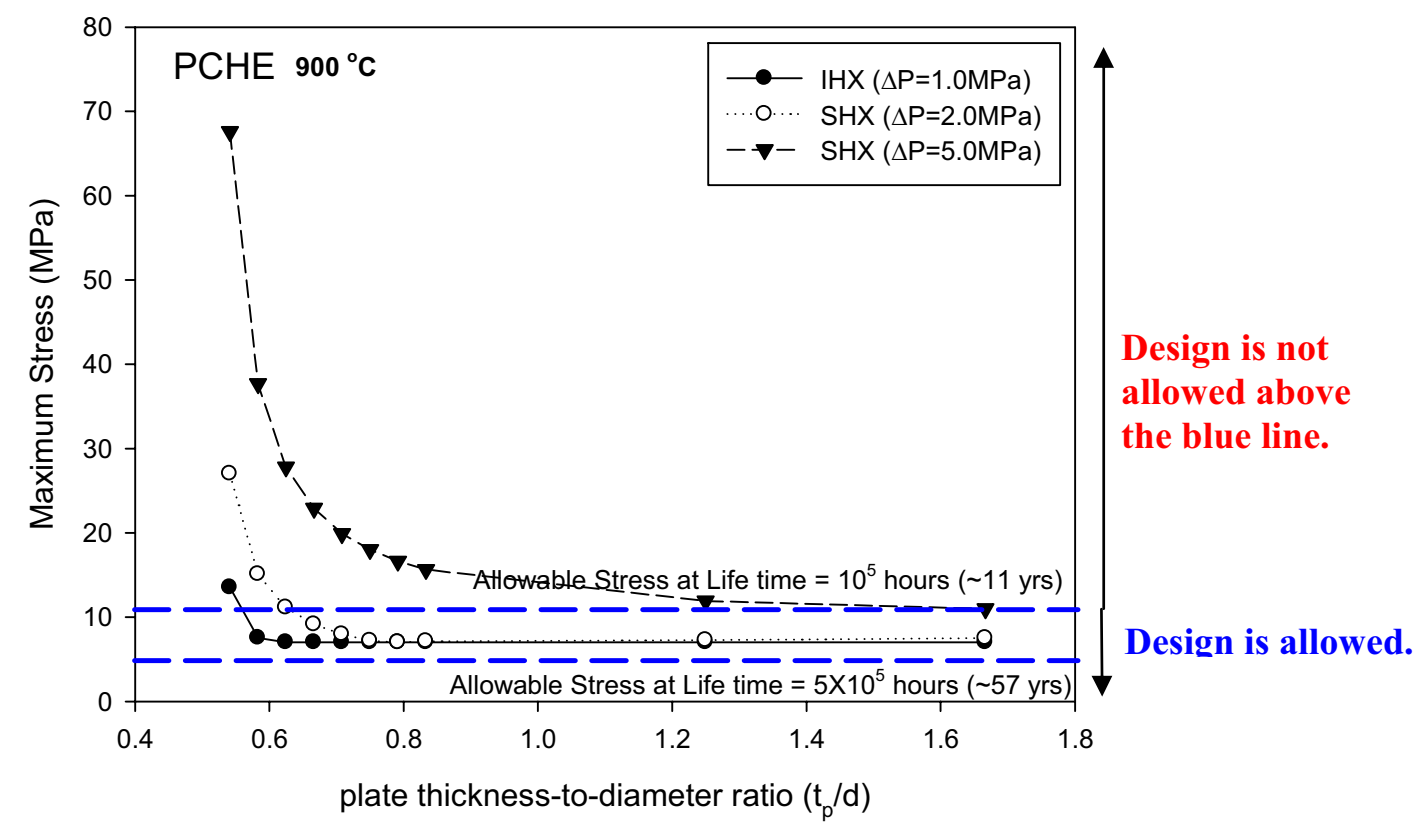

Figure 1-13. Maximum stress as a function of plate thickness-to-diameter ratio (PCHE, $900^{\circ} \mathrm{C}$ ).

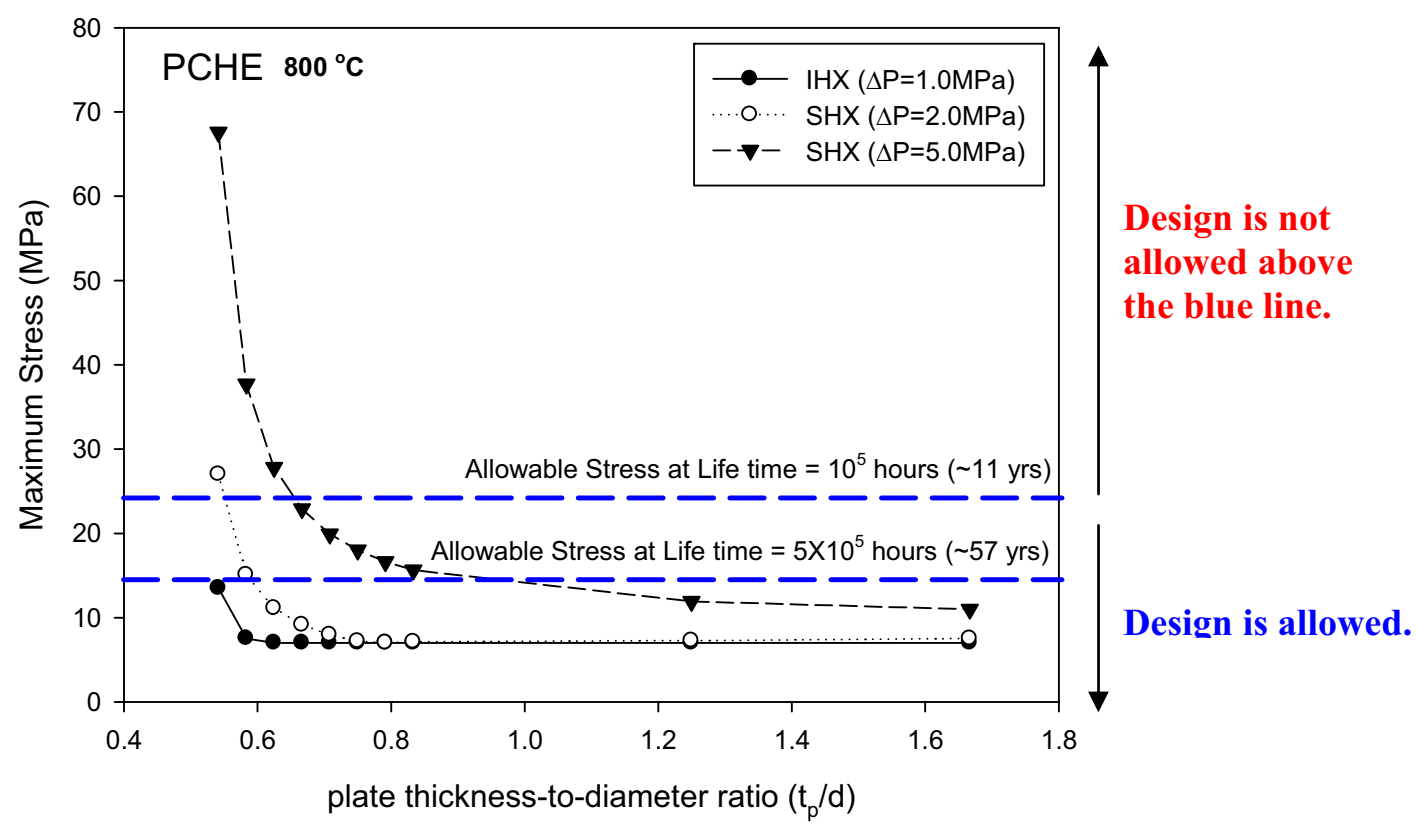

Figure 1-14. Maximum stress as a function of plate thickness-to-diameter ratio (PCHE, $800^{\circ} \mathrm{C}$ ). 


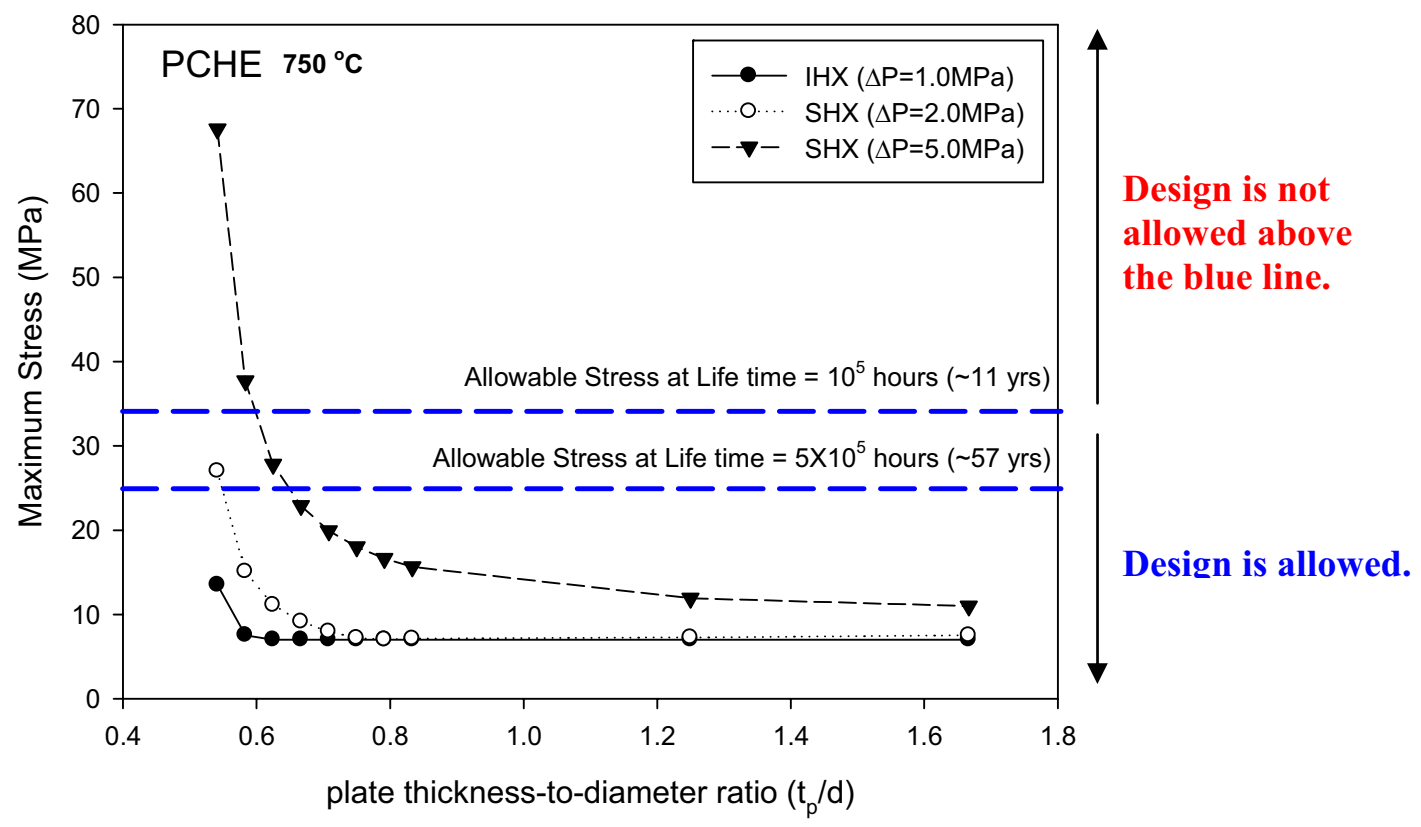

Figure 1-15. Maximum stress as a function of plate thickness-to-diameter ratio (PCHE, $750^{\circ} \mathrm{C}$ ).

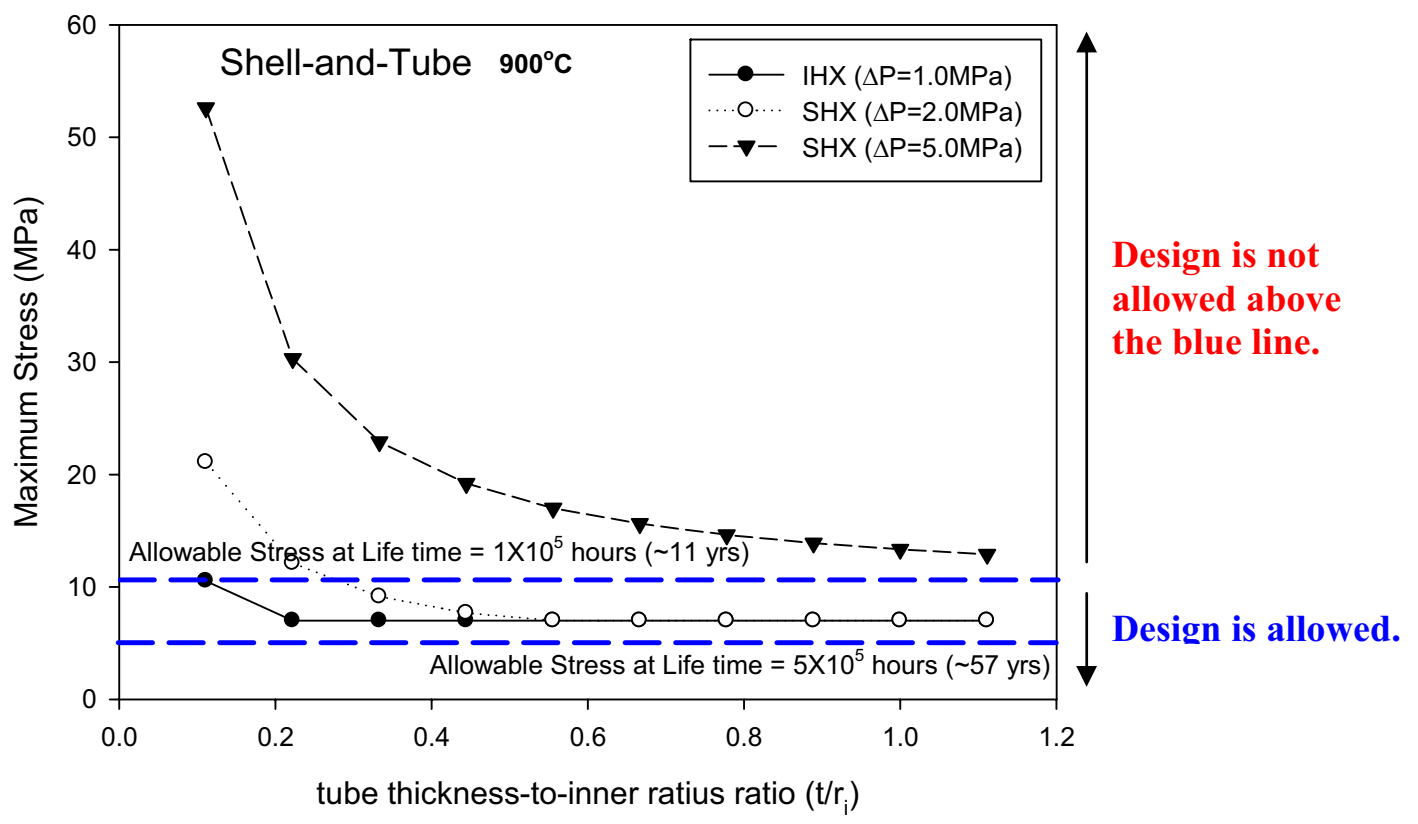

Figure 1-16. Maximum stress as a function of tube thickness-to-radius ratio (shell-and-tube, $900^{\circ} \mathrm{C}$ ). 


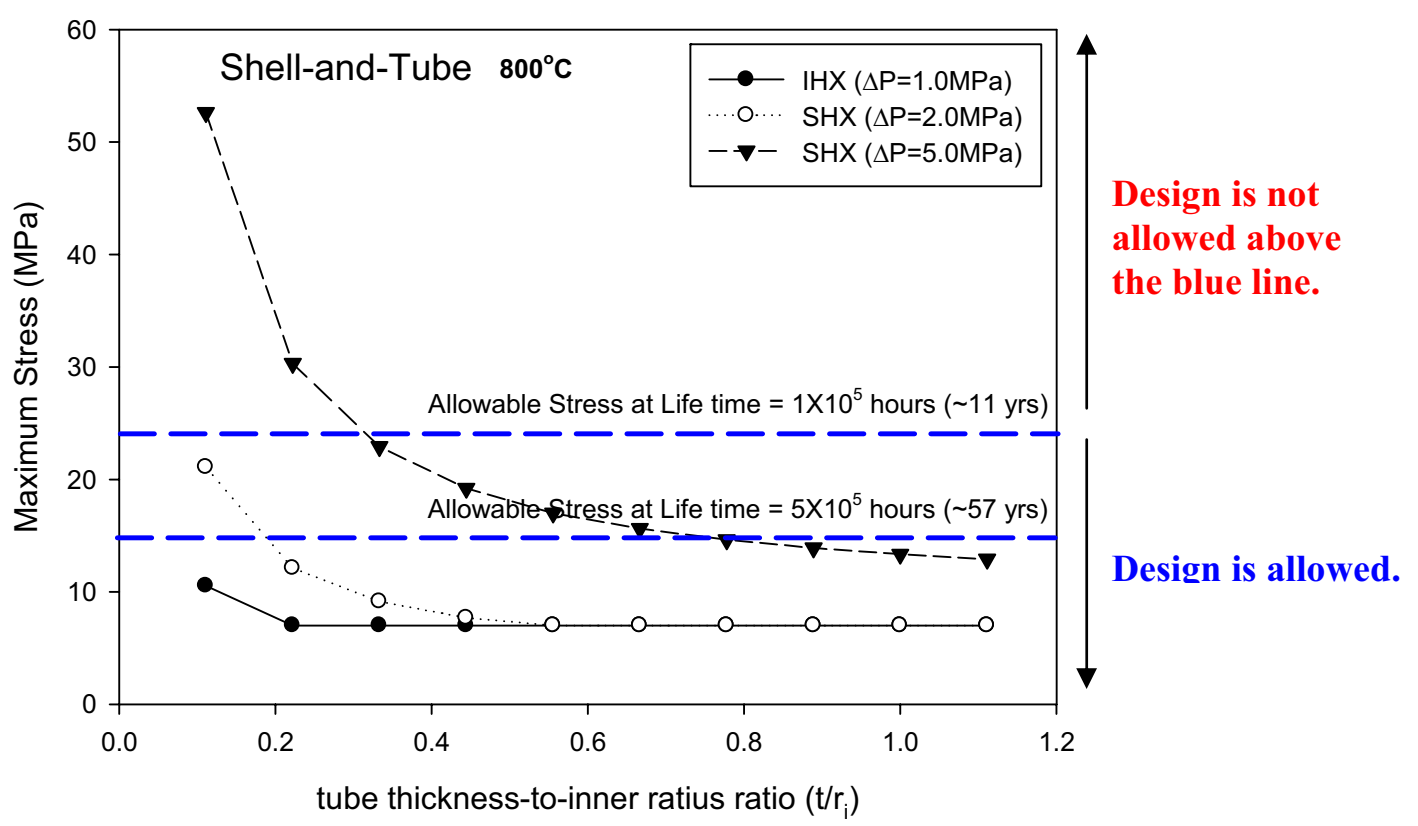

Figure 1-17. Maximum stress as a function of tube thickness-to-radius ratio (shell-and-tube, $800^{\circ} \mathrm{C}$ ).

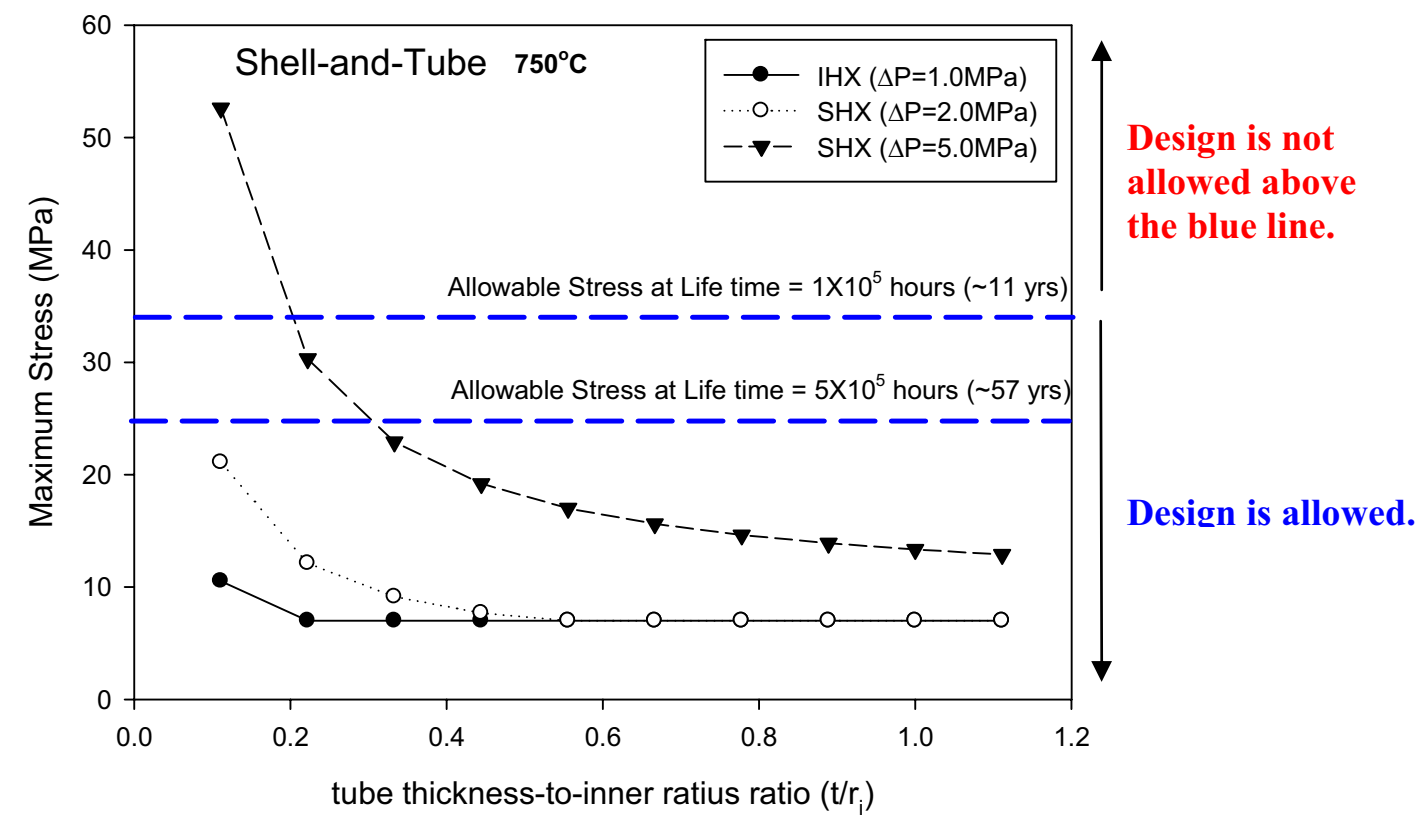

Figure 1-18. Maximum stress as a function of tube thickness-to-radius ratio (shell-and-tube, $750^{\circ} \mathrm{C}$ ). 
The above estimates are summarized in Tables 1-28, 1-29, and 1-30. Table 1-28 summarizes the required thickness estimated for an IHX, which shows that the PCHE can be operated for most of the whole lifetime $(\sim 35$ years $)$ with the reference design $\left(\mathrm{t}_{\mathrm{p}} / \mathrm{d}=0.58\right)$. The tubular-type heat exchangers show similar performance, but in a larger thickness-to-inner radius ratio $\left(\mathrm{t} / \mathrm{r}_{\mathrm{i}}=0.22\right)$ than the reference design $\left(t / r_{i}=0.1\right)$. The lifetime $t / r_{i}$ for the reference tubular heat exchanger design $\left(t / r_{i}=0.1\right)$ is estimated to be $1.0 \times 10^{5} \mathrm{hrs}$ (about 11 years) as presented in Table $1-27$. Below $800^{\circ} \mathrm{C}, \mathrm{PCHE}$ and tubular-type heat exchangers do not show any problems for the 50-year operational design.

Tables 1-29 and 1-30 present the required thickness-to-inner radius ratios for SHXs. Two maximum pressure differences $\left(\Delta \mathrm{P}_{\max }\right)$ were considered between the hot and cold channels: $2.0 \mathrm{MPa}$ and $5.0 \mathrm{MPa}$. When the case result is $\Delta \mathrm{P}_{\max }=2.0 \mathrm{MPa}$, the estimated results were similar to the IHX case, but in the 5.0 MPa range, neither the PCHE nor tubular type heat exchanger can be operated in $900^{\circ} \mathrm{C}$ range for the reasonable lifetime, since the required thicknesses are too large. However, below $800 \times$, the required thicknesses are within the reasonable design range.

Table 1-28. Required thickness for IHX (for $\Delta \mathrm{P}_{\max }=1.0 \mathrm{MPa}$ ).

\begin{tabular}{|l|c|c|c|c|}
\hline & \multicolumn{2}{|c|}{$\begin{array}{c}\text { PCHE } \\
\text { (Plate Thickness/Diameter ) }\end{array}$} & \multicolumn{2}{c|}{$\begin{array}{c}\text { Shell-and-Tube } \\
\text { (Tube Thickness/Inner Radius) }\end{array}$} \\
\hline Temperature & $\mathbf{1 0}^{\mathbf{5}}$ hours & $\mathbf{5 \times \mathbf { 1 0 } ^ { \mathbf { 5 } } \text { hours }}$ & $\mathbf{1 0}^{\mathbf{5}}$ hours & $\mathbf{5 \times \mathbf { 1 0 } ^ { \mathbf { 5 } } \text { hours }}$ \\
\hline $750^{\circ} \mathrm{C}$ & 0.51 & 0.51 & 0.006 & 0.002 \\
\hline $800^{\circ} \mathrm{C}$ & 0.51 & 0.53 & 0.02 & 0.025 \\
\hline $900^{\circ} \mathrm{C}$ & 0.56 & $\infty$ & 0.1 & $\infty$ \\
\hline
\end{tabular}

Table 1-29. Required thickness for SHX (for $\Delta \mathrm{P}_{\max }=2.0 \mathrm{MPa}$ ).

\begin{tabular}{|l|c|c|c|c|}
\hline & \multicolumn{2}{|c|}{$\begin{array}{c}\text { PCHE } \\
\text { (Plate Thickness/Diameter) }\end{array}$} & \multicolumn{2}{c|}{$\begin{array}{c}\text { Shell-and-Tube } \\
\text { (Tube Thickness/Inner Radius) }\end{array}$} \\
\hline Temperature & $\mathbf{1 0}^{\mathbf{5}}$ hours & $\mathbf{5 \times 1 0}^{\mathbf{5}}$ hours & $\mathbf{1 0}^{\mathbf{5}}$ hours & $\mathbf{5 \times \mathbf { 1 0 } ^ { \mathbf { 5 } } \text { hours }}$ \\
\hline $750^{\circ} \mathrm{C}$ & 0.51 & 0.52 & 0.08 & 0.05 \\
\hline $800^{\circ} \mathrm{C}$ & 0.51 & 0.59 & 0.2 & 0.1 \\
\hline $900^{\circ} \mathrm{C}$ & 0.64 & $\infty$ & 0.23 & $\infty$ \\
\hline
\end{tabular}

Table 1-30. Required thickness for SHX (for $\Delta \mathrm{P}_{\max }=5.0 \mathrm{MPa}$ ).

\begin{tabular}{|l|c|c|c|c|}
\hline & \multicolumn{2}{|c|}{$\begin{array}{c}\text { PCHE } \\
\text { (Plate Thickness/Diameter ) }\end{array}$} & \multicolumn{2}{c|}{$\begin{array}{c}\text { Shell-and-Tube } \\
\text { (Tube Thickness/Inner Radius) }\end{array}$} \\
\hline Temperature & $\mathbf{1 0}^{\mathbf{5}}$ hours & $\mathbf{5 \times \mathbf { 1 0 } ^ { \mathbf { 5 } } \text { hours }}$ & $\mathbf{1 0}^{\mathbf{5}}$ hours & $\mathbf{5 \times \mathbf { 1 0 } ^ { \mathbf { 5 } } \text { hours }}$ \\
\hline $750^{\circ} \mathrm{C}$ & 0.6 & 0.62 & 0.2 & 0.31 \\
\hline $800^{\circ} \mathrm{C}$ & 0.65 & 0.93 & 0.3 & 0.8 \\
\hline $900^{\circ} \mathrm{C}$ & 1.65 & $\infty$ & $\infty$ & $\infty$ \\
\hline
\end{tabular}

Figures 1-19 and 1-20 show the relationships between the heat exchanger wall thickness and the estimated lifetime for PCHE and tubular-types, respectively. As shown this figures, the lifetime of the heat exchangers sharply increases in the small thickness. However, the lifetime is suddenly saturated for a certain thickness level. The reason is because of the normal stress on the inner wall. If the wall is getting thicker, the tangential stresses on the tubes are sharply reduced. However, since the normal stress is not affected by the tube thickness, the total effective stress is limited by this value. We used the maximum shear stress theory for failure analysis, so the lifetime is finally determined by the normal stress of the tube inside. 


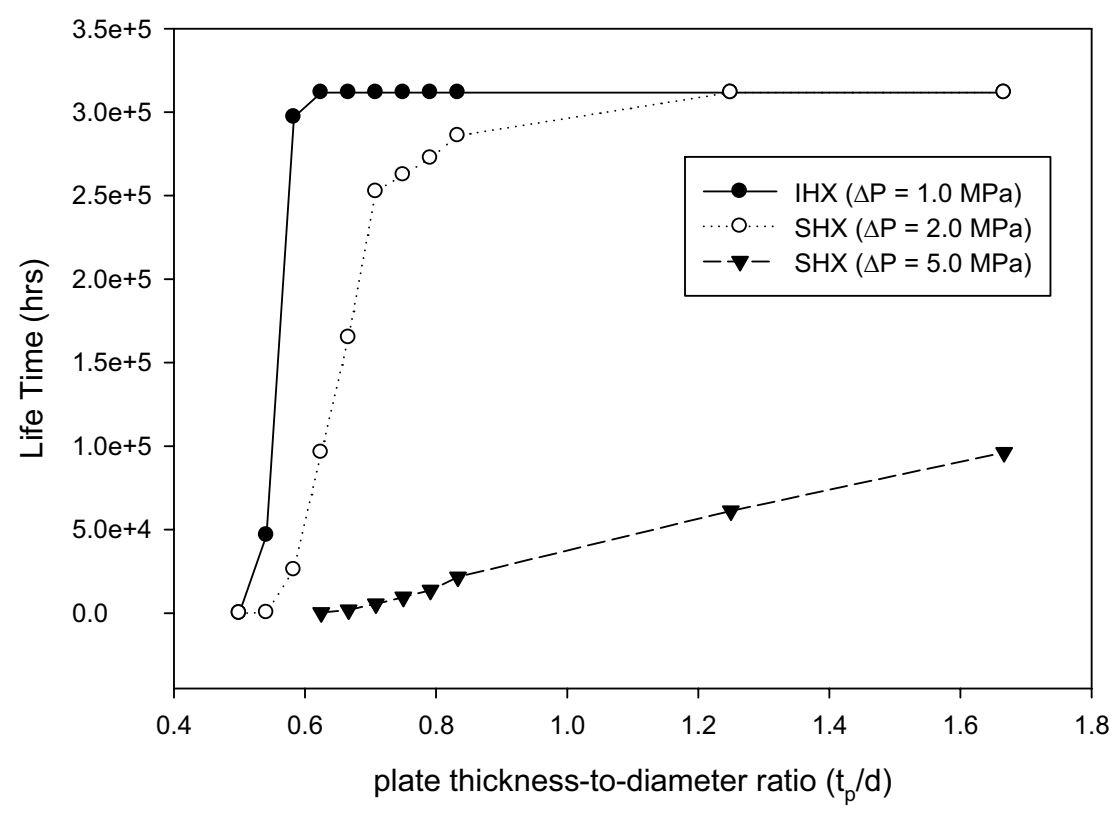

Figure 1-19. Plate thickness-to-diameter ratio vs. estimated heat exchanger lifetime (PCHE).

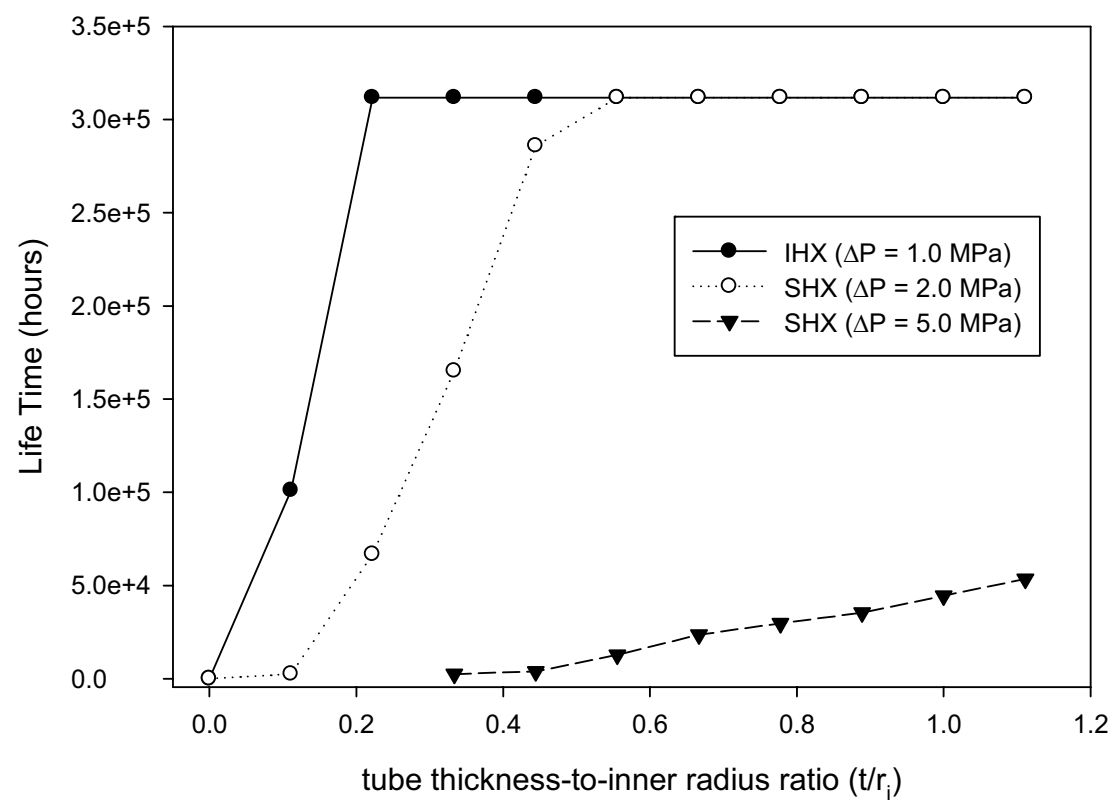

Figure 1-20. Tube thickness-to-inner radius ratio vs. estimated heat exchanger lifetime (shell-and-tube). 


\subsection{Computational Analysis on the Printed Circuit Heat Exchanger Channel Configuration Options}

In the previous sections, we found from some simple thermal designs and stress analyses that the PCHE type is conceptually very adequate for VHTR heat exchanger applications compared to other types. In this section, some computational analyses have been performed for the PCHEs in order to investigate the heat exchanger performance. The two cross-sectional channel configuration options considered were standard and off-set. And the performances, including heat transfer, tritium diffusion, and maximum stress, have been compared together for each option. Finally, this work provides and recommends a better option for PCHE channel configuration, one that can maximize heat exchanger performance. COMSOL Multiphysics 3.4 software was used to analyze the heat transfer and tritium diffusion. The details of this software and the analysis results are summarized in the following Section 4.1. The stress analysis has been performed by ABAQUS code, and the results are described in Section 4.2.

\subsubsection{COMSOL Modeling for Heat Transfer and Tritium Penetration in the PCHE}

COMSOL Multiphysics 3.4 was used to perform this analysis in order to compare the performance of heat transfer and tritium penetration in the PCHEs (COMSOL 2008). The COMSOL Multiphysics (formerly FEMLAB) software is a finite element analysis and solver software package for various physics and engineering applications, especially coupled phenomena and multiphysics. This software offers several application-specific modules including electromagnetic, acoustic, chemical engineering, earth science, heat transfer, fluid dynamics, structure mechanics models, etc. It also allows the user to enter coupled systems of partial differential equations, which can be entered directly or using weak forms. In this work, simple heat transfer and diffusion modules were used for PCHE analysis.

\subsubsection{Geometry and Dimensions}

Figure 1-21 shows the PCHE channel configurations used: standard in-line and off-set. A PCHE normally has a standard in-line configuration, but for this analysis, the off-set configuration was also considered as an alternative. The referenced PCHE configuration had a plate thickness of $0.96 \mathrm{~mm}$ $\left(\mathrm{t}_{\mathrm{p}}=0.96 \mathrm{~mm}\right)$ and a pitch of $1.464 \mathrm{~mm}(\mathrm{p}=1.464 \mathrm{~mm})$. The diameter of the semicircular ports was $1.2 \mathrm{~mm}$ $\left(\mathrm{d}_{\mathrm{t}}=1.2 \mathrm{~mm}\right)$. Calculations were performed for five horizontal pitches $(1.332 \mathrm{~mm}, 1.464 \mathrm{~mm}, 1.728 \mathrm{~mm}$, $1.992 \mathrm{~mm}$, and $2.5 \mathrm{~mm})$ and five plate thicknesses $(0.69 \mathrm{~mm}, 0.96 \mathrm{~mm}, 1.32 \mathrm{~mm}, 2.54 \mathrm{~mm}$, and $3.48 \mathrm{~mm}$ ). The horizontal pitch, plate thickness, and diameter are shown on Figure 1-21. The offset model was made by shifting every other plate by half the model's pitch. 
(a) Standard in-line configuration

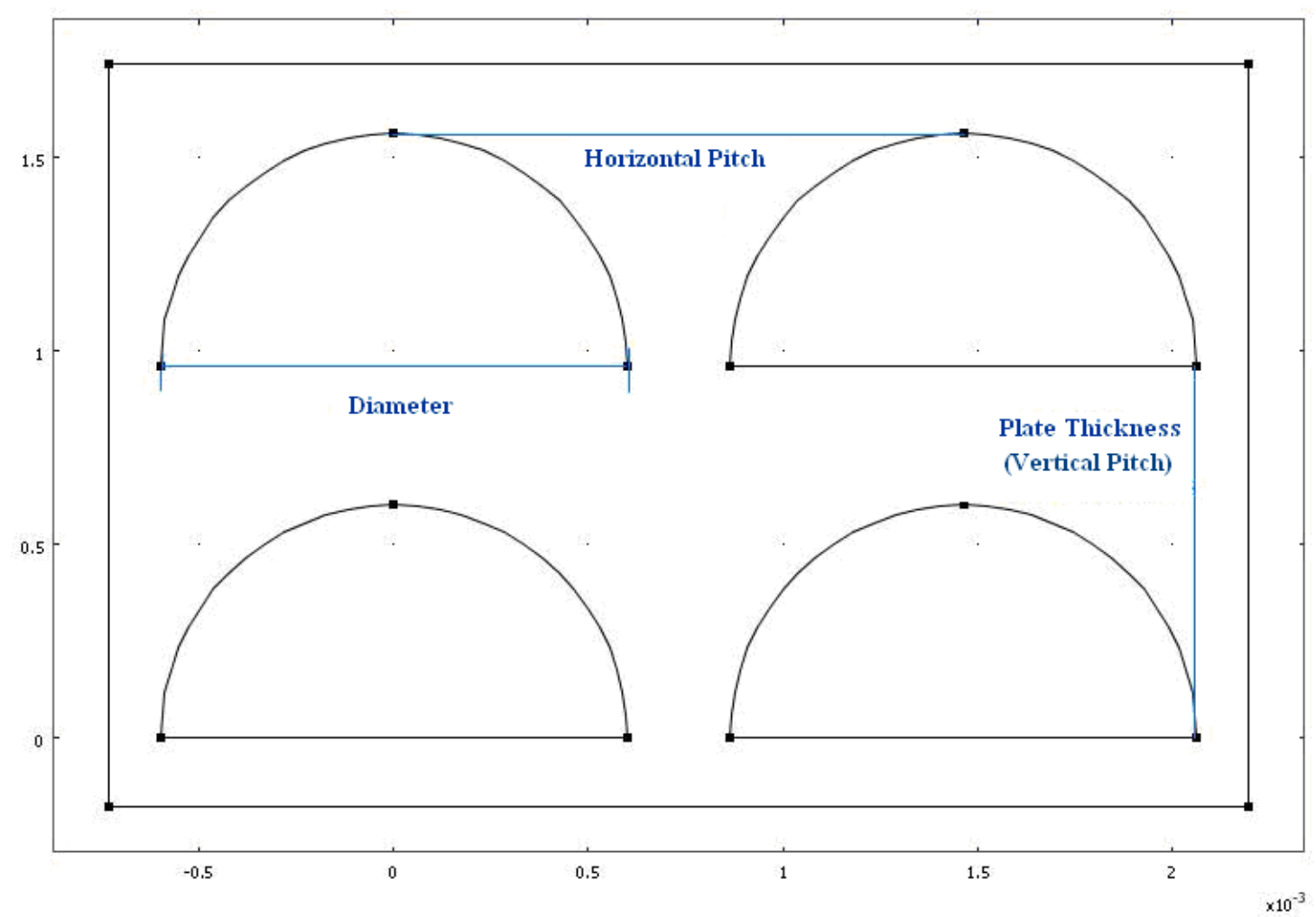

(b) Off-set configuration

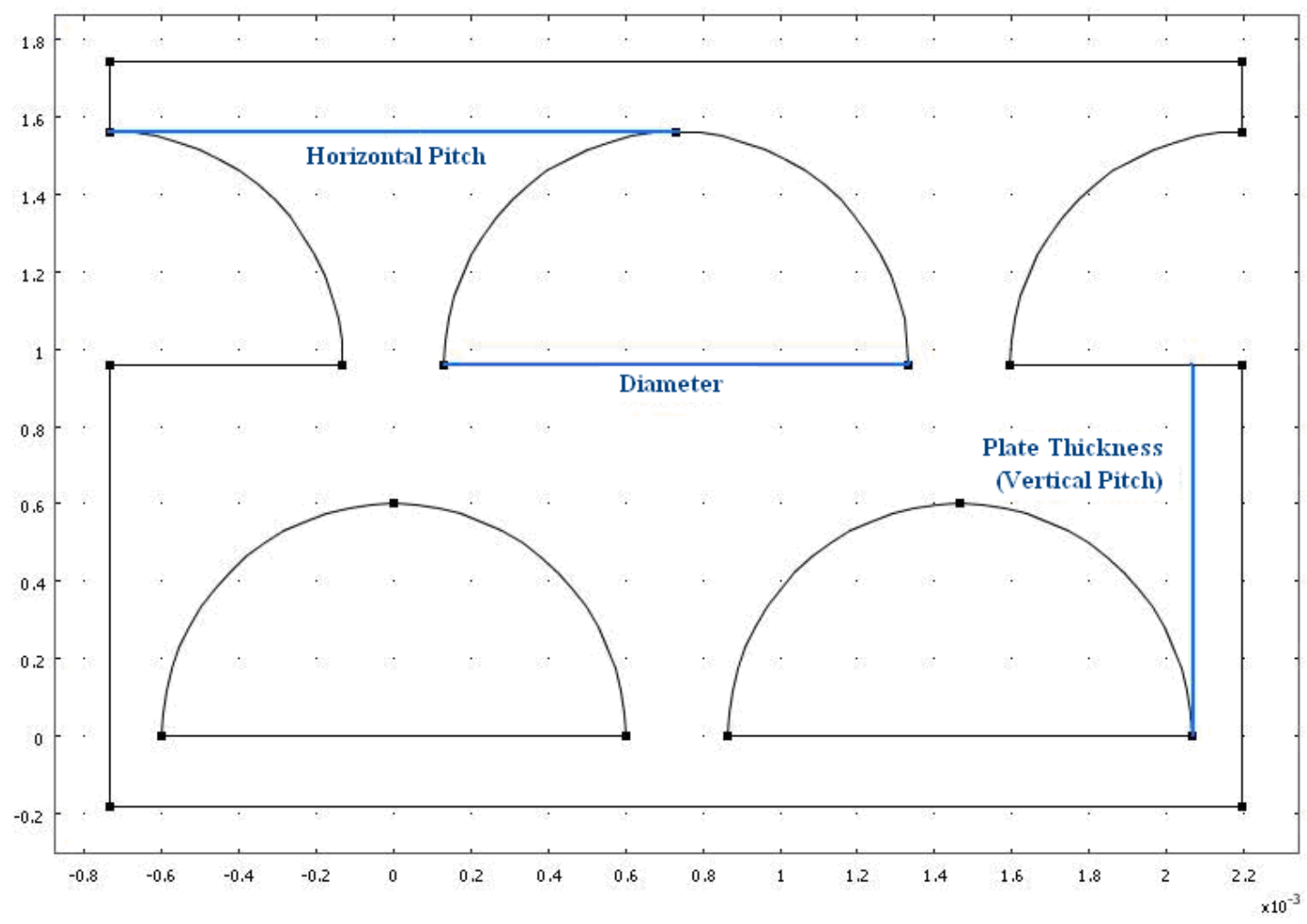

Figure 1-21. PCHE channel configurations. 


\subsubsection{Properties and Boundary Conditions}

The heat transfer and mass diffusion equations for tritium transport were solved in the PCHE solid region, but they were not solved in the fluid region where simple convective heat and mass transfer correlations were used to determine the boundary temperatures and tritium concentrations on the solid surface. Tritium adsorptions or chemisorptions were not considered in this analysis for modeling, so the diffusion in the heat exchanger solid is the rate controlling step. The data for Alloy 800 was therefore implemented into the model because of the lack of Alloy 617 data for the tritium diffusion. Because the purpose of this study is to compare the performance of different channel configurations, the results from Alloy 800 are still valid for other metals such as Alloy 617 and 230. The following diffusion coefficient was used for tritium permeation calculation (Richard 2006):

$$
D_{\text {tritium }}=61.02 \cdot \sqrt{\frac{P}{C_{H_{2}}}} \cdot \exp \left(-\frac{6250}{T}\right)
$$

where,

$$
\begin{array}{ll}
D_{\text {tritium }} & =\text { diffusion coefficient of tritium in Alloy } 800\left(\frac{\mu C i}{m^{2} h r}\right) \\
P & =\text { pressure (atm) } \\
C_{H_{2}} & =\text { hydrogen concentration (ppmv) } \\
T & =\text { absolute solid temperature (K) }
\end{array}
$$

As mentioned above, the boundary conditions for the heat transfer and mass transfer were determined by convective heat/mass transfer correlations. In order to consider this, Schmidt number ( $\mathrm{Sc}), \mathrm{k}_{\text {diffusion }}$, and the diffusion coefficient were calculated based on the bulk conditions of the fluid assumed by the VHTR IHX conditions in Tables 1-31 and 32. The assumed Reynolds numbers (Re) in the hot channel and cold channel are 2,800 and 2,200, respectively. The following equations were selected for determinations of heat transfer and diffusion boundary conditions (Perry's $7^{\text {th }}$ Ed.).

(a) Heat Transfer

$$
\frac{h_{\text {convective }} \cdot d_{h}}{k_{\text {therm }}}=0.023 \cdot \operatorname{Re}^{0.83} S c^{0.44}
$$

(b) Tritium Diffusion

$$
\frac{K_{\text {diffusion }} \cdot d_{h}}{D_{\text {tritium }}}=0.023 \cdot \mathrm{Re}^{0.83} S c^{0.44}
$$

Tables 1-31 and 1-32 summarizes the calculated heat transfer and diffusion coefficients in the PCHE channels. All the fluid properties were obtained from National Institute of Standards and Technology chemistry Webbook (2008). 
Table 1-31. Calculated diffusion coefficients in the PCHE.

\begin{tabular}{|l|c|c|c|c|c|}
\hline & $\begin{array}{c}\text { Diffusion } \\
\text { Coefficient }\end{array}$ & $\begin{array}{c}\mathbf{k}_{\text {diffusion }} \\
\text { (hot) }\end{array}$ & $\begin{array}{c}\mathbf{k}_{\text {diffusion }} \\
\text { (Cold) }\end{array}$ & $\begin{array}{c}\text { Sc } \\
\text { (hot) }\end{array}$ & Sc (cold) \\
\cline { 2 - 6 } & $\mathbf{m}^{2} / \mathbf{s}$ & $\mathbf{m} / \mathbf{s}$ & $\mathbf{m} / \mathbf{s}$ & & \\
\hline Primary Coolant Inlet & $1.799 \mathrm{E}-05$ & 0.385 & & 0.866 & \\
\hline Primary Coolant Outlet & $1.048 \mathrm{E}-05$ & 0.222 & & 0.852 & \\
\hline Secondary Coolant Inlet & $1.020 \mathrm{E}-05$ & & 0.177 & & 0.851 \\
\hline Secondary Coolant Outlet & $1.782 \mathrm{E}-05$ & & 0.311 & & 0.862 \\
\hline $500^{\circ} \mathrm{C}$ & $1.050 \mathrm{E}-05$ & 0.213 & 0.174 & 0.765 & 0.765 \\
\hline $600^{\circ} \mathrm{C}$ & $1.294 \mathrm{E}-05$ & 0.264 & 0.216 & 0.781 & 0.781 \\
\hline $700^{\circ} \mathrm{C}$ & $1.561 \mathrm{E}-05$ & 0.318 & 0.261 & 0.777 & 0.777 \\
\hline $800^{\circ} \mathrm{C}$ & $1.782 \mathrm{E}-05$ & 0.371 & 0.304 & 0.796 & 0.796 \\
\hline $900^{\circ} \mathrm{C}$ & $2.129 \mathrm{E}-05$ & 0.436 & 0.357 & 0.785 & 0.785 \\
\hline
\end{tabular}

Table 1-32. Calculated heat transfer coefficients in the PCHE.

\begin{tabular}{|l|c|c|c|c|}
\hline & $\mathbf{W} / \mathbf{m}^{\mathbf{2}} \mathbf{K}$ & $\mathbf{W} / \mathbf{m}^{\mathbf{2}} \mathbf{K}$ & & \\
\cline { 2 - 5 } & $\begin{array}{c}\mathbf{h}_{\text {convection }} \\
\text { (hot) }\end{array}$ & $\begin{array}{c}\mathbf{h}_{\text {convection }} \\
\text { (Cold) }\end{array}$ & $\begin{array}{c}\text { Pr } \\
\text { (hot) }\end{array}$ & $\begin{array}{c}\text { Pr } \\
\text { (cold) }\end{array}$ \\
\hline Primary Coolant Inlet & 7252.610843 & & 0.659735352 & \\
\hline Primary Coolant Outlet & 5749.518929 & & 0.656930324 & \\
\hline Secondary Coolant Inlet & & 4667.650654 & & 0.65679 \\
\hline Secondary Coolant Outlet & & 5883.805147 & & 0.65969 \\
\hline
\end{tabular}

The analysis was performed with a number of different boundary conditions. The following were the conditions used (slightly modified from Ohashi and Sherman [2007]). As shown below, the temperature in the fluid channels for tritium permeation analysis were matched to be the same for eliminating the effect of temperature gradient.

\section{Tritium Concentration in the Bulk Fluids}

- Primary Coolant Tritium Concentration: $115 \mu \mathrm{Ci} / \mathrm{m}^{3}$

- Secondary Coolant Tritium Concentration: $113 \mu \mathrm{Ci} / \mathrm{m}^{3}$

- Primary Coolant Hydrogen Concentration: 200 ppm

\section{Temperatures in the Bulk Fluids}

For heat transfer analysis:

- Primary Coolant Inlet T: $900^{\circ} \mathrm{C}$

- $\quad$ Primary Coolant Inlet P: 69.08 atm (7 MPa)

- $\quad$ Secondary Coolant Outlet T: $886.3^{\circ} \mathrm{C}$

- Secondary Coolant Outlet P: 68.59 atm (6.95 MPa)

- Primary Coolant Outlet T: $495.5^{\circ} \mathrm{C}$

- Primary Coolant Outlet P: 68.59 atm (6.95 MPa)

- Secondary Coolant Inlet T: $486.3^{\circ} \mathrm{C}$ 
- Secondary Coolant Inlet P: 69.08 atm (7 MPa).

For tritium permeation analysis:

- Primary Coolant T: $500^{\circ} \mathrm{C}$

- Primary Coolant P: 69.08 atm (7 MPa)

- Secondary Coolant T: $500^{\circ} \mathrm{C}$

- Secondary Coolant P: 69.08 atm (7 MPa)

- Primary Coolant T: $600^{\circ} \mathrm{C}$

- Primary Coolant P: $69.08 \mathrm{~atm}(7 \mathrm{MPa})$

- Secondary Coolant T: $600^{\circ} \mathrm{C}$

- Secondary Coolant P: $69.08 \mathrm{~atm}(7 \mathrm{MPa})$

- Primary Coolant T: $700^{\circ} \mathrm{C}$

- Primary Coolant P: 69.08 atm (7 MPa)

- Secondary Coolant T: $700^{\circ} \mathrm{C}$

- Secondary Coolant P: 69.08 atm (7 MPa)

- Primary Coolant T: $800^{\circ} \mathrm{C}$

- Primary Coolant P: 69.08 atm (7 MPa)

- Secondary Coolant T: $800^{\circ} \mathrm{C}$

- Secondary Coolant P: $69.08 \mathrm{~atm}(7 \mathrm{MPa})$

- Primary Coolant T: $900^{\circ} \mathrm{C}$

- Primary Coolant P: 69.08 atm (7 MPa)

- Secondary Coolant T: $900^{\circ} \mathrm{C}$

- Secondary Coolant P: 69.08 atm (7 MPa).

The outer boundary conditions of the COMSOL models were set for two hot channels and two cold channels. In order to accomplish the modeling, a periodic boundary condition was imposed on the wall of the channels described above so that flux calculations assume an infinite array of hot and cold ports and do not take into account the difference in flux at the sides of the heat exchanger. There are approximately 200,000 ports in the PCHE being considered for the NGNP, so the error associated with this assumption is considered to be minimal.

\subsubsection{Method of Grid Sensitivity Study}

The mesh and grid size are very important issues in the computational fluid dynamics (CFD) or FEM code analysis because they highly affect the quantitative values of the simulations. Generally, as the grid and time step are refined, the spatial and temporal discretization errors should asymptotically approach zero, excluding computer round-off error.

In this report, we followed the grid sensitivity analysis procedure proposed by the AIAA (1998) for validation and verification of CFD codes. Since the basic concept of this grid sensitivity study is simply based on the extrapolation methods, the guideline used in CFD codes are still conceptually valid for our case. The following discussion summarizes the grid sensitivity study provided by the National Aeronautics and Space Administration on the "NPARC Alliance CFD Verification and Validation" Website. 


\section{Grid Consideration for a Grid Convergence Study}

In generating a fine grid, one can build in the $\mathrm{n}$ levels of coarser grids by making sure that the number of grid points in each coordinate direction satisfies the relation

$$
N=2^{n} m+1
$$

where $N$ is the total number of grid points in each coordinate direction, $n$ is the level of grids, and $m$ is an arbitrary number defined for each coordinate direction.

For example: if two levels of coarser grids are desired (fine, medium, and coarse grids), the number of grid points in each coordinate direction must equal $4 \mathrm{~m}+1$. The $m$ may be different for each coordinate direction. It is not necessary to halve the number of grid points in each coordinate direction to obtain the coarse grid, but it is important to maintain the same grid generation parameters as the original grid.

\section{Order of Grid Convergence}

The order of grid convergence involves the behavior of the solution error defined as the difference between the discrete solution and the exact solution as

$$
E=f(h)-f_{\text {exact }}=C h^{P}+H \cdot O \cdot T
$$

where $C$ is a constant, $h$ is some measure of grid spacing, $p$ is the order of convergence, and H.O.T is higher order terms. A "second-order" solution would have $p=2$.

Neglecting higher-order terms and taking the logarithm of both sides of the above equation results in

$\log (E)=\log (C)+p \log (h)$

The order of convergence $\mathrm{p}$ can be obtained from the slope of the curve of $\log (\mathrm{E})$ versus $\log (\mathrm{h})$.

A more direct evaluation of $\mathrm{p}$ can be obtained from three solutions using a constant grid refinement ratio $\mathrm{r}$,

$p=\ln \left(\frac{f_{3}-f_{2}}{f_{2}-f_{1}}\right) / \ln (r)$

where $f_{1}, f_{2}$, and $f_{3}$ are results from fine, medium, and coarse grids, respectively.

The order of accuracy is determined by the order of the leading term of the truncation error and is represented with respect to the scale of the discretization, $h$. The local order of accuracy is the order for the stencil representing the discretization of the equation at one location in the grid. The global order of accuracy considers the propagation and accumulation of errors outside the stencil. This propagation causes the global order of accuracy to be, in general, one degree less than the local order of accuracy. The order of accuracy of the boundary conditions can be one order of accuracy lower than the interior order of accuracy without degrading the overall global accuracy.

\section{Asymptotic Range of Convergence}

Assessing the accuracy of code and calculations requires that the grid be sufficiently refined such that the solution is in the asymptotic range of convergence. The asymptotic range of convergence is obtained when the grid spacing is such that the spacing $\mathrm{h}$ and errors $\mathrm{E}$ result in the constancy of $\mathrm{C}$ as in

$C=E / h^{p}$ 


\section{Richardson Extrapolation}

Richardson extrapolation is a method for obtaining a higher-order estimate of the continuum value from a series of lower-order discrete values. A simulation will yield a quantity $f$ that can be expressed in a general form by the series expansion

$$
f=f_{h=0}+g_{1} h+g_{2} h^{2}+g_{3} h^{3}+\ldots
$$

where $h$ is the grid spacing. The quantity $f$ is considered "second-order" if $g_{l}=0.0 . f_{h=0}$ is the continuum value when the mesh is infinitely small.

If one assumes a second-order solution and has computed $\mathrm{f}$ on a two-grid spacing of $\mathrm{h} 1$ and $\mathrm{h} 2$ with $\mathrm{h} 1$ being the finer spacing, then one can write two equations for the above expansion, neglect third-order and higher terms, and solve for $\mathrm{f}_{\mathrm{h}=0}$ to estimate the continuum value,

$$
f_{h=0} \cong f_{1}+\frac{f_{1}-f_{2}}{r^{2}-1}
$$

where the grid refinement ratio is

$$
f=h_{2} / h_{1}
$$

The Richardson extrapolation can be generated for a p-th order methods and r-value of grid ration as

$$
f_{h=0} \cong f_{1}+\frac{f_{1}-f_{2}}{r^{p}-1}
$$

Traditionally, Richardson extrapolation has been used with grid refinement ratios of $r=2$. Thus, the above equation simplifies to

$$
f_{h=0} \cong \frac{4}{3} f_{1}-\frac{1}{3} f_{2}
$$

If a larger number of CFD computations are to be performed, one may wish to use the coarser grid with $\mathrm{h}_{2}$. We will then want to estimate the error on the coarser grid. The Richardson extrapolation can be expressed as

$$
f_{h=0} \cong f_{2}+\frac{\left(f_{1}-f_{2}\right) r^{p}}{r^{p}-1}
$$

The estimated fractional error for $\mathrm{f}_{2}$ is defined as

$$
E_{2}=\frac{\varepsilon \cdot r^{p}}{r^{p}-1}
$$

Richardson extrapolation is based on a Taylor series representation. If there are shocks and other discontinuities present, the Richardson extrapolation is invalid in the region of the discontinuity. 


\section{Grid Convergence Index (GCI)}

Roache suggested a grid convergence index (GCI) to provide a consistent manner of reporting results of grid convergence studies and provide an error band on the grid convergence of the solution.

One significant issue in numerical computation is determining what level of grid resolution is appropriate. This is a function of flow conditions, type of analysis, geometry, and other variables.

The GCI is a measure of the percentage the computed values are away from the values of the asymptotic numerical value, which indicates an error band on how far the solution is from the asymptotic value and how much the solution would change with a further refinement of the grid. A small value of the GCI indicates that the computation is within the asymptotic range.

The GCI on the fine grid is defined as

$G C I_{\text {fine }}=\frac{F_{s}|\varepsilon|}{\left(r^{p}-1\right)}$

where $F s$ is a factor of safety. The refinement may be spatial or in time. The factor of safety is recommended to be $\mathrm{Fs}=3.0$ for comparisons of two grids and $\mathrm{Fs}=1.25$ for comparisons over three or more grids. The higher factor of safety is recommended for reporting purposes and is quite conservative of the actual errors.

The GCI for the coarser grid is defined as

$G C I_{\text {fine }}=\frac{F_{s}|\varepsilon| r^{p}}{\left(r^{p}-1\right)}$

It is important that each grid level yield solutions that are in the asymptotic range of convergence for the computed solution. This can be checked by observing two GCI values as computed over three grids,

$G C I_{23}=r^{p} G C I_{12}$

\section{Required Grid Resolution}

If a desired accuracy level is known and results from the grid resolution study are available, one can then estimate the grid resolution required to obtain level of accuracy,

$$
r^{*}=\left(\frac{G C I^{*}}{G C I_{21}}\right)^{1 / p}
$$

\section{Effective Grid Refinement Ratio}

If one generates a finer or coarser grid and is unsure of the value of grid refinement ratio to use, one can compute an effective grid refinement ratio as

$r_{\text {effective }}=\left(\frac{N_{1}}{N_{2}}\right)^{(1 / D)}$

where $N$ is the total number of grid points used for the grid and $D$ is the dimension of the flow domain. This effective grid refinement ratio can also used for unstructured grids. 


\subsubsection{Results and Discussions}

\section{Heat and Tritium Diffusion Analysis in the PCHEs}

Figures 1-22 and 1-23 are a graphical representation of the concentration and temperature profiles using the Primary Inlet Conditions in the two reference configurations (standard and off-set). Analysis of flux data for seven different temperatures and two different pressures showed a $1 \%$ decrease in tritium flux and a negligible decrease in heat flux when calculated using the reference geometries (horizontal pitch $=1.464 \mathrm{~mm}$; vertical pitch $=0.96 \mathrm{~mm}$; diameter $=1.2 \mathrm{~mm}$. The heat flux for the off-set configuration was equal to $99.98 \%$ of the initial value for the reference configurations. Flux values were extrapolated to find the value as the mesh size approaches zero using Richardson's method, summarized in the previous section. The error associated with this extrapolation is $1.5 \%$ for the initial configuration and $1.7 \%$ for the offset configuration when calculating tritium flux.

(a) Temperature Profiles.

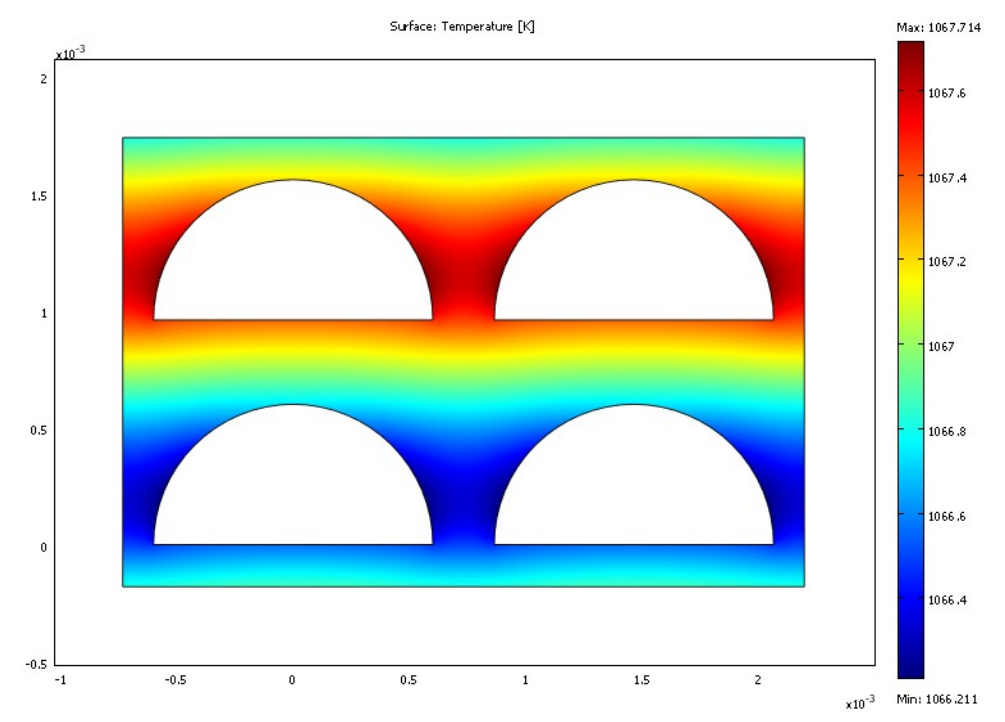

(b) Concentration Profiles.

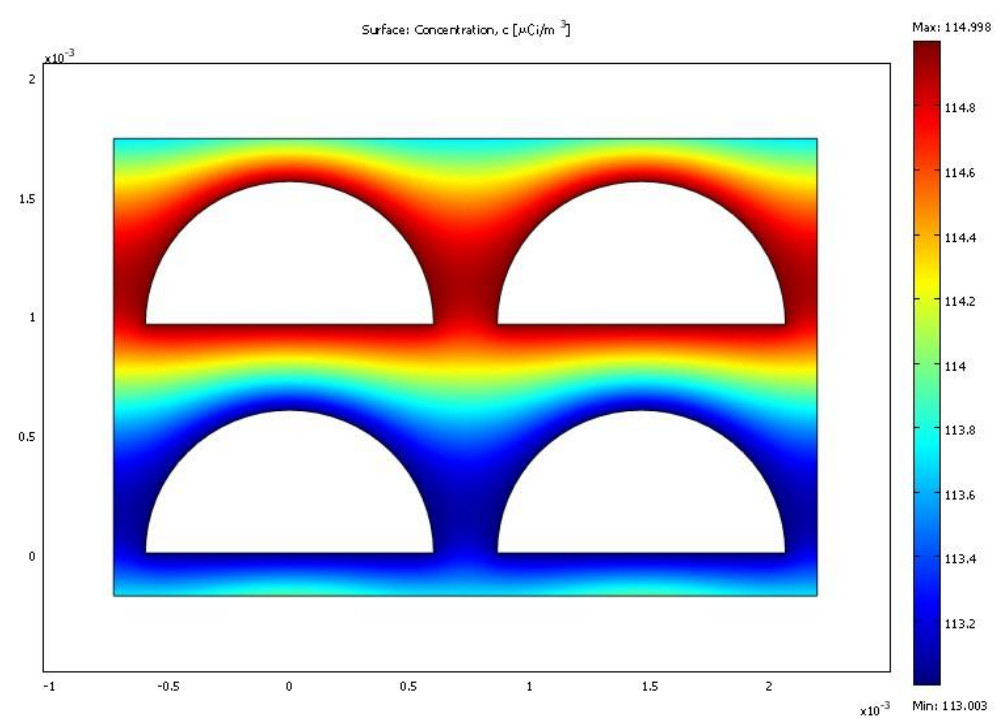

Figure 1-22. Calculated temperature and tritium concentration profiles (for the standard configuration). 
(a) Temperature profile.

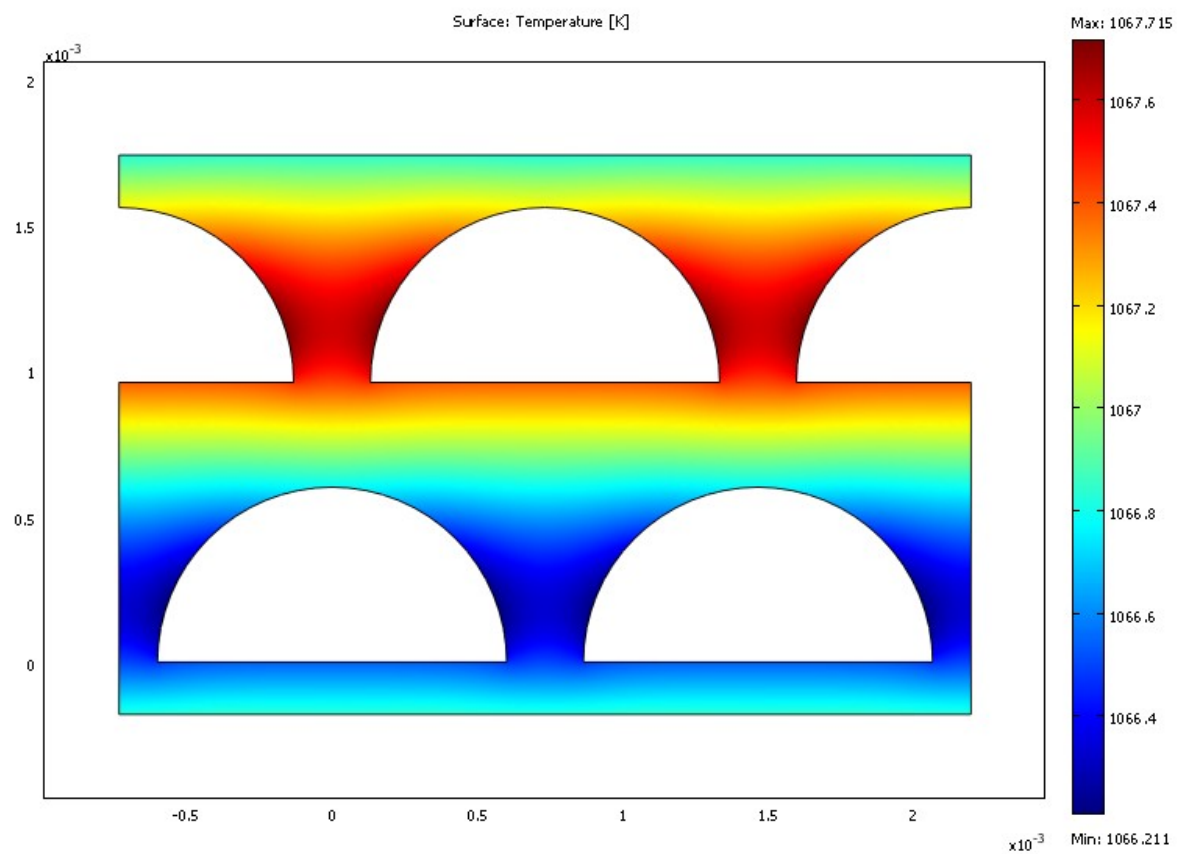

(b) Concentration profile.

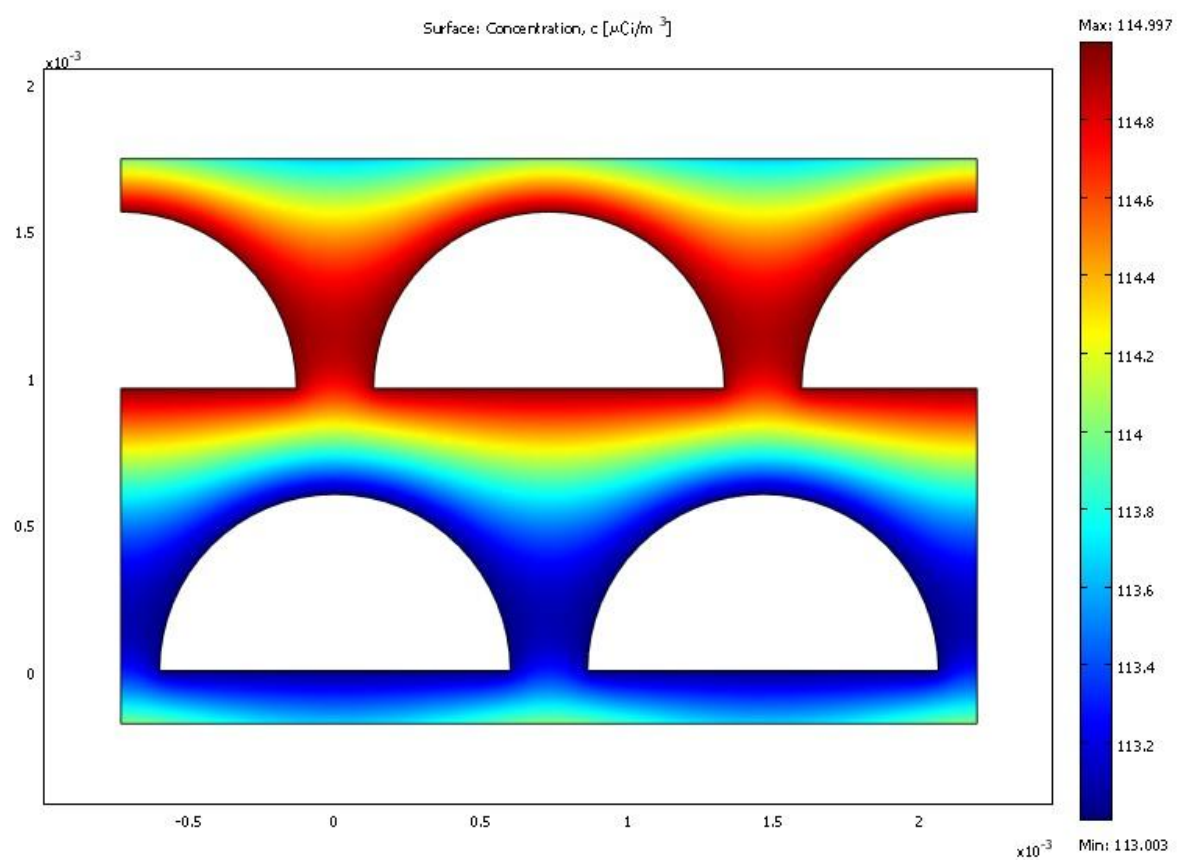

Figure 1-23. Calculated temperature and tritium concentration profiles (for the off-set configuration).

This analysis showed that the majority of resistance to heat transfer is found in the fluid boundary layer, not in the metal itself. In contrast, the majority of resistance to tritium flux is found in the metal itself. Knowing this, the tritium flux can be reduced through the metal without greatly reducing heat transfer. 
Figures 1-24 and 1-25 show profiles of tritium diffusion flux and the main penetration paths for standard and off-set configurations, respectively. As shown in these figures, the tritium flux on the flow channel is not uniform along the surface. Most of the tritium diffusion is concentrated on the center part of the semicircle area. On the other hand, there is very small tritium penetration on the channel side because of very small concentration gradient in this direction. The dead spot area is highly dependent on the channel horizontal pitch.

(a) Diffusion flux.

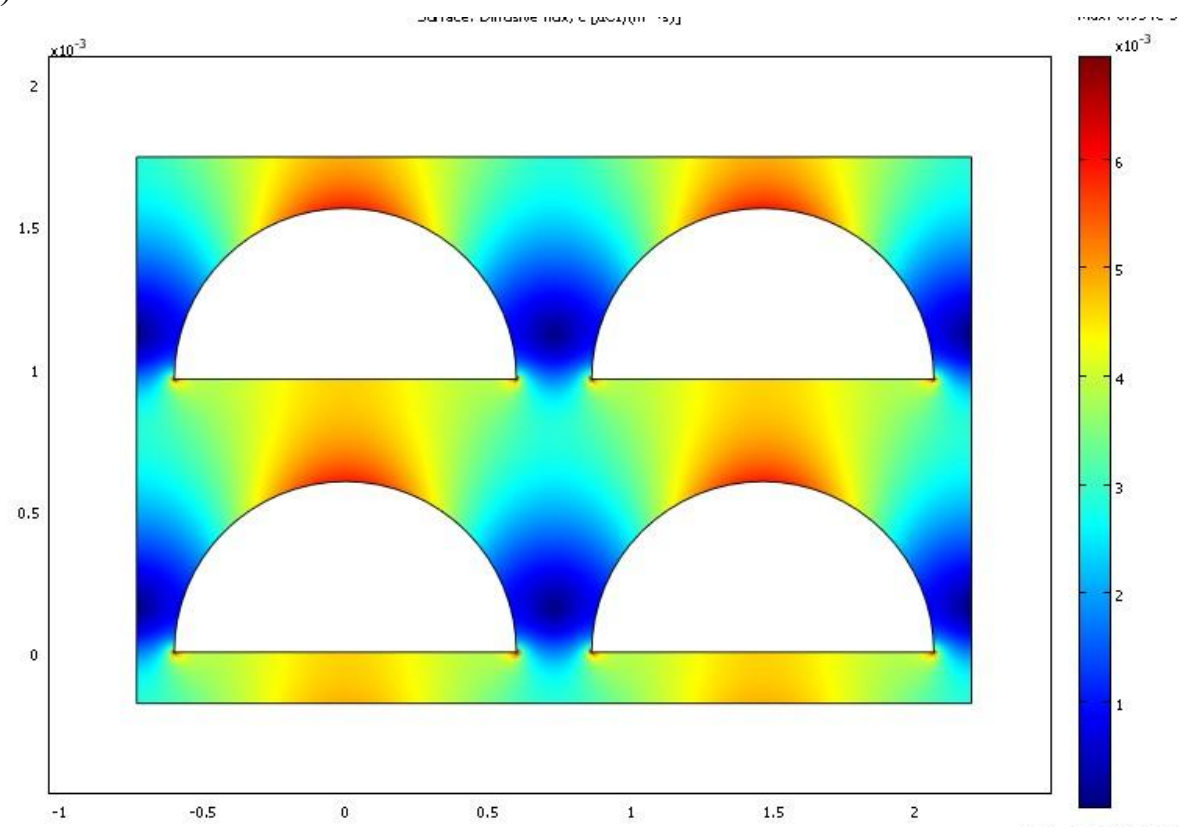

(b) Diffusion path.

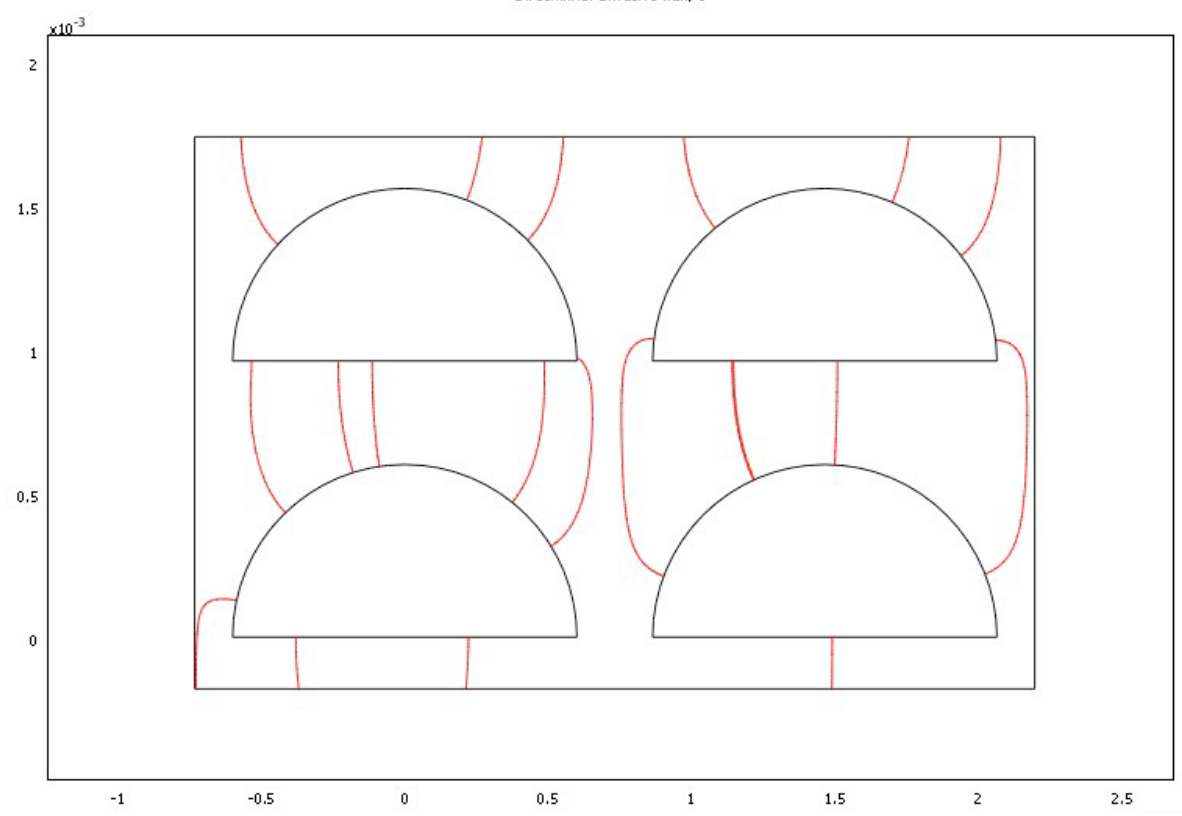

Figure 1-24. Diffusion flux and path of tritium in the PCHE (for the standard configuration). 
(a) Diffusion flux.

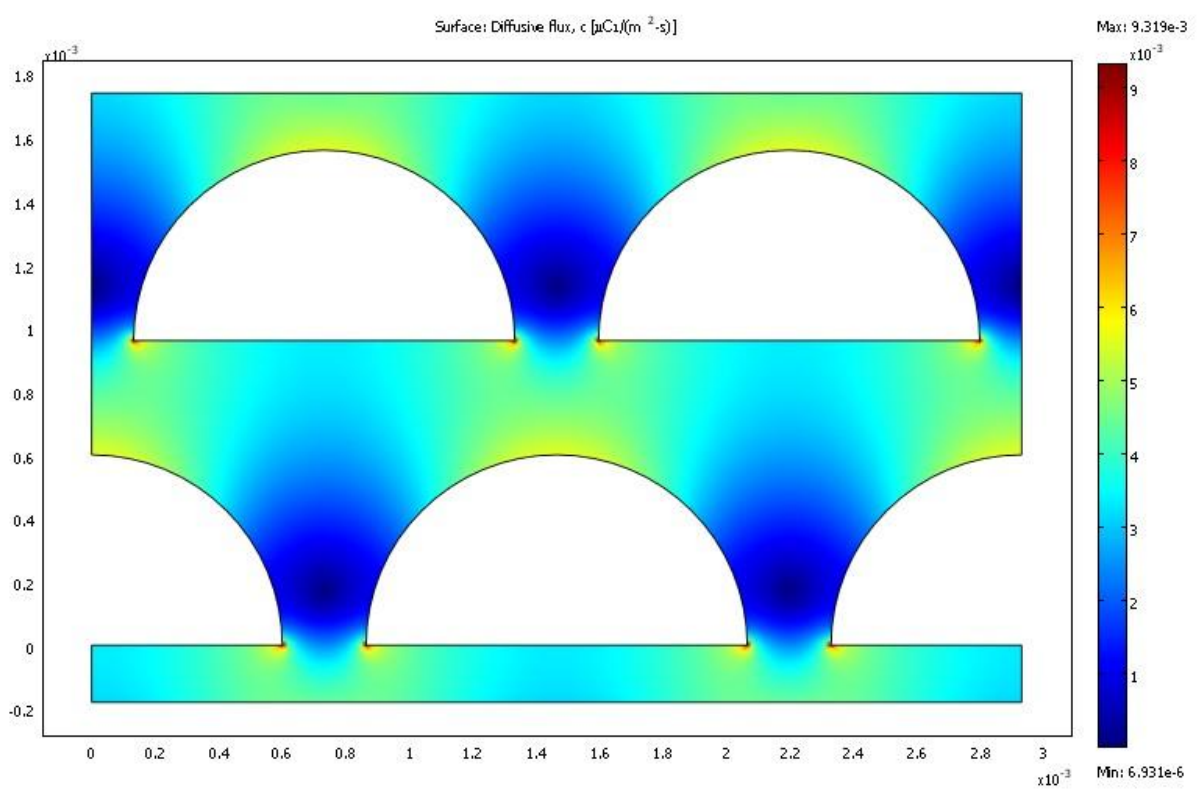

(b) Diffusion path.

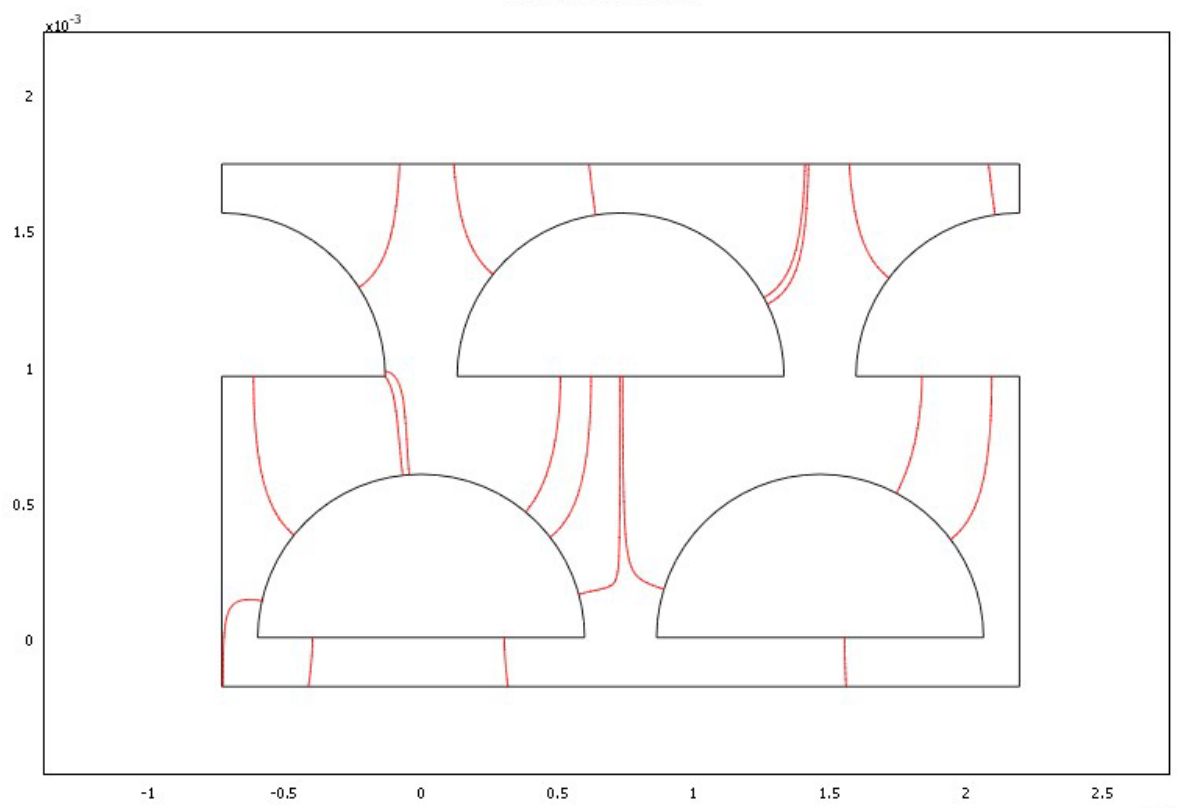

Figure 1-25. Diffusion flux and path of tritium in the PCHE (for the off-set configuration).

Figure 1-26 shows the tritium flux for different horizontal pitches and plate thickness. These calculations represent the flux at the primary coolant inlet side of a counter-current PCHE heat exchanger. This figure shows the tritium penetration flux is significantly decreased by increasing the plate thickness. However, the change of horizontal pitch does not highly affect the tritium penetration flux. According to our calculation, increased horizontal pitch slightly increases the overall tritium penetration rate by increasing the tritium concentration gradient with a longer horizontal pathway on the side of the channels. 
(a) Standard configuration.

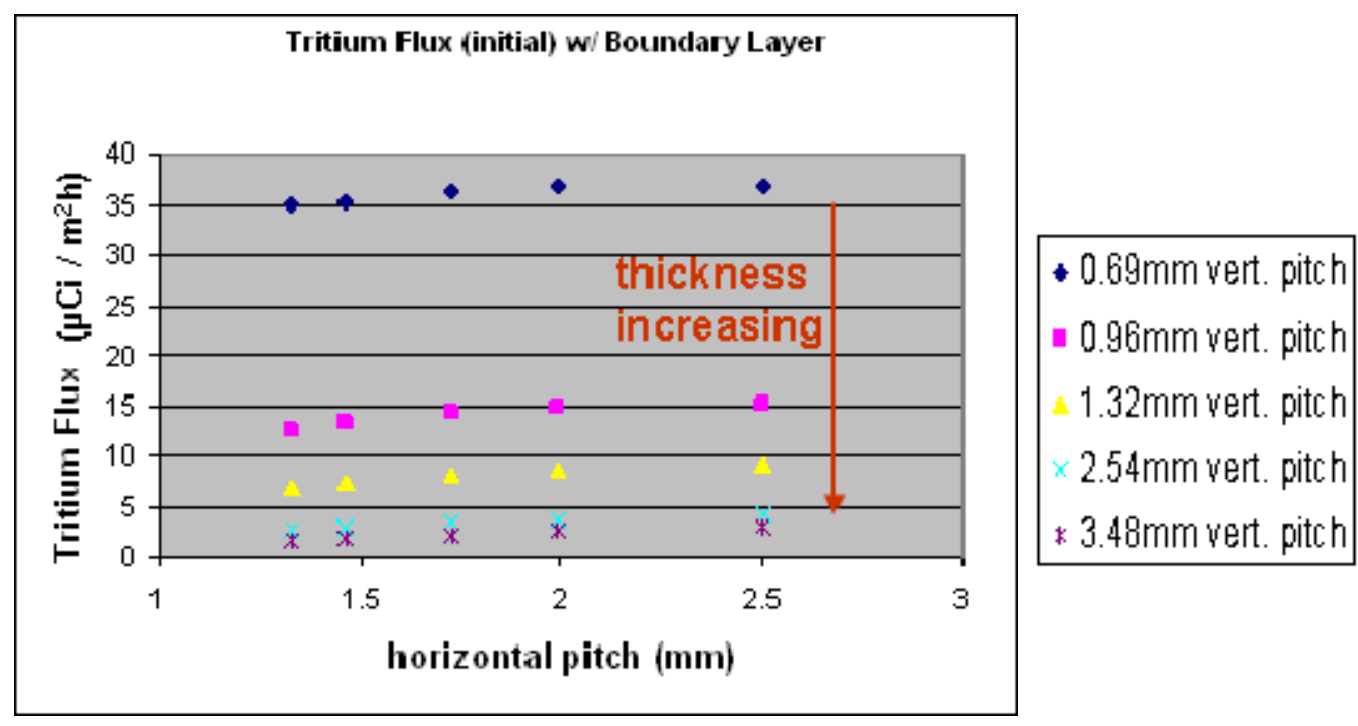

(b) Off-set configuration.

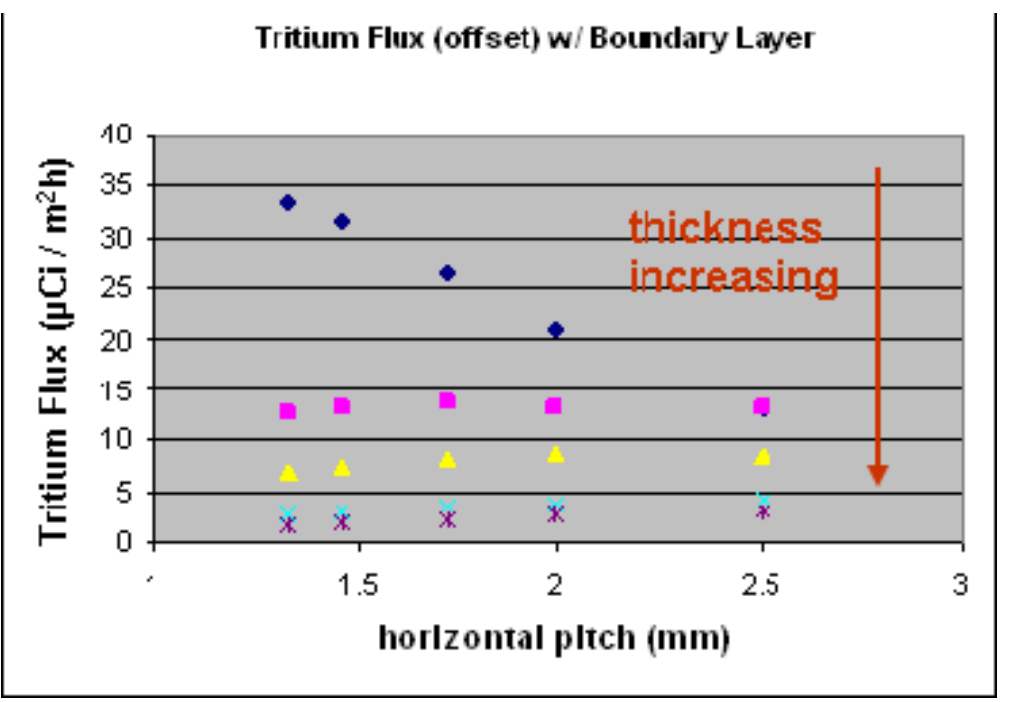

$+0.69 \mathrm{~mm}$ vert. pitch

$0.96 \mathrm{~mm}$ vert. pitch

$1.32 \mathrm{~mm}$ vert. pitch

$2.54 \mathrm{~mm}$ vert. pitch

* $3.48 \mathrm{~mm}$ vert. pitch

Figure 1-26. Tritium flux for different horizontal pitches.

The decreasing trend of the $0.69 \mathrm{~mm}$ vertical pitch on Figure 1-26 (b) still shows higher tritium flux compared with that of higher vertical pitches. The decrease is contributed by the longer horizontal pathway of the channels. The tritium concentration gradient at higher than $0.96 \mathrm{~mm}$ vertical pitch is uniformed, resulting in slight changes in the flux.

Figure 1-27 shows the tritium flux for a different plate thickness. As shown, the tritium flux is exponentially reduced with increased vertical pitch (plate thickness). At the small vertical pitch, the offset configuration showed slightly smaller tritium penetration, but they were almost identical for the large thickness. 


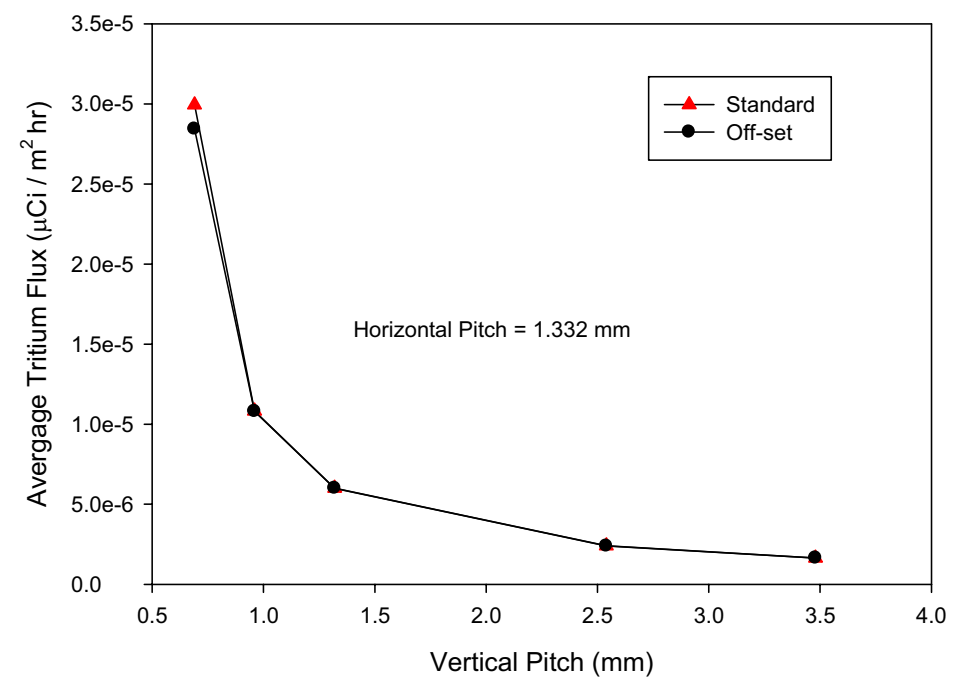

Figure 1-27. Tritium flux for different vertical pitch (plate thickness).

In summary, heat transfer and tritium penetration analyses have been performed for standard and offset channel configurations of the PCHE. Depending on such factors as horizontal and vertical pitch, it was learned that the off-set configuration can be favorable over the standard configuration. It was also learned that flux is weakly dependent on the horizontal pitch - the flux slowly increases as the horizontal pitch slowly increases. This is because of an increased dead space as shown in Figures 1-24 and 1-25. The one exception to this is in the off-set configuration. If the horizontal pitch to vertical pitch ratio is very large, the flux starts to decrease as the horizontal pitch increases. The vertical pitch and flux relationship was much simpler; as the vertical pitch (plate thickness) increases, the flux decreases, which makes sense because there is a longer flux pathway.

Tritium flux was seen to vary widely as the model geometry changed. The majority of the resistance to tritium flux was through the metal, so that as the shape of the metal changed, the flux changed respectively. The flux varied from 23.77 to $262.11 \%$ of the reference flux value $\left(13.3 \mu \mathrm{Ci} / \mathrm{m}^{2} \mathrm{~h}\right)$ as the geometry changed.

Heat flux changed less as the model geometry changed. The majority of the resistance to heat flux was through the helium boundary layer, so the flux only changed a little as the shape of the metal changed. The heat flux varied from 84.28 to $102.89 \%$ of the reference value $\left(149.22 \mathrm{MW} / \mathrm{m}^{2}\right)$ as the geometry changed.

The off-set configuration tended to have slightly less flux for a given horizontal and vertical pitch because the flux pathway tended to be slightly longer, as can be seen in Figures 1-24 and 1-25. This effect was the greatest when the horizontal pitch was large and the vertical pitch was small, because, in this case, the flux pathway was almost lateral instead of longitudinal.

\subsubsection{ABAQUS Modeling for Stress in the PCHE}

Stress analysis was performed on the Heatric's PCHE proposed for the VHTRs using ABAQUS ${ }^{\circledR}$ (ver. 6.75). The purpose of this study was to observe the change in maximum stress to variation in design parameters. For the maximum stress, parametric studies were performed on the normal and off-set channel arrangements as function of the channel's vertical and horizontal pitches. Effects of outer wall pressure and the channel's sharp corner fillet size were also studied on the normal channel arrangement. 


\subsubsection{Geometry and Dimensions}

Figure 1-28 shows the cross sectional views of the PCHE for original and offset arrangements. For the offset arrangement, the rows were offset from each other by half the horizontal pitch, which should be easily accomplished by shifting plates during construction.
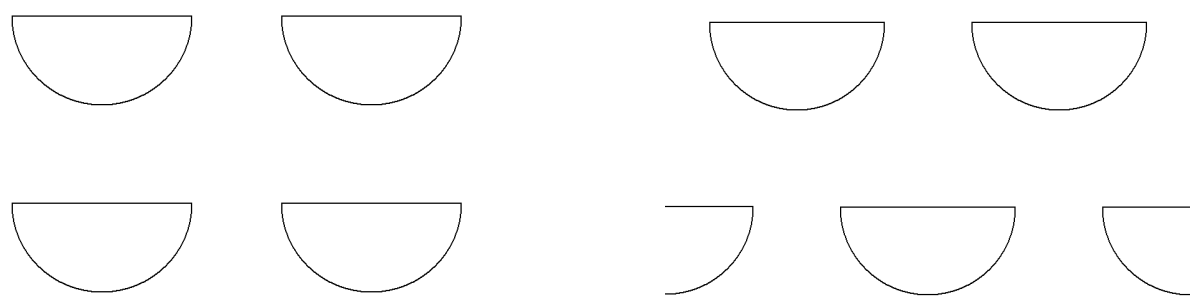

Figure 1-28. Normal (left) and offset (right) channel configurations.

The reference channel dimensions and operating conditions are shown in the Table 1-33. The reference diameter used was the value recommended for nuclear application by Heatric during a workshop meeting with MIT for discussion on the use of PCHE for a gas-cooled fast reactor (Gezelius 2004, p. 167). Meanwhile, the pitch and plate thickness were based on standard design ratios to the diameter employed by Heatric and other PCHE modelers (Gezelius 2004, p. 88). The heat exchanger body temperature was set to $850^{\circ} \mathrm{C}$, well above the minimum temperature of $800^{\circ} \mathrm{C}$ required for SI cycle (Lillo et al. 2005, p. 1). The primary loop pressure was set according to operating pressure of the core (Natesan et al. 2006, p. 85). The secondary loop pressure was set a little below the primary loop channel to observe the stress induced by the pressure difference between the primary and secondary channels. It has been suggested to immerse the entire IHX in a vessel operating at a pressure similar to IHX loops to relieve stress by reducing the pressure difference between the internal channels and outside of the IHX. Hence, the outside pressure was set to $6 \mathrm{MPa}$, the average of the primary and secondary loop pressures.

Table 1-33. Default channel dimensions and operating conditions.

\begin{tabular}{|l|c|}
\hline \multicolumn{2}{|c|}{ Default channel dimensions } \\
\hline Diameter [mm] & 1.2 \\
\hline Horizontal pitch [mm] & 1.464 \\
\hline Vertical pitch [mm] & 0.96 \\
\hline Default operating conditions \\
\hline Heat exchanger body temperature [C] & 850 \\
\hline Primary (hot) loop channel pressure [MPa] & 7 \\
\hline Secondary (cold) loop channel pressure [MPa] & 5 \\
\hline Outside pressure [MPa] & 6 \\
\hline
\end{tabular}

\subsubsection{Material Properties}

The stress analysis was performed for Alloy 617, one of the primary candidate for the PCHE (Natesan et al. 2006, p. i). Basic mechanical properties for Alloy 617 at several temperatures are shown in the Table 1-34. Properties for the $850^{\circ} \mathrm{C}$ are interpolated from $800^{\circ} \mathrm{C}$ and $900^{\circ} \mathrm{C}$ properties. The maximum stress observed from this study was well below the yield stress, thus the stress strain response was assumed to be linear with constant Young's modulus. 
Table 1-34. Alloy 617 mechanical properties (Special Metals Corporation, 2006, p. 2-3).

\begin{tabular}{|c|c|c|c|}
\hline $\begin{array}{c}\text { Temperature } \\
{\left[{ }^{\circ} \mathbf{C}\right]}\end{array}$ & $\begin{array}{c}\text { Young's Modulus } \\
{[\text { GPa] }}\end{array}$ & Poisson's Ratio & $\begin{array}{c}\text { Yield Stress } \\
{[\text { MPa] }}\end{array}$ \\
\hline 800 & 149 & 0.3 & 290 \\
\hline 850 & 153 & 0.3 & 280 \\
\hline 900 & 157 & 0.3 & 200 \\
\hline
\end{tabular}

Figure 1-29 shows the stress versus time-to-1\% strain and time to rupture from creep for Alloy 617. Considering 1\% strain must occur before the rupture, the time-to- $1 \%$ strain can be used as the conservative limit for the allowed stress. Based on Figure 1-29, the allowed stress for $850^{\circ} \mathrm{C}$ is approximately $20 \mathrm{MPa}$ for 11.4 years. By extrapolating the $850^{\circ} \mathrm{C}$ trend line to 50 years, the maximum allowed stress was estimated as $10 \mathrm{MPa}$.
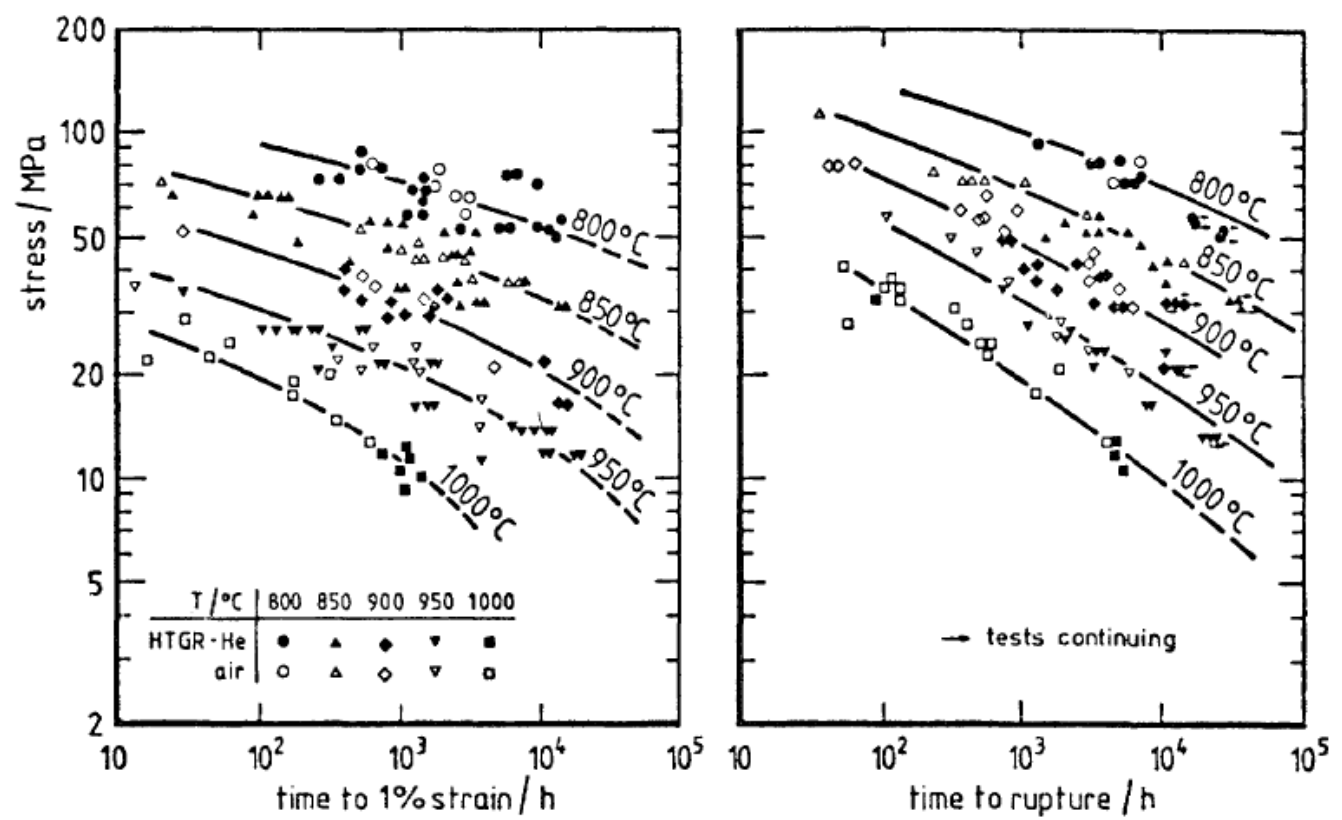

Figure 1-29. Stress versus time-to-1\% strain and time to rupture from creep for several temperatures (Schubert 1984, p. 328).

\subsubsection{Assumptions}

It is acknowledged the actual heat exchanger has some pressure drop associated with flow across the hot and cold loops, and there is a temperature profile in both the cross sectional plane and axial direction. However, the analysis was done in 2-D, which assumes there is no stress variation in axial direction, and material properties were evaluated assuming uniform temperature. These are reasonable considering the model represents a differential segment on the front of the heat exchanger where the temperature is highest, which is the location most vulnerable to creep strain failure. When modeling such a small slice of axial segment, variation of temperature and pressure in axial direction can be neglected. The heat exchanger body temperature can be assumed to be uniform because the temperature gradient from hot to cold channels at a given axial position is small (a couple of degrees Celsius), which makes negligible difference to material properties. The cross-sectional temperature profile generated using COMSOL is shown in the previous section. 
For future reference, the ABAQUS will need to a 3-D model to perform thermal stress analysis, including axial profile. The project started out with 3-D thermal stress analysis as part of the study, but it was postponed and not included in this report because of time constraints.

\subsubsection{Stress vs. Number of Heat Transfer Units}

\section{Model Geometry}

The heat exchanger model is composed of heat transfer units (HTU) that are each composed of a hot and a cold channel surrounded by the outer wall. From a model size stand point, it is impractical to include all of the HTUs present in an actual IHX, so a convergence study was done to determine the minimum number of HTUs needed.

ABAQUS models were analyzed, including HTUs 1, 4 (2x2), 9 (3×3), 25 (5x5), 49 (7x7), and 81 (9x9). For example, Figure 1-30 shows the ABAQUS models for HTUs 1, 9 and 25. Since the model is symmetric about the center, the model was cut in half to reduce the model size. As mentioned earlier, the channel diameter is $1.2 \mathrm{~mm}$, horizontal pitch is $1.464 \mathrm{~mm}$, and vertical pitch is $0.96 \mathrm{~mm}$. The outer wall is $10.18 \mathrm{~mm}$ thick vertically and $10.132 \mathrm{~mm}$ thick horizontally. Although not visible on the figure, the models are $0.1 \mathrm{~mm}$ thick in axial direction (in to the page).

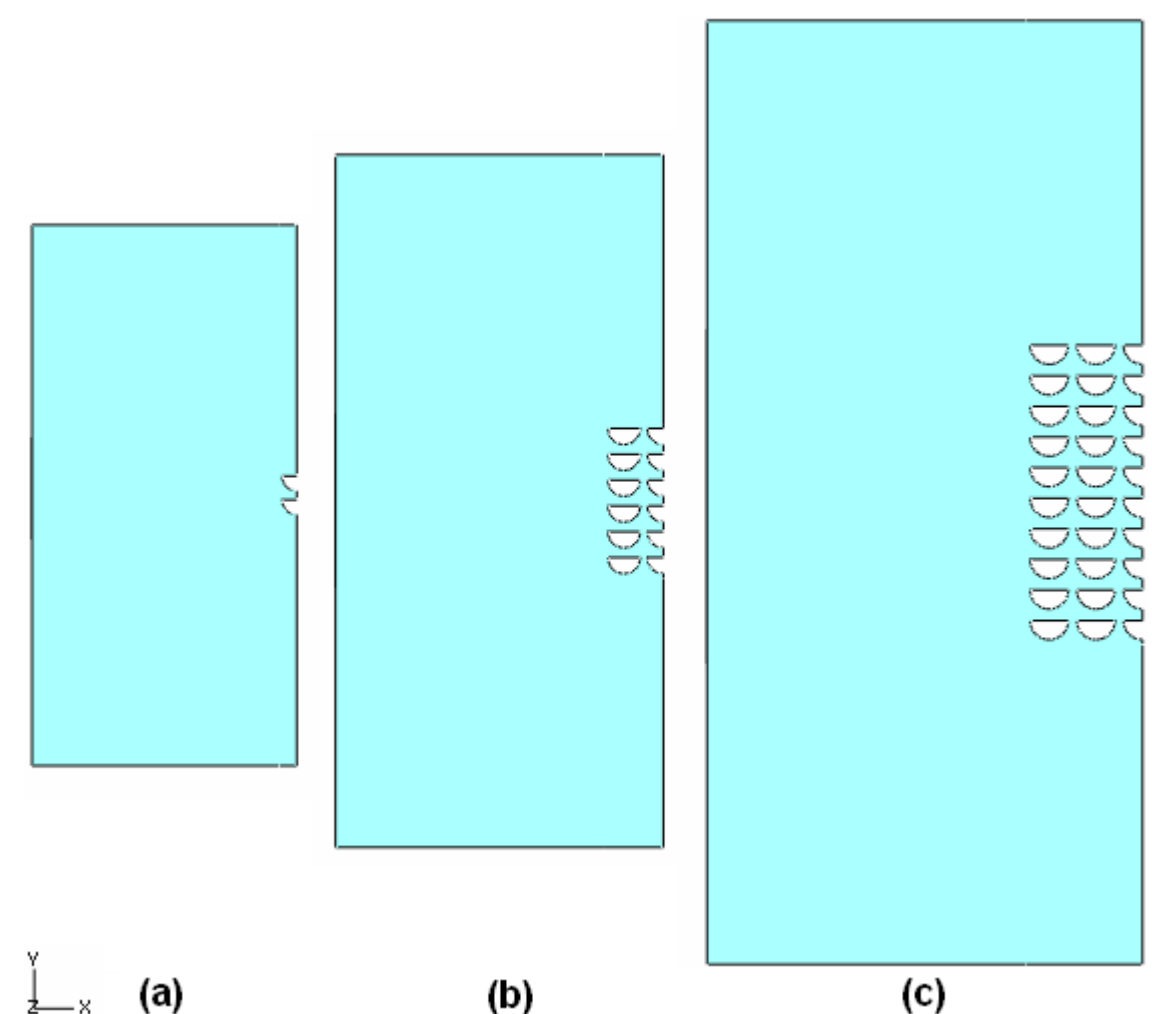

Figure 1-30. ABAQUS models for different numbers of HTUs.

Boundary conditions were given to constrain the front and back in axial direction, which effectively makes the analysis identical to 2-D. It is acknowledged that the thickness is not necessary in the 2-D analysis. Originally the models were created to perform such analyses as axial temperature profile for thermal stress, which required 3-D models, but thermal stress analysis was eventually postponed because of time constraint and limitations on the model size. Hence, the models' 3-D feature remains as a vestigial but unnecessary part of the 2D analysis performed. 
As shown in Figure 1-31, round fillets were used (0.02 $\mathrm{mm}$ in radius) on the channels' sharp corners. This is very important to this particular stress analysis because the maximum stress occurs on the corner. If the corner is modeled as a sharp corner, theoretically the stress is infinite at this location, and stress analysis result will continue to increase with continued mesh refinement (ABAQUS 2004, p.4.49). Normally, omitting such fine detail has a negligible effect on the overall response of the model, but stress a profile close to the singularity will be inaccurate (ABAQUS 2004, p.4.49). Since exact stresses in the corners are required, fillets were used on the corners.

\section{Boundary Conditions}

Pressure applied to the hot channel walls, cold channel walls, and outer walls were $7 \mathrm{MPa}, 5 \mathrm{MPa}$, and $6 \mathrm{MPa}$, respectively. The symmetric boundary condition with respect to $\mathrm{x}$-axis direction was applied to the cut region across the center, which constrains displacement in $\mathrm{x}$ direction and rotation about $\mathrm{y}$ and $\mathrm{z}$ (axial) axes. The symmetric boundary condition with respect to z-axis direction was applied to the front and back surfaces, which constrains displacement in $\mathrm{z}$ direction and rotation about $\mathrm{x}$ and $\mathrm{y}$ axes. The last boundary condition essentially makes the model identical to a 2D model, which assumes such constraints by default.

\section{Partitioning and Meshing}

A locally refined meshing scheme was used to minimize the number of elements. The meshing scheme used is summarized in the Table 1-35. Figure 1-32 shows the model for 25 HTUs, which has the fine seeded borders marked in red and also shows the partition scheme. Figure 1-33 shows the finished mesh grid around a half channel.

Table 1-35. Meshing scheme for HTU study.

\begin{tabular}{|l|l|}
\hline Fine seed (red) [mm] & 0.01 \\
\hline Channel corner fillet [divisions] & 6 \\
\hline Remainder (black) [mm] & 0.2 \\
\hline Mesh control & Wedge sweep \\
\hline Element type & C3D6* \\
\hline Geometric order & Linear \\
\hline Horizontal partition distance, $\mathrm{P}_{\mathrm{h}}[\mathrm{mm}]$ & 3 \\
\hline Vertical partition distance, $\mathrm{P}_{\mathrm{v}}[\mathrm{mm}]$ & 2 \\
\hline \multicolumn{2}{|l}{} \\
\hline * 3-D continuum element with 6 node points (prism shape). \\
\hline
\end{tabular}




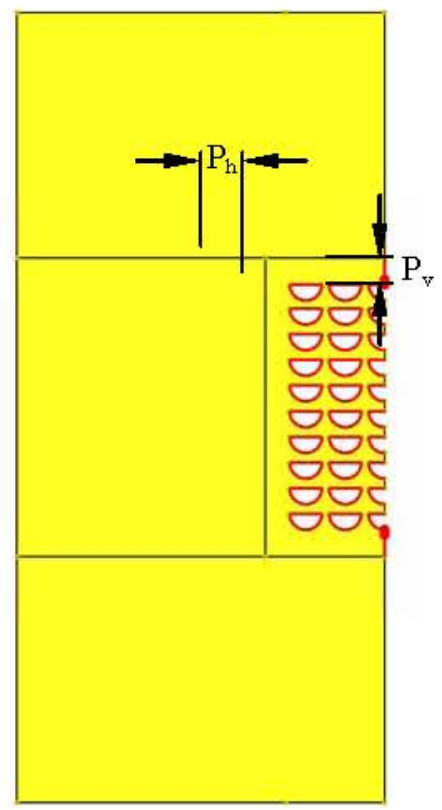

Figure 1-32. The 25 HTU model.

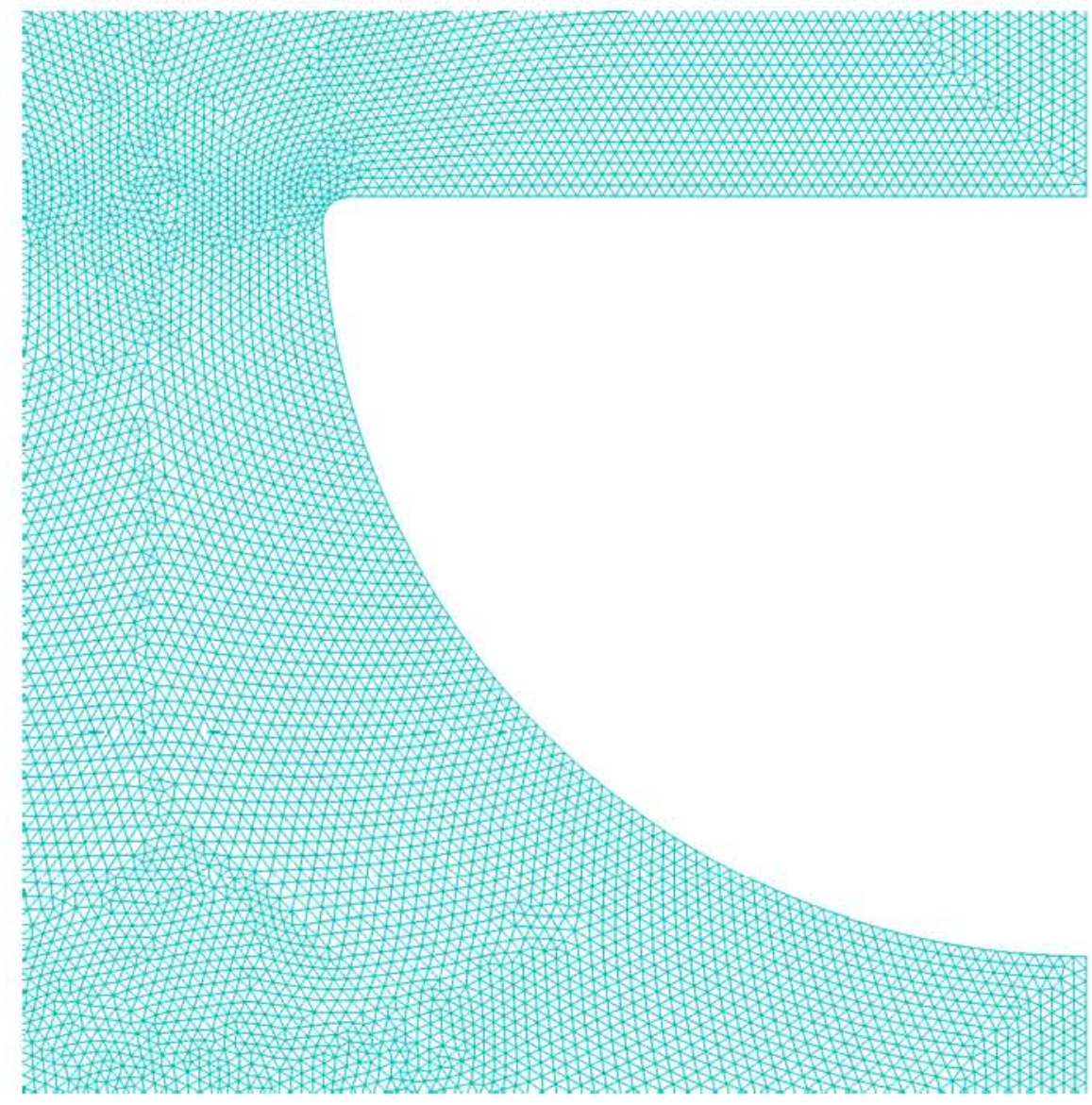

Figure 1-33. Mesh grid around a half channel. 


\section{Results}

Figure 1-34 shows the maximum Von Mises stress as a function of heat transfer units used. The maximum stress limits move out as the number of units used increases, and it is virtually identical from 25 units and beyond. Based on this trend, the $25 \mathrm{HTU}$ model was used on parametric studies for outside pressure, vertical pitch, horizontal pitch, and temperature.

The stress distributions for the $25 \mathrm{HTU}$ model are shown in Figures 1-35, 1-36, and 1-37. Figure 1-35 shows the entire model, Figure 1-36 shows the first three rows of second and third columns, and Figure 137 shows a zoomed-in view of the corner with the maximum stress, which is the left corner of the second row, second column channel. As shown in Figure 1-35, high stress occurs on channel walls, while the outer walls are subjected to relatively low stress. Figure 1-36 shows that the stress is concentrated toward channel corners and is higher on low-pressure channel corners. Figure 1-37 presents a close-up view of the corner experiencing the maximum stress, which is concentrated in close proximity to the corner's curve. High-pressure channel walls expand outward while the low-pressure channel walls get compressed inward. The compression from high-pressure channels invokes a pivot and lever mechanism to the lowpressure channel corners, causing a high concentration of stress.

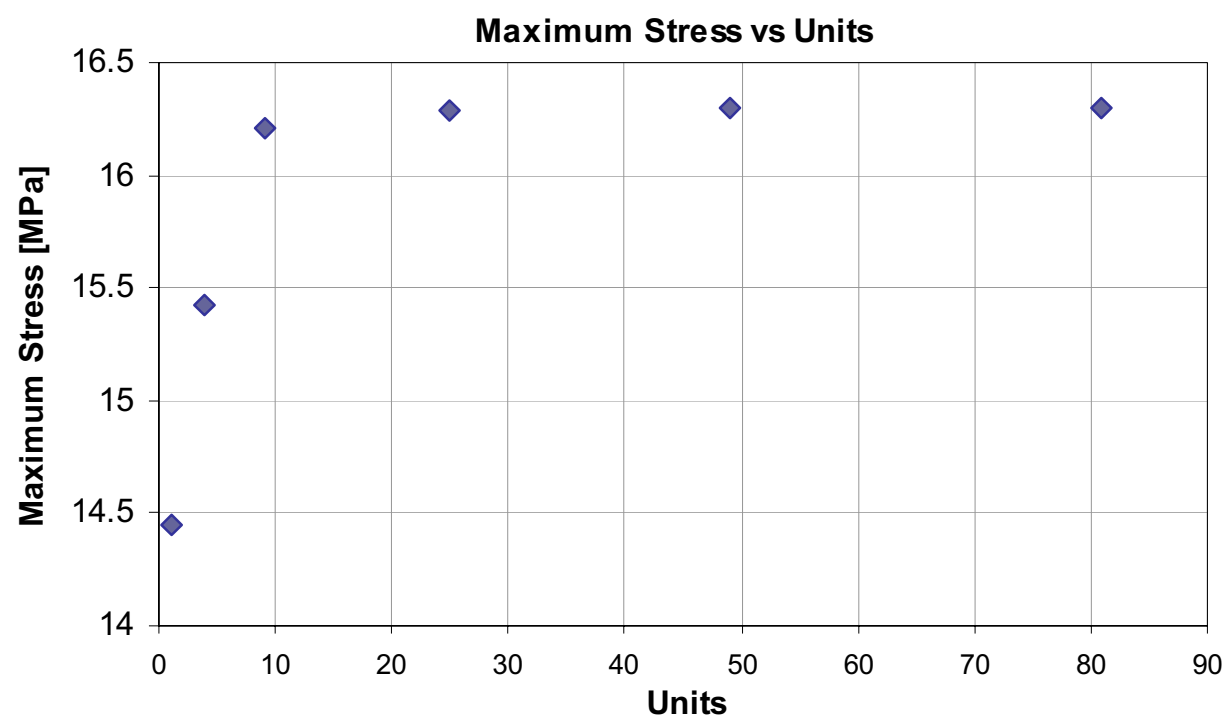

Figure 1-34. Maximum stress as function of heat transfer units used. 

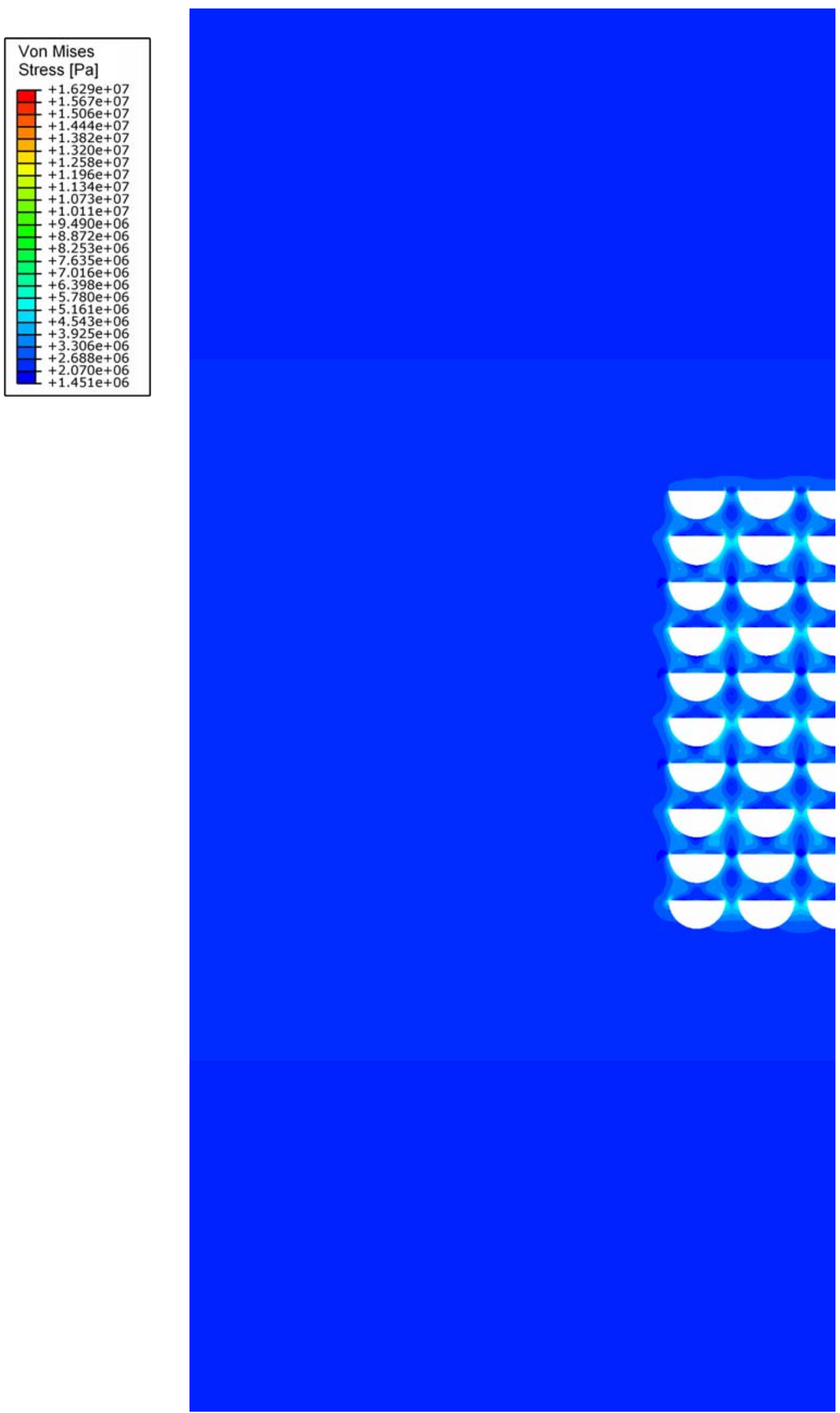

Figure 1-35. Stress distribution of 25 HTUs model, entire model view. 

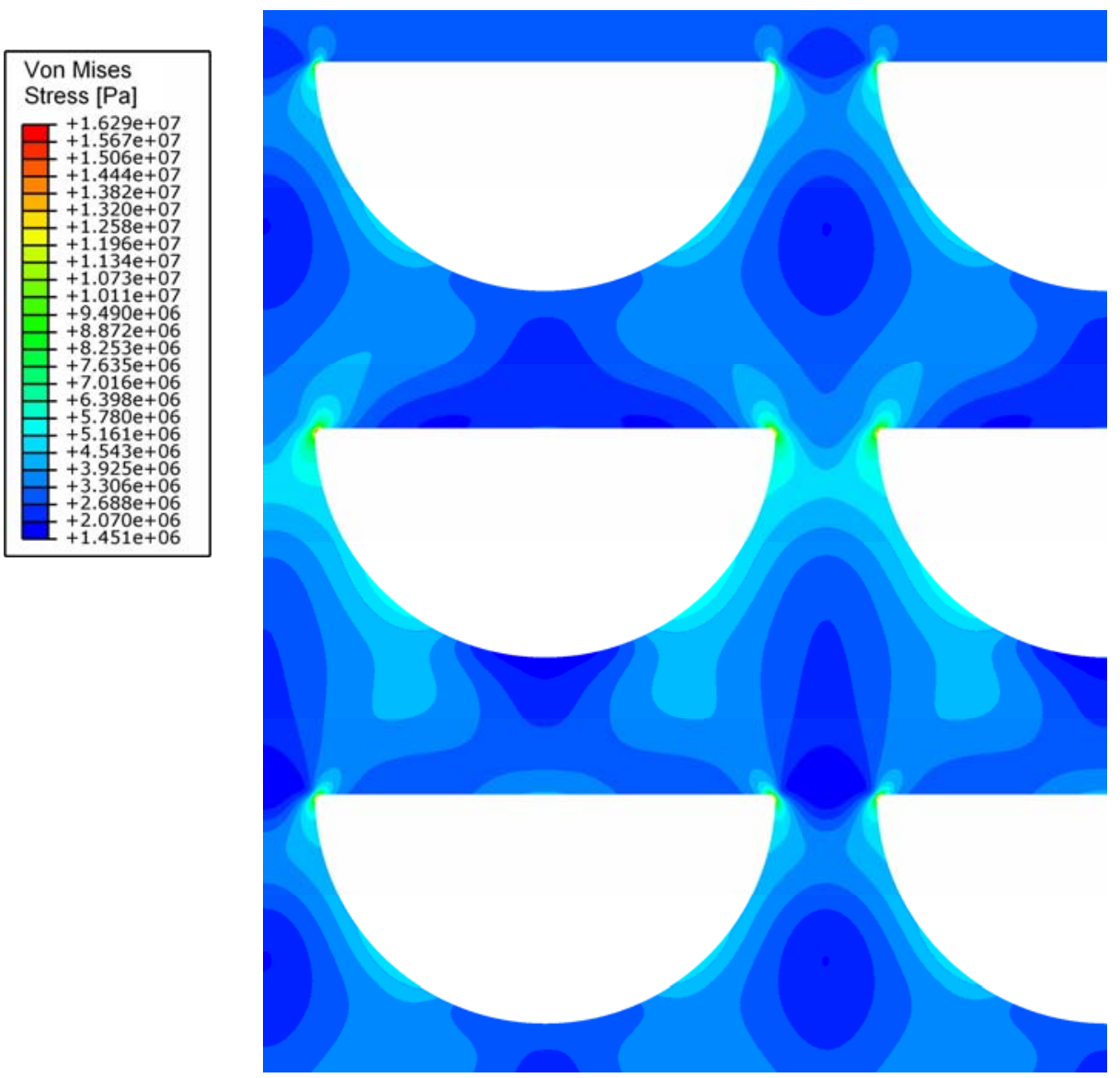

Figure 1-36. Stress distribution of 25 HTUs model, top three rows, second and third columns.
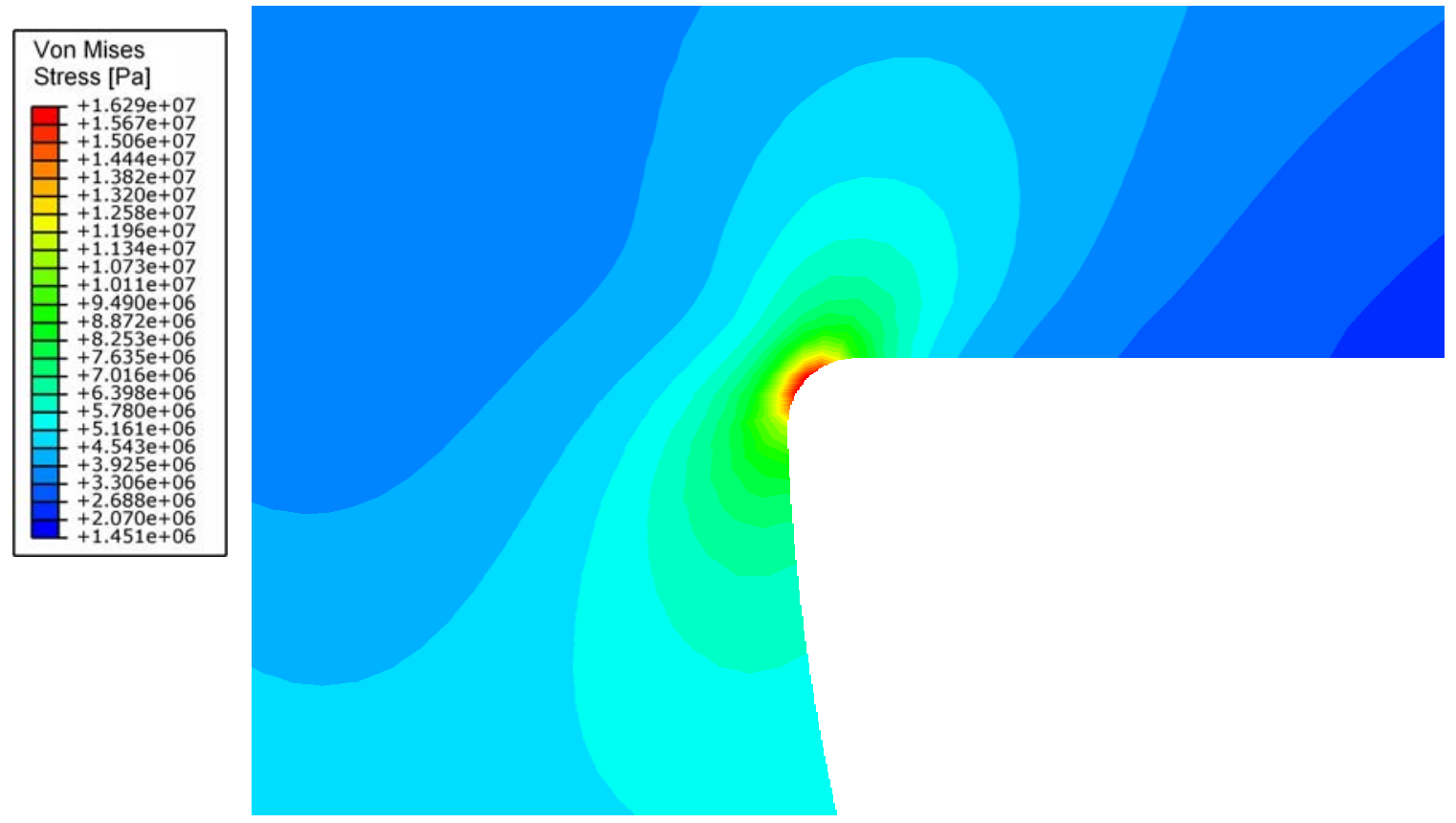

Figure 1-37. Stress distribution of 25 HTUs model, left corner of second row, second column channel view. 


\subsubsection{Stress vs. Outside Pressure}

\section{Model Geometry, Operating Conditions and Meshing}

The 25 HTU model in normal arrangement was used for the outside pressure study. The default channel dimensions and operating conditions shown in the Table 1-33 were used, and only the outside pressure was varied. A meshing scheme identical to the one used in HTU convergence study was used (see Table 1-34).

\section{Results}

Figure 1-38 shows the maximum Von Mises stress as a function of the outside pressure. As can be seen, the stress is minimized when outer wall pressure is set to $6 \mathrm{MPa}$, right between the hot and cold channel pressure. This was anticipated because at $6 \mathrm{MPa}$, the pressure differences from hot and cold channels to the outside pressure are minimized. Based on this, $6 \mathrm{MPa}$ was used for the outside pressure on all of parametric studies.

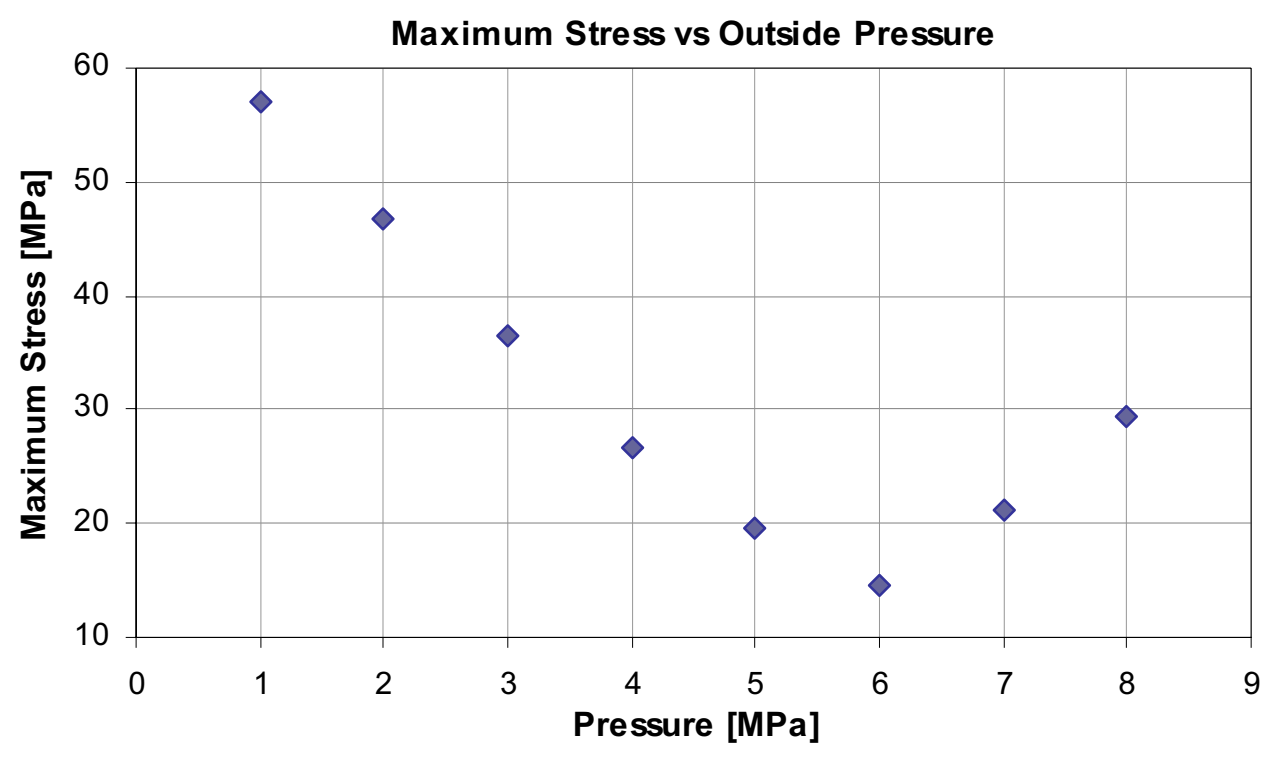

Figure 1-38. Maximum stress as function of the outside pressure for the normal configuration.

\subsubsection{Stress vs. Vertical and Horizontal Pitches}

\section{Model Geometry, Operating Conditions, and Meshing}

For these parametric studies, the $25 \mathrm{HTU}$ model was used in normal and offset arrangements for comparison. The reference channel dimensions and operating conditions were used, and only one parameter (either vertical or horizontal pitch) was varied per case. A slightly altered meshing scheme was used for vertical and horizontal pitch studies because of limitations to the model size, which increases substantially with increase in pitches. In order to use same mesh scheme for the vertical and horizontal pitch studies, the number of elements generated had to be reduced. The new meshing scheme is summarized in the Table 1-36. 
Table 1-36. Meshing scheme for vertical pitch and horizontal pitch studies.

\begin{tabular}{|l|l|}
\hline Fine seed (red) $[\mathrm{mm}]$ & 0.014 \\
\hline Channel corner fillet [divisions] & 4 \\
\hline Remainder (black) [mm] & 0.2 \\
\hline Mesh control & Wedge sweep \\
\hline Element type & C3D6 \\
\hline Geometric order & Linear \\
\hline Horizontal partition distance, $\mathrm{P}_{\mathrm{h}}[\mathrm{mm}]$ & 1.5 \\
\hline Vertical partition distance, $\mathrm{P}_{\mathrm{v}}[\mathrm{mm}]$ & 1 \\
\hline
\end{tabular}

\section{Maximum Stress vs. Vertical Pitch}

Figure 1-39 shows the maximum Von Mises stress as a function of the vertical pitch. As can be seen, the maximum stress decreases with the increasing vertical pitch. The maximum stress occurs on a lowpressure channel corner because of a pivot and lever mechanism where the corner as the pivot and the walls are the lever. The low-pressure channel walls are compressed inward because of high-pressure channels above and below, therefore the most important thing in reducing stress at the corner is reducing deformation of walls at its proximity, which is accomplished by making the wall between channels thicker. The deformation is greater for thinner walls, causing greater stress on the low-pressure channel corners. On the other hand, increasing the thickness makes the body more resistant to deformation induced by the pressure difference, thus, reducing the stress on the corner.

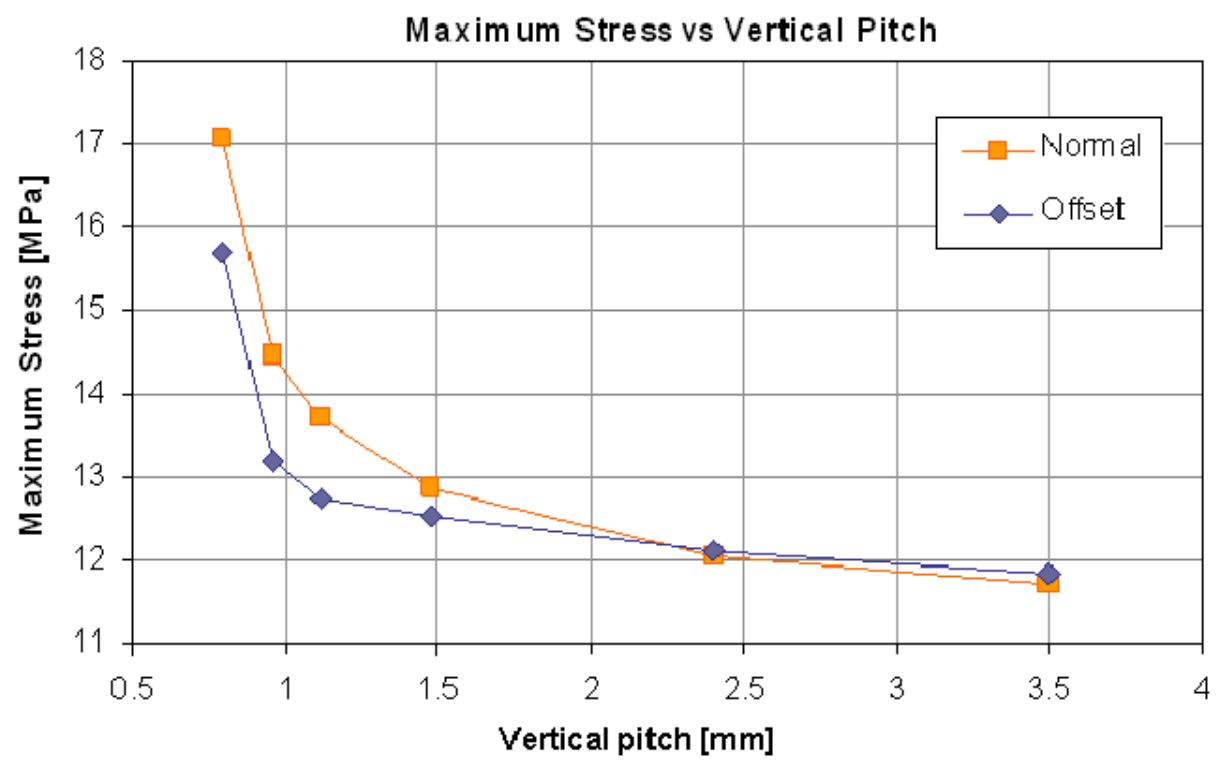

Figure 1-39. Maximum stress as function of the vertical pitch for normal and shifted configurations.

Figures 1-40 and 1-41 show the stress distributions for normal and shifted arrangement with $0.8 \mathrm{~mm}$ vertical pitch. Offsetting the channels reduces the stress because the high-pressure channels are no longer directly above and below the low-pressure channels as seen in Figure 1-41, thus relieving them from the compression caused by the pressure difference. 

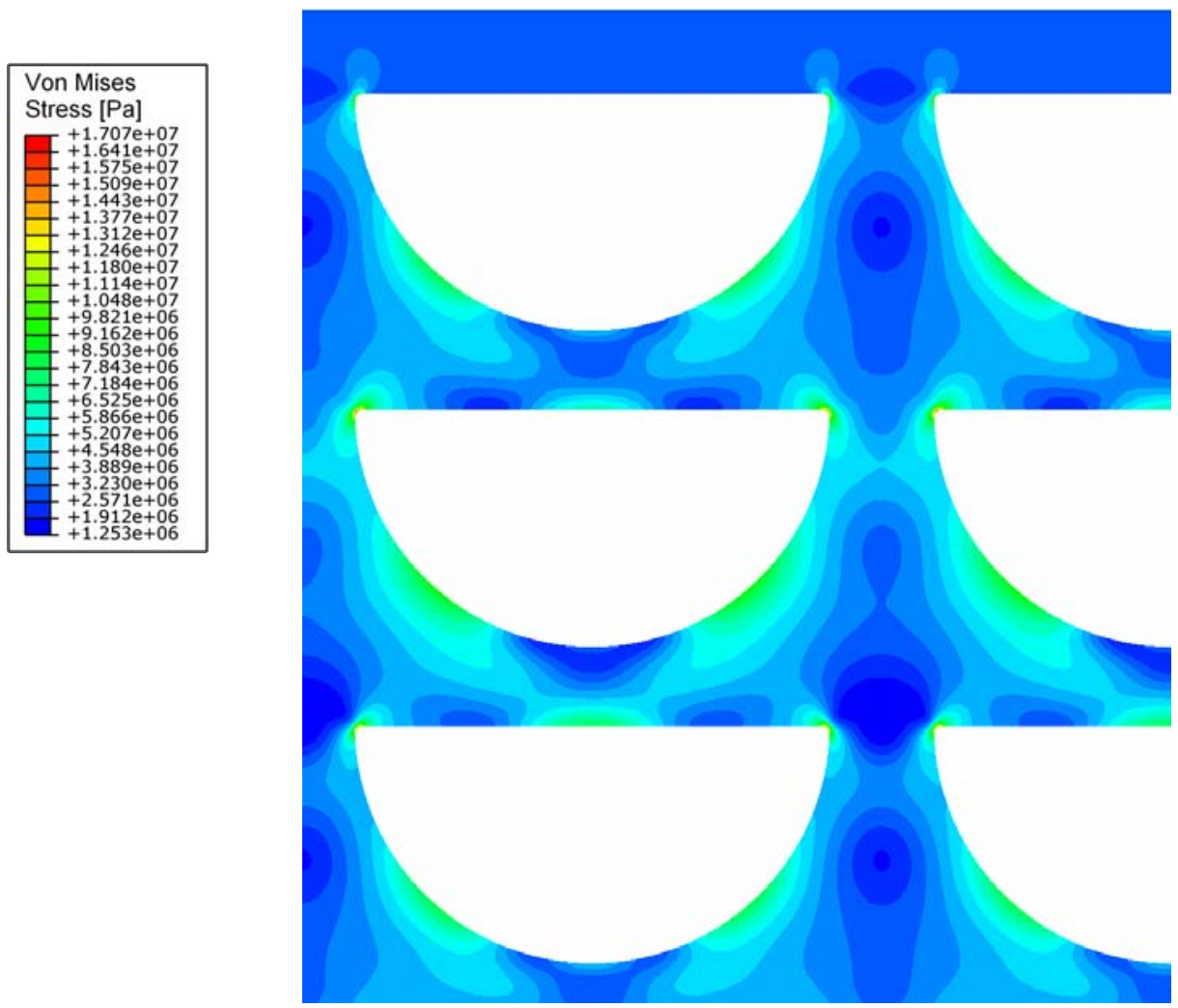

Figure 1-40. Normal $0.8 \mathrm{~mm}$ vertical pitch.

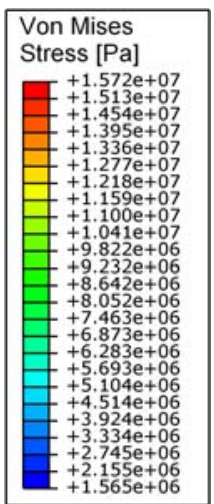

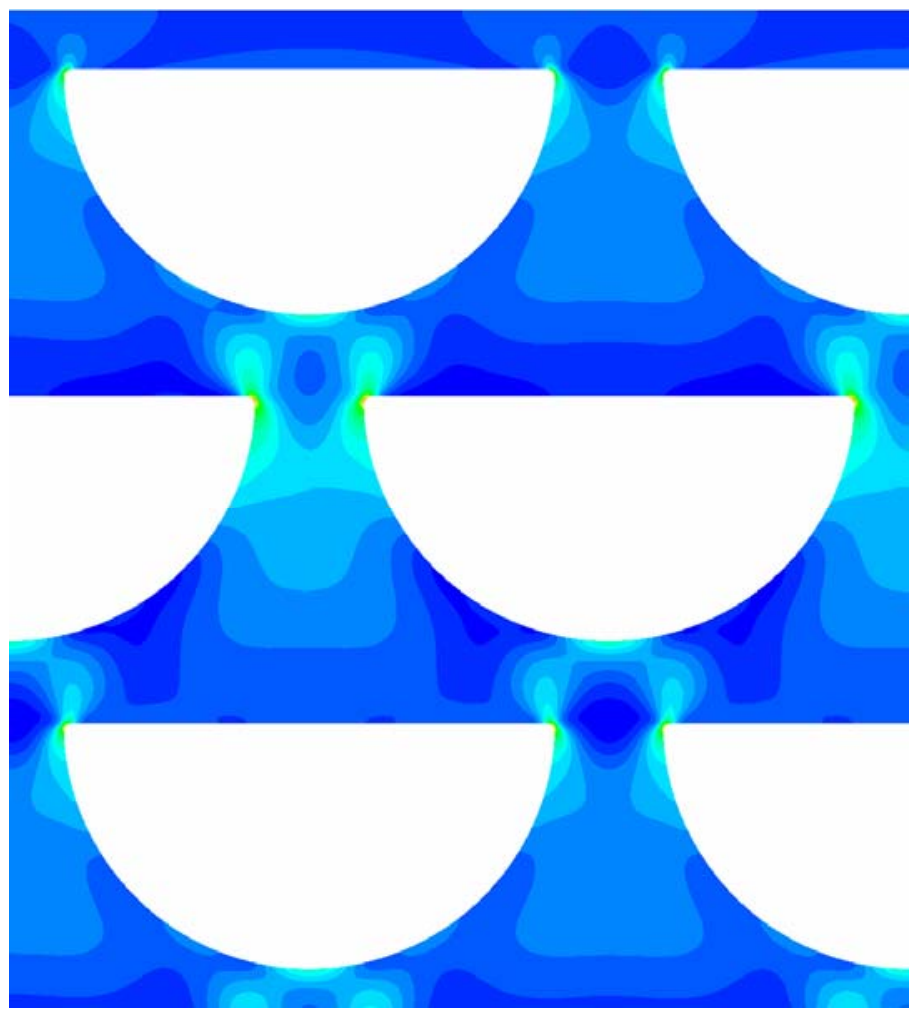

Figure 1-41. Shifted $0.8 \mathrm{~mm}$ vertical pitch. 
Judging from the trend, the stress will not decrease with vertical pitch indefinitely. This is expected since the stress is concentrated around the area near the channel. When the vertical pitch is very thin, increasing its thickness results in significant redistribution of the stress to a larger area. In contrast, when the vertical pitch is very thick, increasing its thickness further makes no difference to the stress redistribution. Figures 1-42 and 1-43 show the stress distributions for normal and shifted arrangement with $2.4 \mathrm{~mm}$ vertical pitch, which can be compared to Figures 1-40 and 1-41 for differences in the stress profile of the walls between channels.

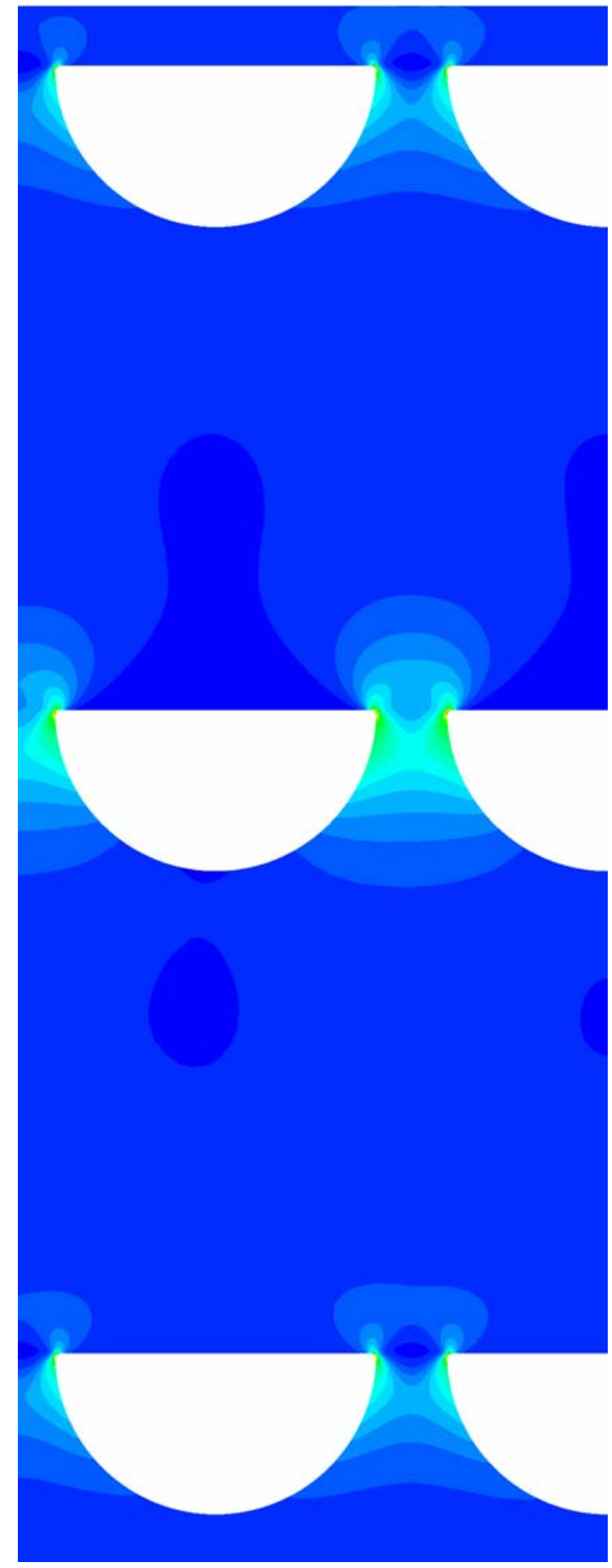

Figure 1-42. Normal $2.4 \mathrm{~mm}$ vertical pitch.

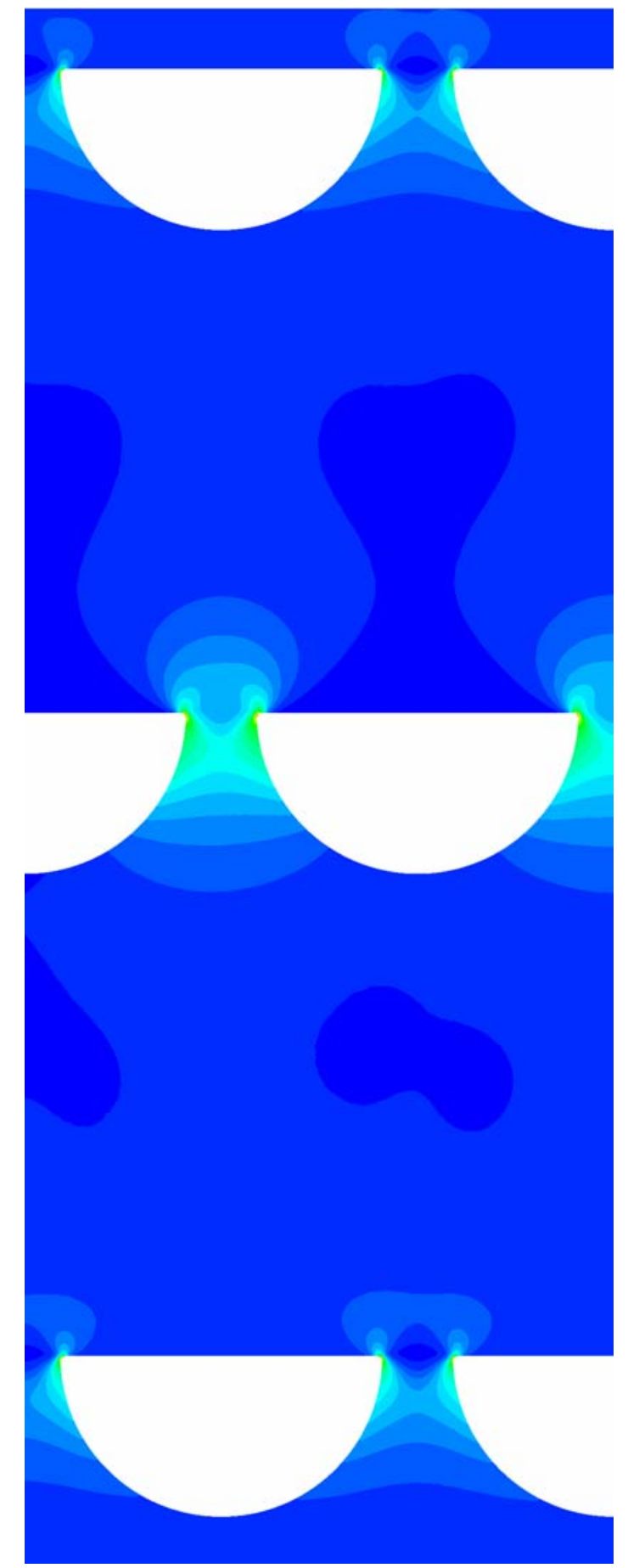

Figure 1-43. Shifted $2.4 \mathrm{~mm}$ vertical pitch. 


\section{Maximum Stress vs. Horizontal Pitch}

Figure 1-44 shows the maximum Von Mises stress as a function of the horizontal pitch. As can be seen, the stress sharply declines and gradually limits out with the increase in the horizontal pitch. The sidewalls between channels essentially hold the top and bottom walls together from falling apart by pressure force exerted in vertical directions. The size of channels does not change, so the total pressure forces in vertical direction also stay the same. On the other hand, as the sidewall thickness is reduced, the total pressure force must be counteracted by a smaller cross-sectional area of thinner sidewall, thus increasing the stress concentration. Because of this, the strain in the proximity of the channel corner is increased, resulting in greater maximum stress. The stress is relieved with increasing horizontal pitch because the stress gets distributed over thicker walls. Figures 1-45 and 1-46 show stress distributions for normal and offset arrangements with $1.264 \mathrm{~mm}$ horizontal pitch, and Figures 1-47 and 1-48 show stress distributions for normal and offset arrangements with $2.4 \mathrm{~mm}$ horizontal pitch, which can be compared for difference in stress distribution on sidewalls of different thicknesses.

As shown in Figures 1-39 and 1-44, increasing horizontal pitch is particularly more effective for the shifted configuration because the high-pressure channels are not directly above and below the lowpressure channels and, as the horizontal pitch increases, the high-pressure channels move away from these regions, further reducing the compression caused by the pressure difference. When the horizontal pitch increases beyond twice the diameter, the high-pressure channels are completely out of the region above and below the low-pressure channels. At this pitch, the channels right above and below each are the channels on every other rows, which have identical pressures, relieving the pressure difference between the channels.

As shown in Figure 1-44, eventually, increasing the horizontal pitch beyond $1.7 \mathrm{~mm}$ for the normal configuration makes no difference to the maximum stress. As shown in Figures 1-47 and 1-48, when the sidewall is very thick, the stress is fully redistributed over its thickness and negligible change would occur to the stress distribution with further increase in horizontal pitch. At very thick horizontal pitch, the only dominant stress mechanism on the corner is the pivot and lever effect. It is most likely that the pivot and lever mechanism is not significantly affected by change in horizontal pitch because channels adjacent to left and right are channels with same pressures. Thus deformation because of pressure difference like the top and bottom walls in the study with vertical pitch is not present on sidewalls.

The minimum stress is reached sooner for normal arrangement because, as shown in Figures 1-45 and 1-47, it does not have secondary effect of shifting the high and low pressures out of alignment. For the offset arrangement, the minimum stress should result once the high and low-pressure channels are completely out of alignment, which is reflected in its trend. 

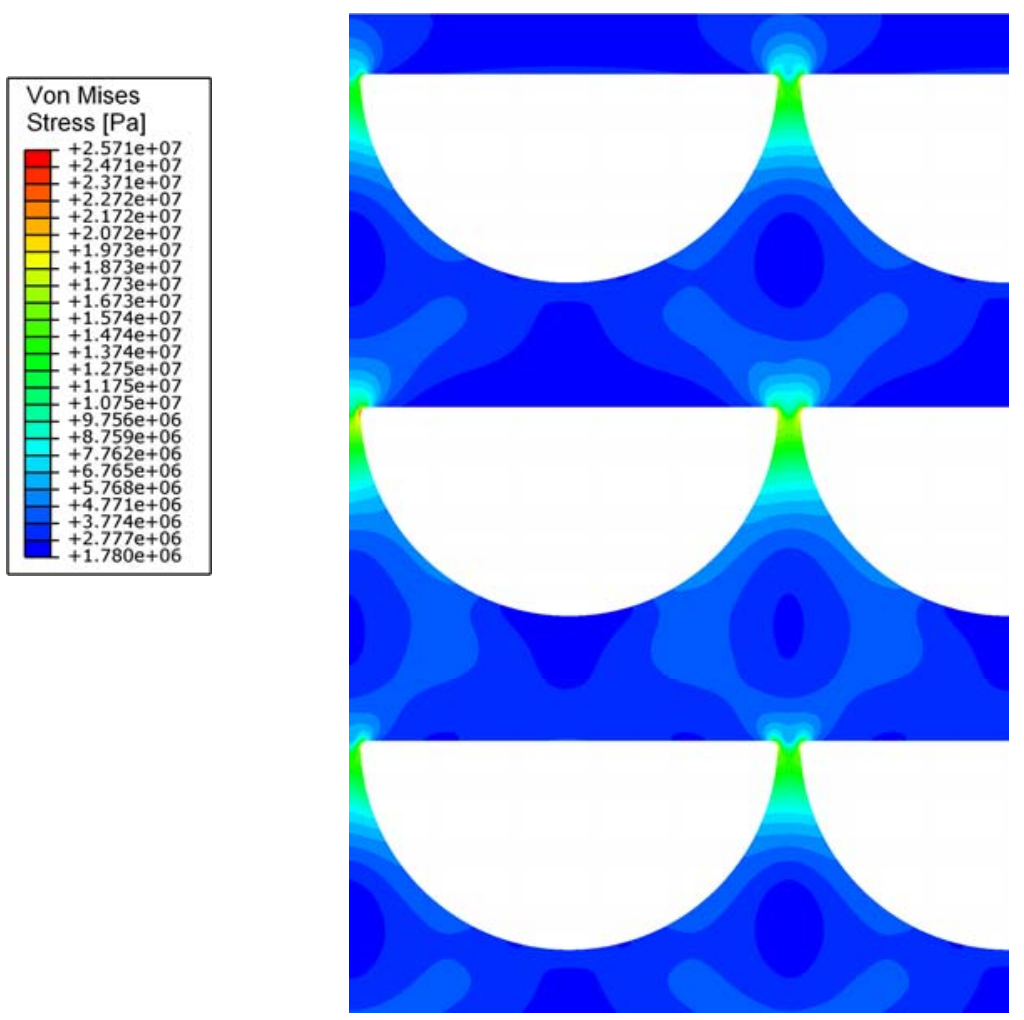

Figure 1-45. Normal $1.264 \mathrm{~mm}$ horizontal pitch.
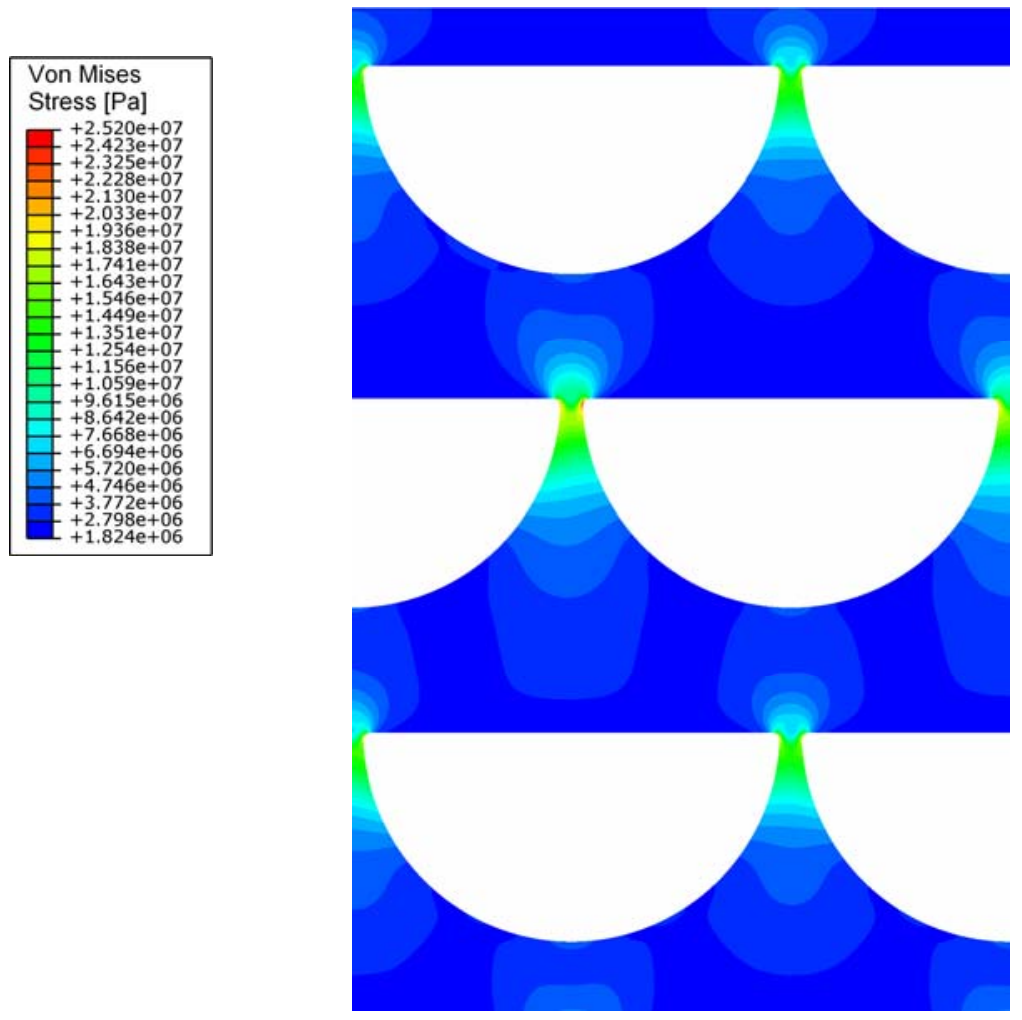

Figure 1-46. Shifted $1.264 \mathrm{~mm}$ horizontal pitch. 


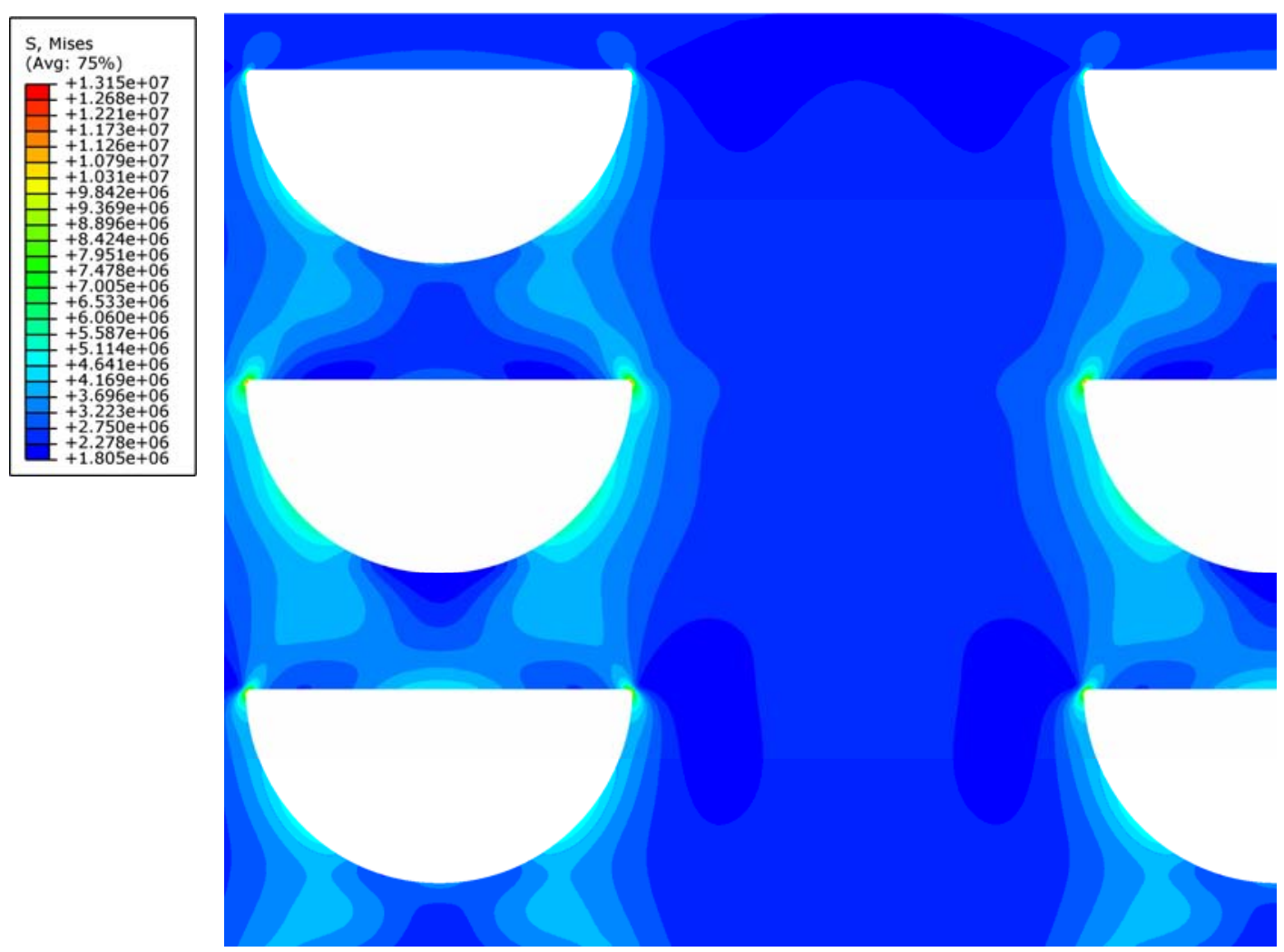

Figure 1-47. Normal $2.6 \mathrm{~mm}$ horizontal pitch.
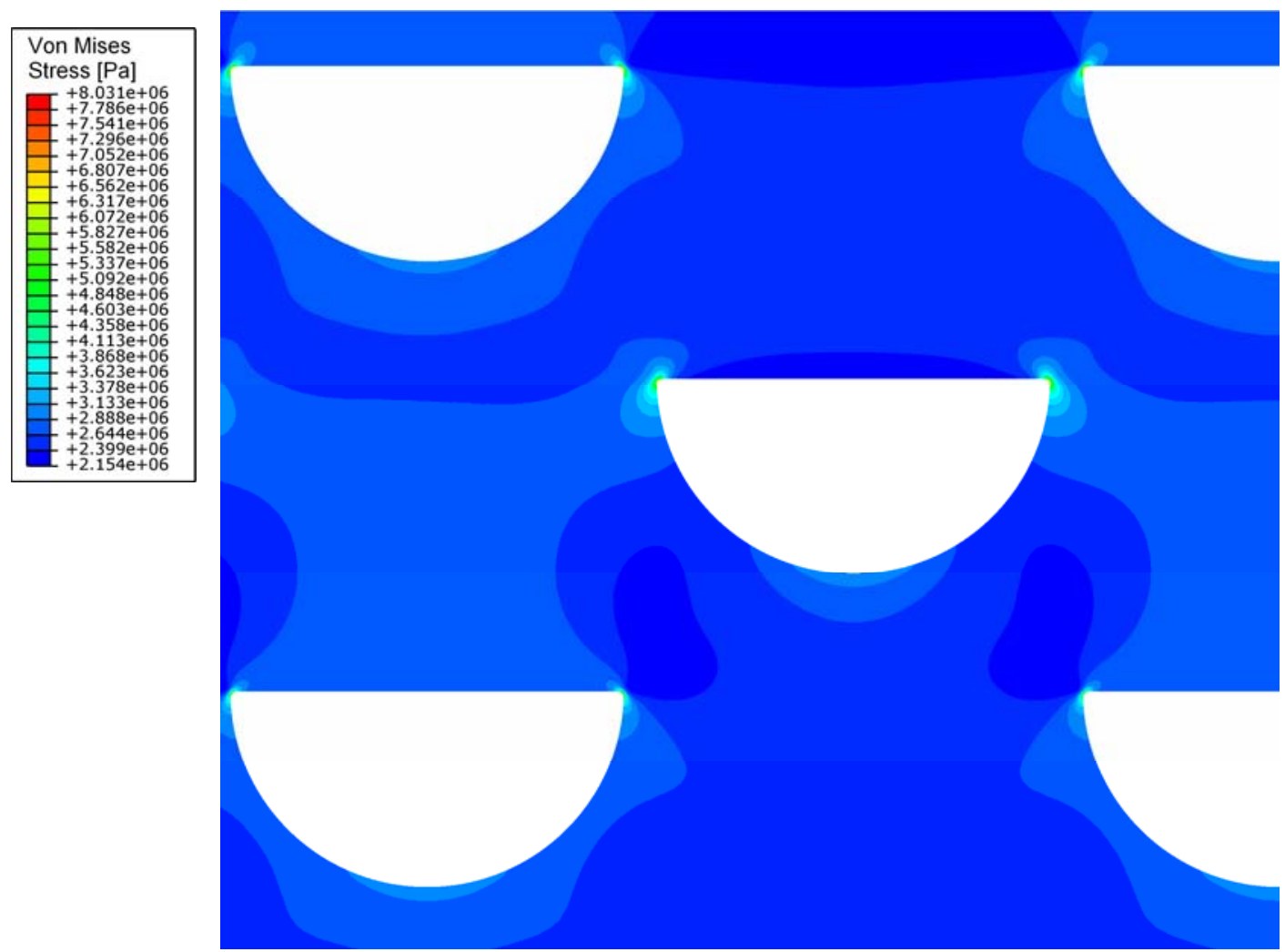

Figure 1-48. Shifted $2.6 \mathrm{~mm}$ horizontal pitch. 


\section{TRITIUM BEHAVIOR STUDY IN THE VHTR SYSTEM}

\subsection{Introduction}

In the VHTR hydrogen production system, tritium permeation from the core into the produced hydrogen is currently one of the most significant issues, because hydrogen isotopes can easily permeate through the high temperature heat exchanger tubes and contaminate product hydrogen. If the hydrogen produced in this system was then used as fuel in fuel cell vehicles, that tritium water would be released to the environment. Because of this potential, tritium contamination of hydrogen is considered in this study.

The tritium generation mechanism is well described by Gainey (1976), and Ohashi and Sherman (2006). The primary tritium birth mechanism is ternary fission of fuel (e.g., ${ }^{233} \mathrm{U},{ }^{235} \mathrm{U},{ }^{239} \mathrm{Pu}$, and ${ }^{241} \mathrm{Pu}$ ) because of thermal neutrons. Tritium is also generated in VHTR from ${ }^{6} \mathrm{Li},{ }^{7} \mathrm{Li},{ }^{3} \mathrm{He}$, and ${ }^{10} \mathrm{~B}$ by neutron capture reactions as the following:

${ }^{6} \mathrm{Li}(\mathrm{n}, \alpha){ }^{3} \mathrm{H}$,

${ }^{7} \mathrm{Li}(\mathrm{n}, \mathrm{n} \alpha){ }^{3} \mathrm{H}$

${ }^{3} \mathrm{He}(\mathrm{n}, \mathrm{p}){ }^{3} \mathrm{H}$

${ }^{10} \mathrm{~B}(\mathrm{n}, 2 \alpha){ }^{3} \mathrm{H}$

${ }^{10} \mathrm{~B}(\mathrm{n}, \alpha){ }^{7} \mathrm{Li}$.

${ }^{6} \mathrm{Li}$ and ${ }^{7} \mathrm{Li}$ are impurities in the core graphite material such as the sleeve, spine, reflector, and fuel matrix. ${ }^{3} \mathrm{He}$ is an impurity in the reactor coolant helium. Because helium coolant leaks from the primary loop to the containment vessel, helium is supplied to the primary coolant as a make-up with an impurity of ${ }^{3} \mathrm{He} .{ }^{10} \mathrm{~B}$ exists in control rods, burnable poisons, and reflectors. Tritium is produced directly from ${ }^{10} \mathrm{~B}$ via Equation (2-4) or via the chain reaction in Equations (2-2) and (2-5).

Tritium generated in the fuel particles by ternary fissions can escape into a primary coolant, permeating several barriers of the fuel particles. In addition, tritium born from ${ }^{10} \mathrm{~B}$ and ${ }^{6} \mathrm{Li}$ can pass into the primary coolant. The principal chemical form for tritium in the reactor coolant was reported as HT $\left({ }^{1} \mathrm{H}-{ }^{3} \mathrm{H}\right)$ because of the isotope exchange reaction between $\mathrm{T}_{2}\left({ }^{3} \mathrm{H}-{ }^{3} \mathrm{H}\right)$ and $\mathrm{H}_{2}$ (Wichner and Dyer 1979). Some of the tritium in the primary coolant is removed by a purification system installed in the primary loop. Some of the tritium can escape outside the coolant by permeation through the components and piping and by leakage with the primary helium coolant. The remaining tritium in the primary coolant permeates through the heat transfer tubes or surfaces of the IHX and gets mixed in with the secondary coolant.

In the secondary loop, some of the tritium is removed by the purification system or escapes outside, just as tritium behaves in the primary loop. The remainder of the tritium in the secondary coolant permeates through heat transfer surfaces and gets mixed into the tertiary coolant. Transportation of tritium into the tertiary coolant is the same as for the secondary coolant. It permeates through the heat transfer surfaces of the process heat exchangers and is mixed into the process chemicals of the hydrogen plant.

Tritium that has permeated the tertiary loop going to the hydrogen plant can react with hydrogen-containing process chemicals through isotopic exchange reactions. For example, the hightemperature electrolysis (HTE) process contains $\mathrm{H}_{2} \mathrm{O}$. Therefore, $\mathrm{HTO}$ (tritiated water) is produced by the isotope exchange reaction between $\mathrm{HT}$ and $\mathrm{H}_{2} \mathrm{O}$. Gaseous HTO and HT escape from the HTE process with the product hydrogen and oxygen. A part of the liquid HTO flows out from the hydrogen plant with the drain water. The remainder of the liquid HTO circulates into the plant with the recycling water and accumulates in the water of the HTE process. The SI process used in hydrogen production also contains 
$\mathrm{H}_{2} \mathrm{O}, \mathrm{H}_{2} \mathrm{SO}_{4}$, and $\mathrm{HI}$ chemicals from which $\mathrm{HTO}, \mathrm{HTSO}_{4}$, and TI may be produced through isotope exchange reactions. These tritium-containing chemicals circulate with and accumulate in process the chemicals. Only gaseous HT and HTO can escape from the SI process with the product hydrogen and oxygen.

Tritium behavior in high temperature gas-cooled reactors (HTGR) has been was well evaluated in several countries in the 1970s (e.g., the Dragon reactor in England (Forsyth 1972), the Peach Bottom HTGR in the U.S. (Wichner and Dyer 1979), and Arbeitsgemeinschaft Versuchsreaktor (AVR) in Germany (Steinwarz, Rohrig, and Nieder 1980). Data from the operation of HTGRs and from laboratory experiments revealed the mechanism of tritium production, transport, and release to the environment. In his review of tritium behavior in an HTGR system, Gainey's (1976) calculations show that tritium releases should be well within current federal guidelines for the nuclear plant. For example, the estimated maximum dose to an average adult for a typical 3,000-MWt HTGR with a cooling tower is 0.38 milligram/year, which is slightly more than one-tenth of the maximum annual dose allowed (Gainey 1976). For this reason, no further laboratory-scale work on tritium was required at that time. However, their tritium calculations were only concerned with general tritium release and did not examine questions related to nuclear hydrogen production. NGNP will use the HTGR as a heat source to produce hydrogen for industry or individual users.

Ohashi and Sherman (2007) recently estimated steady-state tritium movement and accumulation in an NGNP with a hydrogen plant using a high temperature electrolysis process and a thermochemical water splitting sulfur-iodine process using the numerical code THYTAN. Estimated tritium concentrations in product hydrogen and in process chemicals in the hydrogen plant of the NGNP using the high temperature electrolysis process were slightly higher than the drinking water limit defined by the U.S. Environmental Protection Agency and the limit in the effluent at the boundary of an unrestricted area of a nuclear plant as defined by the U.S. Nuclear Regulatory Commission. However, modified designs and operations could bring these concentrations within specified limits. Tritium concentrations in the NGNP using the sulfur iodine process were calculated to be significantly higher and were affected by parameters with large uncertainties (tritium permeability of the process heat exchanger, the hydrogen concentration in the heat transfer and process fluids, and the equilibrium constant of the isotope exchange reaction between HT and $\mathrm{H}_{2} \mathrm{SO}_{4}$ ). These parameters, including tritium generation and the release rate in the reactor core, should be more accurately estimated in the near future to improve the calculations for the sulfur-iodine process. Decreasing the tritium permeation through the heat exchanger between the primary and secondary circuits may be an effective measure for decreasing tritium concentrations in product hydrogen, hydrogen plant, and tertiary coolant.

Based on Ohashi and Sherman's calculation, this study focused on the predictions of the transient tritium behaviors in the NGNP system, finally evaluating how much tritium is contained in the produced hydrogen. To accomplish this, the following tasks were performed in FY 2008:

- Developed a dynamic tritium behavior analysis tool by MATLAB SIMULINK (Mathworks, Inc. 2004)

- Followed-up THYTAN verification and validation work by Ohashi and Sherman (2008)

- Developed THYTAN core input for considering transient tritium source

- Evaluated the effective thickness for tritium permeation in the PCHE type heat exchangers

- Developed a Tritium Penetration Analysis Code for VHTR and Hydrogen Generation System. 
A dynamic tritium behavior analysis code was developed by the Matlab Simulink software package. This code can solve the generations of tritium source and tritium transport equations, including the penetration of tritium through the heat exchanger wall. The following phenomena are currently taken into consideration in this code:

- Tritium birth by ternary fission in the fuel particle and through neutron absorption reactions of ${ }^{6} \mathrm{Li}$,

${ }^{7} \mathrm{Li},{ }^{10} \mathrm{~B}$, and ${ }^{3} \mathrm{He}$ in the core and tritium release to the primary coolant helium

- Tritium and hydrogen permeation through the heat transfer surfaces of the heat exchanger (e.g., IHX), the chemical reactor, and the recuperator

- Tritium and hydrogen permeation assuming a co-axial pipe in the primary and intermediate loops

- Tritium and hydrogen permeation to the outside through the outer walls of components and piping

- Tritium and hydrogen removal by the purification system installed in the primary and secondary loops

- Tritium and hydrogen leakage to the atmosphere or to another loop that accompanies general bulk helium leakage.

\subsubsection{Basic Equations}

The following governing equations were solved in the MATLAB SIMULINK (Mathworks, Inc. 2004) code for analysis of the tritium behaviors in the NGNP system. The basic equations include mass balance, core tritium source, tritium permeation, leakage, and purification system. The ion exchange model is not yet considered in this code. The following equations are based on the report by Ohashi and Sherman (2006).

\subsubsection{Mass Balance}

The current tritium analysis code basically solves the mass balance of tritium-containing chemicals and hydrogen. The mass balance of tritium-containing chemicals and hydrogen in each block is calculated using the following basic equations:

$$
\begin{aligned}
& V_{j} \frac{d C_{i, j}}{d t}=\sum\left(F_{\text {total }, j-1} \cdot C_{i, j-1}\right)-F_{\text {total }, j} \cdot C_{i, j}-S_{i, j} \\
& S_{i, j}=-R_{\text {core }, i, j}+R_{H X, i, j}+R_{\text {copipe }, i, j}+R_{\text {comp }, i, j}+R_{\text {leak }, i, j}+R_{P F, i, j}+R_{\text {reaction }, i, j}
\end{aligned}
$$

where

$$
\begin{aligned}
& V_{j} \quad=\quad \text { the volume of block } j\left[\mathrm{~m}^{3}(\mathrm{STP})\right] \\
& C_{i, j}=\text { the volume fraction of chemical } i \text { in block } j\left[\mathrm{~m}^{3}(\mathrm{STP}) / \mathrm{m}^{3}(\mathrm{STP})\right] \\
& t \quad=\text { time }[\mathrm{s}] \\
& F_{\text {total }, j}=\text { the volumetric flow rate of all chemicals in block } j\left[\mathrm{~m}^{3}(\mathrm{STP}) / \mathrm{s}\right] \\
& S_{i, j} \quad=\quad \text { the total amount of volume change rate of chemical } i \text { in block } j \text { by considering } \\
& \text { generation, release, permeation, removal, leakage, and isotope exchange reactions } \\
& {\left[\mathrm{m}^{3}(\mathrm{STP}) / \mathrm{s}\right]} \\
& R_{\text {core }, i, j}=\text { volumetric release rate from the core to the primary coolant }\left[\mathrm{m}^{3}(\mathrm{STP}) / \mathrm{s}\right] \\
& R_{H X, i, j}=\text { volumetric permeation rate at heat exchanger }\left(\mathrm{i}=\mathrm{H}_{2} \text { and } \mathrm{HT}\right)\left[\mathrm{m}^{3}(\mathrm{STP}) / \mathrm{s}\right] \\
& R_{\text {copipe }, i, j}=\text { volumetric permeation rate at co-axial pipe }\left(\mathrm{i}=\mathrm{H}_{2} \text { and } \mathrm{HT}\right)\left[\mathrm{m}^{3}(\mathrm{STP}) / \mathrm{s}\right]
\end{aligned}
$$


$R_{\text {comp }, i, j}=$ volumetric permeation rate to outside $\left(\mathrm{i}=\mathrm{H}_{2}\right.$ and $\left.\mathrm{HT}\right)\left[\mathrm{m}^{3}(\mathrm{STP}) / \mathrm{s}\right]$

$R_{\text {leak }, i, j}=$ volumetric leak rate with helium leakage $\left(i=\mathrm{H}_{2}, \mathrm{HT}\right.$ and HTO) $\left[\mathrm{m}^{3}(\mathrm{STP}) / \mathrm{s}\right]$

$R_{P F, i, j}=$ volumetric removal rate by purification system $\left(i=\mathrm{H}_{2}\right.$, HT and HTO) $\left[\mathrm{m}^{3}(\mathrm{STP}) / \mathrm{s}\right]$

$R_{\text {reaction }, i, j}=$ volumetric reaction rate by isotope exchange reactions $\left(i=\mathrm{H}_{2}, \mathrm{HT}, \mathrm{HTO}, \mathrm{HTSO}_{4}\right.$ and TI) $\left[\mathrm{m}^{3}(\mathrm{STP}) / \mathrm{s}\right]$.

\subsubsection{Core Model}

There are five different sources for tritium generation in the reactor core: ternary fission, birth from ${ }^{6} \mathrm{Li}$, birth from ${ }^{7} \mathrm{Li}$, birth from ${ }^{3} \mathrm{He}$, and birth from ${ }^{10} \mathrm{~B}$. The detail equations are expressed as follows.

\section{Ternary fission}

$\frac{d\left(N_{T(T e r)}\right)}{d t}=K \cdot P \cdot Y-\lambda \cdot N_{T(T e r)}$

where

$$
\begin{array}{ll}
N_{T(\mathrm{Ter})} & =\text { number of tritium atoms from ternary fission } \\
K & =\text { fission rate per thermal megawatt [fission } / \mathrm{MW} / \mathrm{s}] \\
P & =\text { reactor power }[\mathrm{MW}] \\
Y & =\text { average yield per fission }[1 / \text { fission }] \\
\lambda & =\text { tritium decay constant }[1 / \mathrm{s}] .
\end{array}
$$

\section{Birth from ${ }^{6} \mathbf{L i}$}

$\frac{d\left(N_{L i 6}\right)}{d t}=-\phi_{t h} \cdot \sigma_{L i 6 T} \cdot N_{L i 6}$

$\frac{d\left(N_{T(L i 6)}\right)}{d t}=\phi_{t h} \cdot \sigma_{L i 6 T} \cdot N_{L i 6}-\lambda \cdot N_{T(L i 6)}$

where

$$
\begin{aligned}
& N_{L i 6}=\text { number of }{ }^{6} \mathrm{Li} \text { atoms } \\
& N_{T(L i 6)}=\text { number of tritium atoms from }{ }^{6} \mathrm{Li} \\
& \left.\phi_{t h}=\text { thermal neutron flux [neutrons } / \mathrm{cm}^{2} / \mathrm{s}\right] \\
& \sigma_{L i 6 T}=\text { effective cross section for }{ }^{6} \mathrm{Li}(\mathrm{n}, \alpha){ }^{3} \mathrm{H}\left[\mathrm{cm}^{2}\right] .
\end{aligned}
$$

\section{Birth from ${ }^{7} \mathbf{L i}$}

$$
\begin{aligned}
& \frac{d\left(N_{L i 7}\right)}{d t}=-\phi_{f} \cdot \sigma_{L i 7 H 3} \cdot N_{L i 7} \\
& \frac{d\left(N_{T(L i 7)}\right)}{d t}=\phi_{f} \cdot \sigma_{L i 7 T} \cdot N_{L i 7}-\lambda \cdot N_{T(L i 7)}
\end{aligned}
$$


where

$$
\begin{aligned}
& N_{L i 7}=\text { number of }{ }^{7} \mathrm{Li} \text { atoms, excluding }{ }^{10} \mathrm{~B} \text { source } \\
& N_{T(L i 7)}=\text { number of tritium atoms from }{ }^{7} \mathrm{Li} \text {, excluding birth from }{ }^{10} \mathrm{~B} \\
& \left.\phi_{f}=\text { fast neutron flux [neutrons } / \mathrm{cm}^{2} / \mathrm{s}\right] \\
& \sigma_{L i 7 T}=\text { effective cross section for }{ }^{7} \mathrm{Li}(\mathrm{n}, \mathrm{n} \alpha){ }^{3} \mathrm{H}\left[\mathrm{cm}^{2}\right] .
\end{aligned}
$$

\section{Birth from ${ }^{3} \mathrm{He}$}

$$
\begin{aligned}
& \frac{d\left(N_{H e 3}\right)}{d t}=f \cdot N_{H e 3}^{\circ}-f \cdot N_{H e 3}-\phi_{H e} \cdot \sigma_{H e 3 T} \cdot N_{H e 3} \\
& \frac{d\left(N_{T(H e 3)}\right)}{d t}=\phi_{H e} \cdot \sigma_{H e 3 T} \cdot N_{H e 3}-\lambda \cdot N_{T(H e 3)} \\
& \phi_{H e}=\frac{W_{\text {core }}}{W_{\text {total }}} \cdot \phi_{t h}
\end{aligned}
$$

where

$$
\begin{aligned}
& N_{H e 3}=\text { number of }{ }^{3} \mathrm{He} \text { atoms } \\
& N_{T(H e 3)}=\text { number of tritium atoms from }{ }^{3} \mathrm{He} \\
& f \quad=\text { fractional supply rate of helium coolant }[1 / \mathrm{s}] \\
& N_{H e 3}^{\circ}=\text { number of }{ }^{3} \mathrm{He} \text { atoms in the supply helium } \\
& \sigma_{H e 3 T}=\text { effective cross section for }{ }^{3} \mathrm{He}(\mathrm{n}, \mathrm{p}) \mathrm{T}\left[\mathrm{cm}^{2}\right] \\
& \phi_{H e}=\text { average thermal neutron flux experienced by the total primary helium inventory }\left[\mathrm{n} / \mathrm{cm}^{2} / \mathrm{s}\right] \\
& W_{\text {core }}=\text { helium inventory in core }[\mathrm{kg}] \\
& W_{\text {total }}=\text { total primary helium inventory }[\mathrm{kg}] .
\end{aligned}
$$

\section{Birth from ${ }^{10} B$}

$$
\begin{aligned}
& \frac{d\left(N_{B 10}\right)}{d t}=-\left(\phi_{t h} \cdot \sigma_{B 10 L i 7}+\phi_{f} \cdot \sigma_{B 10 T}\right) \cdot N_{B 10} \\
& \frac{d\left(N_{L i 7(B 10)}\right)}{d t}=\phi_{t h} \cdot \sigma_{B 10 L i 7} \cdot N_{B 10}-\phi_{f} \cdot \sigma_{L i 7 T} \cdot N_{L i 7(B 10)} \\
& \frac{d\left(N_{T(B 10)}\right)}{d t}=\phi_{f} \cdot \sigma_{L i 7 T} \cdot N_{L i 7(B 10)}+\phi_{f} \cdot \sigma_{B 10 T} \cdot N_{B 10}-\lambda \cdot N_{T(B 10)}
\end{aligned}
$$

where

$$
\begin{aligned}
& N_{B 10}=\text { number of }{ }^{10} \mathrm{~B} \text { atoms } \\
& N_{L i 7(B 10)}=\text { number of }{ }^{7} \mathrm{Li} \text { atoms from }{ }^{10} \mathrm{~B} \\
& N_{T(B 10)}=\text { number of tritium from }{ }^{10} \mathrm{~B} \\
& \sigma_{B 10 L i 7}=\text { effective cross section for }{ }^{10} \mathrm{~B}(\mathrm{n}, \alpha){ }^{7} \mathrm{Li}\left[\mathrm{cm}^{2}\right] \\
& \sigma_{B 10 T}=\text { effective cross section for }{ }^{10} \mathrm{~B}(\mathrm{n}, 2 \alpha){ }^{3} \mathrm{H}\left[\mathrm{cm}^{2}\right] .
\end{aligned}
$$




\section{Tritium release rate}

The tritium release rate from the core to the primary coolant, $R_{\text {core }, H T, j}\left[\mathrm{~m}^{3}(\mathrm{STP}) / \mathrm{s}\right]$, is calculated by using the following equations:

$$
\begin{aligned}
\frac{N_{T(\text { total })}}{d t}= & \sum\left\{\alpha_{T e r} \frac{d\left(N_{T(T e r)}\right)}{d t}\right\}+\sum\left[\alpha_{L i}\left\{\frac{d\left(N_{T(L i 6)}\right)}{d t}+\frac{d\left(N_{T(L i 7)}\right)}{d t}\right\}\right] \\
& +\sum\left\{\alpha_{H e 3} \frac{d\left(N_{T(H e 3)}\right)}{d t}\right\}+\sum\left\{\alpha_{B 10} \frac{d\left(N_{T(B 10)}\right)}{d t}\right\} \\
R_{\text {core }, H T, j}= & \frac{N_{T(t o t a l)}}{d t} \times \frac{1}{N_{A}} \times \frac{R \cdot T_{0}}{P_{0}}
\end{aligned}
$$

where

$$
\begin{aligned}
& N_{T \text { (release })}=\text { number of tritium atoms released to the primary coolant } \\
& \begin{array}{ll}
\alpha_{T e r} & =\text { fractional release ratio of tritium produced from ternary fission } \\
\alpha_{L i} & =\text { fractional release ratio of tritium produced from }{ }^{6} \mathrm{Li} \text { and }{ }^{7} \mathrm{Li} \\
\alpha_{H e 3} & =\text { fractional release ratio of tritium produced from }{ }^{3} \mathrm{He} \\
\alpha_{B 10} & =\text { fractional release ratio of tritium produced from }{ }^{10} \mathrm{~B} \\
N_{A} & =\text { Avogadro constant } \\
R & =\text { gas constant }(8.314) \\
T_{0} & =\text { standard temperature }(273.15 \mathrm{~K}) \\
P_{0} & =\text { standard pressure }\left(1.01325 \times 10^{5} \mathrm{~Pa}\right)
\end{array}
\end{aligned}
$$

\subsubsection{Permeation Model}

The permeation rate of $\mathrm{H}_{2}$ at the heat exchanger, $R_{H X, H 2}\left[\mathrm{~m}^{3}(\mathrm{STP}) / \mathrm{s}\right]$, and at the co-axial pipe, $R_{\text {copipe, } H 2}\left[\mathrm{~m}^{3}(\mathrm{STP}) / \mathrm{s}\right]$, is estimated using the following equation:

$R_{H X, H 2, j}\left(\right.$ or $\left.\quad R_{\text {copipe }, H 2, j}\right)=\frac{A}{l} \cdot k_{p, H} \cdot\left(\sqrt{P_{H 2, h}}-\sqrt{P_{H 2, l}}\right)$

where

$A=$ heat transfer area or surface area $\left[\mathrm{m}^{2}\right]$

$l=$ thickness of heat transfer tube or component casing $[\mathrm{m}]$

$k_{p, H}=$ permeability of hydrogen $\left[\mathrm{m}^{3}(\mathrm{STP}) / \mathrm{m} / \mathrm{s} / \mathrm{Pa}^{0.5}\right]$

$P_{H 2, h}=$ partial pressure of $\mathrm{H}_{2}$ at high pressure side $[\mathrm{Pa}]$

$P_{H 2, l}=$ partial pressure of $\mathrm{H}_{2}$ at low pressure side $[\mathrm{Pa}]$

$l$ is calculated by the following equation:

$l=r_{o} \cdot \ln \left(\frac{r_{o}}{r_{i}}\right)$ 
where

$r_{o}=$ outer radius of heat transfer tube [m]

$r_{i}=$ inner radius of heat transfer tube [m].

Permeability is calculated by using the Arrhenius equation:

$k_{p}=f \cdot \exp \left(\frac{-E}{R T}\right)$

where

$f=$ pre-exponential factor of permeability $\left[\mathrm{m}^{3}(\mathrm{STP}) / \mathrm{m} / \mathrm{s} / \mathrm{Pa}^{0.5}\right]$

$E=$ activation energy $[\mathrm{J} / \mathrm{mol}]$

$R=$ ideal gas constant $[\mathrm{J} / \mathrm{mol}-\mathrm{K}]$

$T=$ temperature $[\mathrm{K}]$.

The permeation rate of $\mathrm{H}_{2}$ though the outer wall of the component and piping, $R_{c o m p, H 2}$, is calculated by excluding the $\mathrm{H}_{2}$ partial pressure at the low pressure side as follows:

$$
R_{\text {comp }, H 2, j}=\frac{A}{l} \cdot k_{p, H} \cdot \sqrt{P_{H 2, h}} .
$$

The permeation rate of HT at the heat exchanger, $R_{H X, H 2}\left[\mathrm{~m}^{3}(\mathrm{STP}) / \mathrm{s}\right]$, and at the co-axial pipe, $R_{\text {copipe }, H 2}\left[\mathrm{~m}^{3}(\mathrm{STP}) / \mathrm{s}\right]$, is estimated by considering the effect of the existence of hydrogen on the adsorption-dissociation and recombination-desorption step as follows:

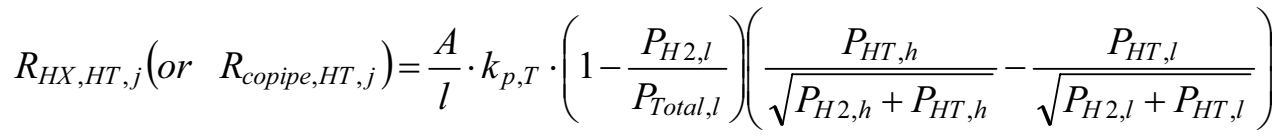

where

$$
\begin{aligned}
& k_{p, T}=\text { permeability of tritium }\left[\mathrm{m}^{3}(\mathrm{STP}) / \mathrm{m} / \mathrm{s} / \mathrm{Pa}^{0.5}\right] \\
& P_{H T, h}=\text { partial pressure of } \mathrm{HT} \text { at high pressure side }[\mathrm{Pa}] \\
& P_{H T, l}=\text { partial pressure of } \mathrm{HT} \text { at low pressure side }[\mathrm{Pa}] \\
& P_{\text {Total }, l}=\text { total pressure at low pressure side }[\mathrm{Pa}] .
\end{aligned}
$$

The permeation rate of HT through the outer wall of the component and piping, $R_{\text {comp }, H T}$, is calculated by using the following equation:

$$
R_{\text {comp }, H T, j}=\frac{A}{l} \cdot k_{p, T} \cdot \frac{P_{H T, h}}{\sqrt{P_{H 2, h}+P_{H T, h}}} .
$$

\subsubsection{Leak Model}

The leak rate of helium from the loop, $R_{\text {leak }, H e}\left[\mathrm{~m}^{3}(\mathrm{STP}) / \mathrm{s}\right]$, can be expressed by the following equation:

$$
R_{\text {leak }, \text { He }}=V_{\text {total }} \cdot L_{R}
$$


where

$$
\begin{aligned}
V_{\text {total }} & =\text { total inventory in loop }\left[\mathrm{m}^{3}(\mathrm{STP})\right] \\
L_{R} & =\text { helium leak rate }[1 / \mathrm{s}] .
\end{aligned}
$$

The leak rate of $\mathrm{H}_{2}, \mathrm{HT}$, and HTO with helium leakage in node $\mathrm{j}, R_{\text {leak }, i, j}$, is calculated by using the following equation:

$$
R_{\text {leak }, i, j}=V_{\text {total }} \cdot L_{R} \cdot \bar{C}_{i} \cdot \frac{V_{j}}{V_{\text {leak }}}\left(i=\mathrm{H}_{2}, \mathrm{HT} \text { and HTO }\right)
$$

where

$\bar{C}_{i}=$ average concentration of chemical $\mathrm{i}$ in nodes with helium leak

$V_{\text {leak }}=$ sum of the inventory of nodes with helium leak.

\subsubsection{Purification System Model}

The removal rate, $R_{P F}$, of hydrogen and tritium-containing chemicals in the primary and intermediate loop by the purification system is expressed by the following equation:

$$
R_{P F, i, j}=F_{P F, H e} \cdot \eta_{i} \cdot C_{i, j}\left(i=\mathrm{H}_{2}, \mathrm{HT} \text {, and } \mathrm{HTO}\right)
$$

where

$$
\begin{aligned}
& F_{P F, H e}=\text { helium flow rate at purification system }\left[\mathrm{m}^{3}(\mathrm{STP}) / \mathrm{s}\right] \\
& \eta_{i}=\text { fractional efficiency of purification system for removing component } \mathrm{i}
\end{aligned}
$$

\subsubsection{Development of Dynamic Tritium Behavior Analysis Code by MATLAB Simulink}

\subsubsection{MATLAB Simulink}

In this work, a portion of the dynamic tritium behavior analysis code was developed by the MATLAB Simulink software package. MATLAB is a high-level technical computing programming language created by MathWorks. It provides easy matrix manipulation, algorithm s implementation, user interface creation, and has numerous built-in numerical methods. Simulink is a commercial tool for modeling, simulating, and analyzing multidomain dynamic systems. Its primary interface is a graphical block diagramming tool and a customizable set of block libraries. It offers tight integration with the rest of the MATLAB environment and drives MATLAB or is scripted from it. It supports linear and nonlinear systems modeled in continuous time, sampled time, or a hybrid of both. Systems can also be multirate, i.e., have different parts that are sampled or updated at different rates.

With Simulink, users can move beyond idealized linear models to explore more realistic nonlinear models, factoring in friction, air resistance, gear slippage, hard stops, and other things that describe realworld phenomena. For this reason, the use of MATLAB Simulink for the current work is quite adequate. For modeling, Simulink provides a graphical user interface (GUI) for building models as block diagrams, using click-and-drag mouse operations. With this interface, models can be drawn just as they are with pencil and paper (or as most textbooks depict them). This leads to an easy and fast code development process compared to the previous simulation packages that required researchers to formulate differential equations and difference equations in a language or program. Simulink includes a comprehensive block 
library of sinks, sources, linear and nonlinear components, and connectors. It can also be customized, allowing users to creating their own blocks.

Models are hierarchical, so they can be built using both top-down and bottom-up approaches. The system can be viewed at a high level, or easily gone through to see increasing levels of model detail. This approach provides insight into how a model is organized and how its parts interact.

\subsubsection{Basic Structure of the Dynamic Tritium Analysis Tool}

The current dynamic tritium analysis code is basically composed of three different types of blocks: Component Blocks, Model Blocks, and Supportive Blocks. The Component Blocks represents the actual reactor or system components, which includes all the models and equations to solve the tritium behaviors in the each component. It is composed of lots of Model Blocks that actually solve various models including mass balance, tritium source, tritium permeation, purification system, and tritium leakage. The Supportive blocks include the Detector Block and Data Storage Block, which provide data handling and manipulation features. The overall categorization of these blocks is as follows:

- Model Blocks

- $\quad$ Mass Balance Model Block

- Core Model Block

- Tertiary Fission Block

- $\quad$ Birth from ${ }^{6} \mathrm{Li}$ Block

- $\quad$ Birth from ${ }^{7}$ Li Block

- $\quad$ Birth from ${ }^{3} \mathrm{He}$ Block

- $\quad$ Birth from ${ }^{10} \mathrm{~B}$ Block

- Permeation Model Block

- Leak Model Block

- Purification System Model Block

- Component Blocks

- $\quad$ Reactor Block

- Mass Balance Model Block

- Core Block

- Permeation Model Block

- Leak Model Block

- Purification System Block

- Pipe Block

- Mass Balance Model Block

- Permeation Model Block

- Leak Model Block

- Purification System Block

- $\quad$ Storage Vessel Block

- Mass Balance Model Block

- Permeation Model Block

- Leak Model Block 
- Purification System Block

- Heat Exchanger Block

- Mass Balance Model Block

- Permeation Model Block

- Flow Splitter Block (no model blocks)

- Flow Mixer Block (no model blocks)

- Boundary Flow Block (no model blocks)

- Supportive Blocks

- Detector Block

\subsubsection{Blocks Summaries}

The basic blocks developed in this work for analysis of tritium behaviors in NGNP systems are summarized in this section.

\section{- Model Blocks}

- Mass Balance Model Block

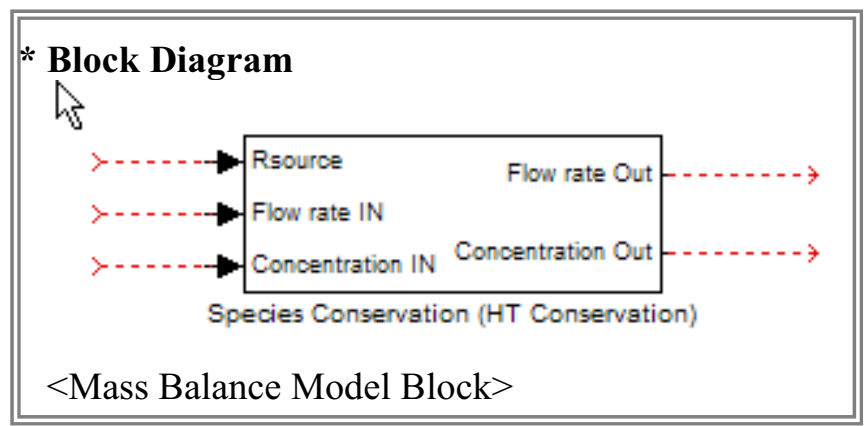

Mass Balance Model Block solves mass balance equations (see Equation 2-6). This model block has three inputs and two outputs.

Resource : species source $\left[\mathrm{m}^{3}(\mathrm{STP}) / \mathrm{s}\right]$

Flow rate IN : total inlet flow rate into the component $\left[\mathrm{m}^{3}(\mathrm{STP}) / \mathrm{s}\right]$

Concentration IN : species concentration of species $\mathrm{i}$ in inflow $\left[\mathrm{m}^{3}(\mathrm{STP}) / \mathrm{m}^{3}(\mathrm{STP})\right]$

Flow rate Out : total outlet flow rate into the component $\left[\mathrm{m}^{3}(\mathrm{STP}) / \mathrm{s}\right]$

Concentration IN : species concentration of species $i$ in the component $\left[\mathrm{m}^{3}(\mathrm{STP}) / \mathrm{m}^{3}(\mathrm{STP})\right]$.

To consider the effect of leak, purification and permeation sources, Leak Model, Purification Model and Permeation Model Blocks are connected to this Block through the Resource port. The detail model configuration in the block is illustrated in Figure 2-1. 


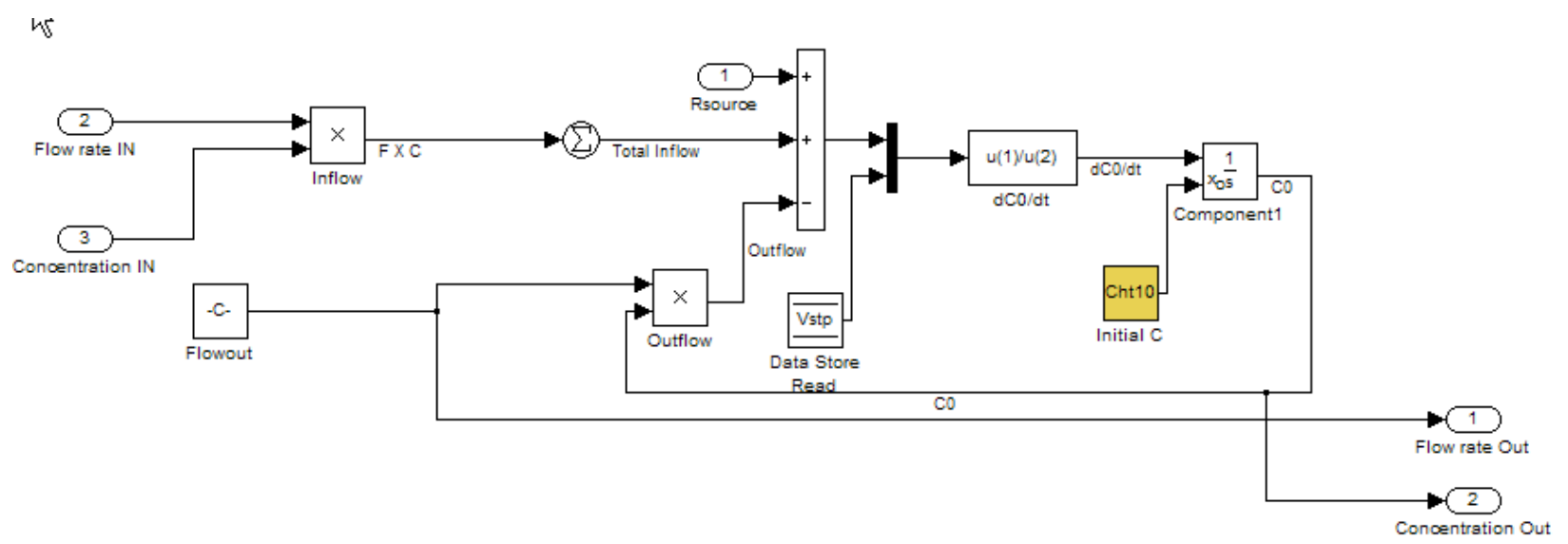

Figure 2-1. Internal structure of the Mass Balance Model Block.

\section{- Core Model Block}

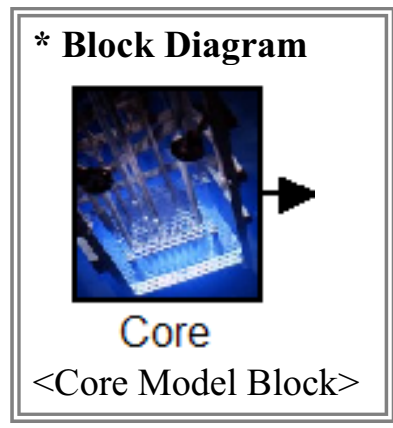

The Core Model Block solves tritium source equations (see Equation (2-8) through (2-20)). It is composed of five different sub-blocks based on the source type (see Figure 2-2). This model block has only one output.

Output-1 : tritium sources from core $\left[\mathrm{m}^{3}(\mathrm{STP}) / \mathrm{s}\right]$

This block is linked to the reactor block by connecting the ports as shown below. Then, it gives tritium sources to the reactor component.

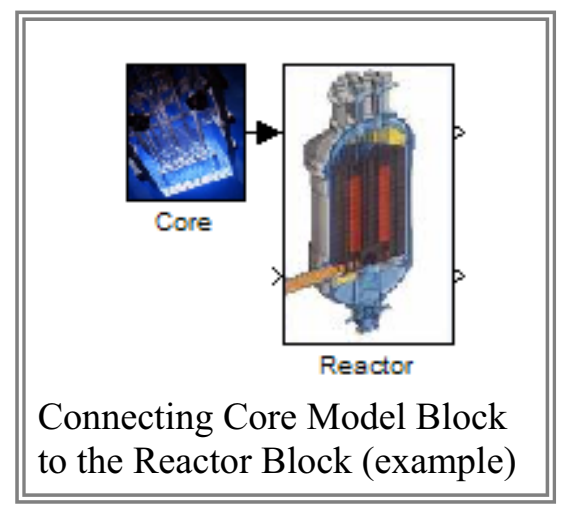

Figure 2-2 shows the internal block diagram of the Core Model Block. The Core Model Block is composed of many sub-blocks that solve each tritium source equation. The core model parameters can be modified by double-click the sub-block for each tritium source (see Figure 2-3). The detail structures of the subcomponents are illustrated in Figures 2-4 through 2-8. 


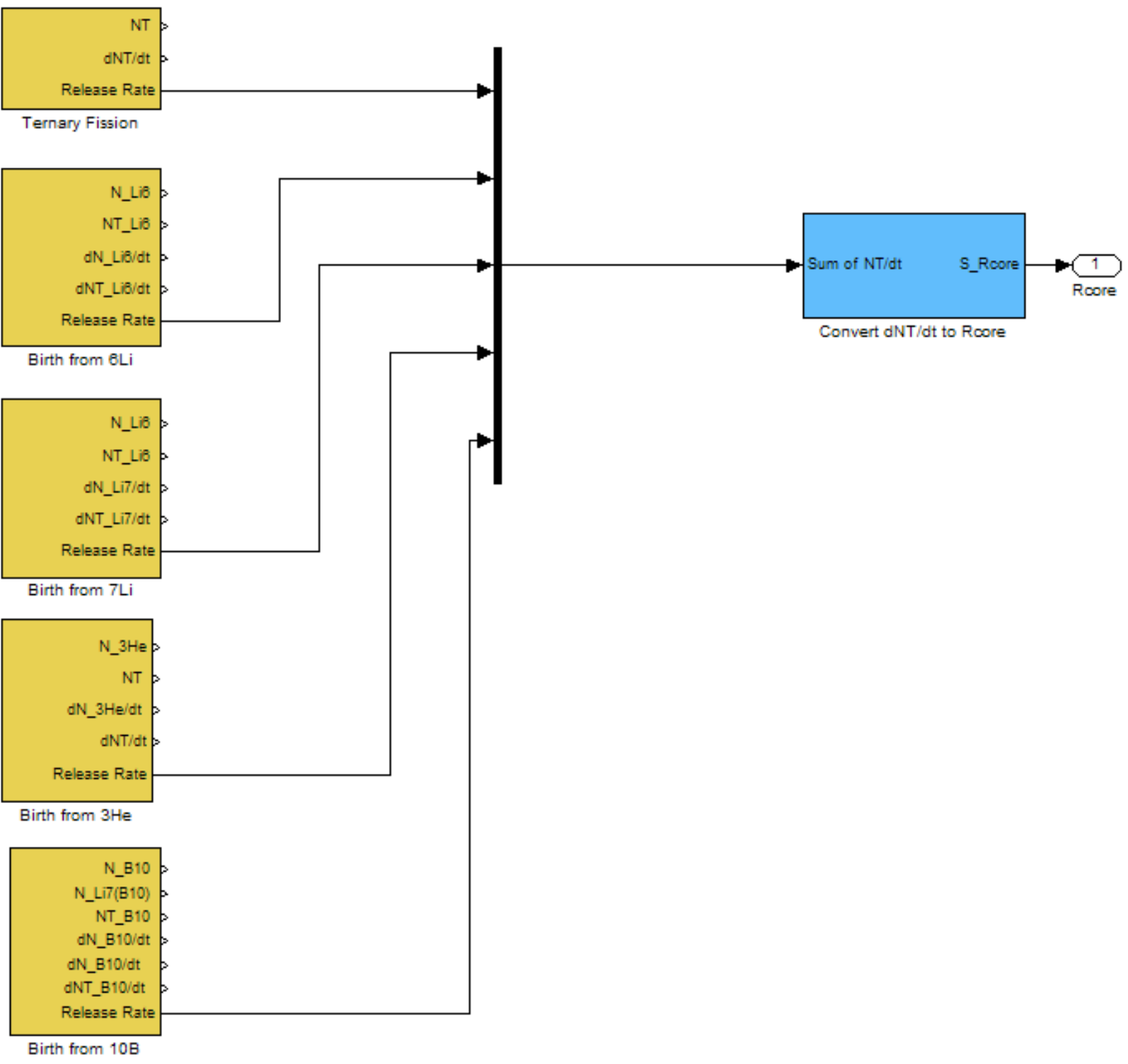

Figure 2-2. Internal block diagram of Core Model Block. 


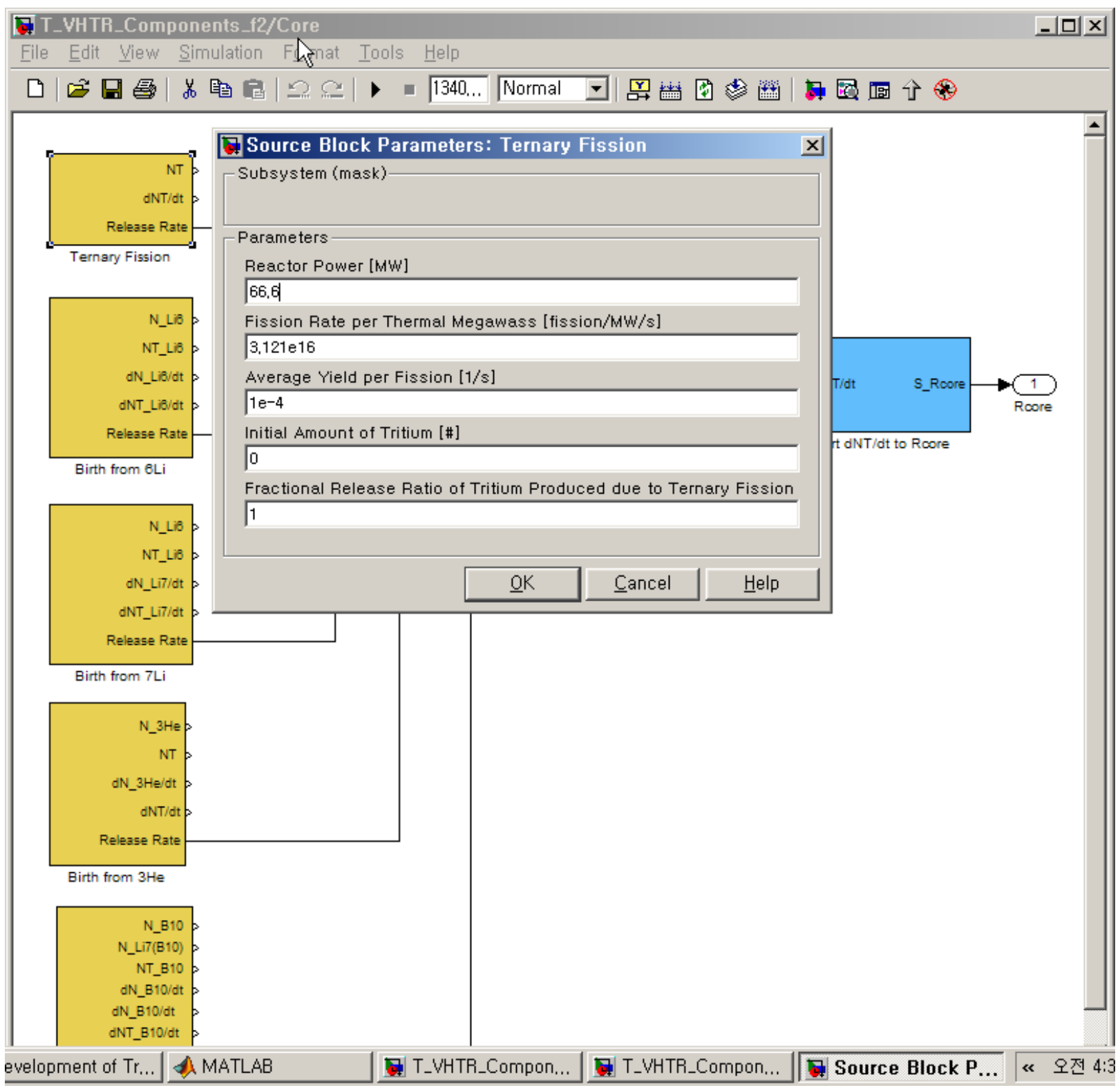

Figure 2-3. Parameter setting window for the tritium source from tertiary fission.

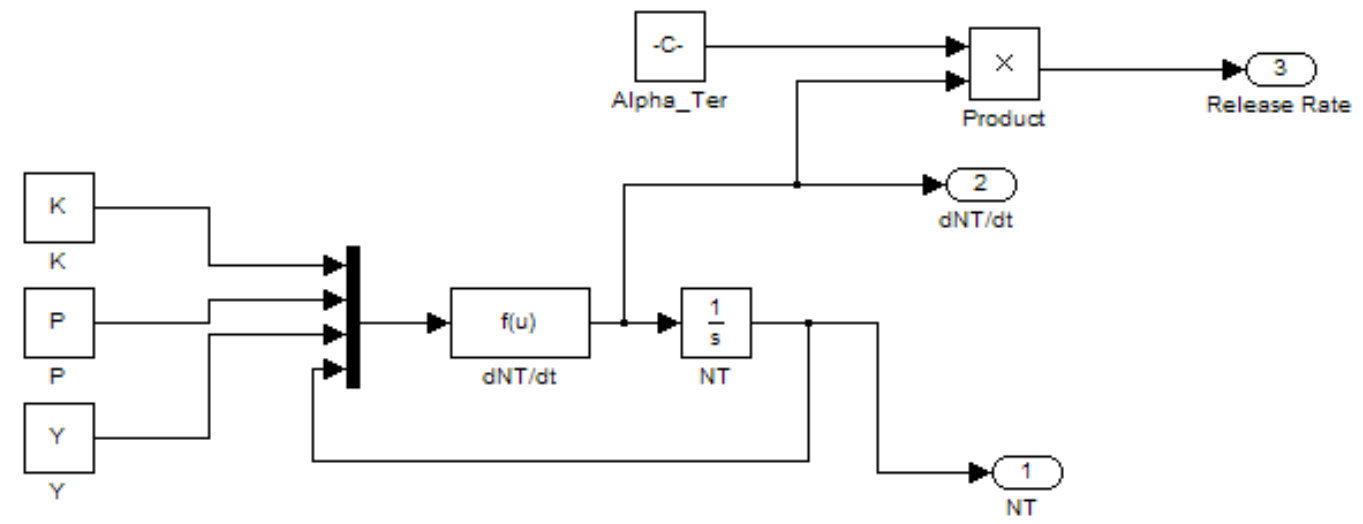

Figure 2-4. Submodel for tritium source from tertiary fission. 


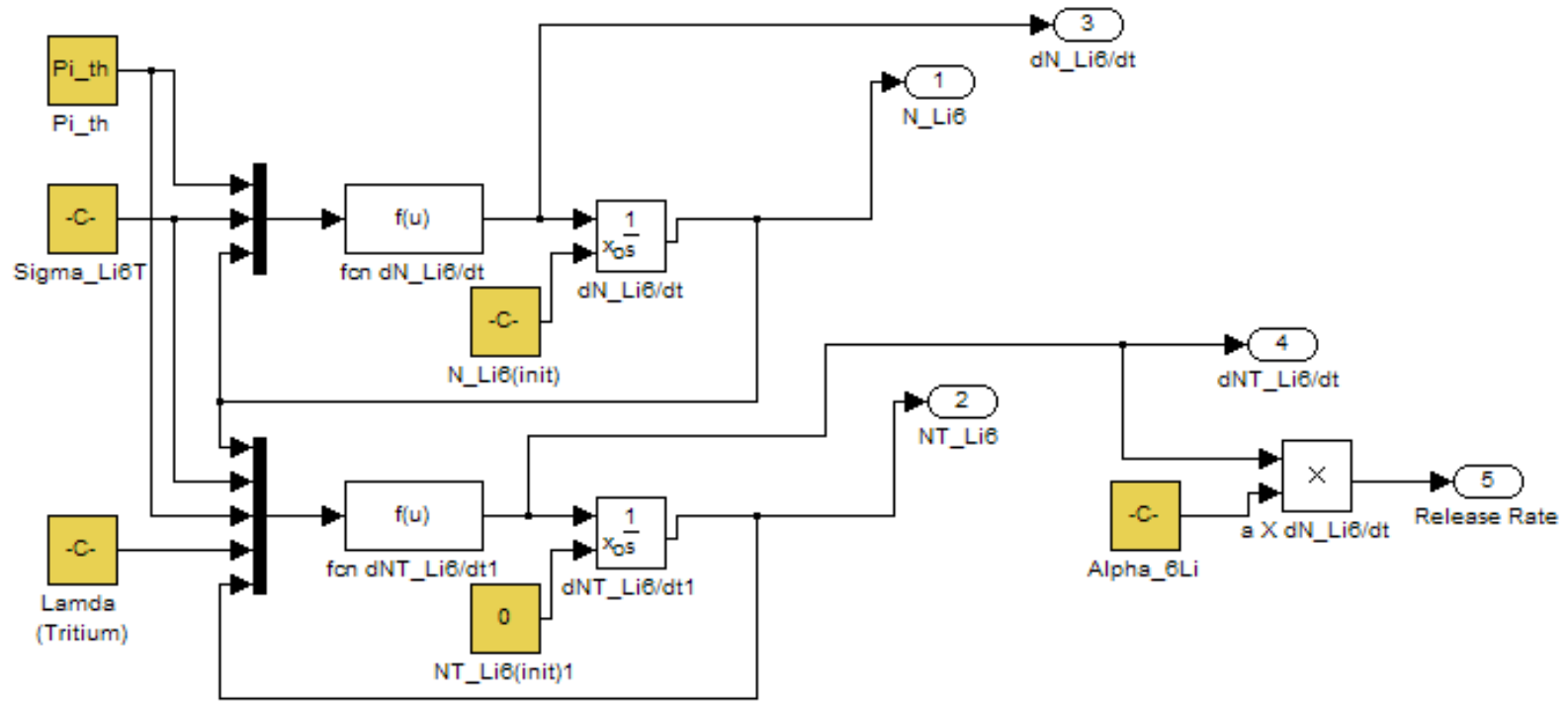

Figure 2-5. Submodel for tritium source from Birth from ${ }^{6} \mathrm{Li}$.

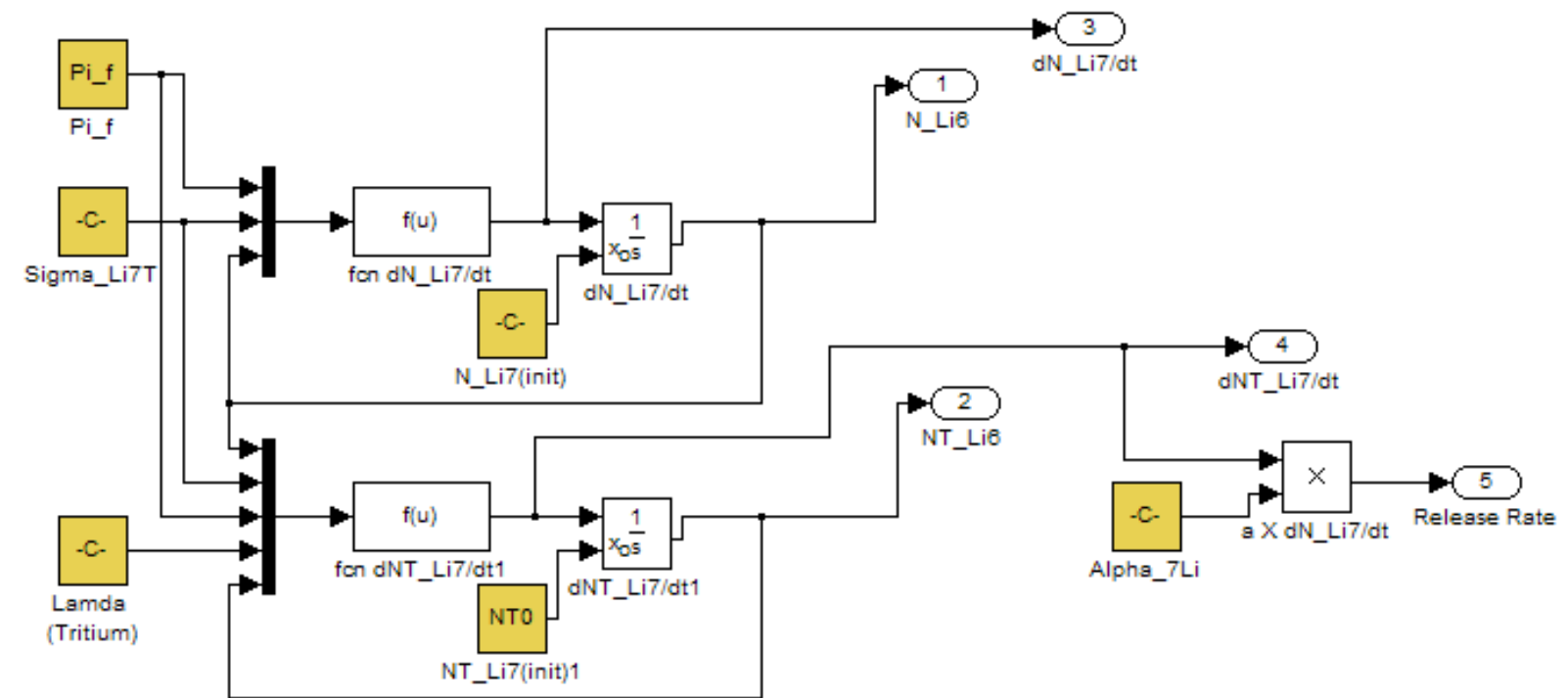

Figure 2-6. Submodel for tritium source from Birth from ${ }^{7} \mathrm{Li}$. 


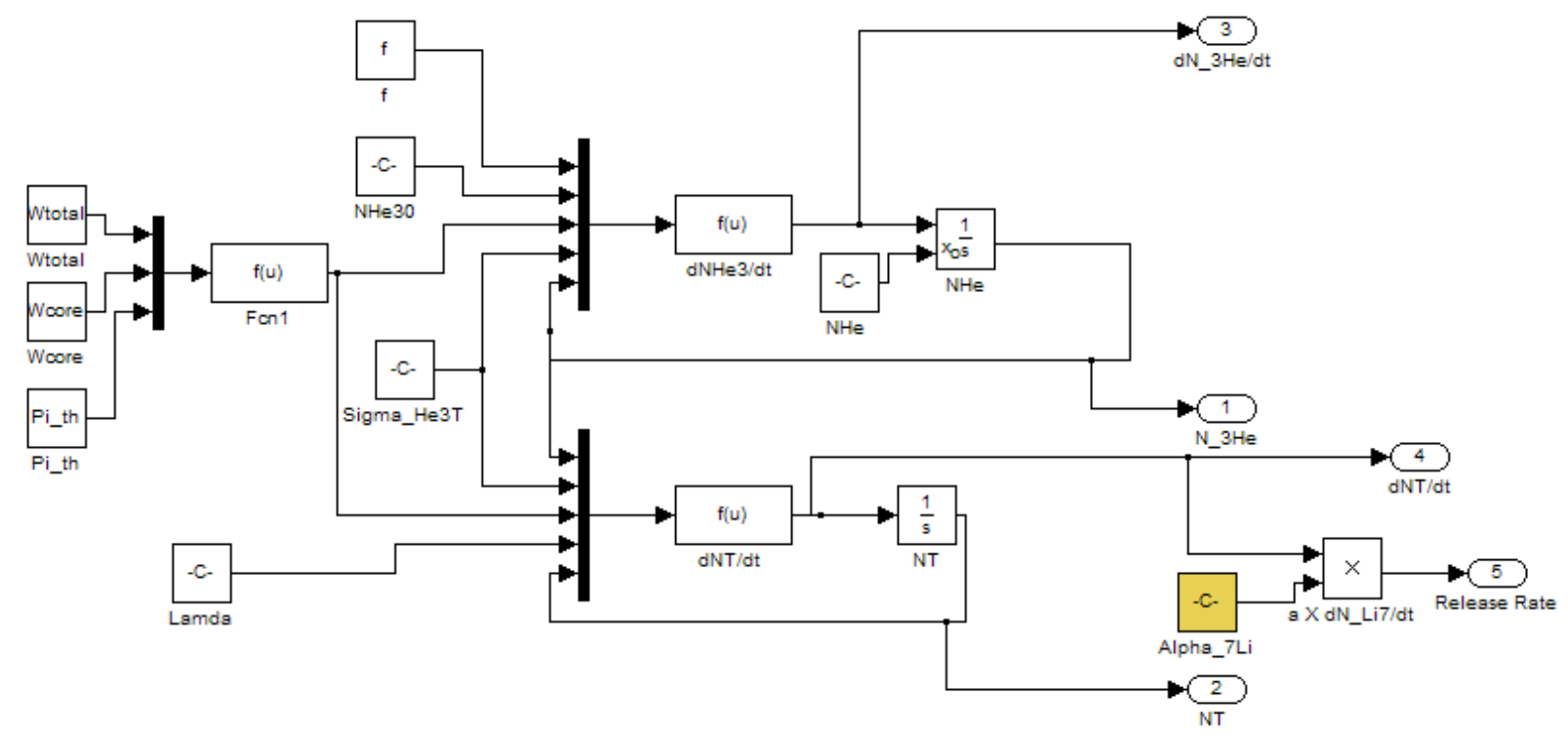

Figure 2-7. Submodel for tritium source from Birth from ${ }^{7} \mathrm{He}$.

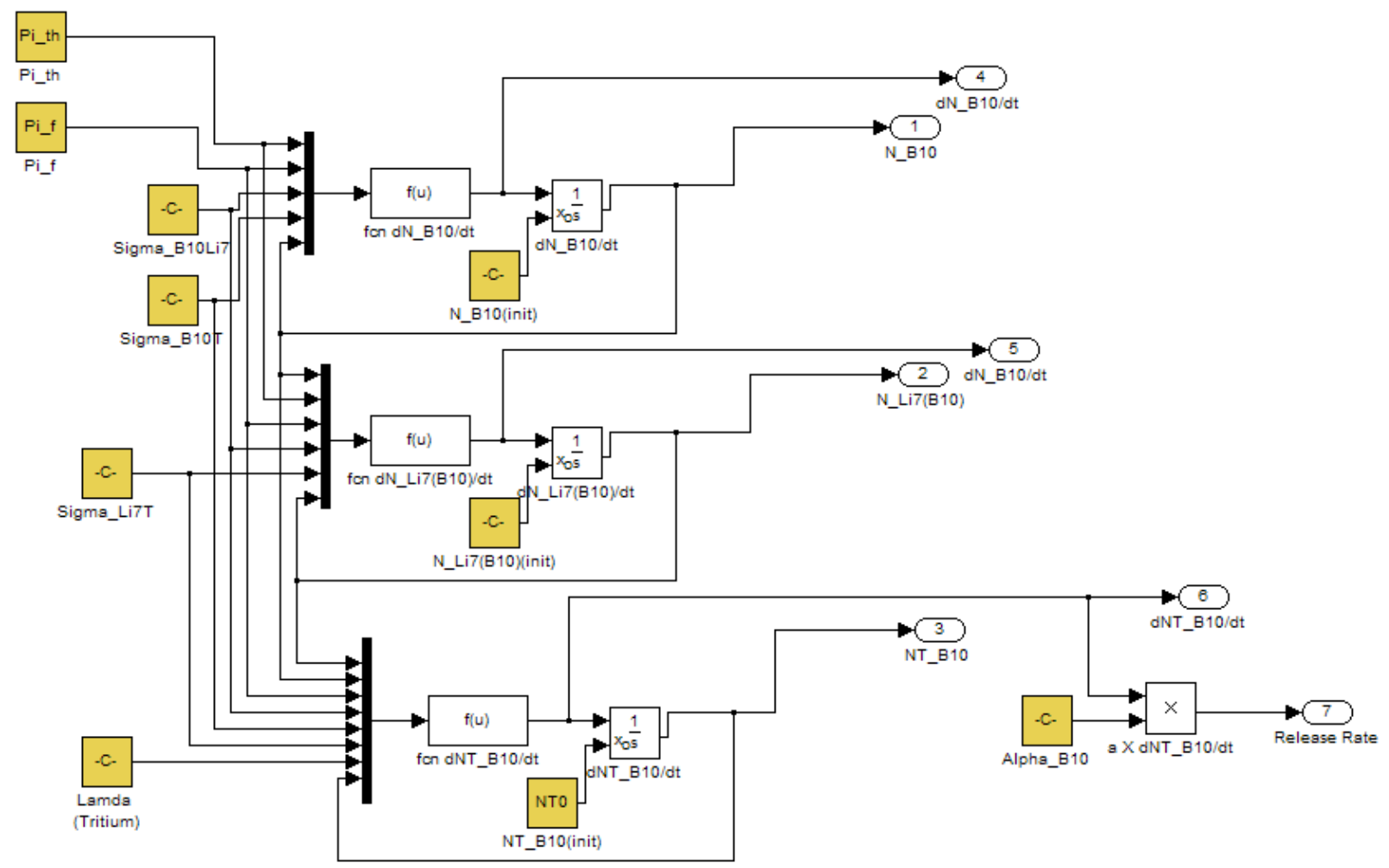

Figure 2-8. Submodel for tritium source from Birth from ${ }^{10} \mathrm{~B}$. 
- Permeation Model Block

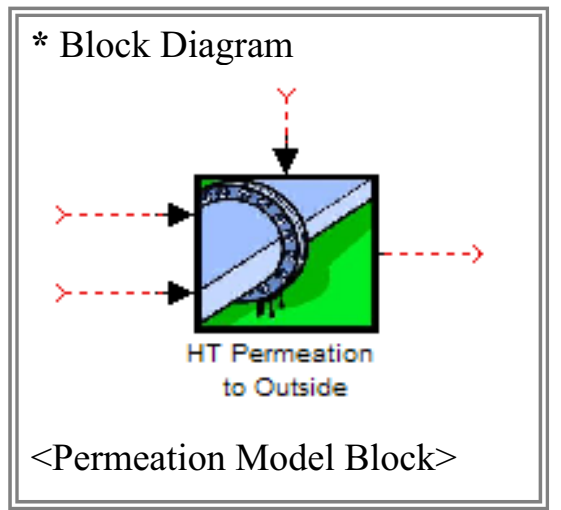

The Permeation Model Block solves the tritium and hydrogen penetration model (see Equations (21) through (26)). This model block has two inputs, one switch, and one output.

Input-1 : tritium partial pressure $[\mathrm{Pa}]$

Input-2 : hydrogen partial pressure $[\mathrm{Pa}]$

Switch-1 (top) : activation of permeation model (true or false)

Output-1 : tritium or hydrogen permeation source $\left[\mathrm{m}^{3}(\mathrm{STP}) / \mathrm{s}\right.$ ]

- $\quad$ Leak Model Block

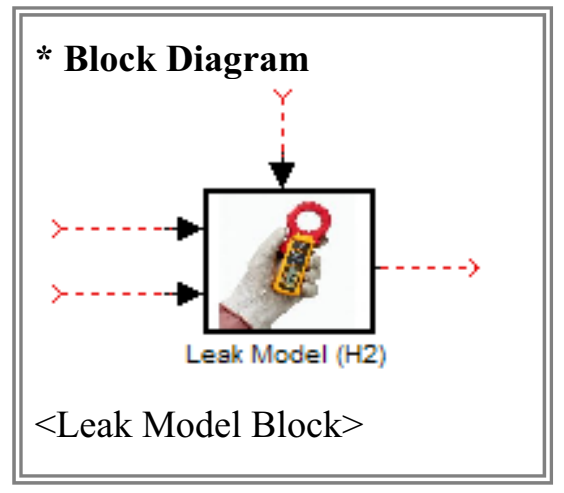

The Leak Model Block solves tritium source or sink from leakage of coolant (see Equation (27), (28)). This model block has two inputs, one switch, and one output.

Input-1 : average concentration of species $\left[\mathrm{m}^{3}(\mathrm{STP}) / \mathrm{m}^{3}(\mathrm{STP})\right]$

Input-2 : volume of the component $\left[\mathrm{m}^{3}(\mathrm{STP})\right]$

Switch-1 (top) : activation of leak model (true or false)

Output-1 : tritium or hydrogen leak rate $\left[\mathrm{m}^{3}(\mathrm{STP}) / \mathrm{s}\right]$ 
- Purification System Model Block

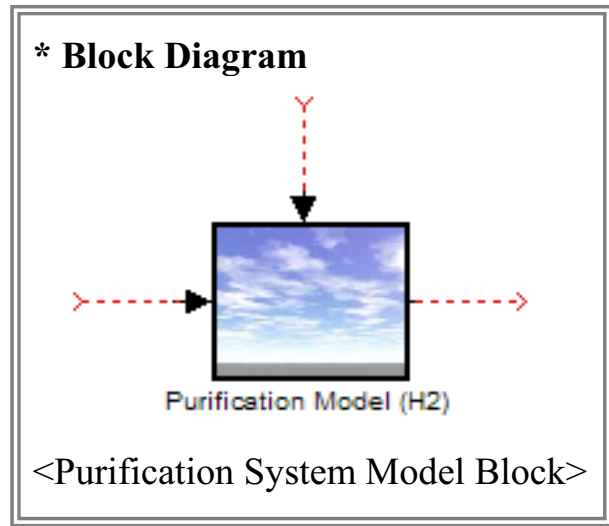

Purification System Model Block solves tritium removal rate by purification system (see Equation (29)). This model block has one input, one switch, and one output.

Input-1 : average concentration of species $\left[\mathrm{m}^{3}(\mathrm{STP}) / \mathrm{m}^{3}(\mathrm{STP})\right]$

Switch-1 (top) : activation of purification model (true or false)

Output-1 : tritium or hydrogen purifying rate $\left[\mathrm{m}^{3}(\mathrm{STP}) / \mathrm{s}\right]$

\section{- Component Blocks}

Component Blocks represent the reactor system components in tritium behavior modeling. The reactor system is modeled by a combination of these Component Blocks. The Component Blocks are developed by assembling and modifying the basic Model Blocks. Details about the Component Blocks are presented below.

- Reactor Block

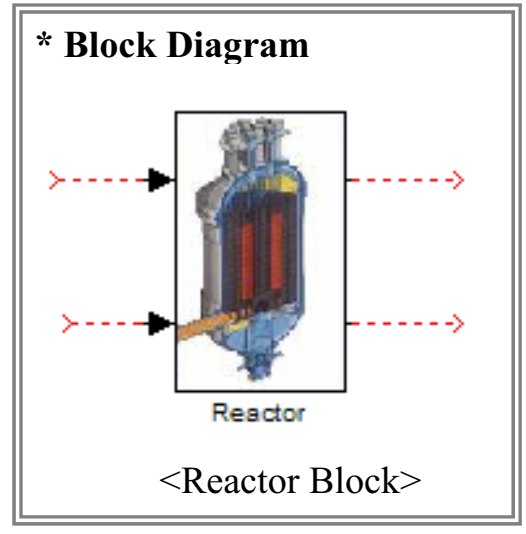

Reactor Block solves tritium behavior in the nuclear reactor. It consists of several model blocks. This block contains mass balance model blocks, core model block, permeation model block, leak model block and purification system model block. This component block has two inputs and two outputs.

Input-1 : tritium sources to core $\left[\mathrm{m}^{3}(\mathrm{STP}) / \mathrm{s}\right]$

Input-2 : in-flow variables (connected from upstream components) 
Output-1 : tritium permeation or leak rate to outside (connected to other components)

Output-2 : out-flow variables (connected to downstream components).

This component has lots of input parameters. By double-clicking the block icon, we can activate the input window to modify them. The detail configuration of the Reactor Block is shown in Figure 2-9. (For more information, please check the block inside.)

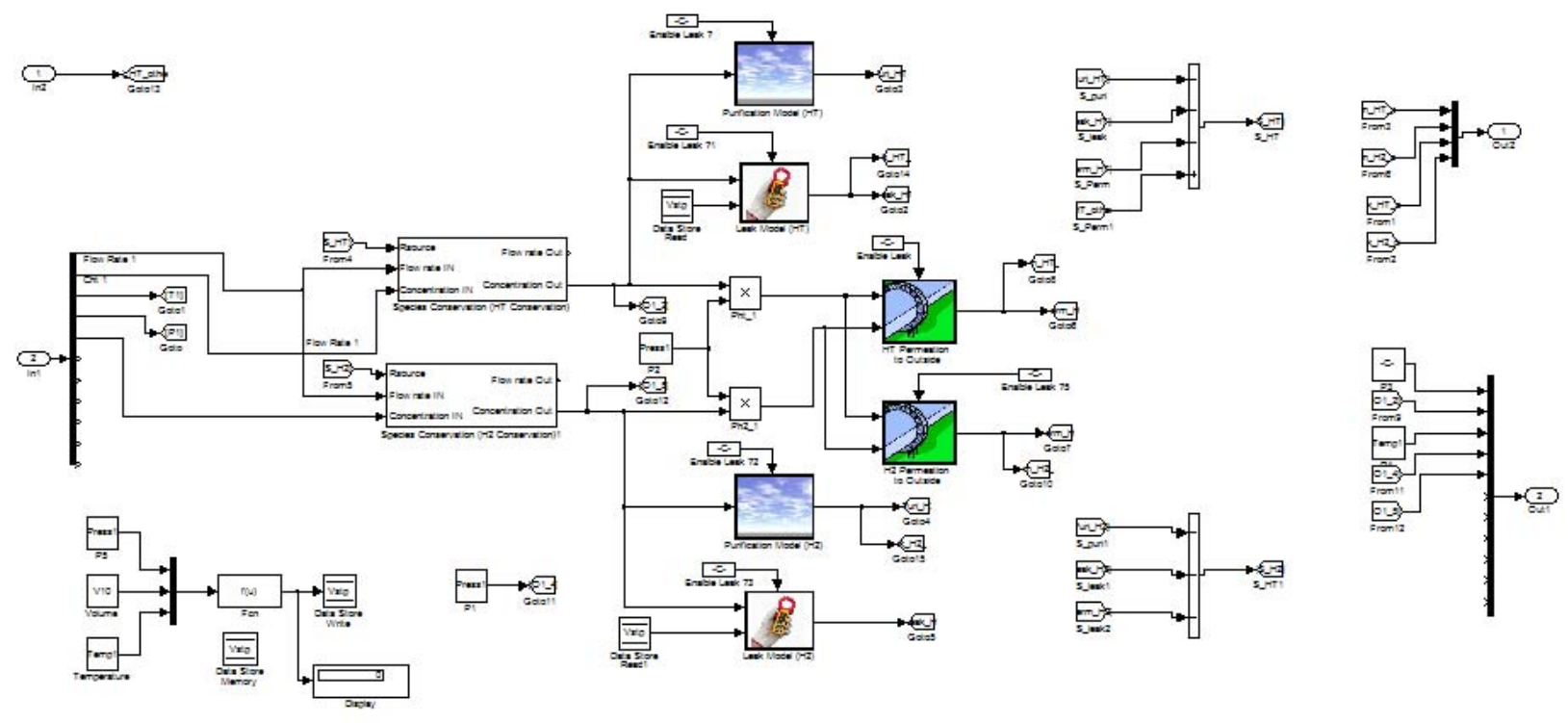

Figure 2-9. Internal block diagram of Reactor Block.

- $\quad$ Pipe Block

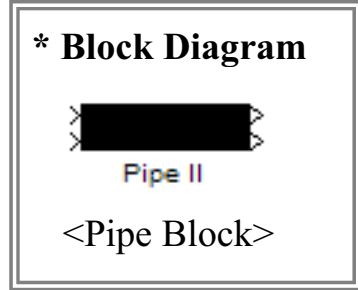

The Pipe Block solves tritium behavior in the pipe. It consists of several model blocks including mass balance model block, permeation model blocks, leak model blocks, and purification model blocks. This component block has two inputs and two outputs.

Input-1 : tritium or hydrogen sources into the pipe $\left[\mathrm{m}^{3}(\mathrm{STP}) / \mathrm{s}\right]$

Input-2 : in-flow variables (connected to other components)

Output-1 : tritium permeation or leak rate to outside $\left[\mathrm{m}^{3}(\mathrm{STP}) / \mathrm{s}\right]$

Output-2 : out-flow variables (connected to other components)

This block has lots of input parameters. By double-clicking the block icon, we can activate the input window to modify them. 


\section{- Storage Vessel Block}

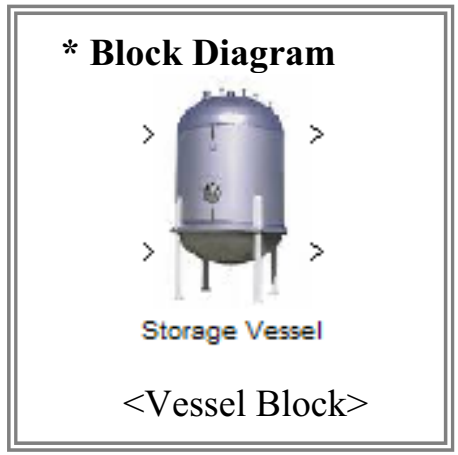

The Storage Vessel Block solves tritium behavior in the vessel. It contains several Model Blocks including mass balance model blocks, permeation model blocks, leak model blocks and purification model block. This component block has two inlets and two outlets.

Inlet-1 : tritium or hydrogen sources into the pipe $\left[\mathrm{m}^{3}(\mathrm{STP}) / \mathrm{s}\right]$

Inlet-2 : in-flow variables (connected to other components)

Outlet-1 : tritium permeation or leak rate to outside $\left[\mathrm{m}^{3}(\mathrm{STP}) / \mathrm{s}\right]$

Outlet-2 : out-flow variables (connected to other components)

This component has lots of input parameters. By double-clicking the block icon, we can activate the input window to modify them.

\section{- Heat Exchanger Block}

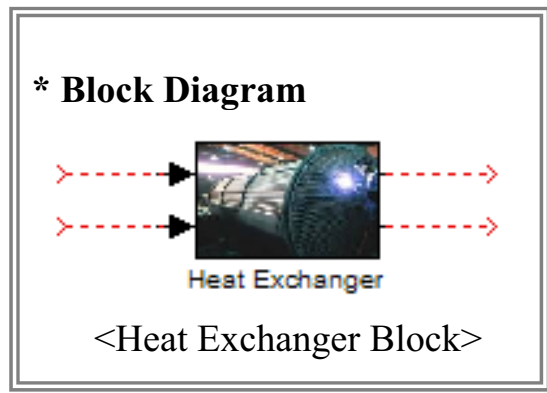

The Heat Exchanger Block solves tritium behavior in the heat exchanger. It consists of several model blocks especially focused on tritium and hydrogen penetration through the wall. This component block contains mass balance model blocks and permeation model blocks. This block has two inputs and two outputs.

Inlet-1 : in-flow variables 1 (connected to other components)

Inlet-2 : in-flow variables 2 (connected to other components)

Outlet-1 : out-flow variables 1 (connected to other components)

Outlet-2 : out-flow variables 2 (connected to other components) 
This component has lots of input parameters. By double-clicking the block icon, we can activate the input window to modify them. The detail configuration of the Reactor Block is shown in Figure 2-10. (For more information, please check the block inside.)
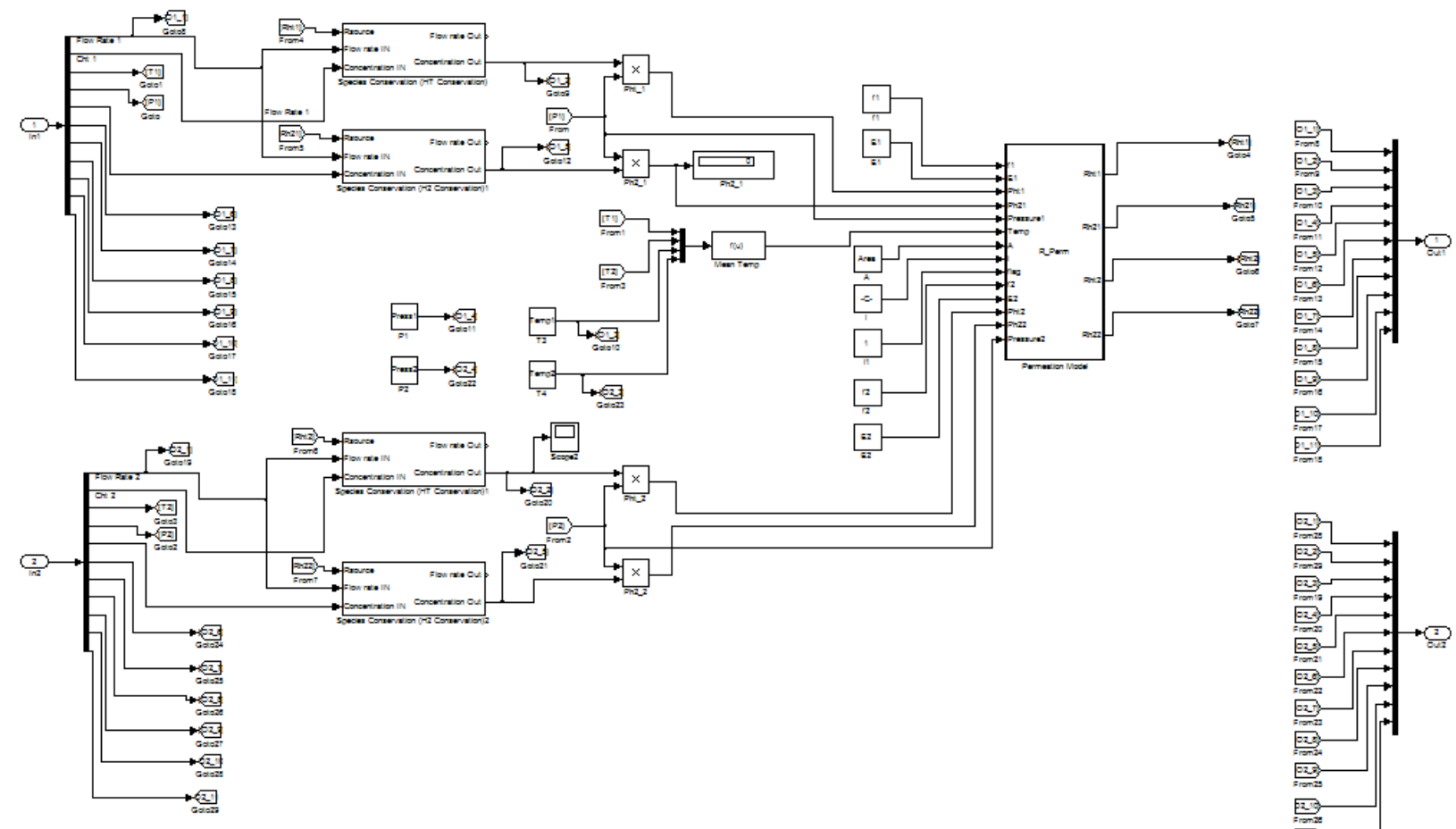

Figure 2-10. Internal block diagram of the Heat Exchanger Block.

\section{- Flow Splitter and Mixer Block}

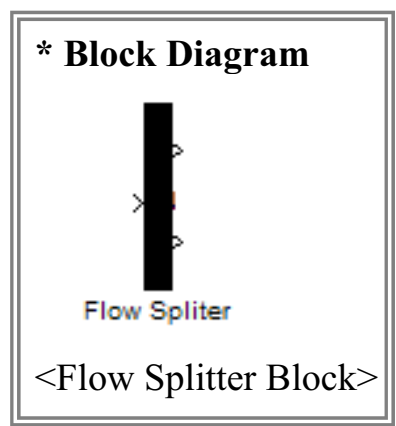

The Flow Splitter Block simply splits the flow into two subflows. It consists of one main stream input and two downstream outputs.
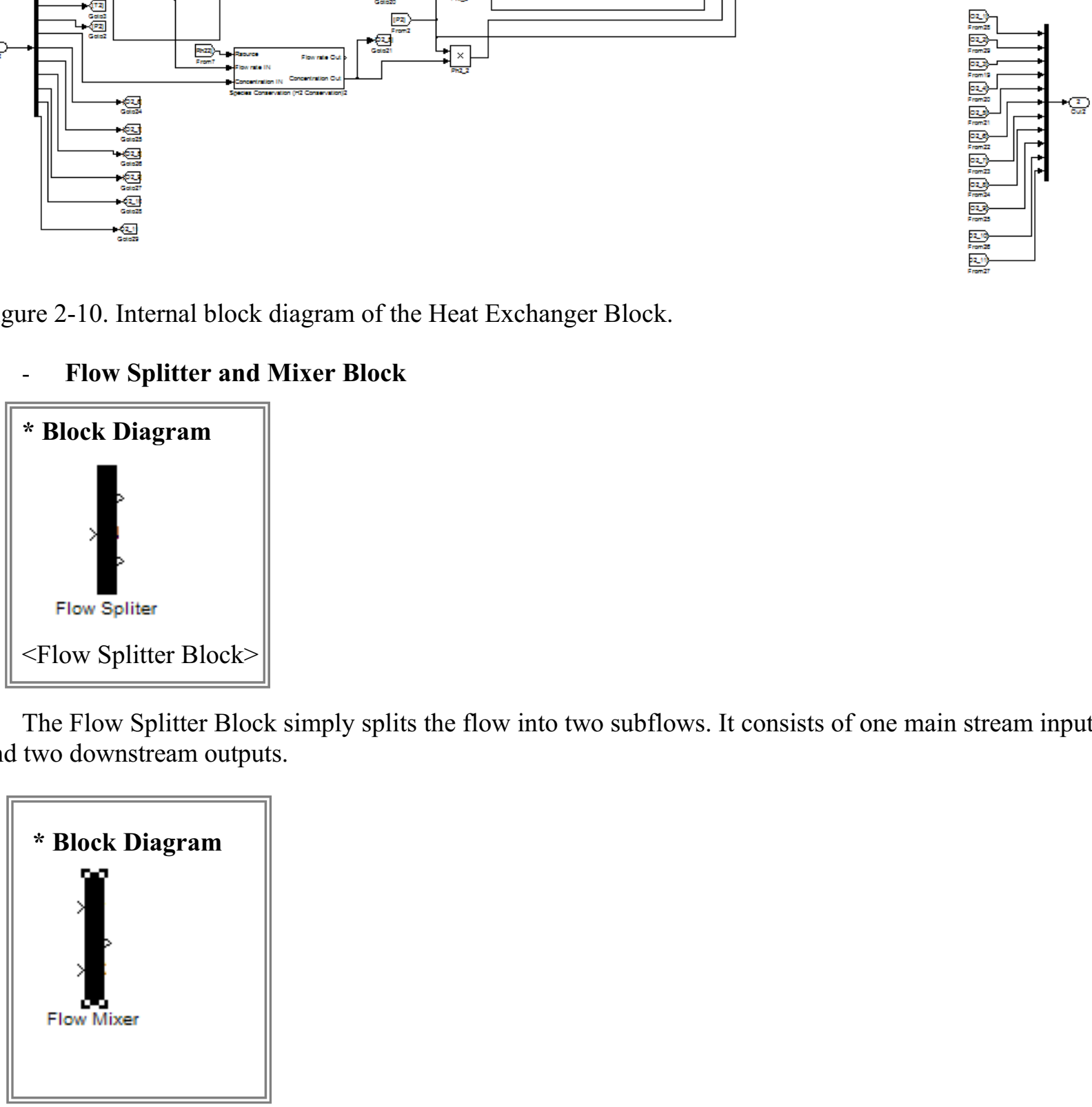


\section{$<$ Flow mixer Block $>$}

The Flow Mixer Block simply combines the two flows into one. It consists of two main stream inputs and one downstream output.

- Boundary Block

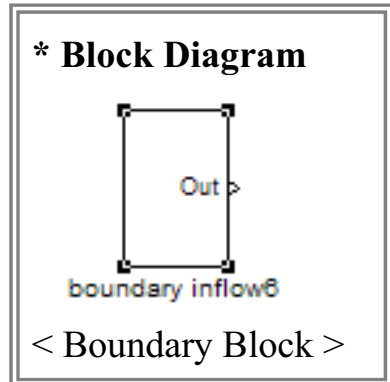

Boundary Block contains flow information. It is linked to other component blocks as a flow input.

\section{- Supportive Blocks}

Supportive Blocks handle and store the simulation data. This block can be linked to any components and linkage lines. It then captures the data from the linked components and export it to the files or graphical plots.

\section{- Detector Block}

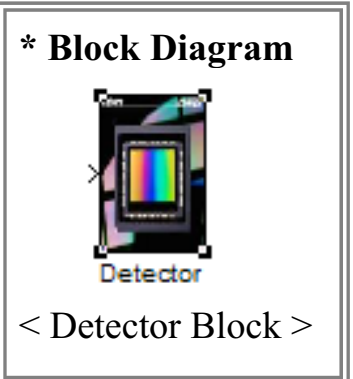

The Detector Block contains displays and plots flow variables. By double-clicking the block icon, the data on the flows or components can be accessed.

\subsubsection{GUI and Snapshot of the Tritium Behavior Analysis Tool}

Figure 2-11 shows the snapshot and user interface of the tritium analysis code. The upper part of the window contains all the system component blocks, which can be dragged and dropped to the work windows (the bottom window). By double-clicking the component icons, the component parameters and input data can be set up. This simple and easy interface is expected to save lots of time for developing input files, which were previously a text based job, consuming much time and efforts. 


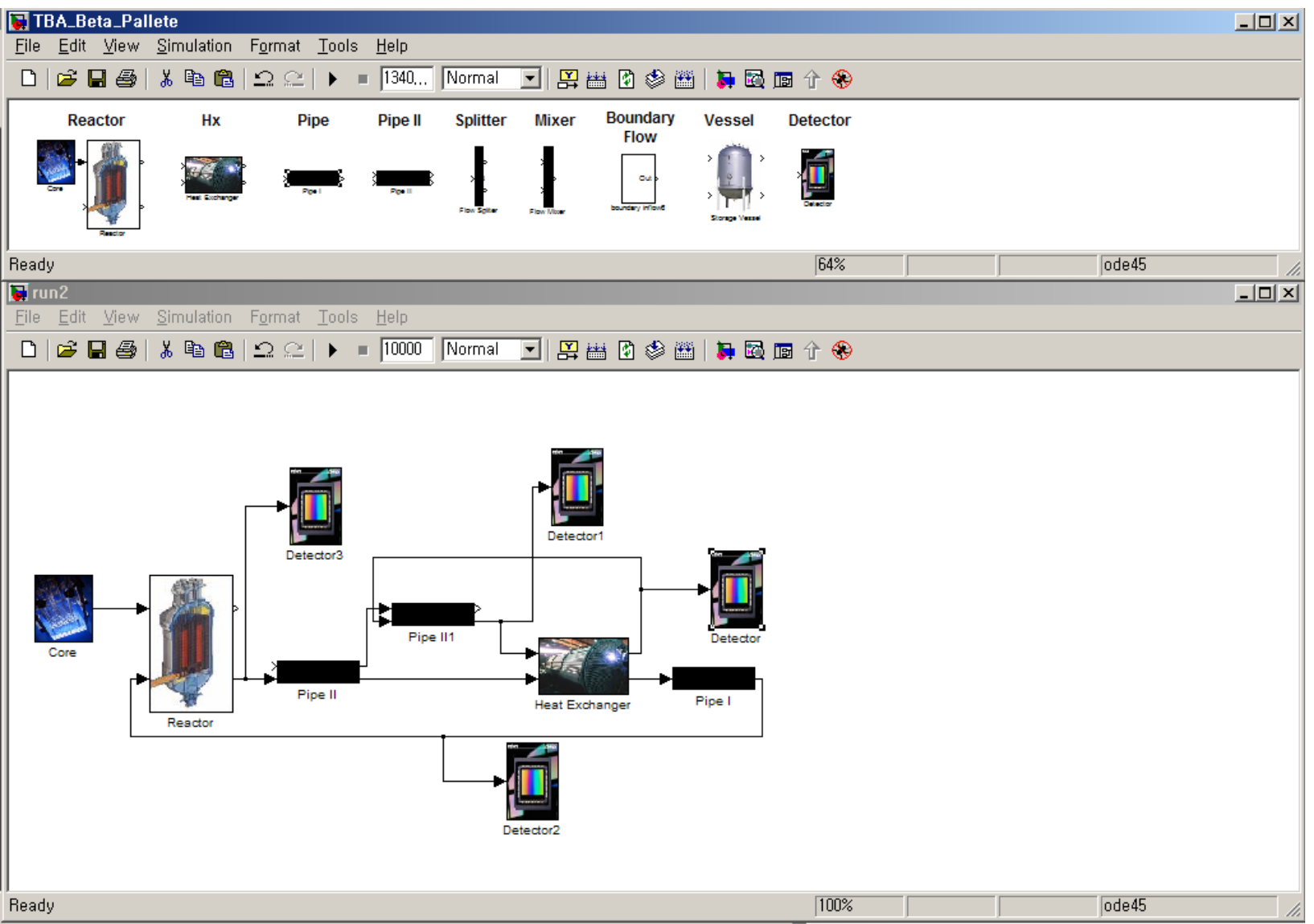

Figure 2-11. GUI and workspace of the current tritium behavior analysis code.

\subsection{Follow-up of THYTAN Verification Study}

This work paralleled the development of INL tritium behavior analysis code described in the previous section by performing some verification works of THYTAN code developed by Japan Atomic Energy Agency and used by Ohashi and Sherman (2007). In order to understand THYTAN code and the Tritium birth mechanism in the HTGR core, we followed up by using the same process used by Ohashi and Sherman (2006) for the Peach Bottom reactor (Scheffel, Baldwin, and Tomlin 1976; Wichner and Dyer 1979).

Figure 2-12 shows a schematic of the Peach Bottom primary loop. The primary circuit consisted of two loops, each containing a helium compressor and steam generator. The total helium flow of $210,000 \mathrm{~kg} / \mathrm{h}$ was divided equally between the two loops. Coolant temperatures at the core inlet and outlet of the rector vessel were 345 and $714^{\circ} \mathrm{C}$, respectively, and the primary loop pressure was approximately $2.4 \mathrm{MPa}(335 \mathrm{psig})$. The reactor and steam generator were connected by a concentric duct. Coolant exiting the reactor flows in the inner pipe of the concentric duct. The steam generators were forced recirculation, drum type boilers that have pendant U-tube economizer, evaporator, and superheater sections.

The tritium birth of the Peach Bottom HTGR at the Core 2 operation was evaluated by Wichner and Dyer (1979), and their data was used by Ohashi and Sherman (1979) to verify THYTAN code. Our calculation results about tritium birth in the reactor core were compared to the data reported by them. Finally, the THYTAN input for the Peach Bottom core was used as basic data for the core input designed for the VHTR with $600 \mathrm{MWt}$. 


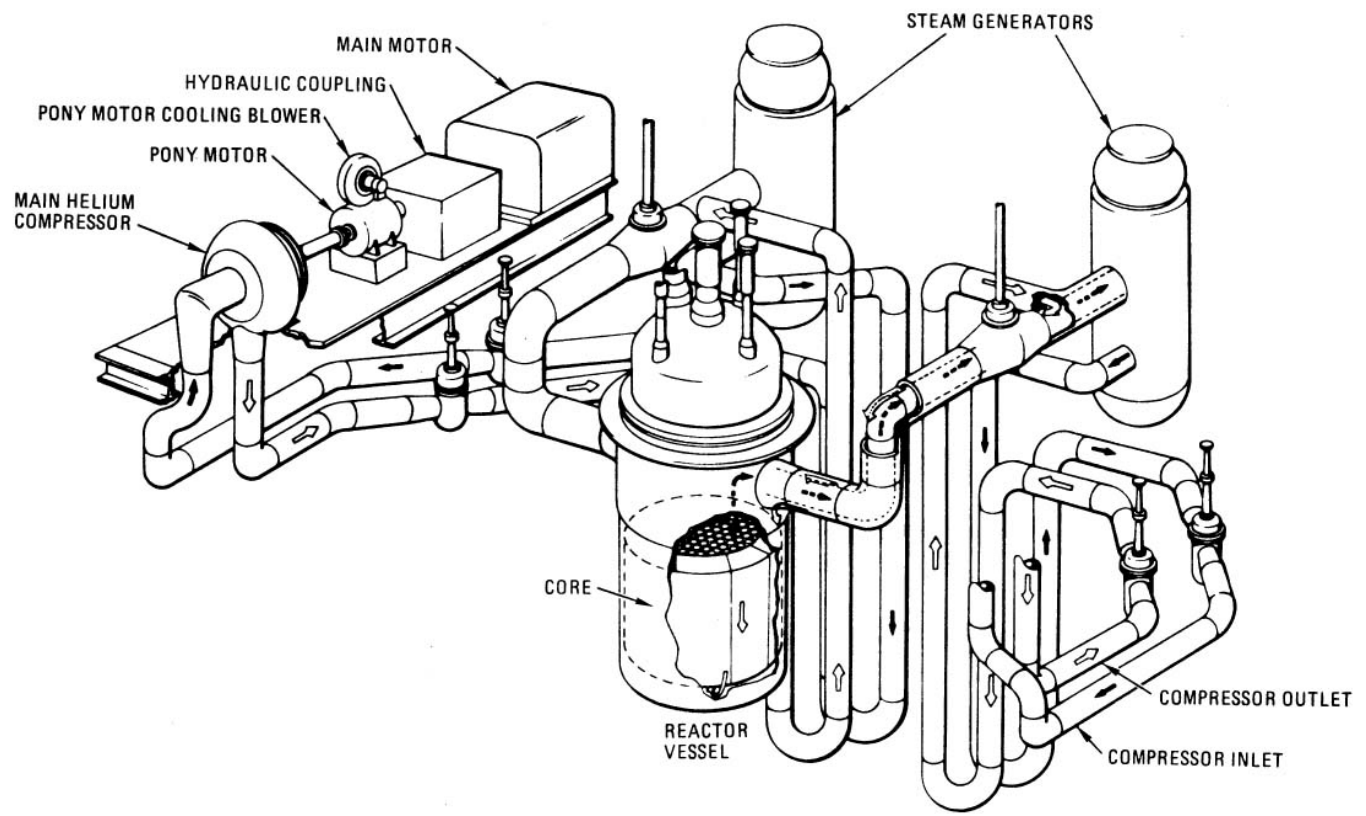

Figure 2-12. Primary coolant system of the Peach Bottom reactor (Wichner and Dyer 1979).

\subsubsection{Verification of Core Model}

Four main tritium sources were taken into consideration in our effort to verify THYTAN code.

- Birth of tritium by ternary fission

- Birth of tritium from lithium

- Birth of tritium from ${ }^{3} \mathrm{He}$ in the coolant

- Birth of tritium from ${ }^{10} \mathrm{~B}$.

\subsubsection{Birth from Ternary Fission}

The following analytical solution was used to estimate the tritium birth in fuel by ternary fission.

$N_{T}\left(t_{f}\right)=K \cdot \bar{P} \cdot Y\left(\frac{1-\exp \left(-\lambda \cdot t_{f}\right)}{\lambda}\right)$

where

$N_{T}\left(t_{f}\right)=$ atoms of tritium at time $t_{f}$

$K=$ fission rate per thermal megawatt $\left(3.121 \times 10^{16}\right.$ fissions $\left./ \mathrm{MW} / \mathrm{s}\right)$

$Y=$ average yield per fission $\left(1 \times 10^{-4}\right)$

$\lambda=$ tritium decay constant $\left(1.793 \times 10^{-19} \mathrm{~s}^{-1}\right)$.

An average power, $\bar{P}$ was calculated using the following equation.

$\bar{P}=P_{\text {rated }}\left(E F P D / t_{f}\right)$ 
where

$P_{\text {rated }}=$ rated power $(115 \mathrm{MWt})$

$E F P=$ equivalent full power days at $\mathrm{EOL}$ (897 days)

$t_{f}=$ duration of Core 2 operation, including shutdown $\left(1.34 \times 10^{8} \mathrm{~s}\right.$ or 1550 days $)$.

Table 2-1 summarizes the computed and reported results. The reported tritium birth by ternary fission during 1,550 days was $1,210 \mathrm{Ci}(=4.43 \mathrm{e} 13 \mathrm{~Bq})$. The calculated value by THYTAN shows very good agreement with the reported and analytical values.

Table 2-1. Comparison of tritium activity by ternary fission.

\begin{tabular}{|c|c|c|c|c|}
\hline \multicolumn{6}{|c|}{ Activity } \\
\hline $\begin{array}{c}\text { Reported Value } \\
(\text { Wichner and Dyer 1979) }\end{array}$ & $\begin{array}{c}\text { Analytical } \\
\text { Solution }\end{array}$ & $\begin{array}{c}\text { Computed Solution from } \\
\text { THYTAN (Ohashi and } \\
\text { Sherman 2007) }\end{array}$ & $\begin{array}{c}\text { Computed Solution } \\
\text { by Current Work }\end{array}$ \\
\hline$(\mathrm{Ci})$ & $(\mathrm{Bq})$ & $(\mathrm{Bq})$ & $(\mathrm{Bq})$ & $(\mathrm{Bq})$ \\
\hline 1,210 & $4.43 \times 10^{13}$ & $4.43 \times 10^{13}$ & $4.42 \times 10^{13}$ & $4.42 \times 10^{13}$ \\
\hline
\end{tabular}

\subsubsection{Birth from Lithium}

The birth of tritium from Lithium was estimated by the following analytical solution:

$$
N_{T}\left(t_{f}\right)=\left(\frac{\phi_{t h} \cdot \sigma_{L i 6 T} \cdot N_{6}(0)}{\lambda-\phi_{t h} \cdot \sigma_{L i 6 T}}\right) \cdot\left[\exp \left(-\phi_{t h} \cdot \sigma_{L i 6 T} \cdot t_{f}\right)-\exp \left(-\lambda \cdot t_{f}\right)\right]
$$

where

$$
\begin{aligned}
& N_{T}\left(t_{f}\right)=\text { atoms of tritium from }{ }^{6} \mathrm{Li} \text { at time } t_{f} \\
& \sigma_{L i 6 T}=\text { effective cross section for }{ }^{6} \mathrm{Li}(\mathrm{n}, \alpha) \mathrm{T}\left(4.08 \times 10^{-22} \mathrm{~cm}^{2}\right) \\
& N_{6}(0)=\text { initial amount of }{ }^{6} \mathrm{Li} \text { atoms. }
\end{aligned}
$$

Table 2-2 summarizes the reported and computed tritium activity. The parameters for the calculation of each graphite components are listed in Tables 2-3 and 2-4 (Ohashi and Sherman 2007). The radial reflector was not replaced at the end of the Core 1 operation. Therefore, the tritium activities in the removal radial reflector and the permanent radial reflector are calculated sequentially.

As reported by Ohashi and Sherman (2007), there were some unknown discrepancies between reported values and the THYTAN calculation that have not yet been revealed. Still, the computed solution by THYTAN showed good agreement with the analytical solution for each component. Our THYTAN solution shows very slight discrepancies with the values reported by Ohashi and Sherman because of the different time step size. However, the discrepancies were still within $1 \%$ of the analytical solution. 
Table 2-2. Comparison of tritium activity from $6 \mathrm{Li}$ at the Core 2 operation of the Peach Bottom reactor.

\begin{tabular}{|l|c|c|c|c|c|}
\hline \multirow{2}{*}{$\begin{array}{c}\text { Graphite } \\
\text { Component }\end{array}$} & \multicolumn{5}{|c|}{ Activity } \\
\hline & \multicolumn{2}{|c|}{ Reported Value } & $\begin{array}{c}\text { Analytical } \\
\text { Solution }\end{array}$ & $\begin{array}{c}\text { THYTAN } \\
\text { (Ohashi and } \\
\text { Sherman 2007) }\end{array}$ & $\begin{array}{c}\text { THYTAN } \\
(\text { Current Work) }\end{array}$ \\
\cline { 2 - 6 }$(\mathrm{Ci})$ & $(\mathrm{Bq})$ & $(\mathrm{Bq})$ & $(\mathrm{Bq})$ & $(\mathrm{Bq})$ \\
\hline Sleeve & 14.0 & $5.13 \times 10^{11}$ & $5.12 \times 10^{11}$ & $5.12 \times 10^{11}$ & $5.10 \times 10^{11}$ \\
\hline Spine & 1.0 & $3.66 \times 10^{10}$ & $3.78 \times 10^{10}$ & $3.78 \times 10^{10}$ & $3.77 \times 10^{11}$ \\
\hline $\begin{array}{l}\text { Removal radial } \\
\text { reflector }\end{array}$ & 16.4 & $6.01 \times 10^{11}$ & $5.76 \times 10^{11}$ & $5.75 \times 10^{11}$ & $5.74 \times 10^{11}$ \\
\hline $\begin{array}{l}\text { Permanent radial } \\
\text { reflector }\end{array}$ & 18.8 & $6.89 \times 10^{11}$ & $6.72 \times 10^{11}$ & $6.69 \times 10^{11}$ & $6.68 \times 10^{11}$ \\
\hline Axial reflector & 9.2 & $3.37 \times 10^{11}$ & $3.42 \times 10^{11}$ & $3.42 \times 10^{11}$ & $3.41 \times 10^{11}$ \\
\hline Fuel matrix & 13.1 & $4.80 \times 10^{11}$ & $5.68 \times 10^{11}$ & $5.68 \times 10^{11}$ & $5.67 \times 10^{11}$ \\
\hline
\end{tabular}

Table 2-3. Parameters for the calculation of tritium birth from ${ }^{6} \mathrm{Li}$ (Ohashi and Sherman 2007).

\begin{tabular}{|c|c|c|}
\hline Component & $\begin{array}{c}\text { Thermal Neutron Flux } \\
\left.\text { (neutrons } / \mathrm{cm}^{2} / \mathbf{s}\right)\end{array}$ & $\begin{array}{c}\text { Initial Amount of }{ }^{6} \mathrm{Li} \\
\text { (moles) }\end{array}$ \\
\hline Sleeve & $2.82 \times 10^{13}$ & $6.99 \times 10^{-4}$ \\
\hline Spine & $2.82 \times 10^{13}$ & $5.17 \times 10^{-5}$ \\
\hline \multirow{2}{*}{ Removal radial reflector } & Core $1: 2.57 \times 10^{13}$ & \multirow{2}{*}{$7.56 \times 10^{-4}$} \\
\hline & Core $2: 2.82 \times 10^{13}$ & \\
\hline \multirow{2}{*}{ Permanent radial reflector } & Core $1: 1.28 \times 10^{13}$ & \multirow{2}{*}{$1.12 \times 10^{-3}$} \\
\hline & Core $2: 1.41 \times 10^{13}$ & \\
\hline Axial reflector & $1.41 \times 10^{13}$ & $6.74 \times 10^{-4}$ \\
\hline Fuel matrix & $2.82 \times 10^{13}$ & $7.76 \times 10^{-4}$ \\
\hline
\end{tabular}

Table 2-4. Input data of THYTAN for calculation of tritium birth from ${ }^{6} \mathrm{Li}$ (Ohashi and Sherman 2007).

\begin{tabular}{|l|c|c|}
\hline \multicolumn{1}{|c|}{ Component } & $\begin{array}{c}\text { Lithium Concentration } \\
\text { (ppm) }\end{array}$ & $\begin{array}{c}\text { Graphite Weight } \\
\text { (kg) }\end{array}$ \\
\hline Sleeve & 0.007 & $9.37 \times 10^{3}$ \\
\hline Spine & 0.001 & $4.85 \times 10^{3}$ \\
\hline Removal radial reflector & 0.007 & $1.01 \times 10^{4}$ \\
\hline Permanent radial reflector & 0.007 & $1.50 \times 10^{4}$ \\
\hline Axial reflector & 0.007 & $9.03 \times 10^{3}$ \\
\hline Fuel matrix & 0.010 & $7.28 \times 10^{3}$ \\
\hline
\end{tabular}




\subsubsection{Birth from ${ }^{3} \mathrm{He}$ in the Coolant}

The birth of tritium from ${ }^{3} \mathrm{He}$ was estimated by the following analytical equations (Wichner and Dyer 1979).

$N_{T 1}=\frac{\left(V_{1}+V_{7}\right) \cdot \phi_{t h} \cdot \sigma_{H e 3 T} \cdot N_{3}}{Q+\lambda \cdot V}$

for the sleeve graphite

$$
N_{T 2}\left(t_{f}\right)=\frac{V_{3}}{V} \cdot \phi_{t h} \cdot \sigma_{H e 3 T} \cdot N_{3}\left[\frac{1-\exp \left(-\lambda \cdot t_{f}\right)}{\lambda}\right]
$$

for the removal radial reflector

$$
N_{T 3}\left(t_{f}\right)=\frac{V_{4}}{V} \cdot \phi_{t h} \cdot \sigma_{H e 3 T} \cdot N_{3}\left[\frac{1-\exp \left(-\lambda \cdot t_{f}\right)}{\lambda}\right]
$$

for the permanent radial reflector

$$
N_{T 4}\left(t_{f}\right)=\frac{V_{6}}{V} \cdot \phi_{t h, 3} \cdot \sigma_{H e 3 T} \cdot N_{3}\left[\frac{1-\exp \left(-\lambda \cdot t_{f}\right)}{\lambda}\right]
$$

for the axial reflector

$$
N_{T 5}\left(t_{f}\right)=\frac{V_{5}}{V} \cdot \phi_{t h, 2} \cdot \sigma_{H e 3 T} \cdot N_{3}\left[\frac{1-\exp \left(-\lambda \cdot t_{f}\right)}{\lambda}\right]
$$

where

$N_{T 1}=$ total moles of tritium circulating in the reactor with the coolant

$N_{T 2}=$ total moles of tritium born in the sleeve graphite from ${ }^{3} \mathrm{He}$

$N_{T 3}=$ total moles of tritium born in the removal radial reflector from ${ }^{3} \mathrm{He}$

$N_{T 4}=$ total moles of tritium born in the permanent reflector from ${ }^{3} \mathrm{He}$

$N_{T 5}=$ total moles of tritium born in the axial reflector from ${ }^{3} \mathrm{He}$

$V_{1}=$ volume of coolant passage in core $\left(1.77 \times 10^{6} \mathrm{~cm}^{3}\right)$

$V_{2}=$ ex-core primary system volume $\left(1.88 \times 10^{8} \mathrm{~cm}^{3}\right)$

$V_{3}=$ connected porosity in sleeve graphite $\left(3.44 \times 10^{5} \mathrm{~cm}^{3}\right)$

$V_{4}=$ connected porosity in removal radial reflector $\left(8.46 \times 10^{5} \mathrm{~cm}^{3}\right)$

$V_{5}=$ connected porosity in axial reflector $\left(3.92 \times 10^{5} \mathrm{~cm}^{3}\right)$

$V_{6}=$ connected porosity in permanent radial reflector $\left(2.32 \times 10^{6} \mathrm{~cm}^{3}\right)$

$V_{7}=$ purge flow volume within the fuel elements $\left(6.32 \times 10^{5} \mathrm{~cm}^{3}\right)$

$V=$ effective helium volume of the primary system

$$
\left(V_{1}+V_{2}+V_{3}+V_{4}+V_{5}+V_{6}\left[1.94 \times 10^{8} \mathrm{~cm}^{3}\right]\right)
$$


$\phi_{t h}=$ average thermal neutron flux in core and removal radial reflector, Core $2\left(2.82 \times 10^{13}\right.$ neutrons $\left./ \mathrm{cm}^{2} / \mathrm{s}\right)$

$\phi_{t h, 2}=$ average thermal neutron flux in axial reflector $\left(1.41 \times 10^{13}\right.$ neutrons $\left./ \mathrm{cm}^{2} / \mathrm{s}\right)$

$\phi_{t h, 3}=$ average thermal neutron flux in permanent radial reflector $\left(1.41 \times 10^{13}\right.$ neutrons $\left./ \mathrm{cm}^{2} / \mathrm{s}\right)$

$\sigma_{H e 3 T}=$ effective cross section for ${ }^{3} \mathrm{He}(\mathrm{n}, \mathrm{p}) \mathrm{T}\left(2.28 \times 10^{-21} \mathrm{~cm}^{2}\right)$

$Q=$ flow to chemical cleanup system plus $10 \%$ of fuel element purge flow $\left(Q_{1}\left(2.40 \times 10^{4} \mathrm{~cm}^{3} / \mathrm{s}\right)\right)+$ leakage flow rate from primary system $\left(Q_{2}\left[25.5 \mathrm{~cm}^{3} / \mathrm{s}\right]\right)$.

The total moles of ${ }^{3} \mathrm{He}$ in the primary system, $N_{3}$, is governed by the relation in the following equation:

$$
\frac{d N_{3}}{d t}=-\sigma_{H e 3 T} \cdot N_{3}\left\{\left(\frac{V_{1}+V_{3}+V_{4}+V_{7}}{V}\right) \cdot \phi_{t h}+\left(\frac{V_{5}+V_{6}}{V}\right) \cdot \phi_{t h, 2}\right\}+Q_{2}\left(\left[{ }^{3} \mathrm{He}\right]_{i}-\left[{ }^{3} \mathrm{He}\right]\right)
$$

where

$$
\begin{aligned}
& {\left[{ }^{3} \mathrm{He}\right]_{i}=} \begin{array}{l}
{ }^{3} \mathrm{He} \text { concentration in makeup helium }\left(5.78 \times 10^{-11} \mathrm{moles} / \mathrm{cm}^{3} \text { based on } 0.16 \mathrm{ppm}{ }^{3} \mathrm{He}\right. \text { in } \\
\text { helium })
\end{array} \\
& {\left[{ }^{3} \mathrm{He}\right]={ }^{3} \mathrm{He} \text { concentration in primary system }\left(=N_{3} / V\right) . }
\end{aligned}
$$

Table 2-5 summarizes the calculated tritium birth from ${ }^{3} \mathrm{He}$ in the Core 2 operation in the Peach Bottom reactor. The input parameters were summarized in Tables 2-6 and 2-7. Ohashi and Sherman (2007) reported that the values are larger than both analytical and computed solutions within 10-60\%. However, the reason is still unknown. On the other hand, the computed results show good agreement with analytical solutions.

Table 2-5. Comparison of tritium activity from ${ }^{3} \mathrm{He}$ at the Core 2 operation of the Peach Bottom HTGR.

\begin{tabular}{|l|c|c|c|c|c|}
\hline \multirow{2}{*}{\multicolumn{1}{c|}{ Region }} & \multicolumn{4}{c|}{ Activity } \\
\hline & \multicolumn{2}{|c|}{$\begin{array}{c}\text { Analytical } \\
\text { Seported Value }\end{array}$} & $\begin{array}{c}\text { THYTAN } \\
\text { (Ohashi and } \\
\text { Sherman 2007) }\end{array}$ & $\begin{array}{c}\text { THYTAN } \\
\text { (Current) }\end{array}$ \\
\cline { 2 - 6 } & $(\mathrm{Ci})$ & $(\mathrm{Bq})$ & $(\mathrm{Bq})$ & $(\mathrm{Bq})$ & $(\mathrm{Bq})$ \\
\hline In sleeve graphite & 5.4 & $1.98 \times 10^{11}$ & $1.31 \times 10^{11}$ & $1.26 \times 10^{11}$ & $1.26 \times 10^{11}$ \\
\hline In removal radial reflector & 13.5 & $4.95 \times 10^{11}$ & $3.20 \times 10^{11}$ & $3.09 \times 10^{11}$ & $3.09 \times 10^{11}$ \\
\hline $\begin{array}{l}\text { In permanent radial } \\
\text { reflector }\end{array}$ & 15.5 & $5.68 \times 10^{11}$ & $5.43 \times 10^{11}$ & $5.24 \times 10^{11}$ & $5.24 \times 10^{11}$ \\
\hline In axial reflector & 3.1 & $1.14 \times 10^{12}$ & $9.17 \times 10^{11}$ & $8.86 \times 10^{11}$ & $8.86 \times 10^{11}$ \\
\hline
\end{tabular}

Table 2-6. Input data of THYTAN for calculation of tritium birth from ${ }^{3} \mathrm{He}$ (Ohashi and Sherman 2007).

\begin{tabular}{l|l|l}
\hline \multicolumn{1}{c|}{ Parameter } & \multicolumn{1}{c}{ Unit } & \multicolumn{1}{c}{ Value } \\
\hline Effective cross section for ${ }^{3} \mathrm{He}(\mathrm{n}, \mathrm{p}) \mathrm{T}$ & $\mathrm{cm}$ & $2.28 \times 10^{-21}$ \\
\hline${ }^{3} \mathrm{He}$ concentration in makeup helium & $\mathrm{ppm}$ & 0.16 \\
\hline Helium inventory in primary system & $\mathrm{kg}$ & 269 \\
\hline
\end{tabular}


Table 2-7. Input data for the subnode of THYTAN for the calculation of tritium birth from ${ }^{3} \mathrm{He}$ (Ohashi and Sherman 2007).

\begin{tabular}{l|c|c}
\hline \multicolumn{1}{c|}{ Subnode } & $\begin{array}{c}\text { Thermal Neutron Flux } \\
(\text { neutrons/cm } / \mathbf{s})\end{array}$ & $\begin{array}{c}\text { Helium Inventory } \\
\text { (kg) }\end{array}$ \\
\hline In circulating coolant & $2.82 \times 10^{13}$ & 3.33 \\
\hline In sleeve graphite & $2.82 \times 10^{13}$ & 0.477 \\
\hline In removal radial reflector & $2.82 \times 10^{13}$ & 1.17 \\
\hline In permanent radial reflector & $1.41 \times 10^{13}$ & 3.22 \\
\hline In axial reflector & $1.41 \times 10^{13}$ & 0.543 \\
\hline
\end{tabular}

\subsubsection{Birth from ${ }^{10} B$}

The tritium birth from ${ }^{10} \mathrm{~B}$ was evaluated by the following equation:

$$
\begin{aligned}
\frac{N_{T}\left(t_{f}\right)}{N_{10}(0)}= & \frac{b \cdot a}{(b-a) \cdot(\lambda-a)}\left(\exp \left(-a \cdot t_{f}\right)-\exp \left(-\lambda \cdot t_{f}\right)\right) \\
& -\frac{b \cdot a}{(b-a) \cdot(\lambda-b)}\left(\exp \left(-b \cdot t_{f}\right)-\exp \left(-\lambda \cdot t_{f}\right)\right) \\
& +\frac{c}{(\lambda-a)}\left(\exp \left(-a \cdot t_{f}\right)-\exp \left(-\lambda \cdot t_{f}\right)\right)
\end{aligned}
$$

where

$$
\begin{array}{ll}
a & =\beta \phi_{t h} \sigma_{B 10 L i 7} \\
b & =\phi_{f} \sigma_{L i T T} \\
c & =\phi_{f} \sigma_{B 10 T} \\
\beta & =\text { self-shielding factor }(0.0141) \\
\phi_{t h} & =\text { average thermal neutron flux }\left(2.82 \times 10^{13} \text { neutrons } / \mathrm{cm}^{2} / \mathrm{s}\right) \\
\phi_{f} & =\text { average fast neutron flux }\left(2.26 \times 10^{13} \text { neutrons } / \mathrm{cm}^{2} / \mathrm{s}\right) \\
\sigma_{B 10 L i 7} & =\text { effective cross section for }{ }^{10} \mathrm{~B}(\mathrm{n}, \alpha){ }^{7} \mathrm{Li}\left(1.63 \times 10^{-21} \mathrm{~cm}^{2}\right) \\
\sigma_{L i 7 T} & =\text { effective cross section for }{ }^{7} \mathrm{Li}(\mathrm{n}, \mathrm{n} \alpha){ }^{3} \mathrm{H}\left(1.53 \times 10^{-25} \mathrm{~cm}^{2}\right) \\
\sigma_{B 10 T}= & \text { effective cross section for }{ }^{10} \mathrm{~B}(\mathrm{n}, 2 \alpha){ }^{3} \mathrm{H}\left(5.00 \times 10^{-26} \mathrm{~cm}^{2}\right) \\
N_{10}(0) & =\text { initial amount of }{ }^{10} \mathrm{~B} \text { atoms }(20.15 \mathrm{moles}) .
\end{array}
$$

Tritium from ${ }^{10} \mathrm{~B}$ is produced in the poisoned spine and in the control rod. However, since the boron level and control rod position varies with time in the control rod, only poisoned spine was taken into consideration here. Table 2-8 shows the calculation result and reported values. Computed values show good agreement with the analytical solutions. 
Table 2-8. Comparison of tritium activity from ${ }^{10} \mathrm{~B}$ in the poisoned spine at the Core 2 operation of Peach Bottom reactor.

\begin{tabular}{|c|c|c|c|c|}
\hline \multicolumn{5}{|c|}{ Activity } \\
\hline \multicolumn{2}{|c|}{ Reported Value } & $\begin{array}{c}\text { Analytical } \\
\text { Solution }\end{array}$ & $\begin{array}{c}\text { THYTAN } \\
\text { (Ohashi and } \\
\text { Sherman 2007) }\end{array}$ & $\begin{array}{c}\text { THYTAN } \\
(\text { Current Work) }\end{array}$ \\
\hline$(\mathrm{Ci})$ & $(\mathrm{Bq})$ & $(\mathrm{Bq})$ & $(\mathrm{Bq})$ & $(\mathrm{Bq})$ \\
\hline 85.7 & $3.14 \times 10^{12}$ & $3.19 \times 10^{12}$ & $3.18 \times 10^{12}$ & $3.18 \times 10^{12}$ \\
\hline
\end{tabular}

\subsubsection{Verification of Permeation Model}

The tritium permeation rate of the heat transfer tubing obtained from the Peach Bottom HTGR steam generator at the end of life was reported by Yang, Baugh, and Baldwin (1977). The reported permeation rate, J, of the Incoloy 800 super-heater tubing, steel evaporator tubing, and low-carbon steel economizer are as follows:

for the economizer

$J=7.78 \times 10^{1} \cdot \exp (-4500 / T)(493 \mathrm{~K}-623 \mathrm{~K})\left[\mu \mathrm{Ci} / \mathrm{m}^{2} / \mathrm{h}\right]$

for the evaporator

$J=6.97 \times 10^{3} \cdot \exp (-6830 / T)(573 \mathrm{~K}-693 \mathrm{~K})\left[\mu \mathrm{Ci} / \mathrm{m}^{2} / \mathrm{h}\right]$

for the superheater

$J=1.72 \times 10^{3} \cdot \exp (-6440 / T)(673 \mathrm{~K}-973 \mathrm{~K})\left[\mu \mathrm{Ci} / \mathrm{m}^{2} / \mathrm{h}\right]$.

Calculation of the tritium permeation rate for the superheater, evaporator, and economizer was carried out by THYTAN using both permeation rates and compared to the reported correlations. Table 2-9 shows the size and dimension of the heat exchangers. The experimental conditions - tritium concentration in the feed side of $0.461 \mathrm{ppb}$, feed helium pressure of $0.1013 \times 10^{5} \mathrm{~Pa}$, and the permeation chamber pressure of $1.33 \times 10^{-3} \mathrm{~Pa}$-were employed as boundary conditions. The effect of impurity hydrogen was ignored. The hydrogen concentration of $199 \mathrm{ppm}$ was assumed for the boundary condition for the primary side.

Table 2-9. The heat transfer tube dimensions of the steam generator in the Peach Bottom reactor (Ohashi and Sherman 2007).

\begin{tabular}{l|c|c|c}
\hline \multicolumn{1}{c|}{ Sample } & $\begin{array}{c}\text { Effective Area } \\
\left(\mathbf{m}^{\mathbf{2}}\right)\end{array}$ & $\begin{array}{c}\text { Outer Radius } \\
(\mathbf{m})\end{array}$ & $\begin{array}{c}\text { Inner Radius } \\
(\mathbf{m})\end{array}$ \\
\hline Economizer (inlet) & $103.47 \times 10^{-4}$ & $9.525 \times 10^{-3}$ & $7.300 \times 10^{-3}$ \\
\hline Evaporator (inlet) & $68.34 \times 10^{-4}$ & $6.350 \times 10^{-3}$ & $4.775 \times 10^{-3}$ \\
\hline Superheater (inlet) & $90.16 \times 10^{-4}$ & $9.525 \times 10^{-3}$ & $6.350 \times 10^{-3}$ \\
\hline
\end{tabular}

Table 2-10 summarizes the analytical solutions of Equations (2-40) through (2-42) and the computed results. As shown in this table, the computed solution is in good agreement with the analytical solution. 
Table 2-10. Comparison of permeation rate.

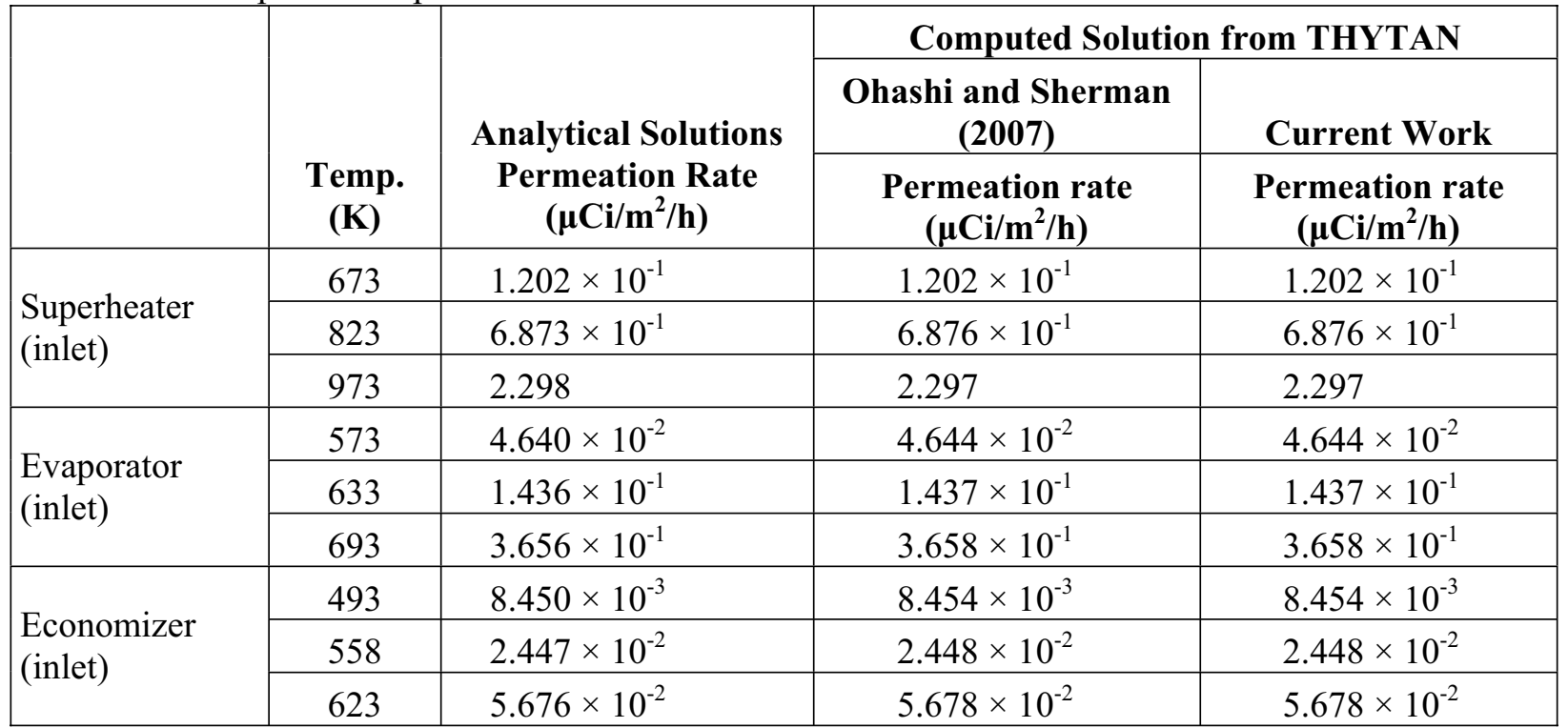

\subsubsection{Verification of Leak Model}

In order to verify the leak model of THYTAN, the tritium concentration in the containment vessel was estimated by THYTAN, using the reported leak rate and the tritium concentration in the primary loop as Ohashi and Sherman (2007) did. The numerical analysis result from THYTAN on the tritium concentration in the containment vessel was compared with the experimental result and the reported analytical solution. Figure 2-13 shows the calculation of leakage by THYTAN code.

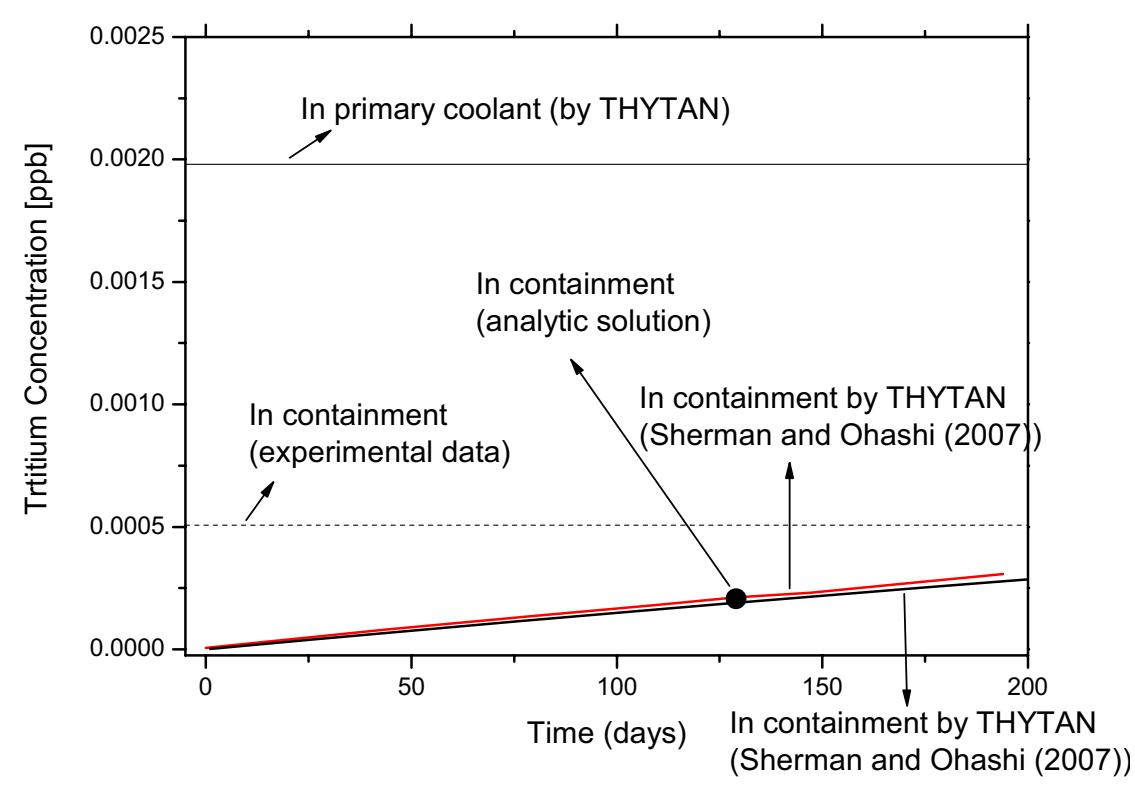

Figure 2-13. Comparison of tritium concentrations in the containment vessel of the Peach Bottom reactor. 
The input data of THYTAN is summarized in Table 2-11. Because information on the containment vessel temperature is not available, the average containment vessel temperature is assumed to be $323 \mathrm{~K}$. The tritium concentration in the primary loop of $2 \times 10^{5} \mu \mathrm{Ci} / \mathrm{cm}^{3}$ corresponds to $1.98 \times 10^{3} \mathrm{ppb}$ under the reported average temperature of $809 \mathrm{~K}$ and a pressure of $23 \mathrm{~atm}$ in the primary coolant. In order to keep the tritium concentration in the primary coolant $1.98 \times 10^{3} \mathrm{ppb}$, the tritium release rate to the primary coolant was adjusted by the core model. The initial concentration of tritium in the containment vessel was set at 0 .

As a result, the computed tritium concentration by THYTAN code showed good agreement with analytical solutions. However, the computed solutions were less than the reported experimental data observed in 1971 during the special tritium survey.

Table 2-11. Input data of THYTAN for verification of the leak model (Ohashi and Sherman 2007).

\begin{tabular}{|c|c|c|}
\hline Parameter & Unit & Value \\
\hline Leak rate from primary to containment vessel & $1 / \mathrm{h}$ & $4.15 \times 10^{-4 \mathrm{a}}$ \\
\hline Primary loop volume & $\mathrm{m}^{3}$ & 232 \\
\hline Primary loop pressure & $\mathrm{Pa}$ & $2.33 \times 10^{6 \mathrm{~b}}$ \\
\hline Primary loop temperature & $\mathrm{K}$ & 809 \\
\hline Leak rate from containment vessel to atmosphere & $1 / \mathrm{h}$ & $4.17 \times 10^{-4 c}$ \\
\hline Containment vessel volume & $\mathrm{m}^{3}$ & $1.56 \times 10^{4 \mathrm{~d}}$ \\
\hline Containment vessel pressure & $\mathrm{Pa}$ & $1.57 \times 10^{5 \mathrm{e}}$ \\
\hline Containment vessel temperature & $\mathrm{K}$ & $323^{f}$ \\
\hline \multicolumn{3}{|c|}{$\begin{array}{l}\text { a. Based on } 3.2 \mathrm{~kg} / \text { day. } \\
\text { b. Based on } 23 \mathrm{~atm} \text {. } \\
\text { c. Based on } 0.1 \% \text { day. } \\
\text { d. Based on a nitrogen volume of } 2.04 \times 104 \mathrm{~m}^{3} \text { at a pressure of } 1.57 \times 10^{5} \mathrm{~Pa} \text { and assumed temperature of } 323 \mathrm{~K} \text {. } \\
\text { e. Based on } 8 \text { psig. } \\
\text { f. Assumed. }\end{array}$} \\
\hline
\end{tabular}

\subsubsection{Verification of Purification System Model}

The purification system model was verified by the following simple analytical equation:

$$
\begin{aligned}
V_{j} \frac{d C_{i, j}}{d t} & =-R_{P F, i, j} \\
& =-F_{P F, H e} \cdot \eta_{i} \cdot C_{i, j} .
\end{aligned}
$$

The solution for $C_{i, j}$ is found in the following equation:

$C_{i, j}(t)=C_{0, i, j} \cdot \exp \left(-\frac{F_{P F, H e} \cdot \eta_{i}}{V_{j}} \cdot t\right)$

where

$C_{0, i, j}=$ initial concentration of chemical $\mathrm{i}$ in node $\mathrm{j}\left[\mathrm{m}^{3}(\mathrm{STP}) / \mathrm{m}^{3}(\mathrm{STP})\right]$.

Table 2-13 summarizes the boundary conditions for verification of the purification system model. The HT concentration was calculated during 3,000 sec. 
Table 2-12. THYTAN boundary conditions for verification of the purification system model (Ohashi and Sherman 2007).

\begin{tabular}{l|l|l|l}
\hline \multicolumn{1}{c|}{ Parameter } & \multicolumn{1}{c|}{ Symbol } & \multicolumn{1}{c}{ Unit } & \multicolumn{1}{c}{ Value } \\
\hline Inventory & $V_{j}$ & $\mathrm{~m}^{3}(\mathrm{STP})$ & 1 \\
\hline $\begin{array}{l}\text { Helium flow rate at purification } \\
\text { system }\end{array}$ & $F_{P F, H e}$ & $\mathrm{~m}^{3}(\mathrm{STP})$ & $1.0 \times 10^{-3}$ \\
\hline $\begin{array}{l}\text { Fractional efficiency of purification } \\
\text { system for HT }\end{array}$ & $\eta_{H T}$ & - & 0.9 \\
\hline \begin{tabular}{l} 
Initial concentration of HT \\
\hline
\end{tabular} & $C_{0, H T, j}$ & $\mathrm{~m}^{3}(\mathrm{STP}) / \mathrm{m}^{3}(\mathrm{STP})$ & $1.0 \times 10^{-9}$ \\
\hline
\end{tabular}

Figure 2-14 shows the comparisons between analytical solution and computational results by THYTAN. As shown in this figure, both the analytical solution and the THYTAN results are in good agreement.

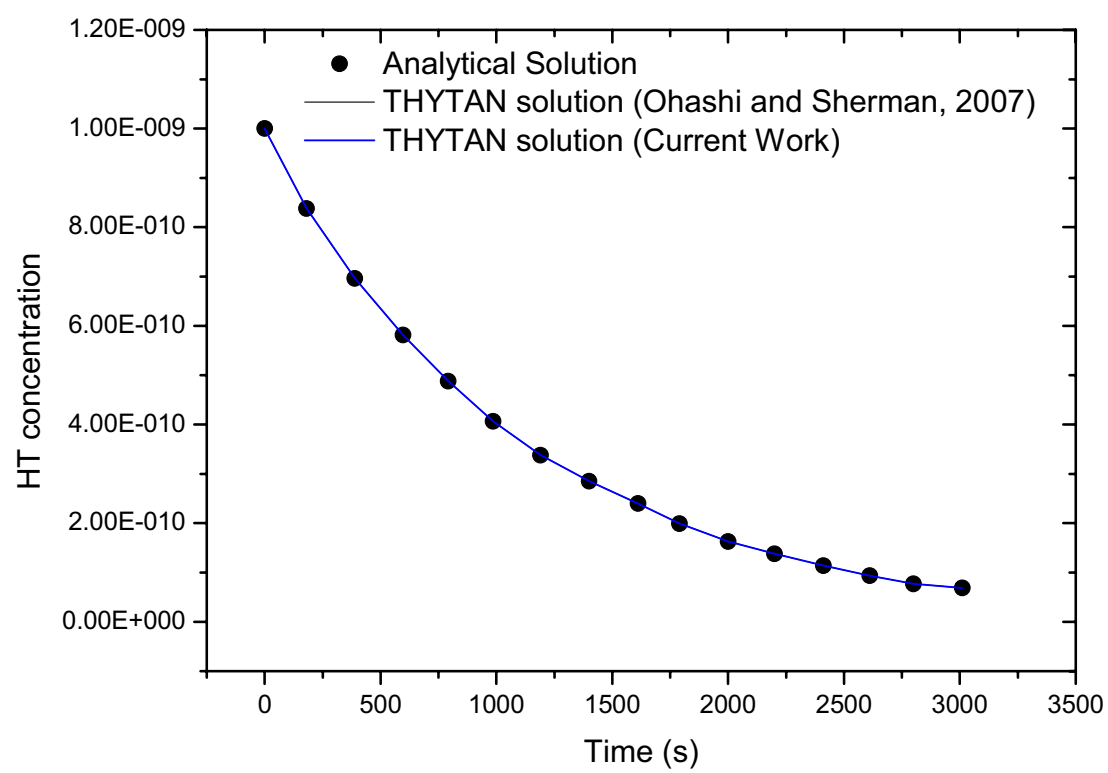

Figure 2-14. Comparisons between analytical solution and THYTAN results for verification of the purification system.

\subsection{Development of THYTAN Core Input for Transient Analysis of VHTR Tritium Behaviors}

For simplicity, Ohashi and Sherman's (2006) previous tritium analysis of NGNP systems assumed that the tritium generation from the reactor core was to be constant based on the average tritium generation data from other HTGRs. However, because impurities and system conditions are continuously changing during plant operation, the tritium generation should be considered time variant functions for dynamic simulations. Lots of additional data are required for dynamic simulation, including tritium source terms, component sizes, and details of plant operating history and conditions. In this fiscal year, we developed a THYTAN VHTR core input file for later transient simulation by upgrading Ohashi and Sherman's steady-state input. 
As previously described, tritium is produced in the VHTR by various sources such as ternary fissions and activation reactions with impurities and boron in the materials. The helium coolant itself is also a tritium source in the form of neutron absorbing nuclide ${ }^{3} \mathrm{He}$ with its extremely low isotope abundance. Table 2-13 summarizes the tritium production reaction and cross section (Wichner 1979).

Table 2-13. Tritium production reaction and cross section (Wichner 1979).

\begin{tabular}{|l|c|c|}
\hline \multicolumn{1}{|c|}{ Production Reaction } & Cross section (barns) & Energy range (eV) \\
\hline${ }^{3} \mathrm{He}(\mathrm{n}, \mathrm{p}) \mathrm{T}$ & 2,280 & $0-2.38$ \\
\hline${ }^{6} \mathrm{Li}(\mathrm{n}, \mathrm{a}) \mathrm{T}$ & 408 & $0-2.38$ \\
\hline${ }^{10} \mathrm{~B}(\mathrm{n}, 2 \mathrm{a}) \mathrm{T}$ & 0.050 & $>0.18 \times 10^{6}$ \\
\hline${ }^{10} \mathrm{~B}(\mathrm{n}, \mathrm{a}){ }^{7} \mathrm{Li}$ & 1,630 & $0-2.38$ \\
\hline${ }^{7} \mathrm{Li}(\mathrm{n}, \mathrm{n}$ ' $\mathrm{a}) \mathrm{T}$ & 0.153 & $>0.18 \times 10^{6}$ \\
\hline
\end{tabular}

Compared with these sources, the contributions of other tritium producing reactions with nuclides such as ${ }^{9} \mathrm{Be}$ or ${ }^{12} \mathrm{C}$ are negligible (Steinwarz et al. 1984).

\subsubsection{Input Parameters for Tritium Source from Ternary Fission}

If we assume an average yield (Y) of tritium atoms per fission, the tritium production rate from fission can be expressed as

$$
\frac{d N_{T}(t)}{d t}=K Y P(t)-\lambda N_{T}(t)
$$

where

$$
\begin{array}{ll}
N_{T}(t) & =\text { atoms of tritium at time } \mathrm{t} \\
K & =\text { fission rate per thermal megawatt }\left(=3.121 \times 10^{16} \text { fissions } / \mathrm{sec} \mathrm{MWt}\right) \\
P(t) & =\text { power at time } \mathrm{HWt}) \\
\lambda & =\text { decay constant }\left(1.793 \times 10^{-9} \mathrm{sec}^{-1}\right) \\
\mathrm{Y} & =\text { average yield per fission }\left(1 \times 10^{-4}\right) .
\end{array}
$$

Table 2-14 summarizes the necessary information for tritium source of ternary fission.

Table 2-14. Basic data for THYTAN evaluation of ternary fission.

\begin{tabular}{|l|l|c|}
\hline & \multicolumn{1}{|c|}{ Unit } & Values \\
\hline Reactor Power (P) & MWt & 600 \\
\hline Fission Rate (K) & Fissions/MW sec & $3.12 \mathrm{e} 16$ \\
\hline Average Yield Per Fission (Y) & 1/fission & $1.0 \mathrm{e}-4$ \\
\hline Failure Fraction of Fuel Particles & - & 0.3 \\
\hline
\end{tabular}

\subsubsection{Input Parameters for Tritium Source from ${ }^{3} \mathrm{He}$ in the Coolant}

Tritium is produced from ${ }^{3} \mathrm{He}$ via an $(\mathrm{n}, \mathrm{P})$ reaction with thermal neutrons. The level of ${ }^{3} \mathrm{He}$ contamination in commercially available sources varies, but in general, helium from natural gas wells contains approximately $0.2 \mathrm{ppm}$, while the ${ }^{3} \mathrm{He}$ level in the atmospheric is about 10 times higher than that (Steinwarz et al. 1980). Hence, this report assumes the ${ }^{3} \mathrm{He}$ supply level to be $0.2 \mathrm{ppm}$. 
Generally, the He coolant suffers from leakage during routine operations. In Dragon, the leak rate reached $2.0 \mathrm{~kg} /$ day at the beginning of 1974 and after months of research a number of leaks were found in the stainless steel pipe work leading to the helium purification plant (Simon et. al. 1980). To compensate for helium leaks, fresh helium should be continuously added to the primary circuit. In this work, the tritium leakage rate and total helium inventory were assumed to be $0.01 \% /$ day $\left(1.57 \mathrm{e}-9 \mathrm{sec}^{-1}\right)$ and $4,535 \mathrm{~kg}$, respectively (Yook 2007).

The inventory of the primary system includes the coolant passages between the fuel elements $\left(\mathrm{V}_{1}\right)$, and the piping, plenums, and steam-generator tubing forming the ex-core primary system volume $\left(\mathrm{V}_{2}\right)$. In addition, the connected porosity in portions of the graphite core components is readily accessible to ${ }^{3} \mathrm{He}$ permeation $\left(\mathrm{V}_{2}, \mathrm{~V}_{3}, \mathrm{~V}_{5}, \mathrm{~V}_{6}\right.$ and $\left.\mathrm{V}_{7}\right)$. Therefore, the effective He volume of the primary system includes

$$
V=V_{1}+V_{2}+V_{3}+V_{4}+V_{5}+V_{6}
$$

where

$V_{1}=$ Volume of coolant passages in core

$V_{2}=$ ex-core primary system volume

$V_{3}=$ connected porosity in sleeve graphite

$V_{4}=$ connected porosity in removable radial reflector

$V_{5}=$ connected porosity in axial reflector

$V_{6}=$ connected porosity in permanent radial reflector

Tables 2-15 and 2-16 summarize the parameters used for estimating tritium production from ${ }^{3} \mathrm{He}$ in this work (Yook 2007).

Table 2-15. Basic data for THYTAN evaluation of ${ }^{3} \mathrm{He}$ Source.

\begin{tabular}{|l|l|l|}
\hline & \multicolumn{1}{|c|}{ Unit } & \multicolumn{1}{c|}{ Values } \\
\hline Primary Helium Inventory & $\mathrm{kg}$ & 4,536 \\
\hline Helium Supply Rate & $1 / \mathrm{sec}$ & $1.57 \mathrm{e}-9$ \\
\hline${ }^{3} \mathrm{He}$ Concentration in Supply Helium & $\mathrm{ppm}$ & 0.2 \\
\hline
\end{tabular}

Table 2-16. Parameters used for estimating tritium production from ${ }^{3} \mathrm{He}$.

\begin{tabular}{|l|c|c|c|}
\hline & $\begin{array}{c}\text { Inventory } \\
(\mathbf{k g})\end{array}$ & $\begin{array}{c}\text { Thermal Neutron Flux } \\
\left(\mathbf{n} / \mathbf{c m}^{2} \mathbf{s e c}\right)\end{array}$ & $\begin{array}{c}\text { Ratio of release } \\
\text { to birth rate }\end{array}$ \\
\hline Coolant Passage in the Core $\left(\mathrm{V}_{1}\right)$ & 109 & $3.73 \mathrm{e} 13$ & 1.0 \\
\hline Ex-core Loop $\left(\mathrm{V}_{2}\right)$ & 4370 & 0 & 1.0 \\
\hline Central Graphite Passage $\left(\mathrm{V}_{3}\right)$ & 0 & $3.73 \mathrm{e} 13$ & 1.0 \\
\hline Removal Passage $\left(\mathrm{V}_{4}\right)$ & 21 & $3.73 \mathrm{e} 13$ & 1.0 \\
\hline Axial Passage $\left(\mathrm{V}_{5}\right)$ & 39 & $3.73 \mathrm{e} 13$ & 1.0 \\
\hline Permanent Passage $\left(\mathrm{V}_{6}\right)$ & 0 & $3.73 \mathrm{e} 13$ & 1.0 \\
\hline Purge Flow Passage $\left(\mathrm{V}_{7}\right)$ & 0 & $3.73 \mathrm{e} 13$ & 1.0 \\
\hline
\end{tabular}

Tritons from the ${ }^{3} \mathrm{He}(\mathrm{n}, \mathrm{p}) \mathrm{T}$ reaction in the primary coolant will come to rest in solids as fractions, which vary from region to region depending on the space associated with channels and fabricated holes, clearance annuli, and pores (GA 2006). 
The recoil energy of a triton is about $0.2 \mathrm{MeV}$ leading to an estimated range of $0.05 \mathrm{~cm}$ in helium at $47.6 \mathrm{~atm}$ and $1,000^{\circ} \mathrm{C}$. In the case of pores, because they are generally smaller than $0.05 \mathrm{~cm}$, the fraction bound is taken as unity (GA 2006). A planar approximation is used for the clearance annuli (tolerances between graphite blocks or between the fuel rods and the graphite blocks containing them). If the width of the gap exceeds the recoil range,

Fraction Bound $=$ range $/(2 \cdot$ width $)$, range $<$ width ,

If the width of the gap is less than the recoil range,

Fraction Bound $=($ range - width $/ 2) /$ range, range $>$ width

For large cylindrical channels or holes,

Fraction Bound = range/ channel diameter

The fraction bound for this work was determined to be 0.025 by Equation (2-49); therefore, the release rate is 0.975 .

\subsubsection{Input Parameters for Tritium Source from Li in Graphite}

The necessary parameter for Li source in graphite are summarized in Table 2-17. Generally, the Li level in graphite is too low to determine an appropriate average concentration for large graphite mass from the perspective of analytical chemistry and the sampling procedure. Furthermore, the Li content in graphite varies with the production region and company. For example, AVR has the core and reflector graphite with $0.5 \mathrm{ppm}$ and $0.1 \mathrm{ppm}$ in Li level, respectively (Steinwartz 1980), while High Temperature Reactor-10 Megawatt (HTR-10) assumes $10 \mathrm{ppb}$ (Steinwartz 1984). The Li concentration is around $5 \mathrm{ppb}$ in ATR-2E block graphite and less than $0.8 \mathrm{ppb}$ in spherical graphite fuel elements (Kirch et al. 1980). The Li concentrations for Peach Bottom were measured in the selected samples of Peach Bottom graphite, and the average of these values yields $7.0 \mathrm{ppb}$. In this report, the value $7.0 \mathrm{ppb}$ was assumed.

The release rate of tritium, which is bound interstitially in graphite, is expected to be quite slow because a temperature of at least $1,200^{\circ} \mathrm{C}$ is required for tritium desorption from graphite. A retention fraction of 0.99 was used for this work, based on the recommendation of TRITGO (computer model) manual (GA 2006).

The weight of the graphite was determined by the volume of the region multiplied by graphite density $\left(1.74 \mathrm{~g} / \mathrm{cm}^{3}\right)$ (Park et al. 2007).

Table 2-17. Parameters used for estimating tritium production from Li.

\begin{tabular}{|l|c|c|c|c|}
\hline & $\begin{array}{c}\text { Impurity } \\
\text { Concentration } \\
(\mathbf{p p m})\end{array}$ & $\begin{array}{c}\text { Weight of } \\
\text { Graphite } \\
\mathbf{( k g )}\end{array}$ & $\begin{array}{c}\text { Thermal } \\
\text { Neutron Flux } \\
\left(\mathbf{n} / \mathbf{c m}^{2} \mathbf{s e c}\right)\end{array}$ & $\begin{array}{c}\text { Fast Neutron } \\
\text { Flux } \\
\left(\mathbf{n} / \mathbf{c m}^{2} \mathbf{~ s e c}\right)\end{array}$ \\
\hline Inner Core & 0.007 & 44452 & $3.73 \mathrm{e} 13$ & $7.02 \mathrm{e} 13$ \\
\hline Outer Core & 0.007 & 45359 & $3.73 \mathrm{e} 13$ & $7.02 \mathrm{e} 13$ \\
\hline Top Reflector & 0.007 & 23768 & $3.73 \mathrm{e} 13$ & $3.68 \mathrm{e} 13$ \\
\hline Bottom Reflector & 0.007 & 31706 & $3.73 \mathrm{e} 13$ & $3.68 \mathrm{e} 13$ \\
\hline Inner Reflector & 0.007 & 128366 & $3.73 \mathrm{e} 13$ & $3.68 \mathrm{e} 13$ \\
\hline Side Reflector & 0.007 & 417359 & $3.73 \mathrm{e} 13$ & $3.68 \mathrm{e} 13$ \\
\hline
\end{tabular}




\subsubsection{Input Parameters for Tritium Source from ${ }^{10} \mathrm{~B}$ in Graphite}

Tritium formed from the boron in the control rods is not easily estimated because of the varying quantity in the active core. In addition, the mass of boron in the control rods is not specified in any reference and can be surmised only from the amount of excess reactivity they control.

According to Peach Bottom reactor data (Wicher et al. 1979), tritium generated in the control rods are the main source of tritium generation in the neutron reaction. But, the most of tritium in the control rods remains within the generated site (Yook 2007).

The input of the tritium source from ${ }^{10} \mathrm{~B}$ was developed based on the TRITGO input for VHTR by Park et al. (2007).

Table 2-18. Parameters used for estimating tritium production from Li.

\begin{tabular}{|l|c|c|c|c|}
\hline & $\begin{array}{c}\text { Boron } \\
\text { Concentration } \\
(\mathbf{p p m})\end{array}$ & $\begin{array}{c}\text { Regional } \\
\text { Weight } \\
\mathbf{( k g )}\end{array}$ & $\begin{array}{c}\text { Thermal } \\
\text { Neutron Flux } \\
\left(\mathbf{n} / \mathbf{c m}^{2} \mathbf{s e c}\right)\end{array}$ & $\begin{array}{c}\text { Fast Neutron } \\
\text { Flux } \\
\left(\mathbf{n} / \mathbf{c m}^{\mathbf{2}} \mathbf{s e c}\right)\end{array}$ \\
\hline Inner Core & 41 & 44,452 & $3.73 \mathrm{e} 13$ & $7.02 \mathrm{e} 13$ \\
\hline Outer Core & 41 & 45,359 & $3.73 \mathrm{e} 13$ & $7.02 \mathrm{e} 13$ \\
\hline Top Reflector & 2 & 23,768 & $3.73 \mathrm{e} 13$ & $3.68 \mathrm{e} 13$ \\
\hline Bottom Reflector & 2 & 31,706 & $3.73 \mathrm{e} 13$ & $3.68 \mathrm{e} 13$ \\
\hline Inner Reflector & 2 & 128,366 & $3.73 \mathrm{e} 13$ & $3.68 \mathrm{e} 13$ \\
\hline Side Reflector & 2 & 417,359 & $3.73 \mathrm{e} 13$ & $3.68 \mathrm{e} 13$ \\
\hline Control Rod & $1 \mathrm{e} 6$ & 251 & $1.20 \mathrm{e} 13$ & $1.20 \mathrm{e} 13$ \\
\hline
\end{tabular}

\subsection{Evaluation of the Effective Thickness for Tritium Permeation in PCHEs}

In the VHTR system, heat exchangers are the main route of tritium permeation. Therefore, when we estimate the tritium distributions and contamination levels in hydrogen from the hydrogen production plant, it is very important to predict accurate tritium penetration rates. Generally, the tritium penetration rate $\left(\mathrm{N}_{\mathrm{HT}}\right)$ is determined by the following equation:

$$
N_{H T}=\frac{A}{l} \cdot k \cdot\left(P_{H T, h}^{n}-P_{H T, l}{ }^{n}\right)
$$

where

$A=$ heat transfer area or surface area $\left[\mathrm{m}^{2}\right]$

$l=$ thickness of heat transfer tube or component casing $[\mathrm{m}]$

$k=$ permeability of $\mathrm{HT}\left[\mathrm{m}^{3}(\mathrm{STP}) / \mathrm{m} / \mathrm{s} / \mathrm{Pa}^{0.5}\right]$

$P_{H T, h}=$ partial pressure of $\mathrm{HT}$ at high pressure side $[\mathrm{Pa}]$

$P_{H T, l}=$ partial pressure of $\mathrm{HT}$ at low pressure side $[\mathrm{Pa}]$

$\mathrm{N}=$ order of permeation.

Applying this equation to shell-and-tube type heat exchangers is quite easy and straight forward. However, when applying it to PCHEs, we meet some difficulties for determining the thickness of heat 
transfer tubes because of the unique shape and geometry of these channels. Tritium penetration rates vary significantly along the channel surface as shown in the previous chapter. For this reason, the effective thickness of the tritium penetration path in PCHEs was estimated in this section.

When using geometries other than the typical shapes such as circles and plates, it is often useful to calculate an effective thickness for a model. This thickness represents the thickness of a plate that would have the same flux rate as the model itself. In order to estimate the effective thickness of PCHEs, Equation (2-50) was modified to the following diffusion equations by substituting $P_{H T}{ }^{n}$ with $X_{H T}$.

$$
N_{H T}=\frac{k}{t_{\text {eff. }}}\left(X_{H T, h}-X_{H T, l}\right)
$$

where

$$
\begin{aligned}
& t_{\text {eff. }}=\text { effective thickness for tritium permeation }[\mathrm{m}] \\
& X_{H T}=P_{H T}{ }^{n}
\end{aligned}
$$

To determine the $N_{H T}$, COMSOL software and modeling used in Section 1.4.1 were also used in here. The boundary conditions of $X_{H T}$ and the values of $k$ were also determined based on this model. Theoretically, the effective thickness is independent of diffusivity, concentration, flux, temperature, pressure, and flow rates. The effective thickness can be obtained by the following equation:

$$
t_{\text {eff. }}=\frac{k}{N_{H T}}\left(X_{H T, h}-X_{H T, l}\right)
$$

In the above equation, $\mathrm{k}$ and $\mathrm{X}_{\mathrm{HT}}$ are fixed values during the calculations for a given temperature, pressure and boundary tritium concentration. However, $\mathrm{N}_{\mathrm{HT}}$ and $\mathrm{A}$ are variables related to the channel dimensions - diameter, plate thickness, and horizontal pitches - used in the modeling. Therefore, the different effective thicknesses will be obtained for the different channel dimensions by Equation (2-52) because of the different $\mathrm{N}_{\mathrm{TH}}$ values calculated by COMSOL.

Similar to Chapter 1.4.1, two channel configurations were taken into consideration: standard in-line configuration and off-set configuration. The reference PCHE configuration had a plate thickness of $0.96 \mathrm{~mm}\left(\mathrm{t}_{\mathrm{p}}=0.96 \mathrm{~mm}\right)$ and a pitch of $1.464 \mathrm{~mm}(\mathrm{p}=1.464 \mathrm{~mm})$. The diameter of the semicircular ports was $1.2 \mathrm{~mm}\left(\mathrm{~d}_{\mathrm{t}}=1.2 \mathrm{~mm}\right)$. Calculations were performed for five horizontal pitches $(1.332 \mathrm{~mm}$, $1.464 \mathrm{~mm}, 1.728 \mathrm{~mm}, 1.992 \mathrm{~mm}$, and $2.5 \mathrm{~mm})$, and five plate thicknesses $(0.69 \mathrm{~mm}, 0.96 \mathrm{~mm}, 1.32 \mathrm{~mm}$, $2.54 \mathrm{~mm}$, and $3.48 \mathrm{~mm}$ ). The horizontal pitch, plate thickness, and diameter are shown on Figure 2-15. The offset model was made by shifting every other plate by half the model's pitch.

Table 2-19 summarizes the effective thicknesses of the reference geometry for various temperatures. As shown in the table, the effective thickness is not affected by the temperature, and it confirms that the permeability does not affect the effective thickness. In this table, the effective thickness in the off-set geometry is a little bit larger than in the standard geometry, which is because the diffusion path in the offset design is larger than the standard design. However, the differences are very slight. One important finding in this result is that the effective thickness $(0.49 \mathrm{~mm})$ in the PCHE is much smaller than the average thickness between two channels $(0.66 \mathrm{~mm})$, which is because most of the tritium has penetrated through the shortest parts of the channel distance. Therefore, determination of the tube thickness by the average channel distance may result in much less tritium penetration through this PCHE walls. 


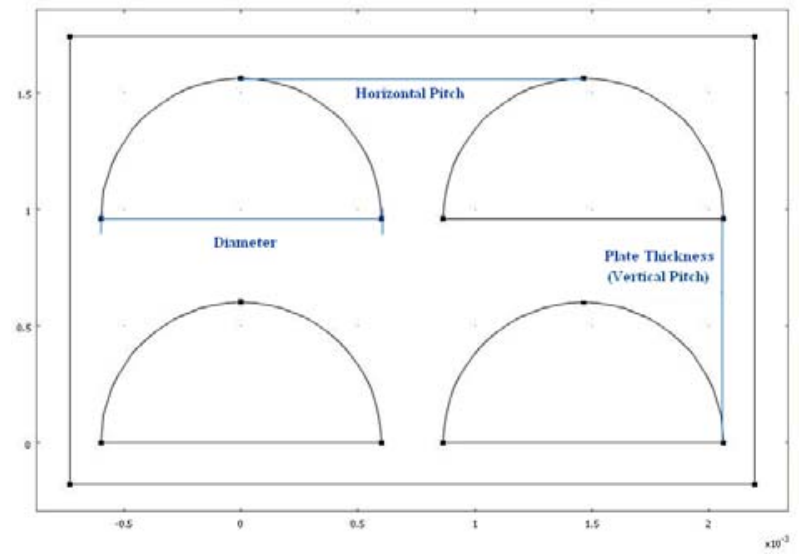

(a) Standard in-line configuration Figure 2-15. PCHE channel configurations.

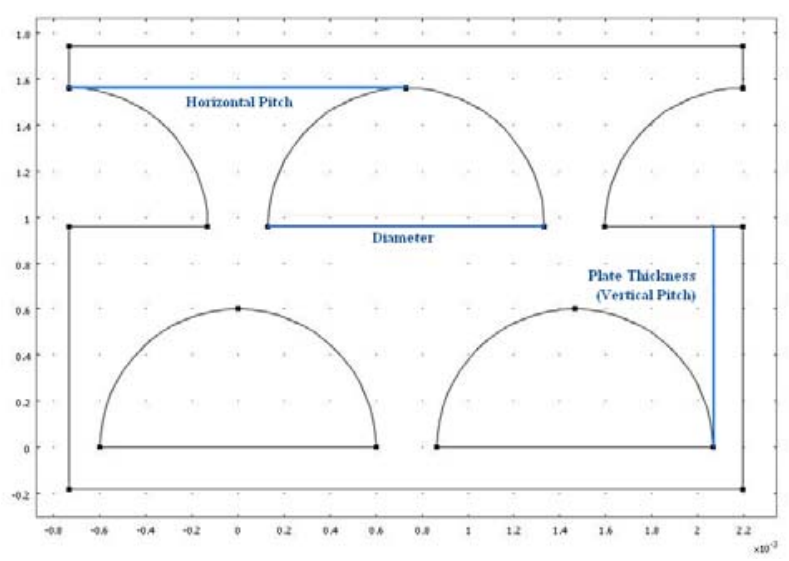

(b) Off-set configuration

Table 2-19. Effective Thickness over a Temperature Range.

\begin{tabular}{|l|c|c|}
\hline & $\begin{array}{c}\text { Effective Thickness } \\
\text { for Mass Flux } \\
\text { (m) }\end{array}$ & $\begin{array}{c}\text { Effective Thickness } \\
\text { for Mass Flux } \\
\text { (m) }\end{array}$ \\
\cline { 2 - 3 } & Initial & Offset \\
\hline $500^{\circ} \mathrm{C}$ & 0.0004876 & 0.000491788 \\
\hline $600^{\circ} \mathrm{C}$ & 0.00048787 & 0.000492015 \\
\hline $700^{\circ} \mathrm{C}$ & 0.0004882 & 0.000492604 \\
\hline $800^{\circ} \mathrm{C}$ & 0.000488612 & 0.000493233 \\
\hline $900^{\circ} \mathrm{C}$ & 0.000489025 & 0.00049379 \\
\hline
\end{tabular}

In order to correlate the effective thickness as a function of channel dimensions (channel diameter, plate thickness, and horizontal pitch), the effective thicknesses have been obtained by Equation (2-52) and COMSOL modeling of various channel dimensions. Figure 2-16 shows the effective thickness of the PCHE for various pitch-to-diameter ratios in vertical and horizontal directions, which is increased with vertical pitches, and decreased with horizontal pitches. However, the effect of the vertical pitch is more significant. 
(a) Standard configuration.

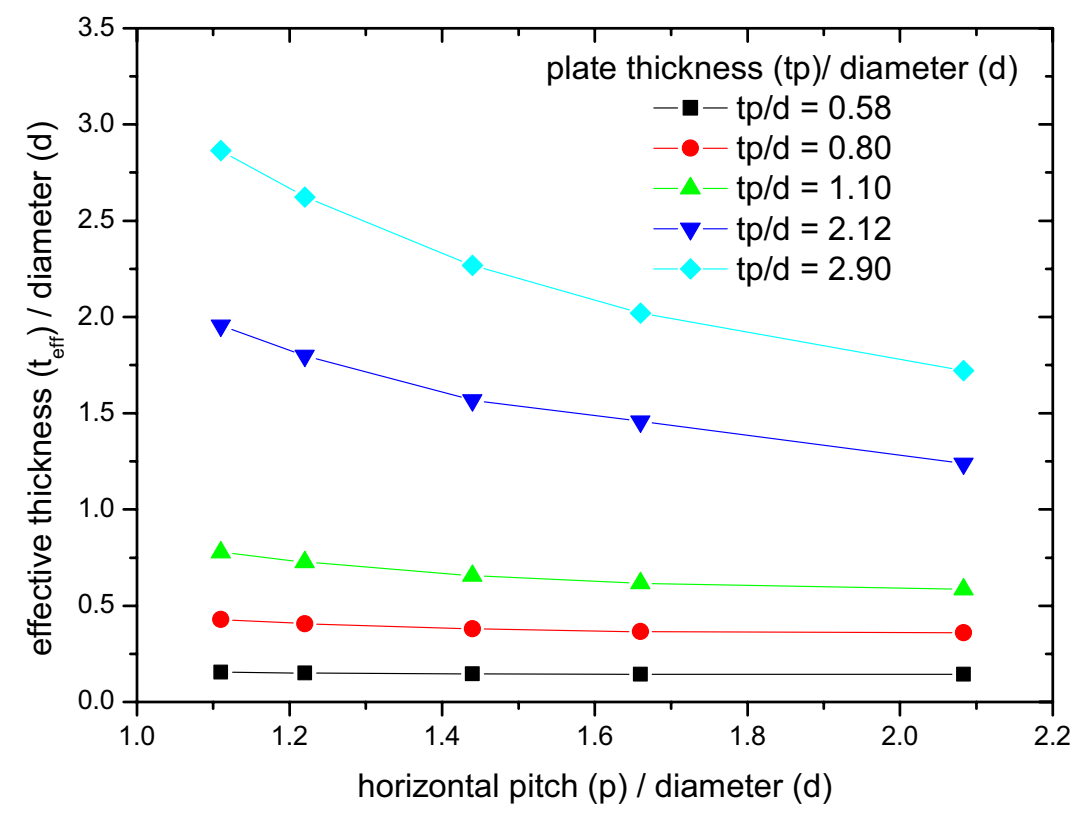

(b) Off-set configuration.

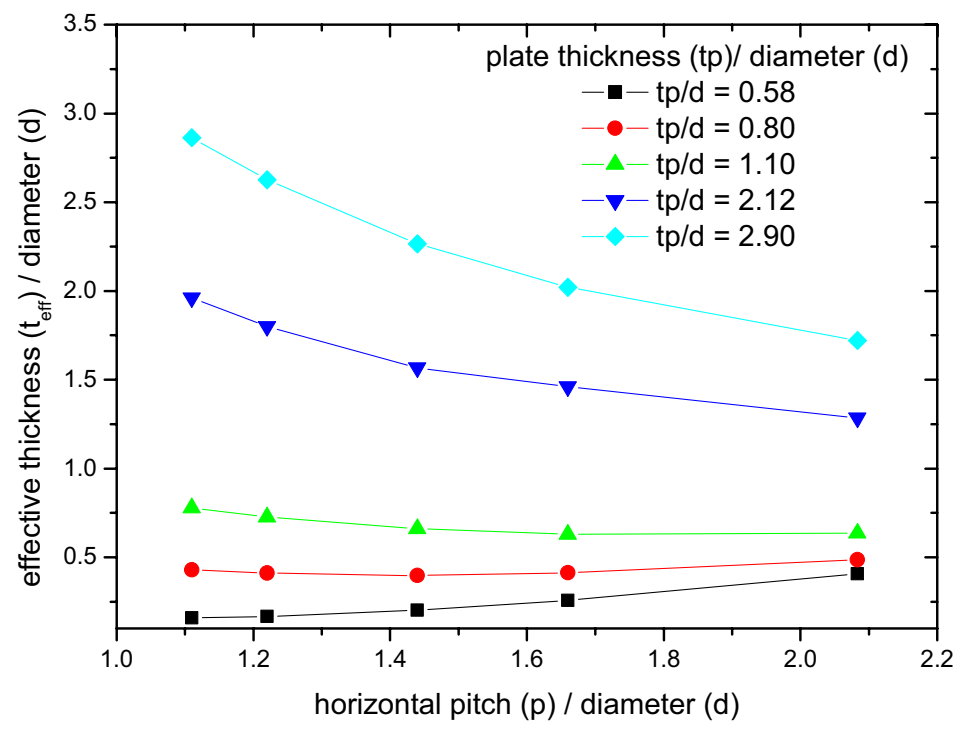

Figure 2-16. Effective thickness for various channel dimensions (diameter, pitch and thickness).

By regressing the data shown in Figure 2-18, the effective thickness correlations were developed for standard and offset configurations. In order to generalize the correlations, all the geometric parameters were normalized by the channel diameter, $d$. Therefore, the dimensionless effective thickness $\left(t_{\text {eff }} / d\right)$ was finally expressed by dimensionless plate thickness $\left(\mathrm{t}_{\mathrm{p}} / \mathrm{d}\right)$ and dimensionless pitch $(\mathrm{p} / \mathrm{d})$. The correlations for both standard and off-set configurations are described below. 
Standard configuration

$$
\begin{array}{ll}
\frac{t_{\text {eff. }}}{d}=0.8 \cdot\left(\frac{t_{p}}{d}\right)^{2.92} \cdot\left(\frac{p}{d}\right)^{-0.19} & \left(\frac{t_{p}}{d}<0.8\right) \\
\frac{t_{\text {eff }} \cdot}{d}=0.67 \cdot\left(\frac{t_{p}}{d}\right)^{1.51} \cdot\left(\frac{p}{d}\right)^{-0.61} & \left(\frac{t_{p}}{d}>0.8\right)
\end{array}
$$

Off-set configuration

$$
\begin{array}{ll}
\frac{t_{\text {eff. }}}{d}=0.48 \cdot\left(\frac{t_{p}}{d}\right)^{1.94} \cdot\left(\frac{p}{d}\right)^{-0.85} & \left(\frac{t_{p}}{d}<0.8\right) \\
\frac{t_{\text {eff. }}}{d}=0.65 \cdot\left(\frac{t_{p}}{d}\right)^{1.35} \cdot\left(\frac{p}{d}\right)^{-0.26} & \left(\frac{t_{p}}{d}>0.8\right)
\end{array}
$$

where

$$
\begin{aligned}
d & =\text { channel diameter }[\mathrm{m}] \\
t_{p} & =\text { channel vertical thickness }[\mathrm{m}] \\
p & =\text { channel horizontal pitch }[\mathrm{m}]
\end{aligned}
$$




\section{SUMMARY}

Two important issues associated with VHTR systems were investigated: heat exchangers and tritium permeation. The tasks performed and results obtained in this study are summarized in this section.

\subsection{Design Options for NGNP Heat Exchanger}

\subsubsection{Heat Exchanger Thermal Design and Design Options}

The following heat exchanger options, applicable to VHTRs, were selected from three categories (heat exchanger types, heat exchanger serial arrangement, and PCHE channel layouts) for consideration in this report:

- Heat exchanger types: PCHE, shell-and-tube, and helical coil

- Heat exchanger arrangements: single- and two-stage

- PCHE channel layout configurations: standard in-line and off-set configurations

- In addition, cross-flow and counter-current flow were considered in the PCHE design, and straight pipe and U-tube configurations were considered in the shell-and-tube heat exchanger design.

The reference reactor had $600 \mathrm{MWt}$, and two different system configurations were considered for the thermal design. The following results were obtained from this research:

- The PCHE has much smaller size (or volume) than the tubular type heat exchangers (shell-and-tube or helical coil). In high temperature applications, the smaller volume of heat exchanger is generally preferred because (1) the high alloy metals or ceramics are very costly, and (2) the smaller heat exchanger can reduce the total system size. The total core volumes for exchanging heat are $5-6 \mathrm{~m}^{3}$ for the PCHE design, 400-600 $\mathrm{m}^{3}$ for the shell-and-tube design, and 160-190 $\mathrm{m}^{3}$ for the helical coil design. The small size of the PCHEs contributes to the high surface area density and the high heat transfer coefficient caused by the small channel size.

- The PCHE has much smaller heat transfer area compared to other options. The reduced heat transfer area leads to less tritium penetration through the heat exchangers. For $600 \mathrm{MWt}$ design, the heat exchanger requires about 4,500-6,500 $\mathrm{m}^{2}$ for PCHEs, 28,000-32,000 $\mathrm{m}^{2}$ for shell-and-tube heat exchangers, and $13,000 \mathrm{~m}^{3}$ for helical coil heat exchangers. When considering the effect of heat exchanger wall thickness together, the PCHE is estimated to show about one-half less tritium penetration than the shell-and-tube design.

- The PCHE shows better heat transfer performance than other types, but it requires much larger friction loss at the same flow length. Therefore, for the same pressure drop, the PCHE requires too short a flow length, which would lead to potential thermal stress problems because the temperature gradient in the flow direction is too large.

- The PCHE requires a large number of small modules for large duty, which would lead to a very complex system. The PCHE design also requires a complex manifold and flow connections between modules.

- The shell-and-tube and helical coil designs are proven technologies, and the problems and limitation of the heat exchangers are well identified. It is therefore more easily applied to the VHTR application in the near term. The PCHE needs more research and validation for the VHTR application.

- Tubular heat exchangers allow in-service inspections and have well-established maintenance methods, whereas defects and failures in PCHE during operations will be hard to find and maintenance will be more difficult compared to the tubular design. 
- A two-stage heat exchanger arrangement has been proposed in to reduce risk and cost for VHTR applications. The two-stage concept splits the heat exchanger into two modules - a high temperature unit and low temperature unit - at the separation temperature of $750^{\circ} \mathrm{C}$. The high temperature unit is designed for replacement within the plant's lifetime while the low temperature unit is designed for lifetime operation. Alloy $800 \mathrm{H}$ is a potential candidate for the low temperature unit; Alloys 617 and 230 are candidates for the high temperature unit. Conceptually, this is very good, but according calculations, the high temperature unit requires almost two-thirds of the total heat exchanger size, which means that the most of that unit should be replaced during the plant's lifetime. This is impractical when compared to the single-stage design.

- An $800^{\circ} \mathrm{C}$ separation temperature was considered in order to reduce the size of the high temperature unit. The size of the LMTD was even decreased compared to the $760^{\circ} \mathrm{C}$ case, but the duty of the high temperature unit was significantly reduced, resulting in a significant reduction in heat exchanger capacity. In this design, the size of the high temperature unit was about one-half that of the total heat exchanger size. However, in this scenario, the material for the low temperature unit is required to be Alloy 617 or 230 . We therefore will need some optimization study to determine the best separation temperature.

\subsubsection{Stress Analysis of the VHTR Heat Exchangers}

Simple stress analyses on the PCHE and the tubular heat exchangers were performed. Based on these analyses, the lifetimes of the reference design IHXs and SHXs have been estimated and the thickness required for a certain lifetime has been calculated. For conservative analyses, Alloy 617 has been selected as the structure material. The maximum pressure difference between hot and cold channels was $1.0 \mathrm{MPa}$ for the IHX, 2.0 MPa for the SHX, and 5.0 MPa for another SHX. The following results were obtained from this research:

- The IHX lifetime of the reference design is about 35 years for the PCHE design, and 10 years for the tubular design at the operating temperature of $900^{\circ} \mathrm{C}$. The reason for the longer lifetime of the PCHE design is because of the larger thickness-to-channel radius ratio $\left(t / r_{i}\right)$. The values of $t / r_{i}$ for the tubular design with commercial pipes are less than 0.3, while the values for PCHE are usually more than 0.5.

- The lifetime of the PCHE for SHX with $\Delta \mathrm{P}_{\max }=2.0$ is close to the IHX, but for the shell-and-tube design at $900^{\circ} \mathrm{C}$ drops to 1.5 years. This is because of the low $t / r_{i}$ values. It means that the PCHE is theoretically more secure than the shell-and-tube design in the aspect of mechanical stress.

- The lifetime of the PCHE for SHX with $\Delta \mathrm{P}_{\max }=5.0$ is about 4,000 hours at $900^{\circ} \mathrm{C}$. The reference tubular design cannot be operated at this condition. Based on this analysis, the PCHE is also inadequate for this application because 4,000 hours is still too short a period when compared to the whole plant's lifetime (about 50 years).

- The tube wall or plate thickness required for some VHTR operating conditions were analyzed in this report. According to the results, the PCHE type is more suitable for VHTR applications than the tubular design because the tubular design would require a large tube thickness to accommodate commercially available pipes.

\subsubsection{Computational Analysis of PCHE Channel Configuration Options}

Two channel configurations of the PCHEs were investigated using Finite Element Methods (FEM) focused on heat transfer, tritium diffusion, and stress. The two channel options considered are standard inline and off-set. COMSOL Multiphysics software was used to analyze heat transfer and tritium diffusion. Various horizontal channel pitches and plate thicknesses were taken into consideration. ABAQUS ${ }^{\circledR}$ (ver. 6.75) was used to perform stress analyses. The following results were obtained from this research: 
- The effect of the standard off-set option on the heat transfer was very slight because the heat transfer resistance in the heat exchanger is mainly on the fluid boundary layers.

- Off-setting the channels slightly decreased the rate of tritium diffusion because the main resistance of the tritium diffusion is in the solid metal structure. However, the reduction is negligible.

- Increasing the plate thickness significantly reduces the heat transfer and diffusion rate, and increasing the horizontal pitch slightly increases the diffusion rate. However, the effect of the horizontal pitch was much smaller than the plate thickness. The tritium rate increases with the horizontal pitch because the dead spot decreases on the channel side.

- The off-set design reduced stress concentration by a maximum of $50 \%$, which is significant, since the lifetime of the materials are exponentially decreased by the maximum stress. The $50 \%$ stress reduction will lead to a significant increase in unit lifetime.

\subsection{Tritium Behavior Study in the VHTR System}

\subsubsection{Heat Exchanger Thermal Design and Design Options}

In the VHTR hydrogen system, tritium permeation from the core into the produced hydrogen is a serious concern because the tritium can easily permeate high temperature heat exchanger tubes and contaminate the product hydrogen. In this report, several separate works have been performed for analysis of the tritium behaviors in the VHTR hydrogen system. The following results were obtained from this research:

- A portion of dynamic tritium behavior analysis code was developed using a MATLAB Simulink software package. In this code, (1) tritium generations by five different sources (Ternary fission and neutron reactions of ${ }^{6} \mathrm{Li},{ }^{7} \mathrm{Li},{ }^{10} \mathrm{~B}$ and ${ }^{3} \mathrm{He}$ ), (2) tritium penetration through metals, (3) leakage of coolant, and (4) purification system were considered using the mass balance equations of various species (HT, $\mathrm{H}_{2}, \mathrm{H}_{2} \mathrm{O}$, HTO, etc.). The code is based on the graphical user interface that allows users to drag-and-drop when analyzing and estimating tritium behaviors in complex systems.

- In parallel with code development, the THYTAN code used by Ohashi and Sherman (2006) was successfully verified by comparing the analytical solutions with Peach Bottom data. The code inputs were also prepared for transient analysis of the VHTR hydrogen system.

- As the first step of the transient tritium behavior analysis in the VHTR hydrogen system, the THYTAN tritium generation input file was developed. The input data were collected from various sources.

- A FEM analysis was performed using COMSOL Multiphysics to get a more accurate prediction of the tritium permeation through the heat exchangers. Based on that analysis, the effective thickness of the models was much less than the average because the majority of the tritium passes through the middle of the models. Therefore, the effective thickness is more similar to the minimum thickness than to the average distance. A general correlation to predict the effective thickness for tritium permeation was developed which selected tube diameter, horizontal pitch, and plate thickness as the main variables. 


\section{REFERENCES}

ABAQUS, Inc, 2004, "Getting Started with ABAQUS."

AIAA, 1998, "Guide for the Verification and Validation of Computational Fluid Dynamics Simulations," AIAA G-077-1998, http://www.grc.nasa.gov/WWW/wind/valid/homepage.html.

ASME, 2004, “ASME Electronic Stress Tables,” Section II, Part D-Properties.

ASPEN Technology, 2004, HYSYS Process Version 2.2.2, www.aspentech.com.

Bejan., A and Kraus, D., 2003, Heat Transfer Hand Book, John Wiley \& Son, ISBN 978-0-471-39015-2.

Bell, K. J., 2004, "Heat Exchanger Design for the Process Industries," Journal of Heat Transfer, Vol. 126, pp. $877-885$.

Bell, K. J., 1981, "Preliminary design of shell and tube heat exchangers, Heat Exchangers: ThermalHydraulic Fundamentals and Design," Kakac, S., Bergles, A. E., and Mayinger, F., Eds., Hemisphere, Washington, D.C.

Brent, A., 1989, "Fundamentals of Composites Manufacturing Materials Methods and Applications," Society of Manufacturing Engineers, Dearborn, MI.

Collins, J. A., 1981, Failure of Materials in Mechanical Design-Analysis, Prediction, Prevention, Wiley.

COMSOL Group, "Modeling of COMSOL Multihphysics," 2008.

Crandal, S. H., Dahl, N. C. and Lardner, T. J., 1972, An Introduction to the Mechanics of Solids, Second Edition, McGraw-Hill Book Company, New York.

Davis, C. B., Oh, C. H., Barnar, R. B., Sherman, S. R. and Wilson, D. F., 2005, Thermal-Hydraulic Analyses of Heat Transfer Fluid Requirements and Characteristics for Coupling A Hydrogen Production Plant to a High Temperature Nuclear Reactor, INL/EXT-05-00453.

Dewson, S., Li, X., 2005, "Selection Criteria for the High Temperature Reactor Intermediate Heat Exchanger," Proceedings of ICAPP' 05, Seoul, Korea, May 15-19.

Dewson, S. J. and Thonon, B., 2003, The Development of High Efficiency Heat Exchangers for Helium Gas Cooled Reactors, ICAPP03.

Dostal, V., Driscoll, M. J., Hejzlar, P., 2004, “A Supercritical Carbon Dioxide Cycle for Next Generation Nuclear Reactors,” MIT-ANP-TR-100, March 2004.

Forsyth, N., 1974, "Tritium production and distribution in High Temperature Gas Cooled Reactors: Tritium generation, retention, distribution, and environmental release in a national 1,500 MW(th) HTR,” O.E.C.D. High Temperature Reactor Project DRAGON, DP REPORT 905, October 1974.

Gainey, B. W., 1976, A Review of Tritium Behavior in HTGR Systems, GA A13461, General Atomic Company, April 30, 1976.

General Atomic Company, 1978, "Metallurgical Examination of Primary Circuit Components from the Peach Bottom HTGR, GA A14506, General Atomic Company, February 1978.

General Atomics, 2006, TRITGO Code Description and User's Guide, GA Project 20128, 2006.

Gezelius, K., 2004, "Design of Compact Intermediate Heat Exchangers for Gas Cooled Fast Reactors," Degree of Master Dissertation, MIT.

Heatric ${ }^{\mathrm{TM}}$, 2003, Workshop at MIT on 2nd October 2003, Cambridge: MA.

Hesselgreaves, J. E., 2001, “Compact Heat Exchangers,” PERGAMON, ISBN 0-08-042839-8. 
Hewitt, G. F., 2002, Heat Exchanger Design Handbook, Begell House, INC., New York, 2002.

Kakac, S., Liu, H., 2002, Heat Exchangers: Selection, Rating, and Thermal Design, CRC Press, ISBN 0-8493-0902-6.

Kato, R., Nishihara, T., Kumitomi, K., 2007, "Design of the Intermediate Heat Exchanger for the High Temperature Gas-cooled Reactor Hydrogen Cogeneration System," Japanese Nuclear Society, Vo. 6, No. 2, pp. 141-148.

Kays, W. M. and Crawford, M. E., 1981, Convective Heat and Mass Transfer, 2nd ed., McGraw-Hill, New York, 1981.

Kern, D. Q., 1991, Process Heat Transfer, McGraw-Hill, New York, p 143.

Kirch, N. and Scheidler, G., 1980, Control of the Tritium Path in Process Heat HTRs, IWGGCR/2, IAEA.

Lillo T. M., Williamson R. L., Reed T. R., Davis C. B., Ginosar D. M., 2005, Engineering Analysis of Intermediate Loop and Process Heat Exchanger Requirements to Include Configuration Analysis and Materials Needs," INL/EXT-05-00690, Idaho National Laboratory, Idaho Falls, ID.

Martin, J., 1962, Mechanical Behavior of Engineering Materials, Prentice-Hall, Inc.

Mckellar, M. G., 1992, “Optimization of a Household Refrigerator Considering Alternative Refrigerants," Ph.D. Thesis, Department of Mechanical Engineering, Purdue University, August 1992.

Natesan, K. et al., 2006, Preliminary Issues Associated with the Next Generation Nuclear Plant Intermediate Heat Exchanger Design, ANL/EXT-06/46.

National Institute of Standards and Technology, 2005, "Thermophysical Properties of Fluid Systems," http://webbook.nist.gov/chemistry/fluid/.

Oh, C. H., Davis, C. B., Han, J., Barner, R., Sherman, S. R., Vilim, R., Lee, Y. J., Lee, W. J., 2006, HyPEP FY06 Report: Models and Methods, INL/EXT-06-011725, September 2006.

Oh, C. H., Kim, E. S., Sherman, S. R., Vilim, R., Lee, Y. J. and Lee, W. J., 2007, HyPEP FY-07 Annual Report: A Hydrogen Production Plant Efficiency Calculation Program, INL/EXT-07-13078.

Ohadi, M. M. and Buckey, S. G., 2001, "High temperature heat exchangers and microscale combustion systems: applications to thermal system miniaturization," Experimental Thermal and Fluid Science, Vol. 25, pp. 207-217.

Ohashi, H. and Sherman, S, 2007, Tritium Movement and Accumulation in the NGNP System Interface and Hydrogen Plant, INL/EXT-07-12746.

Park, I. G, Kim, D. H. and Lee, W. J., 2007, A sample calculation of tritium production and distribution at VHTR by using TRITGO code, KAERI/TR-3362.

Patterson, M, Personal Communication, 2008, "NGNP Internal Summary, Conceptual Design Studies for NGNP," Project Status Meeting, Feb. 7, 2008.

Perry, R. H., Green, D. W., 1997, Perry's Chemical Engineers” Handbook: 7th Edition.

Richards, M. B., Shenoy, A. S., Brown, L. C., Buckingham, R. T., Harvego, E.A., Peddicord, K. L., Reza, S. M. M., Coupey, J. P., Apr. 2006, H2-MHR Pre-Conceptual Report: SI-Based Plant, General Atomics Report GA-A25401.

Schubert, F., 1984, "Evaluation of Materials for Heat Exchanging Components in Advanced Helium-Cooled Reactors," IAEA Specialists Meeting on Heat Exchanging Components of Gas-Cooled Reactors, Dusseldorf, Germany, IWGGCR-9, 309. 
Shah, R. K. and Joshi, S. D., 1987, Convective Heat Transfer in Curved Pipes, in Handbook of SinglePhase Convective Heat Transfer, Kakac, S., Shah, R. K., and Aung, W. Eds., John Wiley \& Sons, New York, Ch. 5.

Simon, R. A., Carp, P. D., 1980, Operating Experience with the DRAGON high Temperature Reactor Experiment, IWGGCR/2, IAEA.

Slater, J. W., 2008, "Examining Spatial (Grid) Convergence," http://www.grc.nasa.gov/WWW/wind/valid/tutorial/spatconv.html.

Special Metals Corporation, 2006, "Inconel Alloy 617," http://www.specialmetals.com/documents/Inconel\%20alloy\%20617.pdf

Srinivasan, P.S., Nandapurkar, S.S., and Holland, F. A., 1970, "Friction for Coils," Trans. Inst. Chem. Eng., 48, T156.

Steinwarz, W., D. Stover, R. Hecker, and W. Thiele, 1984, "Distribution of tritium in a nuclear process heat plant with HTR,” Nuclear Engineering and Design, Vol. 78, pp. 267-272.

Steinwarz, W., H. D. Rohrig, and R. Nieder, 1980, Tritium Behavior in an HTR System Based on AVR Experience, IWGGCR2, International Atomic Energy Agency, Vienna (Austria), pp. 153160.

Sunden, B., 2005, "High Temperature Heat Exchangers (HTHE)," Proceedings of Fifth International conference on Enhanced, Compact and Ultra-Compact Heat Exchangers: Science, Engineering and Technology, Hoboken, NJ, USA, September 2005.

Wichner, R. P. and F. F. Dyer, 1979, Distribution and Transport of Tritium in the Peach Bottom HTGR, ORNL 5497, Oak Ridge National Laboratory, August 1979.

Wolf, L., Kazmi, M., Todreas, N. E., 2004, "Introduction to Structural Mechanics," Lecture Note of Engineering of Nuclear Reactors, 2004.

Yang, L., W. A. Baugh, and N. L. Baldwin, 1977, Study of Tritium Permeation Through Peach Bottom Steam Generator Tubes, GA A14376, General Atomics Company, June 1977.

Yook, D. K., "A Study on the Methodology for Tritium Behavior in the Gas Cooled Reactor for Hydrogen Production System," Korea Advanced Institute of Science and Technology, Doctorial Thesis, 2007.

Zukauskas, A. A., 1987, "Convective Heat Transfer in Cross Flow," in Handbook of Single-Phase Convective Heat Transfer, Kakac, S., Shah, R. K., and Aung, W., Eds., John Wiley \& Sons, New York, 1987, Ch. 5. 


\section{Appendix A \\ High Temperature Heat Exchanger Selection and Design Guideline}




\section{Appendix A \\ High Temperature Heat Exchanger Selection and Design Guideline}

Heat exchanger design is generally flexible depending on the criteria and designer's decision. This appendix briefly summarizes the methods and guidelines for selecting and designing heat exchangers. It especially focuses on the high temperature heat exchanger (HTHE) design, which was extensively considered for the intermediate heat exchanger (IHX) design process described in Appendix B.

\section{A-1. GENERAL HTHE ISSUES}

HTHE technology has become important for improving performance in power generation. For this reason, many researchers have been studying the development of a heat exchanger operating with high temperature gas. The HTHE has some different characteristics compared with the general low temperature heat exchangers because of high temperatures and pressures. Sunden (2005) summarizes these characteristics as follows:

- Radiation heat transfer may have a significant role in the high temperature units.

- Tube diameters and pitch should be larger in high temperature units so that the pressure drop is kept low. The cost of adding a fan or blower to work at high temperatures might be prohibitive.

- Even though the gases have low heat transfer coefficients, fins are generally not used in high temperature units because (a) the gaseous stream usually carries suspended dirt particles that will foul or fill up the space between the fins and make a finned tube worse than a plain, and (b) the gas velocity is low because of low available pressure drop, hence, the advantage of fins is negligible.

- The materials for construction are different in both cases. High temperature units use ceramics or high alloy and costly tubing; low-temperature units usually use low alloy tubing.

- The selection of materials, their thicknesses, and the mechanical design are governed by the thermal stress in the high temperature units. Other factors to consider are the extent of material oxidation, thermal shock bearing capability, erosion because of suspended dirt particles, and fouling and corrosion because of metallic salts, sulfates, etc. Stress analysis has to be carried out for a safe and reliable design.

- Differential expansion is an important factor in high temperature units and should be accounted for by using expansion bellows or bayonet-type units. Floating tube sheets cannot generally by used, because sealing gasket or packing materials do not work effectively at such high temperatures.

- Heat losses from the outside surface to the environment have to be considered in the mechanical design of the unit and the foundation design.

- Gases, air, or liquid metals and molten salts are preferred over steam for high temperature heat transfer because the latter requires a thick shell and tubes to contain its high pressure.

Therefore, the followings should be considered in design of IHX (Sunden 2005):

- The thermal stress during the startup, shutdown, and load fluctuations of HTHEs, can be significant. Heat exchangers must be designed accordingly for reliability and long life.

- The thermal capacitance should be reduced for high temperature heat exchangers for shorter startup time.

- High temperature heat exchangers require costly materials, which contributes to the high balance of power plant cost. Heat exchanger costs increase significantly with temperatures above $675^{\circ} \mathrm{C}$. 


\section{A-2. HEAT EXCHANGERS TYPES AND CLASSIFICATIONS}

Heat exchangers are used in a variety of applications, including power production, process, chemical and food industry, electronics, environmental engineering, waste heat recovery, manufacturing industry, air conditioning, refrigeration, and space application. Heat exchangers can be generally classified as follows (Kakac and Liu 2002):

\section{- Recuperator/Regenerator}

- Recuperations

- Regenerations

- Transfer Process

- Direct contact

- Indirect contact

- Geometry of Construction

- Tubular heat exchanger

- Double pipe heat exchanger

- High pressure (in both side)

- Low heat transfer area

- Shell and Tube heat exchanger

- Thermal expansion problem

- Cleaning

- Spiral tube type heat exchanger

- Thermal expansion problem

- Cleaning problem

- Plate heat exchanger

- $\quad$ Gasketed plate heat exchanger $\left(25\right.$ bar, $\left.250^{\circ} \mathrm{C}\right)$

- $\quad$ Spiral plate heat exchanger $\left(15 \mathrm{bar}, 500^{\circ} \mathrm{C}\right)$

- Lamella heat exchanger $\left(35 \mathrm{bar}, 500^{\circ} \mathrm{C}\right)$

- Extended surface heat exchanger

- Plate-fin heat exchanger

- Tubular-fin heat exchanger (Gas to Liquid)

\section{- Heat Transfer Mechanism}

- $\quad$ Single-phase convection on both sides

- Single-phase convection on one side, two-phase convection on the other side

- Two-phase convection on both sides

\section{- Flow Arrangement}

- Parallel flow

- Counter flow

- Cross flow.

The heat exchanger type is usually determined in terms of their construction and geometrical features. As seen in the above categorization, there are two main types of heat exchangers: tubular and plate. Tubular heat exchangers are built of circular tubes. One fluid flows inside the tubes and the other flows on the outside of the tubes. Tube diameter, the number of tubes, the tube length, the pitch of the tubes, and the tube arrangement are flexible. Shell-and-tube type or helical-coil (spiral-tube) type are in this 
category. Shell-and-tube heat exchangers are the most adaptive type of heat exchangers (see Figure A-1(a)). They are built of round tubes mounted in large cylindrical shells. They provide a relatively large ratio of heat transfer area to volume and weight and can be easily cleaned. They provide great flexibility to meet almost any service requirement. Helical-coil type heat exchangers consists of spirally wound coils placed in a shell (see Figure A-1(b)). The heat transfer coefficient is higher in a spiral tube than in a straight tube. Spiral-tube heat exchangers are generally suitable for thermal expansion and clean fluids, since cleaning is almost impossible.

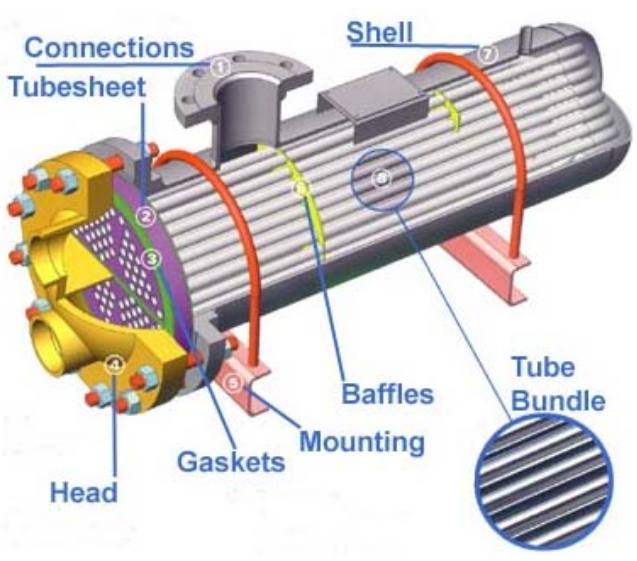

(a) Shell-and-tube heat exchanger

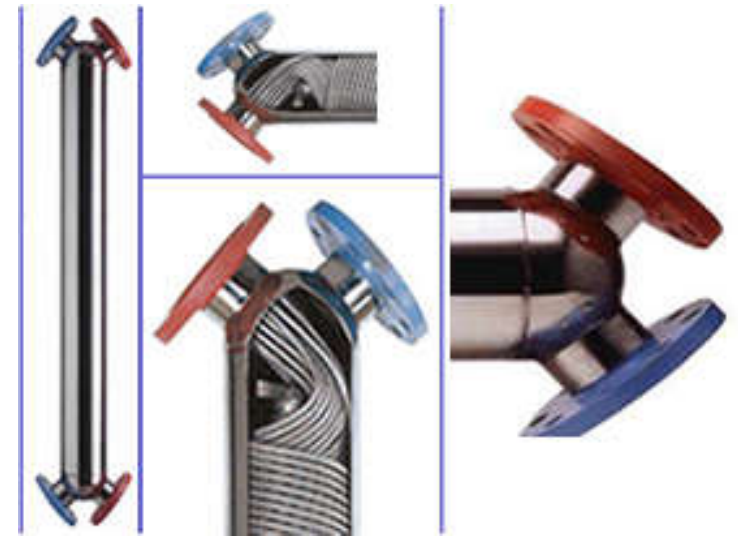

(b) Helical-coil heat exchanger

Figure A-1. Tubular type heat exchangers.

Plate-type heat exchangers are built of thin plates forming flow channels. The fluid streams are separated by flat plates with smooth or corrugated fins. Compact heat exchangers, including plate-fin heat exchangers, printed circuit heat exchangers (PCHE), and tubular-fin heat exchangers, are in this category (see Figure A-2). A heat exchanger having a surface area density greater than about $700 \mathrm{~m}^{2} / \mathrm{m}^{3}$ is quite arbitrary and referred to as a compact heat exchanger. Compact heat exchangers are widely used in industry, especially as gas-to-gas heat exchangers or liquid-to-gas heat exchangers.
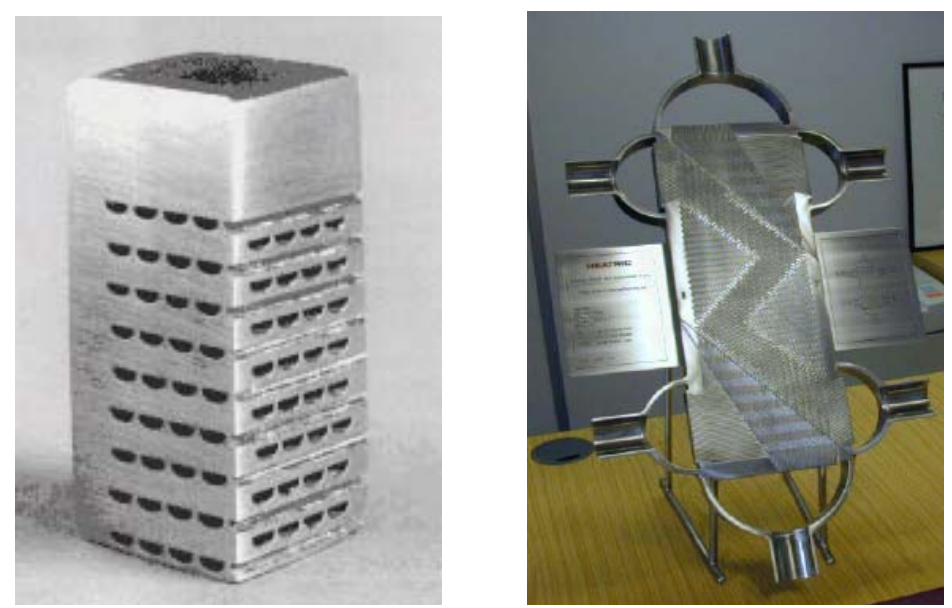

Figure A-2. Printed circuit heat exchanger (PCHE).

Table A-1 summarizes the degree of compactness for different types of heat exchangers. The compactness of heat exchanger can be described by surface area density. This table shows that the PCHE has much larger surface area density, $2,000 \mathrm{~m}^{2} / \mathrm{m}^{3}$, than the shell-and-tube heat exchangers, $100 \mathrm{~m}^{2} / \mathrm{m}^{3}$. It means that conceptually, the PCHE can be much smaller an perform the same as the shell-and-tube types. 
Table A-1. Comparisons of heat exchanger compactness.

\begin{tabular}{|l|c|c|}
\hline \multicolumn{1}{|c|}{ Exchanger Type } & Channel Size & Area Density \\
\hline Shell \& Tube & $10-50 \mathrm{~mm}$ & $100 \mathrm{~m}^{2} / \mathrm{m}^{3}$ \\
\hline Plate type & $5 \mathrm{~mm}$ & $200 \mathrm{~m}^{2} / \mathrm{m}^{3}$ \\
\hline Plate fin & $2 \mathrm{~mm}$ & $1,000 \mathrm{~m}^{2} / \mathrm{m}^{3}$ \\
\hline PCHE & $1 \mathrm{~mm}$ & $2,000 \mathrm{~m}^{2} / \mathrm{m}^{3}$ \\
\hline
\end{tabular}

Table A-2 shows the usual operating ranges of heat exchangers. According to this table, PCHE can withstand the highest pressure and temperature $\left(900^{\circ} \mathrm{C}, 1,000 \mathrm{bar}\right)$. Shell-and-tube type can be operated up to $650^{\circ} \mathrm{C}$ and 1,400 bar. Other types of heat exchangers cannot be operated at high temperature and pressure conditions.

Table A-2. Usual operating ranges (can be wider with special materials).

\begin{tabular}{|l|c|c|}
\hline \multicolumn{1}{|c|}{ Exchanger Type } & Temperature $\left[{ }^{\circ} \mathbf{C}\right]$ & Pressure [bar] \\
\hline Shell \& Tube & $-25-650$ & $300 / 1,400$ \\
\hline Gasketted Plate Frame & $-35-180$ & 25 \\
\hline Brazed PHE & $-195-200$ & 30 \\
\hline Welded PHEs & $\sim 350$ & 70 \\
\hline Spiral HE & $\sim 400$ & 18 \\
\hline Plate-fin (PFHE) & $\sim 65$ & 90 \\
\hline PCHE & $-200-900$ & 1,000 \\
\hline
\end{tabular}

\section{A-3. GENERAL SELECTION GUIDELINE FOR HEAT EXCHANGERS}

Bell (1981) suggested the following criteria for heat exchanger selection from various types:

- It must satisfy the process specification (performance): temperature and pressure.

- It must withstand service conditions of the plant environment (reliability): temperature, pressure and fouling.

- It must be maintainable for cleaning or replacement of a special component.

- It should be cost effective: installed, operating, and maintenance costs

- Site requirements or limitations: diameter, length, weight, and tube configurations, and lifting and servicing capability or inventory considerations.

Therefore, the followings are considered as main design factors for the selection and design of the IHX in a VHTR.

- Materials

- Pressure drop

- Pressure level

- Fouling

- Manufacturing techniques

- Size 
- Cost

- Corrosion control

- Cleaning problem.

\section{A-4. MATERIAL SELECTION FOR HIGH TEMPERATURE HEAT EXCHANGERS}

In the high temperature application, one of the most important things is material selection. There are four main categories of high temperature materials; high temperature nickel-based alloy, high temperature ferritic steels and advanced carbon, silicon carbide composite ( $\mathrm{SiC}$ ), and ceramics. (Sunden 2005)

High temperature nickel based material has good potential for helium and molten salts up to $750^{\circ} \mathrm{C}$. High temperature ferrite steels shows good performance under fusion and fission neutron irradiation, to temperature around $750^{\circ} \mathrm{C}$. Advanced carbon and silicon carbide composite has excellent mechanical strength to temperatures exceeding $1,000^{\circ} \mathrm{C}$. It is currently used for high temperature rocket nozzles to eliminate the need for nozzle cooling and for thermal protection of the space shuttle nose and wing leading edges. Many options are available that trade fabrication flexibility and cost, neutron irradiation performance, and coolant compatibility. Table A-3 compares the properties of most commonly used high temperature materials (Ohadi and Buckley 2001). It includes Ni based alloy, Ceramic materials and Carbon and $\mathrm{SiC}$ composite. Figure A-3 shows the specific strength versus temperature for various composite materials.

Table A-3. Selected properties of most commonly used high temperature materials and fabrication technologies (Ohadi and Buckley 2001).

\begin{tabular}{|c|c|c|c|c|}
\hline $\begin{array}{l}\text { High temp. material/ } \\
\text { fabrication technology }\end{array}$ & $\begin{array}{l}\text { Metallic } \mathrm{Ni} \text { alloys } \\
\text { (Inconel 718) }\end{array}$ & $\begin{array}{l}\text { Ceramics oxides of } \mathrm{Al}, \mathrm{Si}, \mathrm{Sr}, \mathrm{Ti}, \mathrm{Y} \text {, } \\
\mathrm{Be}, \mathrm{Zr}, \mathrm{B} \text { and } \mathrm{SiN}, \mathrm{AlN}, \mathrm{B} 4 \mathrm{C}, \mathrm{BN} \text {, } \\
\text { WC } 94 / \mathrm{C} 06\end{array}$ & $\begin{array}{l}\text { Carbon-carbon } \\
\text { composite }\end{array}$ & $\begin{array}{l}\text { Carbon fiber-SiC } \\
\text { composite }\end{array}$ \\
\hline Temperature range & $1200-1250^{\circ} \mathrm{C}$ & $1500-2500{ }^{\circ} \mathrm{C}$ & $\begin{array}{l}3300{ }^{\circ} \mathrm{C} \text { (inert } \\
\text { environment) } 1400- \\
1650^{\circ} \mathrm{C} \text { (with } \mathrm{SiC} \\
\text { layer) }\end{array}$ & $1400-1650^{\circ} \mathrm{C}$ \\
\hline Density & $8.19 \mathrm{~g} / \mathrm{cm}^{3}$ & $1.8-14.95$ & 2.25 & $1.7-2.2$ \\
\hline Hardness & $250-410$ (Brinell) & $400-3000 \mathrm{kgf} / \mathrm{mm}^{2}(\mathrm{~V})$ & $0.5-1.0$ (Mohs) & $2400-3500(\mathrm{~V})$ \\
\hline Elongation & $<15 \%$ & $\mathrm{~N} / \mathrm{A}$ & N/A & - \\
\hline Tensile strength & $800-1360 \mathrm{MPa}$ & $48-2000$ & 33 (Bulk Mod.) & $1400-4500$ \\
\hline Tensile modulus & $50 \mathrm{GPa}$ & $140-600$ & 4.8 & $140-720$ \\
\hline Strength of HE & $\begin{array}{l}\text { Strength - adequate, } \\
\text { but limited due to } \\
\text { creep and thermal exp }\end{array}$ & $\begin{array}{l}\text { Strength - not adequate, low } \\
\text { mechanical parameters for stress. } \\
\text { Good thermal and } \\
\text { electrical parameters }\end{array}$ & $\begin{array}{l}\text { Strength - poor, } \\
\text { oxidation starts } \\
\text { at } 300{ }^{\circ} \mathrm{C}\end{array}$ & $\begin{array}{l}\text { Highest due to carbon } \\
\text { fiber and } \mathrm{SiC}\end{array}$ \\
\hline Electrical conductivity & $125 \mu \Omega \mathrm{cm}$ & $2 \mathrm{E}-06-1 \mathrm{E}+18 \Omega \mathrm{cm}$ & $1375 \mu \Omega \mathrm{cm}$ & $1375 \mu \Omega \mathrm{cm}$ \\
\hline Thermal conductivity & $11.2 \mathrm{~W} / \mathrm{m} \mathrm{K}$ & $0.05-300$ & $80-240$ & Today up to 1200 \\
\hline Thermal expansion & $13 \mathrm{E}-061 / \mathrm{K}$ & $0.54-10 \mathrm{E}-061 / \mathrm{K}$ & $0.6-4.3 \mathrm{E}-061 / \mathrm{K}$ & $\begin{array}{l}-0.26-(-1.5) \mathrm{E}-061 / \\
\mathrm{K} \text { (Longitudinal) }+25 \\
\mathrm{E}-061 / \mathrm{K} \text { (Trans- } \\
\text { verse) }\end{array}$ \\
\hline Comments & $\begin{array}{l}\text { Metallic expansion } \\
\text { joints are the weak link }\end{array}$ & $\begin{array}{l}\text { Often very expensive fabrication } \\
\text { cost for conventional applications. } \\
\text { Technology proprietary for the most } \\
\text { part. Technologically hard to } \\
\text { produce }\end{array}$ & $\begin{array}{l}\text { Life-time is low even } \\
\text { protected by } \mathrm{SiC} \\
\text { (adhesion is poor) }\end{array}$ & $\begin{array}{l}\text { Comparatively less } \\
\text { expensive, successful } \\
\text { proprietary fabrication } \\
\text { technologies available. }\end{array}$ \\
\hline
\end{tabular}




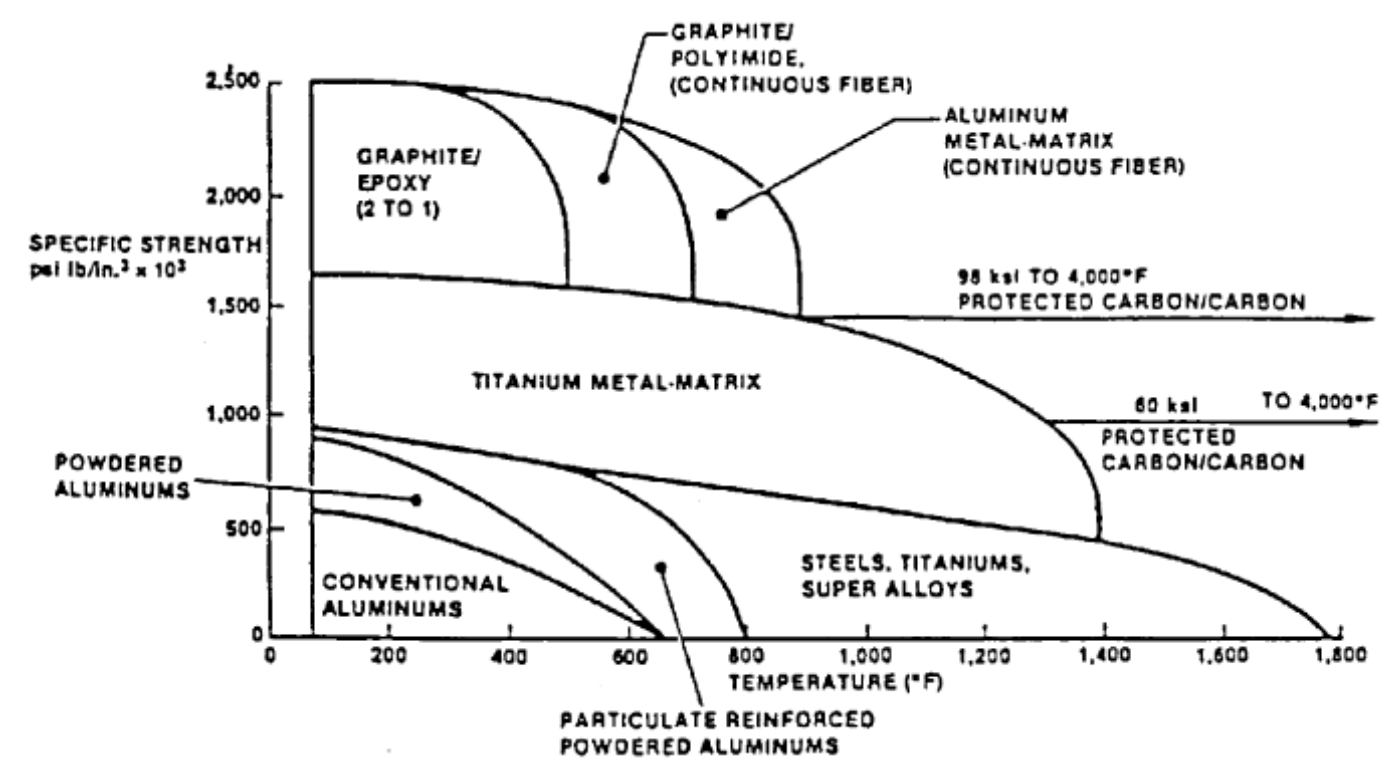

Figure A-3. Specific strength vs. temperature (Brent 1989).

Dewson and Li [2005] carried out some material selection studies for VHTR IHXs. They selected eight candidate materials based on ASME VIII (Boiler and Pressure Vessel Code) and compared them. The materials included Alloy 617, Alloy 556, Alloy 800H, Alloy 880 HT, Alloy 330, Alloy 230, Alloy heat exchanger, $253 \mathrm{MA}$. Table A-4 lists the allowable design stress (S) at $898^{\circ} \mathrm{C}$, the minimum required mechanical properties (ultimate tensile stress [UTS]), $0.2 \%$ proof stress $(0.2 \% \mathrm{PS})$, and elongation (El) at room temperature together with the nominal compositions of the alloys. They extensively compared the mechanical properties, physical properties, and corrosion resistance for the candidate materials, and finally concluded that Alloy 617 and 230 are the most suitable materials for an IHX.

Table A-4. Candidate materials for IHXs of VHTR (Dewson and Li 2005).

\begin{tabular}{|c|c|c|c|c|c|c|c|}
\hline Alloys & UNS No & $\begin{array}{l}\mathbf{T}_{\max } \\
\left({ }^{\circ} \mathbf{C}\right)\end{array}$ & $\begin{array}{l}\mathrm{S}^{2} 98^{\circ} \mathrm{C} \\
(\mathrm{MPa})\end{array}$ & $\begin{array}{l}\text { UTS } \\
\text { (MPa) }\end{array}$ & $\begin{array}{l}\text { 0.2\%PS } \\
\text { (MPa) }\end{array}$ & $\begin{array}{c}\text { El } \\
(\%)\end{array}$ & $\begin{array}{c}\text { Nominal compositions } \\
(\mathbf{w t} \%)\end{array}$ \\
\hline 617 & N06617 & 982 & 12.4 & 655 & 240 & 30 & $52 \mathrm{Ni}-22 \mathrm{Cr}-13 \mathrm{Co}-9 \mathrm{Mo}-1.2 \mathrm{Al}$ \\
\hline 556 & $\mathrm{R} 30556$ & 898 & 11.0 & 690 & 310 & 40 & $\begin{array}{l}21 \mathrm{Ni}-30 \mathrm{Fe}-22 \mathrm{Cr}-18 \mathrm{Co}-3 \mathrm{Mo}- \\
3 \mathrm{~W}-0.3 \mathrm{Al}\end{array}$ \\
\hline $800 \mathrm{HT}$ & N08811 & 898 & 6.3 & 450 & 170 & 30 & $33 \mathrm{Ni}-42 \mathrm{Fe}-21 \mathrm{Cr}$ \\
\hline $800 \mathrm{H}$ & N08810 & 898 & 5.9 & 450 & 170 & 30 & $33 \mathrm{Ni}-42 \mathrm{Fe}-21 \mathrm{Cr}$ \\
\hline 330 & N08330 & 898 & 3.3 & 483 & 207 & 30 & $\mathrm{Fe}-35 \mathrm{Ni}-19 \mathrm{Cr}-1.25 \mathrm{Si}$ \\
\hline 230 & N06230 & 898 & 10.3 & 760 & 310 & 40 & $\begin{array}{l}57 \mathrm{Ni}-22 \mathrm{Cr}-14 \mathrm{~W}-2 \mathrm{Mo}-0.3 \mathrm{Al}- \\
0.05 \mathrm{La}\end{array}$ \\
\hline $\mathrm{HX}$ & N06002 & 898 & 8.3 & 655 & 240 & 35 & $47 \mathrm{Ni}-22 \mathrm{Cr}-9 \mathrm{Mo}-18 \mathrm{Fe}$ \\
\hline $253 \mathrm{MA}$ & S30815 & 898 & 4.9 & 600 & 310 & 40 & $\mathrm{Fe}-21 \mathrm{Cr}-11 \mathrm{Ni}-0.2 \mathrm{~N}$ \\
\hline
\end{tabular}




\section{A-5. HEAT EXCHANGER DESIGN METHODOLOGY}

A selected heat exchanger must satisfy the process requirements with the allowable pressure drops until the next scheduled cleaning of the plant. The basic logical structure of the process heat exchanger design procedure summarized in this section is well explained by Bell (2003).

Figure A-4 shows the diagram of the logical process for heat exchanger design. The fundamental goal of any such process is to find the optimal design among the infinite set of designs that could satisfy the thermal/hydraulic and mechanical requirements. Because of large number of qualitative factors in the design process, optimal needs to be considered broadly. Generally, the design process aims at the least costly (which usually means the smallest) heat exchangers that meet the required thermal duty within the allowed pressure drops and satisfy mechanical requirements.

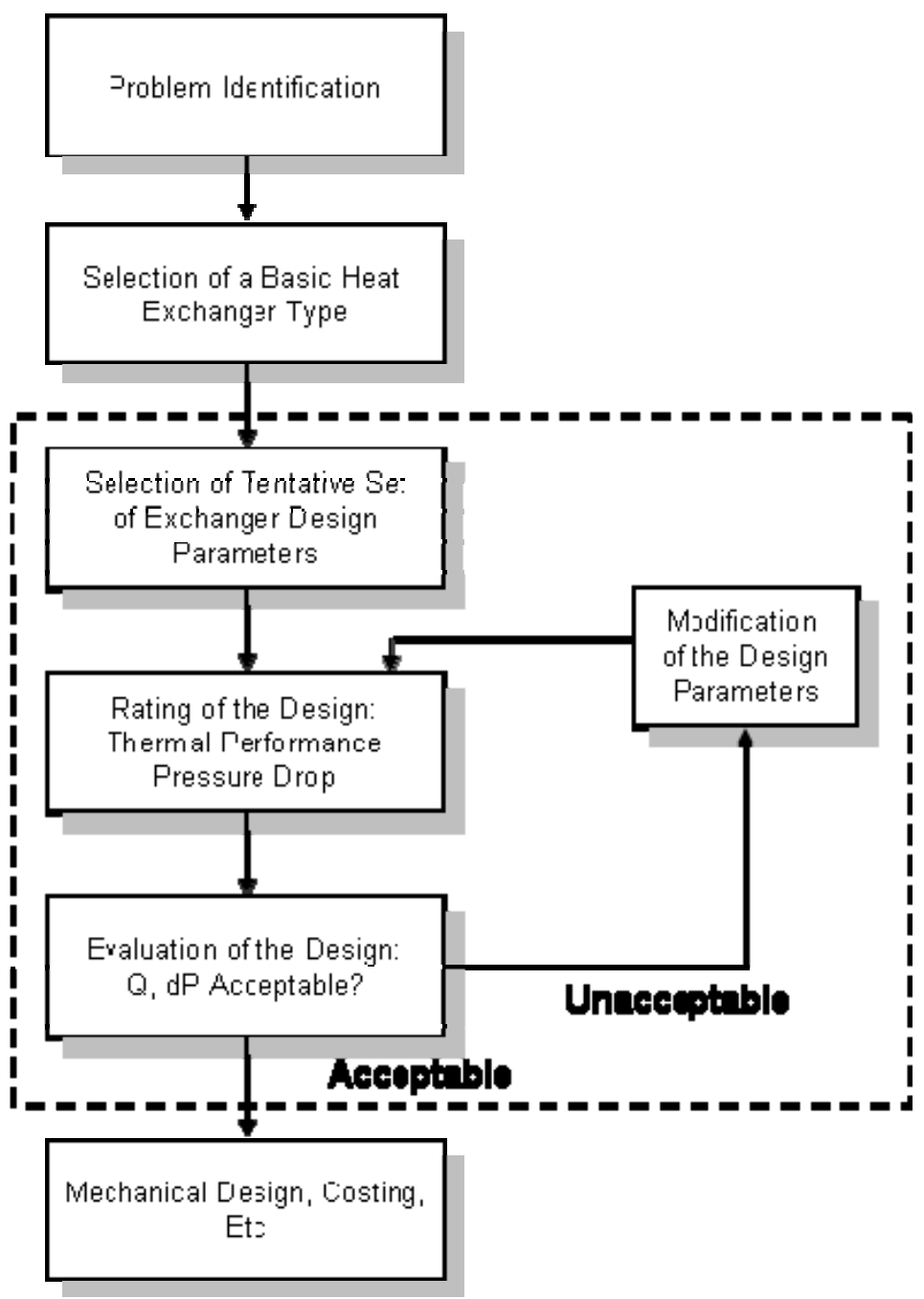

Figure A-4. Basic logical structure of the process heat exchanger design procedure (Bell 2005). 
The first step of the design procedure is to define the problem and provide the designer with all the data required to solve the problem. This will include the flow rates, compositions, temperatures, pressures, etc.; design fouling resistances based on the experience with the same or similar materials; and additional requirements and limitations on diameter, length, weight, piping connections, supports, and construction features.

The next step is to select a basic exchanger type; a shell-and-tube versus a welded plate, etc. In fact, there is an increasingly wide choice of exchanger configurations available for most applications, and some of the established practices should at least be re-examined to see if there might be attractive alternatives. The following factors should be considered in this step (Bell 2005).

- Level of confidence in the design method - is the method backed up by solid performance data either from the laboratory or the field?

- Level of confidence in the fabrication technique - does the equipment have a good service experience record? What lifetime can be expected?

- Level of confidence in plant operating and maintenance personnel with respect to this equipment - do they know the characteristics of this equipment, and are they able to maintain and clean it?

- Operational flexibility - can this equipment or its operating conditions be adjusted or modified to meet likely changes in plant requirement?

- Cost of the equipment.

The next step is to select a tentative but sufficient set of exchanger design parameters to allow the rating procedure to work. For the case of a shell-and-tube heat exchanger, these would include the process specifications, Tubular Exchangers Manufacturer's Association (TEMA) exchanger configuration identifier, the shell diameter, the tube diameter and wall thickness, tube layout, baffle type, baffle spacing and cut, and etc. Additional information would include nozzle orientation data, maximum allowable diameter and length, type of bypass sealing devices, and the requirement that TEMA construction standards for such items as tube-to-baffle clearance would be met. If a hand design method is to be used, these values can be estimated as close as possible.

The next step is to rate the performance of the starting design for the specified service. It takes specified streams and their input conditions and calculates the changes in temperature and pressure affected on those streams by the specified heat exchanger. The thermal rating output is either the outlet temperatures and corresponding thermal duty of the exchanger if the length has been specified, or the length required for the otherwise specified exchanger to satisfy the thermal duty given in the input data. The pressure drops of each stream are also calculated.

In the design case, the heat duty is compared to that required and the pressure drops to those allowed. If the duty is sufficient and both pressure drops are near but below the allowed values, the thermal/hydraulic design is complete and the designer can move the cleaning up and verify the mechanical design, cost estimations, etc. If all of those conditions are not satisfied, the designer or the program moves on to the design modification step. The purpose of this step is to examine the output of the rating program and determine what is good and acceptable and what was unacceptable in the case that was rated. Then, the designer or the program must select what can be changed to most efficiently correct the deficiency without too badly upsetting that which was good. 


\section{A-6. SHELL-AND-TUBE HEAT EXCHANGER GENERAL DESIGN GUIDELINE AND CONSTRAINT}

The shell-and-tube heat exchanger are the most common type. They are built of round tubes mounted in a cylindrical shell with the tubes parallel to the shell. This section summarizes the general guideline and design constraints for this type of heat exchanger. The design options and parameters are based on the standard suggested by TEMA.

\section{A-6.1 Shell Type}

Figure A-5 shows most common shell types standardized by TEMA. Of these types, the E shell generally provides the lowest cost and best performance, which makes it the most widely used for most applications. F shell is more effective than E shell in thermal performance, but it has a higher pressure drop. This type is combined with the $U$ tube bundles. F shell can always avoid temperature cross, but it is difficult to seal the longitudinal baffles after maintenance. J shell split the flow arrangement to minimize vibration problem, and $\mathrm{X}$ shell with cross-bundle fluid flow is an excellent choice for vacuum condensation applications.
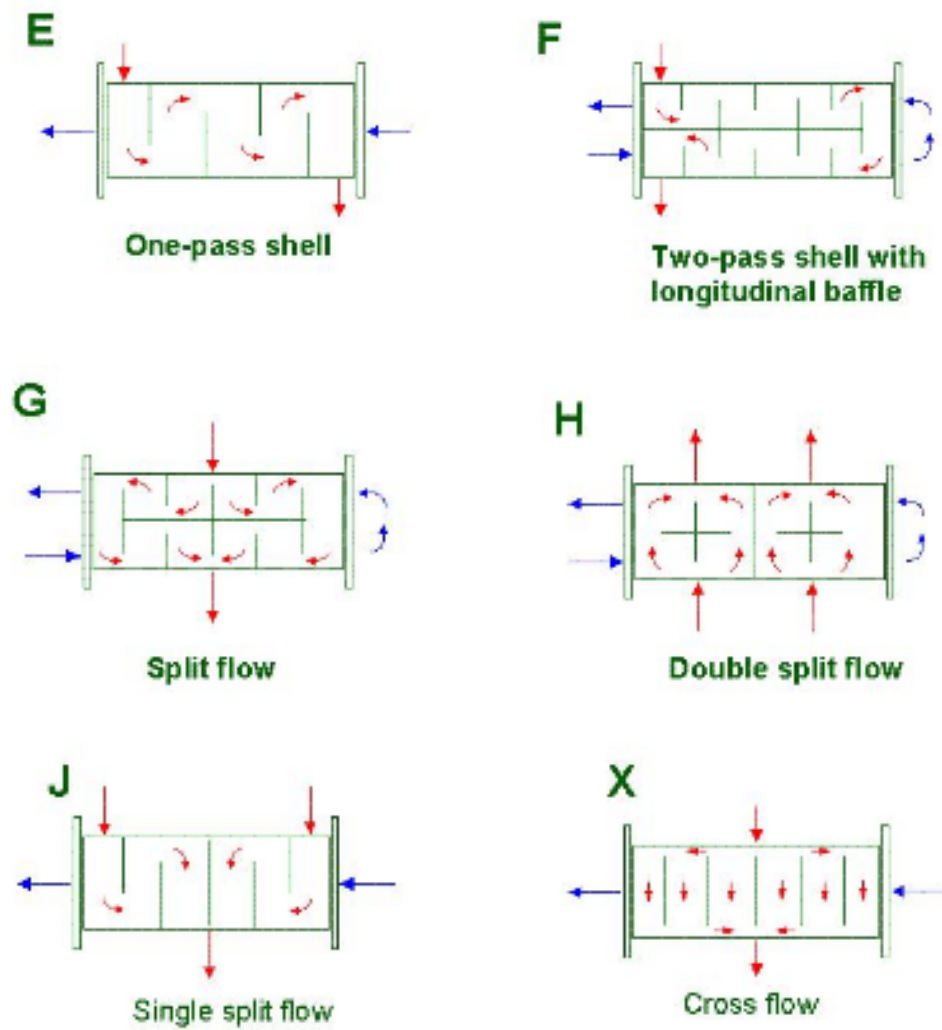

Figure A-5. Schematics of most common TEMA shell types (ASPEN 2005).

\section{A-6.2 Tube Bundle Type/Tubes and Tube Passes/Tube Layout}

The selection and design of tube bundle types generally focus on accommodating thermal expansion, ease of cleaning, or the least expensive construction. The most common type is a straight tube bundle. One design variation is the U-tube type. In this type, thermal expansion is unlimited because of the independent expansion of tubes and shell. But it cannot be cleaned by mechanical means because of the 
U-bend and individual tubes can only be replaced in the outer row. A fixed-tube sheet configuration has only limited thermal expansion, and permits no access to the tubes from outside. However, cleaning is mechanically easy. Several designs have been developed that permit the tube sheet to float, that is, to move with thermal expansion.

Generally, a large number of tube passes are used to increase tube-side fluid velocity and the heat transfer coefficient (within the available pressure drop) and to minimize fouling. Tube materials are usually low carbon steel, low alloy steel, stainless steel, copper, cupronickel, aluminum, or titanium. The thickness of the heat exchanger tubes is standardized in terms of the Birmingham Wire Gage of the tubes (Refer to Heat Exchanger Design Handbook, Kakac 2002). TEMA lists nine standard tube sizes ranging from 6.35 to $50.8 \mathrm{~mm}(0.25$ to $2 \mathrm{in}$.) in diameter. The most common sizes used are $16 \mathrm{~mm}(0.625 \mathrm{in}$.), $19.05 \mathrm{~mm}(0.75 \mathrm{in}$.) and $25.4 \mathrm{~mm}$ ( $1 \mathrm{in}$.). For $U$ tubes, the thinning effect at bends should be considered. Usually, smaller tube diameters are preferred for greater area/volume density, but they are limited to 20 $\mathrm{mm}(3 / 4 \mathrm{in}$.) for the purpose of cleaning. Tube length affects the cost and operation of heat exchangers. The longer the tube, the fewer tubes are needed, fewer holes are drilled, and the shell diameters are decreased, resulting in lower cost. However, there are limits to this. Usually, shell-diameter-to-tub-length ratio should be within one-fifth to one-fifteenth. Standard tube lengths are 2.44, 3.05, 3.66, 4.27, and 6.1 $\mathrm{m}$. For gas plants and special applications, much longer lengths are possible (20 $\mathrm{m}$ or more), with the maximum tube length being about $30 \mathrm{~m}$, due to transportation limits.

Tube layout is characterized by the included angle between tubes, as shown in Figure A-6. Since the layout of 30 degrees provides the greatest tube density, it is the most generally used. Pitch-to-diameter ratio is selected between 1.25 and 1.5 .

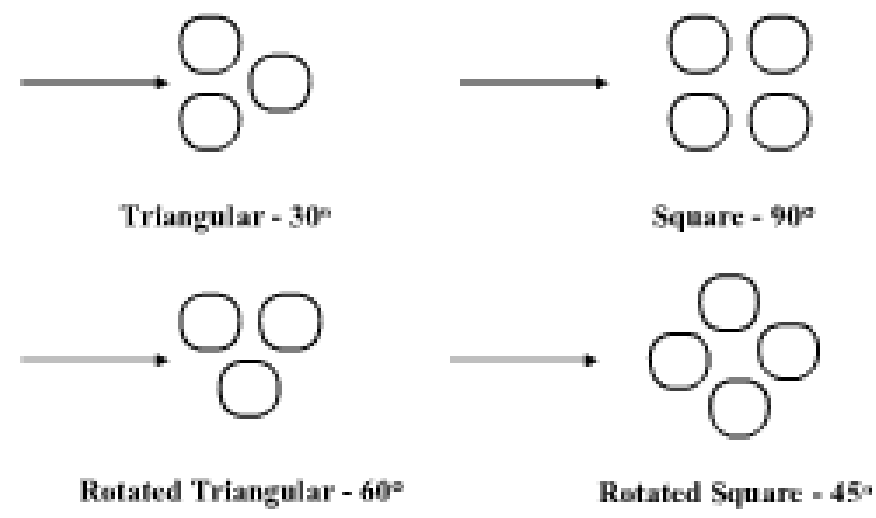

Figure A-6. Tube layouts.

\section{A-6.3 Baffle Type and Geometry}

Baffles serve two functions. One is to support the tubes for structural rigidity, preventing tube vibration and sagging; the other is to divert flow across the bundle to obtain higher heat transfer coefficient. They can be classified as transverse and longitudinal types. The most frequently used type is single and double segmental baffles. Baffle spacing must be chosen very carefully. Optimum baffle spacing is somewhere between 0.4 and 0.6 of the shell diameter and a baffle cut of $25-35 \%$ is usually recommended. Minimum recommended spacing is $50 \mathrm{~mm}$. Maximum baffle spacing is controlled by the maximum unsupported length given in TEMA (UNS $=2 *$ baffle spacing) and vibration analyses. Small baffle spacing $(<0.2$ times shell diameter) can reduce the cross flow because of leakage. Rod or grid baffles are formed by a grid or strip supports. In this baffle type, the flow is essentially longitudinal, resulting in low pressure drop. 


\section{A-6.4 Allocation of Streams}

A decision must be made as to which fluid will flow through the tubes and which will flow through the shell. Generally, the following things are considered:

- More seriously fouling fluid flow through the tubes.

- High pressure fluid flows through the tubes.

- The corrosive fluid must flow through the tubes; otherwise both the shell and tubes will be corroded.

- Lower heat transfer coefficients flow on the shell side, since it is easy to design outside finned tubes.

If problems arise when the above requirements are in conflict, the most economical choices must be found by estimating trade-offs.

\section{A-6.5 Construction}

Standard pipe sizes are normally used for shell size up to $610 \mathrm{~mm}$ (24 in.). The diameter generally increases in $50 \mathrm{~mm}$ increments for sizes over $610 \mathrm{~mm}$. Most manufacturers are limited to a maximum shell size of $1,800 \mathrm{~mm}$ in diameter, but there are some capable of manufacturing units over 4,300 $\mathrm{mm}$ in diameter. In general, the cost of the exchanger increases significantly as the diameter increases because of the mechanical design requirement to increase the thickness of the vessel cylinder, body flanges, and tube sheets.

\section{A-6.6 Vibration}

Tube vibration is generally a result of one or more of the followings.

- High fluid velocity

- Large unsupported tube span

- Tube material defects

- Manufacturing process

- Exchanger design/application

- Fluid elastic instability/vortex shedding/turbulent buffering

- Damage patterns by the vibration are:

- Collision damage: impact of tubes against each other

- Baffle damage: tube wall thinning at baffles

- Fatigue: tube failure at the tube sheets

- Tube joint failure: leakage at tube to tube sheet joint

- Tube material defect propagation: failure at inherent tube defect.

Figure A-7 shows the area prone to vibration. To relieve vibration, ratio of cross velocity to critical velocity should be less than 1.0, and vertex shedding amplitude should be less than the limit governed primarily by the tube diameter. In addition, turbulent buffering amplitude should be less than the recommended maximum limit based on the tube diameter. 


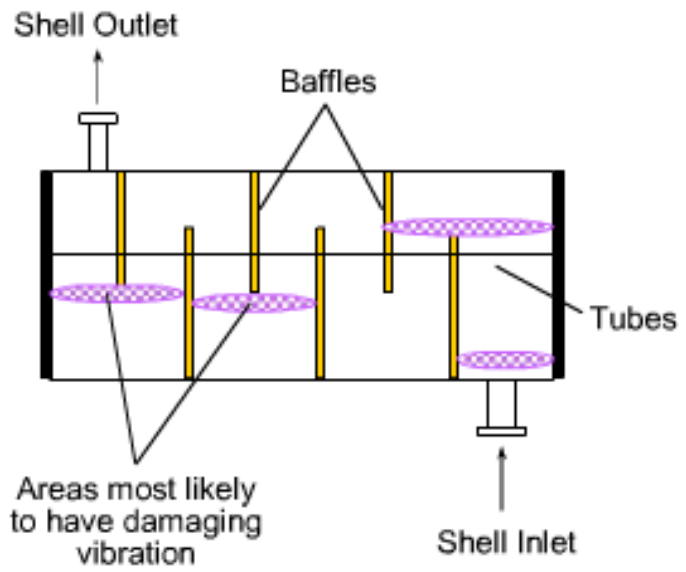

Figure A-7. Areas prone to vibration (ASPEN 2005).

\section{A-6.7 Modification of Design Parameters}

For the heat exchanger to meet the requirements, main design parameters should be modified. Table A-5. summarizes the guideline for design parameters changes and criteria.

Table A-5. Guideline for design parameter change.

\begin{tabular}{|c|c|c|c|c|c|c|}
\hline $\begin{array}{c}\text { Adjusted } \\
\text { Parameters } \\
\text { Optimized } \\
\text { by Program } \\
\end{array}$ & $\begin{array}{c}\text { High } \\
\text { Pressure } \\
\text { Drop Shell } \\
\text { Side } \\
\end{array}$ & $\begin{array}{c}\text { High } \\
\text { Pressure } \\
\text { Drop Tube } \\
\text { Side } \\
\end{array}$ & $\begin{array}{c}\text { Low } \\
\text { Coefficient } \\
\text { Shell Side } \\
\end{array}$ & $\begin{array}{l}\text { Low } \\
\text { Coefficient } \\
\text { Tube Side } \\
\end{array}$ & $\begin{array}{c}\text { Temperature } \\
\text { Cross }\end{array}$ & $\begin{array}{c}\text { Vibration } \\
\text { Indication }\end{array}$ \\
\hline Baffle type & $\begin{array}{l}\begin{array}{l}\text { Double/Triple } \\
\text { segmental }\end{array} \\
\end{array}$ & - & $\begin{array}{l}\text { Single } \\
\text { Segmental } \\
\end{array}$ & - & - & $\begin{array}{l}\begin{array}{l}\text { Double/triple } \\
\text { segmental }\end{array} \\
\end{array}$ \\
\hline Shell type & $\begin{array}{l}\text { J or X type } \\
\text { shell }\end{array}$ & - & $\begin{array}{l}\text { E or F type } \\
\text { shell }\end{array}$ & - & $\begin{array}{l}\text { E,F or G type } \\
\text { shell }\end{array}$ & $\begin{array}{l}\text { J or X type } \\
\text { shell }\end{array}$ \\
\hline Tube pattern & $\begin{array}{l}\text { Rotated } \\
\text { square or } \\
\text { square }\end{array}$ & - & Triangular & - & - & $\begin{array}{l}\text { Rotated } \\
\text { Square }\end{array}$ \\
\hline $\begin{array}{l}\text { Tube } \\
\text { diameter }\end{array}$ & $\begin{array}{l}\text { Increase to } 1 " \\
\text { or } 1 / 25,\end{array}$ & $\begin{array}{l}\text { Increase to } \\
1 " \text { to } 1.25^{\prime}\end{array}$ & $\begin{array}{l}\text { Decrease to } \\
0.625^{\prime \prime} \text { or } \\
0.5^{\prime \prime}\end{array}$ & $\begin{array}{l}\text { Decrease to } \\
0.625 \text { " or } \\
0.5 "\end{array}$ & - & $\begin{array}{l}\text { Increase to } \\
1 " \text { or } 1.25 "\end{array}$ \\
\hline Baffle cut & $\begin{array}{l}\text { Use } 30 \% \text { to } \\
40 \%\end{array}$ & - & $\begin{array}{l}\text { Use } 15 \% \text { to } \\
20 \%\end{array}$ & - & - & - \\
\hline Tube pitch & $\begin{array}{l}\text { Increase to } 1.4 \\
\text { or } 1.5 \mathrm{X} \text { tube } \\
\text { OD }\end{array}$ & - & $\begin{array}{l}\text { Limit to } \\
\text { TEMA std } \\
\text { spacing }\end{array}$ & - & - & $\begin{array}{l}\text { Increase to } \\
1.4 \text { or } 1.5 \mathrm{X} \\
\text { tube OD }\end{array}$ \\
\hline $\begin{array}{l}\text { Fluid } \\
\text { allocation }\end{array}$ & Switch sides & Switch sides & Switch sides & Switch sides & - & Switch sides \\
\hline Arrangement & $\begin{array}{l}\text { Increase \# of } \\
\text { exch. In } \\
\text { parallel }\end{array}$ & $\begin{array}{l}\text { Increase \# of } \\
\text { exch. In } \\
\text { parallel }\end{array}$ & $\begin{array}{l}\text { Increase \# of } \\
\text { exch. In } \\
\text { series }\end{array}$ & - & $\begin{array}{l}\text { Increase \# of } \\
\text { exch. In } \\
\text { series }\end{array}$ & $\begin{array}{l}\text { Increase \# of } \\
\text { exch. In } \\
\text { parallel }\end{array}$ \\
\hline $\begin{array}{l}\text { \# Tube } \\
\text { passes }\end{array}$ & - & Plain & - & $\begin{array}{l}\text { Increase \# of } \\
\text { tube passes }\end{array}$ & $\begin{array}{l}\text { Limit to one } \\
\text { tube pass }\end{array}$ & - \\
\hline Tube type & Plain & & $\begin{array}{l}\text { Ext. } \\
\text { Enhanced }\end{array}$ & $\begin{array}{l}\text { Internally } \\
\text { enhanced }\end{array}$ & - & - \\
\hline
\end{tabular}




\section{A-7. PCHE DESIGN GUIDELINE AND CONSTRAINT}

The PCHE is a compact heat exchanger manufactured by Heatric. The flow path of this heat exchanger is created by chemical etching on the metal sheet, and they are combined though a diffusion bonding technique. A PCHE is all welded so there is no braze material employed in construction, and no gaskets are required. Hence the potential for leakage and fluid compatibility difficulties are reduced and the high level of constructional integrity renders the designs exceptionally well suited to critical high pressure applications, such as gas compression cooling exchangers on offshore platforms.

The thermal design of printed circuit heat exchangers is subjected to very few constraints. Fluids may be liquid, gas or two-phase, multistream and multipass configurations can be assembled and flow arrangements can be truly counter-current, co-current or cross-flow, or a combination of these, at any required pressure drop.

Where required, high heat exchange effectiveness (over 98\%) can be achieved through very close temperature approaches in counter-flow. To simplify control or further maximize energy efficiency, more than two fluids can exchange heat in a single core. Heat loads can vary from a few watts to many megawatts, and these exchanger's can weight from a few kilograms to thousands of kilograms.

Flow induced vibration, an important source of failure in shell-and-tube exchangers, is absent from printed heat exchangers.

Lots of useful information for PCHE design was reported by Gezelius 2004 in his thesis, which includes the summary of the workshop in 2003 between MIT and Heatric. In this part, we summarized the guideline and criteria for designing the PCHE for IHX.

- No gasket and blazing (risk of leak is considerably reduced): two order of magnitude lower

- Very low vibration damage

- No fouling under clean gas condition

- Surface area density: about $2,500 \mathrm{~m}^{2} / \mathrm{m}^{3}$

- No heat transfer and friction factor correlations are available

- Semi-circular cross-section

- Width: 1.0-2.0 mm (2.0 mm shows maximum thermal performance and economic efficiency but for nuclear application, $1.2 \mathrm{~mm}$ is suggested.)

- Depth: 0.5-1.0 mm

- Weight based costing: $\$ 30 / \mathrm{kg}$ for stainless steel, $\$ 120 / \mathrm{kg}$ for titanium, expected to be less than $\$ 40 / \mathrm{kg}$ for nuclear application

- Carbon steel is typically not used because of the small channel diameter vulnerable to corrosion and unsuitability for diffusion bonding.

- Average mass-to-duty ratio: 0.2 tones/MW (13.5 tones/MW in shell-and-tube design)

- No constraint to the pressure drop

- Plate thickness: 0.8D (D: channel diameter)

- Channel pitch: 1.22D (D: channel diameter) 
- Multiport Printed Circuit Heat Exchanger module size: width: $0.5 \mathrm{~m}$ (1.5m is max), height: $0.6 \mathrm{~m}$, depth: $0.4 \sim 0.6 \mathrm{~m}$.

- Fatigue can be caused by thermal transient.

- Only pressure drop restrict the velocity.

- Minimum life is 20 years. 


\section{Appendix B \\ Thermal Design Method of Helical Coil Heat Exchanger}




\section{Appendix B Thermal Design Method of Helical Coil Heat Exchanger}

A simple thermal design method for helical coil heat exchangers is described in this appendix.

Figures B-1 and B-2 show the schematics of helical coil heat exchangers and the tube bundles for HTTR IHX (Kato et al. 2007).

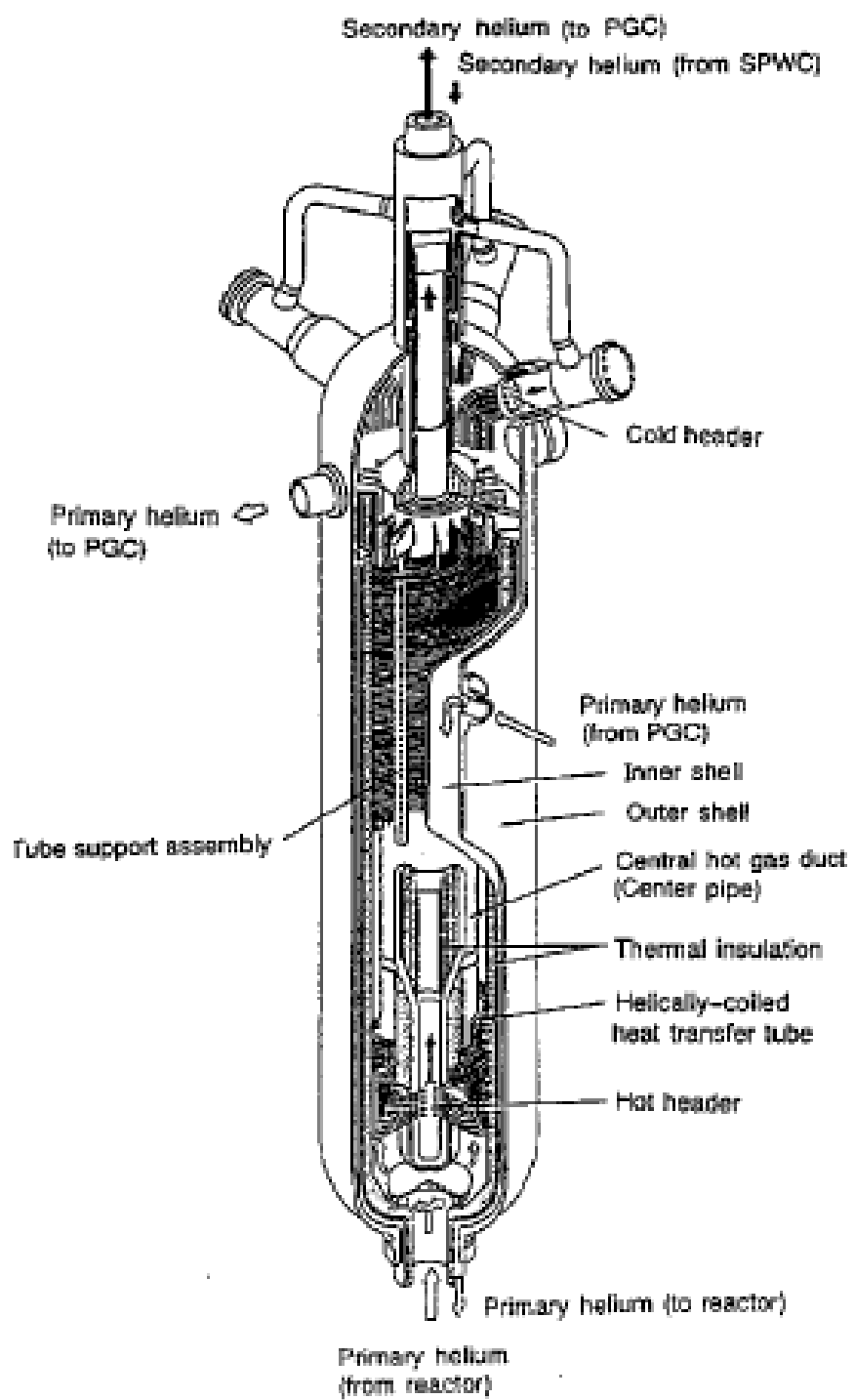

Figure B-1. Schematics of HTTR IHX (Kato et al. 2007). 


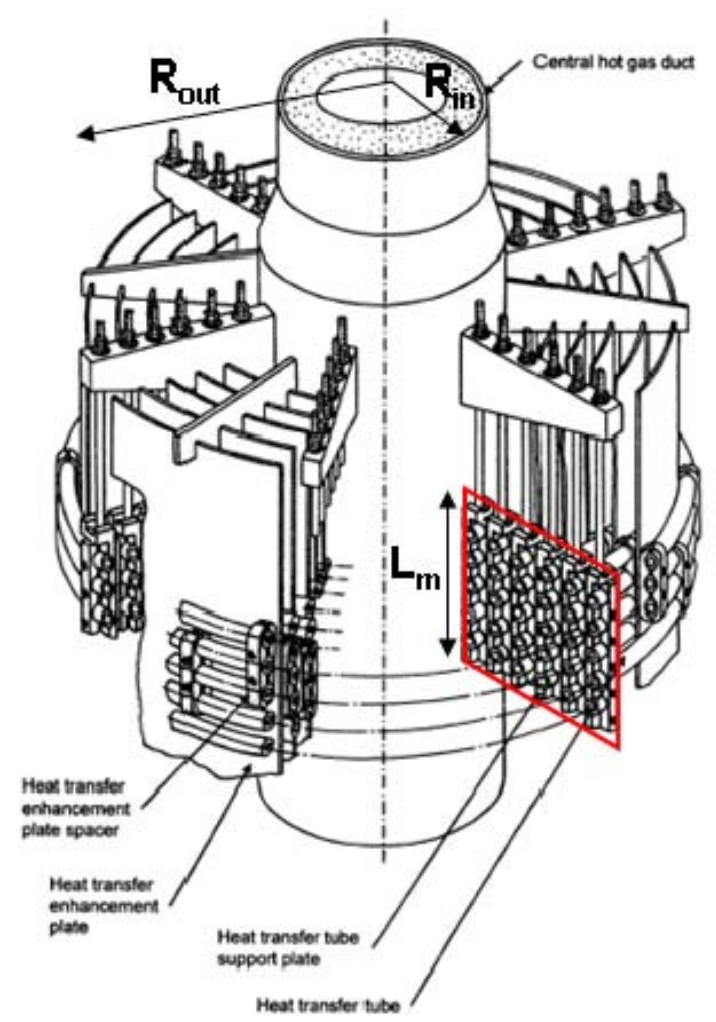

Figure B-2. Structural diagram of heat transfer tube bundle of HTTR (Kato et al. 2007).

\section{B-1. GEOMETRICAL PARAMETERS}

In this type of heat exchanger, the number of tubes in the bundle can be determined by

$$
N_{t}=\frac{\left(R_{\text {out }}-R_{\text {in }}\right)}{p} \times \frac{L_{m}}{p} .
$$

where

$$
\begin{aligned}
& N_{t}=\text { Number of tubes in the bundle (\#) } \\
& R_{\text {in }}=\text { Shell inner diameter }(\mathrm{m}) \\
& R_{\text {out }}=\text { Shell outer diameter }(\mathrm{m}) \\
& L_{m}=\text { Tube bundle height }(\mathrm{m}) \\
& p=\text { Tube pitch (m) }
\end{aligned}
$$

The $R_{\text {out }}$ and $R_{\text {in }}$ has the following relationship because the tube bundles connected at the inner hot duct.

$$
\left(R_{\text {out }}-R_{\text {in }}\right) \leq 2 \pi \cdot R_{\text {in }}
$$


Therefore, minimum $R_{\text {in }}$ can be expressed as follows:

$$
R_{\text {in }}=\frac{R_{\text {out }}}{3 \pi}
$$

The tube lengths can be calculated as follows:

1. Inner layer

$L_{t, i n}=2 \pi R_{i n} \times N_{b}$

2. Outer layer

$$
L_{t, \text { out }}=2 \pi R_{\text {out }} \times N_{b}
$$

3. Middle layer

$$
L_{t, \text { middle }}=\pi\left(R_{\text {in }}+R_{\text {out }}\right) \times N_{b}
$$

where

$L_{t, \text { in }}=$ Tube length in the inner layer $(\mathrm{m})$

$L_{t, \text { out }}=$ Tube length in the outer layer $(\mathrm{m})$

$L_{t, \text { middle }}=$ Tube length in the middle layer (m)

$N_{b} \quad=\quad$ Number of rotations of the tube bundle (m)

The shell length is calculated by

$L_{s}=L_{m} \times N_{b}$

The tube outer surface area can be approximately determined as follows:

$A_{h}=\pi d_{0} \cdot L_{t, \text { middle }} \cdot N_{t}$

\section{B-1.1 Heat Transfer Correlations}

The heat transfer of the heat exchanger can be expressed by

$Q=U \cdot A_{s} \cdot \Delta T_{\mathrm{ln}}$

where

$$
U \approx \frac{1}{\frac{1}{h_{s}}+R_{w}+\frac{1}{h_{t}}}
$$

$\Delta T_{\ln }$ is $\log$ mean temperature. 
The heat transfer coefficient in the shell and tubes can be expressed as follows:

1. Shell Side - inline tube bundles in smooth pipe (Zukauskas 1987)

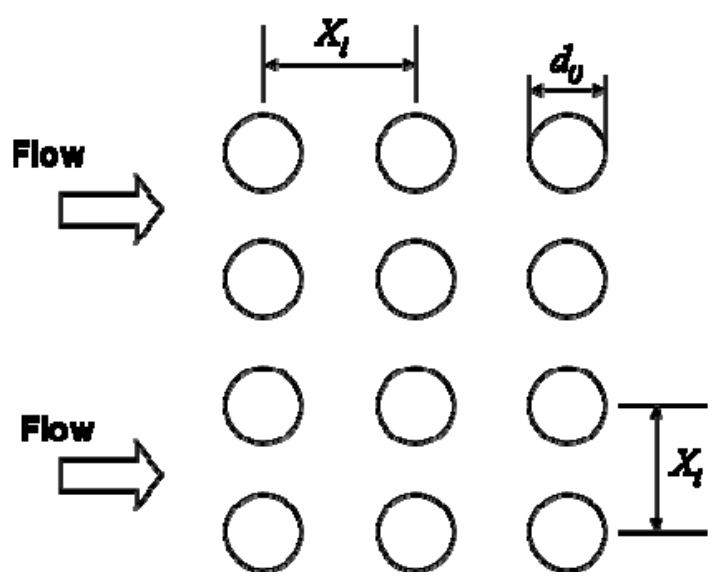

Figure B-3. Tube Bundle Arrangement (inline array).

$$
\begin{aligned}
& N u_{b}=0.9 \cdot c_{n} \operatorname{Re}_{b}{ }^{0.4} \operatorname{Pr}_{b}^{0.36}\left(\frac{\operatorname{Pr}_{b}}{\operatorname{Pr}_{w}}\right)^{0.25} \quad\left(\text { for } \operatorname{Re}_{\mathrm{b}}=1-10^{2}\right) \\
& N u_{b}=0.52 \cdot c_{n} \operatorname{Re}_{b}{ }^{0.5} \operatorname{Pr}_{b}^{0.36}\left(\frac{\operatorname{Pr}_{b}}{\operatorname{Pr}_{w}}\right)^{0.25} \quad\left(\text { for } \operatorname{Re}_{\mathrm{b}}=10^{2}-10^{3}\right) \\
& N u_{b}=0.27 \cdot c_{n} \operatorname{Re}_{b}^{0.63} \operatorname{Pr}_{b}^{0.36}\left(\frac{\operatorname{Pr}_{b}}{\operatorname{Pr}_{w}}\right)^{0.25} \quad\left(\text { for } \operatorname{Re}_{\mathrm{b}}=10^{3}-2 \mathrm{X} 10^{5}\right) \\
& N u_{b}=0.033 \cdot c_{n} \operatorname{Re}_{b}{ }^{0.8} \operatorname{Pr}_{b}{ }^{0.4}\left(\frac{\operatorname{Pr}_{b}}{\operatorname{Pr}_{w}}\right)^{0.25} \quad\left(\text { for } \operatorname{Re}_{\mathrm{b}}=2 \mathrm{X} 10^{5}-2 \mathrm{X} 10^{6}\right)
\end{aligned}
$$

where,

$c_{n}=$ a correction factor for the number of tube rows (the effect of the number of tubes becomes negligible only when $\mathrm{n}>16$.)

$P r_{b}=$ Prandtl number for the bulk mean temperature

$P r_{w}=$ Prandtl number for the wall temperature 
The Reynolds number $\left(R e_{b}\right)$ is defined based on the average velocity through the narrowest cross section formed by array, that is, the maximum average velocity.

$\operatorname{Re}_{b}=\frac{U_{0} d_{0} \rho}{\mu}$

where

$U_{0}=\frac{\dot{m}_{s}}{\rho \cdot \pi\left(R_{\text {out }}{ }^{2}-R_{\text {in }}{ }^{2}\right) \cdot\left(1-d_{0} / p\right)}$

(b) Tube Side — helical coil for turbulent flow (Schmidt's correlation [Shah et al. 1987])

$$
\frac{N u_{c}}{N u_{s}}=1.0+3.6\left[1-\left(\frac{a}{R}\right)\right]\left(\frac{a}{R}\right)^{0.8}
$$

where

$$
\begin{aligned}
& N u_{c}=\text { Nusselt Number for the curved coil } \\
& N u_{s}=\text { Straight Tube Nusselt Number } \\
& a=\text { Radius of the tube }\left(=d_{0} / 2\right) \\
& R=\text { Radius of the curvature }\left(R_{\text {in }} \sim R_{\text {out }}\right)
\end{aligned}
$$

The straight tube Nusselt number for turbulent flow can be calculated by Dittus-Boelter correlation (Kays and Crawford 1981) as

$$
N u_{s}=0.022 \operatorname{Re}_{b}^{0.8} \operatorname{Pr}_{b}^{0.5}
$$

\section{B-1.2 Pressure Drop in Tube Bundles}

1. Shell Side-Pressure drop in tube bundles in cross flow (Kakac and Liu 2002)

The pressure drop of multirow bundle is given by

$$
\Delta P_{\text {shell }}=\left(\frac{E u}{\chi}\right) \chi \frac{1}{2} \rho U_{0}^{2} \cdot n
$$

where

$$
\begin{aligned}
\mathrm{Eu} & =\text { Euler number } \\
\chi & =\text { correction factor } \\
\mathrm{N} & =\text { number of tube rows counted in the flow direction }
\end{aligned}
$$


2. Tube Side - Pressure drop in tube bundles in cross flow (Kakac and Liu 2002)

The pressure drop in the tube can be calculated by

$$
\Delta P_{\text {tubes }}=4 f \frac{L}{d_{i}} \rho \frac{u_{m}{ }^{2}}{2}
$$

where

$$
\begin{aligned}
f & =\text { friction factor } \\
L & =\text { tube length }(\mathrm{m}) \\
D_{i} & =\text { tube inner diameter }(\mathrm{m}) \\
u_{m} & =\text { mean flow velocity in the tube }(\mathrm{m} / \mathrm{s})
\end{aligned}
$$

The mean velocity can be determined by

$$
u_{m}=\frac{\dot{m}_{t}}{\rho \cdot\left(\pi \cdot d_{i}^{2}\right) \cdot N_{t}}
$$

The friction factor of the helical coil for the turbulent flow is as follows (Srinivasan et al. 1970):

$$
f_{c}\left(\frac{R}{a}\right)^{0.5}=0.0084\left[\operatorname{Re}\left(\frac{R}{a}\right)^{-2}\right]^{-0.2} \text { for } \operatorname{Re}\left(\frac{R}{a}\right)^{-2}<700 \text { and } 7<\frac{R}{a}<104 \text {. }
$$

